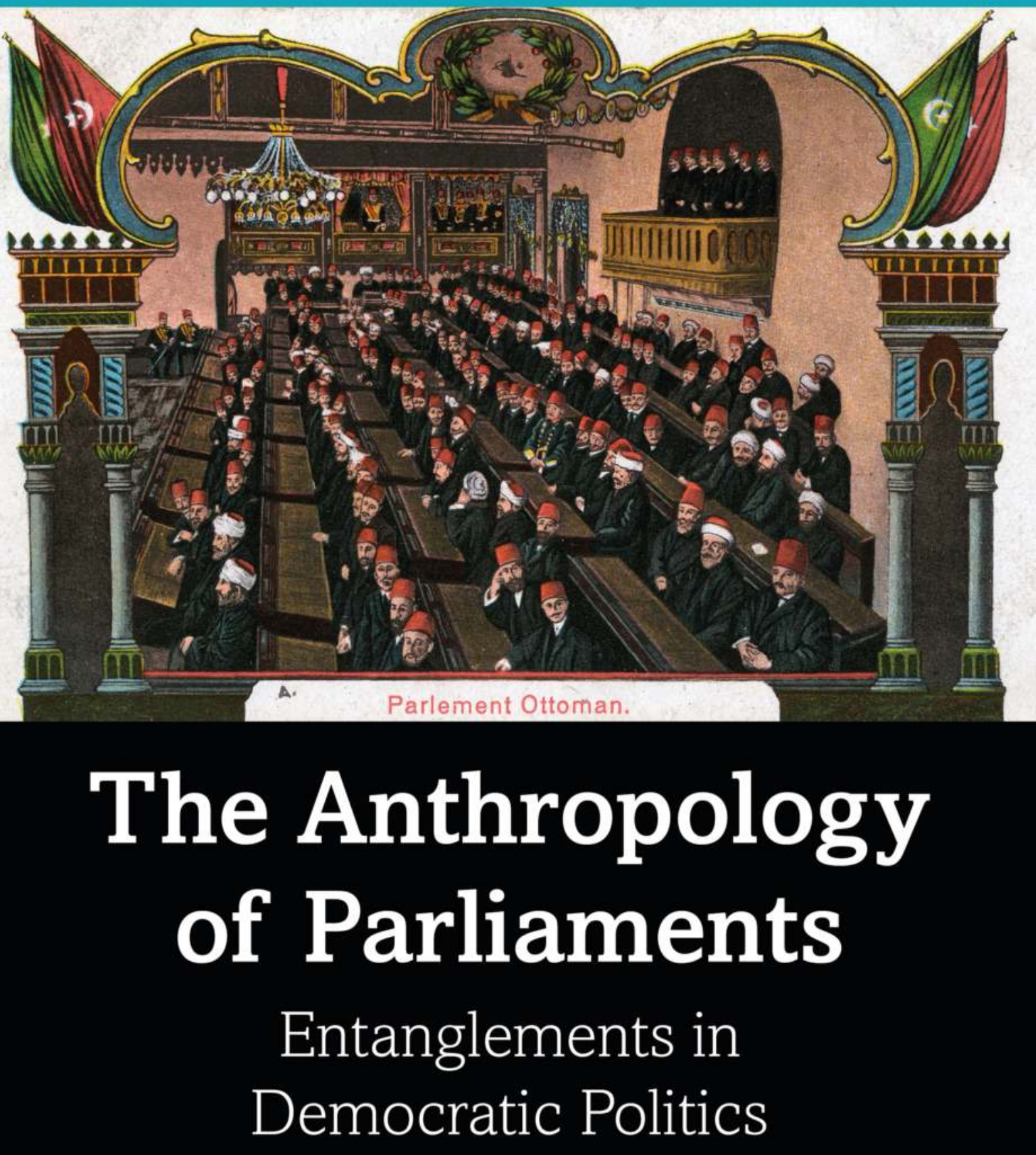

Emma Crewe

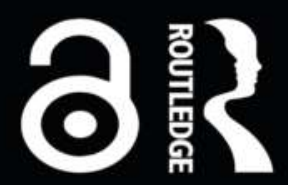




\section{THE ANTHROPOLOGY OF PARLIAMENTS}

The Anthropology of Parliaments offers a fresh, comparative approach to analysing parliaments and democratic politics, drawing together rare ethnographic work by anthropologists and politics scholars from around the world.

Crewe's insights deepen our understanding of the complexity of political institutions. She reveals how elected politicians navigate relationships by forging alliances and thwarting opponents; how parliamentary buildings are constructed as sites of work, debate and the nation in miniature; and how politicians and officials engage with hierarchies, continuity and change. This book also proposes how to study parliaments through an anthropological lens while in conversation with other disciplines. The dive into ethnographies from across Africa, the Americas, Asia, Europe, the Middle East and the Pacific Region demolishes hackneyed geo-political categories and culminates in a new comparative theory about the contradictions in everyday political work.

This important book will be of interest to anyone studying parliaments but especially those in the disciplines of anthropology and sociology; politics, legal and development studies; and international relations.

Emma Crewe is Professor of Social Anthropology at SOAS, University of London, UK. 
'With characteristic wit and imagination, Emma Crewe casts her anthropological eye across the spectrum of parliamentary politics. This book is the product of those enquiries - it is sparklingly fresh, insightful, and as ever with this author, more interested in illumination than condemnation.'

Jonathan Spencer, University of Edinburgh, UK.

'This is a pioneering anthropological exploration of parliaments from the UK to East Africa and South Asia, through a rigorous, imaginative and productive crossing of disciplinary boundaries. Emma Crewe's study of the sociality of parliaments - elections, representation and scrutiny - is complemented by a fascinating account of the culture of parliaments - their rhythms, riffs and rituals - both drawing on a formidable volume of primary research, from the constituency level to every imaginable aspect of parliamentary practice.'

Niraja Gopal Jayal, Jawaharlal Nehru University, India. 


\section{THE ANTHROPOLOGY OF PARLIAMENTS}

Entanglements in Democratic Politics

Emma Crewe 
First published 2021

by Routledge

2 Park Square, Milton Park, Abingdon, Oxon OX14 4RN

and by Routledge

605 Third Avenue, New York, NY 10158

Routledge is an imprint of the Taylor E Francis Group, an informa business

(C) 2021 Emma Crewe

The right of Emma Crewe to be identified as author of this work has been asserted by them in accordance with sections 77 and 78 of the Copyright, Designs and Patents Act 1988

Trademark notice: Product or corporate names may be trademarks or registered trademarks, and are used only for identification and explanation without intent to infringe.

The Open Access version of this book, available at www.taylorfrancis.com, has been made available under a Creative Commons Attribution-Non CommercialNo Derivatives 4.0 license.

British Library Cataloguing-in-Publication Data

A catalogue record for this book is available from the British Library

Library of Congress Cataloging-in-Publication Data

Names: Crewe, Emma, 1962- author.

Title: The anthropology of parliaments : entanglements in democratic politics / Emma Crewe.

Description: Abingdon, Oxon ; New York, NY : Routledge, 2021. | Includes bibliographical references and index.

Identifiers: LCCN 2020054562 | ISBN 9781350089600 (hardback) |

ISBN 9781350089594 (paperback) | ISBN 9781003084488 (ebook)

Subjects: LCSH: Legislative bodies. | Parliamentary practice. | Democracy.|

Comparative government.

Classification: LCC JF511 .C74 2021 | DDC 328.3--dc23

LC record available at https://lccn.loc.gov/2020054562

ISBN: 978-1-350-08960-0 (hbk)

ISBN: 978-1-350-08959-4 (pbk)

ISBN: 978-1-003-08448-8 (ebk)

DOI: $10.4324 / 9781003084488$

Typeset in Bembo

by Taylor \& Francis Books 
To my brother Pg and sister Bel 
$\because$ Taylor \& Francis

Taylor \& Francis Group

http://taylorandfrancis.com 


\section{CONTENTS}

1 Introducing parliaments and anthropology 1

A map of this book 3

Parliaments and legislatures 6

What is anthropology? 9

My own entry into parliaments 16

\section{PART I}

The sociality of parliaments

2 The alchemy of voting 30

Elections: socially, historically and technologically embedded 31

Vernacular election games in the UK 34

Quiet rebellions: voting shifts as an indicator of social change 44

Fetishising the vote 49

3 Representing

What is political representation? 55

Feminist theories of under-representation 59

The anthropology of representing and ignoring 65 
In UK constituencies: the collective MP 69

Resonance and alienation 74

4 Scrutiny of the state

Anthropologists on the shape of the state 83

Reading the runes: making law in the UK 86

Crocodiles and snakes 91

Critique as scrutiny 97

Scrutiny as part of shapeshifting work 100

\section{PART II}

\section{The cultures of parliaments}

5 Rhythms of performance

Agendas and diaries of time and space 110

The emotional gestures of minds and bodies 116

Breaking rhythms: moving on or staying put 127

6 Riffs of meaning

Ideology and knowledge 132

Rhetoric: communicating riffs of meaning 139

Networked advocacy 145

7 Rituals and symbols in politics

Ritualised decision-making 157

Ceremonies of state 165

Rituals, solidarity and violence 169

\section{PART III}

\section{Politics with the dial turned up}

8 A sense of proportion

Everyday political work: walking between friends and foes 175

Disentangling power 181

The democracy dials 187 
9 Improvising together

Researching as learning and (in the fullness of time) advocacy 195

Entangled, reflexive anthropology: how and why? 201

What we don't know 206

References

Index 


\section{ACKNOWLEDGEMENTS}

In writing this book I have incurred even more debts of gratitude than usual. My thanks to various research funders: of my study on the House of Lords (Economic and Social Research Council, 1998-2001, R000237788), on the House of Commons (Leverhulme Trust, 2011-13, RF-2011-261-00004), of research with my colleagues in Bangladesh and Ethiopia (Economic and Social Research Council, 2014-17, ES/L005409/1), supporting artists and scholars in Ethiopia and Myanmar to study parliaments (Arts and Humanities Research Council and Global Challenges Research Fund 2017-21, AH/R005435/1), and generously covering the time it took to write this book and the cost of making it open access (European Research Council, 2019-24, 834986).

I have lent heavily on my colleagues in the Global Research Network on Parliaments and People - especially Richard Axelby, Jastinder Kaur and Bethel Worku-Dix in SOAS; they have given me ideas, encouragement and comments from beginning to end. I also appreciate hugely the comments from other colleagues in SOAS - David Mosse and Amir Massoumian; colleagues on my ERC-funded ethnographies of parliaments project - Cristiane Brum Bernardes and Mitiku Gabrehiwot Tesfaye; as well as João Mineiro, Julian Spencer-Churchill and David Beamish (former Clerk of the Parliaments). Other GRNPP Fellows Cristina Leston-Bandeira, Shirin Rai and Niraja Gopal Jayal were a huge inspiration. I thank all the politicians who gave me their time and stories, most recently Steve Hogg (my own ward district councillor) and Hilary Burn (Chair of the Parish Councils Airport Association), as well as fellow activist John Adams (Stop Bristol Airport Expansion) for doing politics with me and then checking the text. All protagonists in my narratives have checked that they are anonymised or, if named, that they recognise themselves and the events in the account. Theo Walker's drawings are brilliant and he is a pleasure to work with. Thanks to Routledge, and especially Katherine Ong and Amy Doffegnies, for guiding, editing and publishing this book. 
My family, and especially my husband Nicholas, daughters Cleo and Scarlett, and step-son Joe, give me far more patience and advice than I deserve. I thank my mother, Sally, for teaching me to be curious and my father, Colin for provoking me into doing politics. I dedicate this book to my brother and sister, Pg and Bel Crewe, who initiated me into the art of collaboration. After all, politics begins in the family. 
$\because$ Taylor \& Francis

Taylor \& Francis Group

http://taylorandfrancis.com 


\section{INTRODUCING PARLIAMENTS AND ANTHROPOLOGY}

In the state opening of the 1908 Ottoman Parliament in Istanbul, seen on the cover of this book, the representatives are uniformly male, formal, and clothed in black. Globally our political institutions remain blighted by male dominance. But if you consider the various constituencies these politicians represent, you might also see this as a vast and diverse empire on show. In contrast to European colonial nations, it is claimed that all Ottoman subjects were citizens with the same political rights and were represented in the Parliament (Türesay 2013). These Ottoman Members of Parliament discussed Westminster in a debate during the following year, and were disinclined to emulate it:

ABDÜLAZIZ MECDI EFENDI (KARESI): Do the parliamentary system and equality reign supreme in England?

KOZMIDI EFENDI (ISTANBUL): I'm not referring to England here. I am an Ottoman, was born an Ottoman, and was brought up an Ottoman. Anything else simply doesn't concern me.

ABDÜLAZIZ MECDI EFENDI (KARESI): The parliamentary system in England is 225 years old. And there's not a single Indian member of Parliament.

KOZMIDI EFENDI (ISTANBUL): You don't seem to understand England very well. India is a colony.

A few years earlier the Westminster Parliament had had a solitary Indian MP, Dadabhai Naoroji, the Honourable Member for Finsbury Central. Born into a poor Parsi family in Bombay, he was a fierce critic of British colonialism and its economic rapacity. With justice: he concluded that a quarter of India's revenues were being appropriated by the UK. A founder member of the Indian National Congress in 1885, he decided 'it is in Parliament (London) that our chief battle has 
to be fought'. Incredibly, he won his seat in 1892, effectively one man representing the interests of the whole Indian subcontinent in the UK Parliament: 287 million people. Towards the end of his term he asked in the House of Commons:

suppose this House was cleared of Englishmen and filled with foreigners, or perhaps shut up altogether, all power and plans in their hands, eating and carrying away much of the wealth of this country year after year, in short Britain reduced to the present condition and system of government of India, would the Britons submit to it a single day if they could help it? ${ }^{1}$

If you look at who sits in parliaments, much is revealed about a nation. And yet, although social anthropologists have been studying politicians and other leaders, since around the time Dadbhai Naoroji won his seat, they have rarely ventured into parliaments. The study of politicians requires an understanding of the highly skilled work involved in doing politics. It is an arena of power, a jostling for public recognition and an encounter with difference. It involves struggling with friends and foes to realise aspirations, share resources, discipline people or thwart opponents' goals. It happens informally in families, communities, organisations, in the street, and formally within institutions across and between nations. Of those institutions, it is parliaments - politicians' workplaces - that tend to be the most ritualised, exposed and complex political spaces within a governance world, although courts are serious competitors. It is a place where hierarchies, power, conflict, rituals, rules, are always found alongside loyalty and disobedience.

Although it is work, politics is also entangled with people's social, cultural and emotional life so it can be intoxicating, addictive, unsettling or, at times, deadly dull. These entanglements make it difficult to write about. If you focus on only individuals doing politics (politicians, for example) and the institutions that allow them to organise themselves (political parties or parliaments) and the outputs they produce (acts, budgets, regulations, policies, reports) but fail to look at processes - the relationships, communication and emotions that keep their show on the road - then you can only ever achieve an impoverished analysis. To understand parliaments, you have to look at the complex range of connections, networks and exclusions they form across nations.

My purpose in this book is to summarise what anthropologists have written about parliaments so far and provoke questions for future research, both for those already studying parliaments as well as those who might be tempted, enticing new anthropologists (and ethnographically inclined scholars from other disciplines) into these absorbing fieldwork sites, to continue with what previous anthropologists have already shown: that anthropology can be useful to the study of parliaments. I make no claim to be comprehensive, holistic or systematic about explaining parliaments in this book and my own fieldwork site of Westminster gets more of my attention than others. I can do no more than offer some anthropological brushstrokes about what parliaments are, what people say about them and do in them, continually asking who, what, where, when, how and why, always worrying about what I/we don't know. I hope this approach to the study of parliament offers a 
tapestry - a weaving of ideas about past, present and future, both broad patterns and depth through detail, narratives with plots and characters, and both contextspecific and generalisable theories. I aim to offer insight into both parliaments and anthropology at the same time.

\section{A map of this book}

This book is primarily written for researchers and students, especially those who already study parliaments or might do so in the future. If interested in researching parliaments ethnographically, then this is the book for you. You are most likely to be an anthropologist, as I am, or from a discipline that already dominates the study of parliament (history, political science, gender studies, public administration and legal studies). But you may be trained in a discipline that has mostly stayed away but would enrich our understanding (psychology, organisational studies, theatre studies, linguistics ...). I have distilled what has been written so far about parliaments through an anthropological lens so that you have an introduction to these exotic and unfamiliar institutions. For these disciplines, I'm explaining my version of anthropology and aiming to offer novel insights into institutions that you may not have considered from an entangled socio-political and cultural angle. It may interest teachers and students of politics and maybe a few with a keen interest in following politicians as an utterly compelling intellectual spectator sport.

To watch your own democracy, or better still to participate in it, requires knowledge of the arena at the centre and anthropology sheds light on parliaments through a particular and illuminating filter. Take the Westminster Parliament, as I have done in this book a great deal (because it is the one I know best): anthropology has helped me to wrestle with a series of questions and puzzles about gender, whipping, emotion, ritual, conflict and political work left unsolved by political science.

To find your way around this book, it might help if I explain its narrative structure. Each chapter can be read on its own, offering a way to inquire into a specific theme, while overall I am making an argument about how to study political organisations through an anthropological lens. I will explain this general argument first before I introduce you to each chapter. After a brief introduction to parliaments, anthropology and how I came to be doing anthropological research on parliaments, I present this book in three parts. The first is about how politics is entangled in sociality, the second grapples with culture and the third is about power and knowledge. The first part relies on a partly conventional way of understanding politicians' work as processes of campaigning, representation and scrutiny of government, in the hope that this way of conceiving of it will be recognisable to everyone. But I question the idea of MPs' work as divisible into roles. Typologies classifying MPs into these 'roles' miss the entanglements between them, the difference between claims they make and what happens in practice, and diversity among MPs. My conclusion on summarising these strands of politicians' 
work is to note the overlaps, contradictions, conflicting pressures and endless shapeshifting they have to do to adjust to multitudes of audiences.

So, Part I leaves me with this empirical question: if the work of MPs creates this confusing mess of pressures and expectations, which they have no choice but to respond to in democracies, then what are the continuities and breaks across the various encounters and sites? In Part II I offer a systematic way to study how MPs work by looking at the performance of rhythms through time and space, the riffs of meaning and how riffs and rhythms are organised by and through rituals, both in parliament and outside. This could be a way of considering the differences between MPs but also the patterns of interaction through speeches, debates, documents, meetings, conferences, 'surgeries', digital channels and so on. To understand both the individuals and groups, we need to research the relationships between them and consider what formal structures influence these (e.g., political parties) as well as informal sedimented hierarchies (e.g., gendered inequality in conversation with class, age, race ...). Part II still fails to resolve this further problem: how do we develop a sense of proportion to make sense of all this interaction? What is significant and what is trivial and who decides?

In Part III I write about significance. Much that I have written about politicians' work in Parts I and II is true of people working in any organisation and certainly those aspiring to do public good. We are all shapeshifters if we go out into the world of work. In Part III I turn to what is specific to politicians and other leaders. Whether navigating friendship and enmity, or engaging in continual power struggles, politicians are doing what we all do but in magnified ways. It is this magnification that makes them unique, or at least unusual. Politicians are more exposed, have more capacity for impact and are connected to huge numbers, so their entangled political work is like the work done by the rest of us but with the dial turned up. I end up explaining how I have come to these conclusions, building on the research of other anthropologists. Researchers and politicians can learn from each other's craft: to do good research you have to be politically savvy; to be an effective politician you'd be wise to learn - that is, do research in the broadest sense of the word - with intensity. The starting point for both, if wise, is to acknowledge their ignorance and assume a position of uncertainty.

My argument about the nature of politicians' work as entangled, shapeshifting and magnified is built up chapter by chapter. In Chapter 2 I begin by summarising the anthropological work on elections. When you stand for election you don't know whether you or your party will be in government, so you have to make hypothetical promises. It is anxiety making, intoxicating and highly addictive for those standing. Voters don't necessarily need to agree wholeheartedly with their representative; they vote for a candidate or party that is intelligible, recognisable and (in some cases and in some ways) trustworthy. The loyalty crafted in relationships in the run up to these events often proves important in doing politics once they are in parliament.

I discuss another even more complicated kind of voting within parliaments. When verbal battles over policy, law and government are fought by political 
parties, their members have to decide whether or not to support their own side, which they usually do. But rebellions mean that the government party, which nearly always has a majority, can't always assume victory, with a few exceptions, for example, in Bangladesh where it is illegal to vote against your party. In the UK rebellions against your own party have been increasing for over half a century (Cowley 2005), revealing much about political but also cultural change both inside and outside parliament. A recurrent theme of this is the connection between parliament and the rest of society; it is a microcosm of wider society - because within it are representatives of (nearly) all people in a nation - so unsurprisingly politics in parliament reveals change that is happening elsewhere because it unfolds within MPs' domains in amplified forms.

In Chapter 3 I write about another area of political work that has exercised scholars for as long as they have studied democracy: representation. Rather than taking the representation by elected politicians as a literal process of championing the interests of the electorate, I write about different understandings of this claim - for example, by politicians, feminists and constituents in different countries. We can't fathom this process until we take a far closer look at what interactions and results this claim produces in different places. Scrutiny is the focus of Chapter 4. For democracy to work, law-making, policy development and administration of the state have to be scrutinised by politicians, the media, civil society, academics, even the Twitterati. While legal scholars look at what happens to swathes of documents to assess the quality of this scrutiny, I followed 250 words as they travelled through parliament and were pored over, debated and revised. The role of civil society is easily overlooked in these processes because its appearance in the legal and parliamentary texts is more marginal than it is in the reality of face-to-face and mediated encounters. 'Evidence' is idealised, and seen as especially pure and efficacious if scientific or legal, whereas I argue it is its entanglement with politics that creates and sustains democratic processes. To deny the politics in evidence is anti-democratic.

Chapters 5, 6 and 7 bring culture into the entanglements. Under the influence of Lefebvre and Mead, I am pulling at my own long-standing bias towards mind and history to write about bodies and geography in the rhythms of parliamentary work in Chapter 5. How do MPs navigate time and space - as individuals and groups - and what are the patterns of continuity as opposed to the breakdowns in these rhythms? More familiar to the study of parliaments, in Chapter 6 I consider the riffs of meaning to make sense of the content of political ideas and how they influence what MPs think, say and do. I take up Barth's distinction between different types of knowledge - ideas about the world or ideology, communication (such as political rhetoric), and transmission through social relations (2002). I relate an example of advocacy to explore the social relations involved, a story about how a network in rural England influenced a district council to turn down a planning application. Through rhythms and riffs, it becomes possible to see one way of systematically studying how political work happens between politicians and those they interact with. 
Since politicians are connected to every person in a nation (at least symbolically), if you amass information about their political rhythms and riffs - including who they help and who they neglect - then how can you judge what to focus on? How do you know what is politically significant? In Chapter 7 I address this question by arguing that rituals and symbols reveal the struggles for status and power, the contests over meaning, and the intensity of the stake in decision-making. Observing the formality of rituals, and the emotional reaction to symbolism, tells you when something important is going on.

My final question for Part III is this: what matters to people and how do you tell? Politics happens when emotion becomes magnified within social relationships, especially at moments of negotiation, and although we are all involved in politics, for politicians the intensity tends to be greater. Politicians do politics with the dial turned up. Why is this? Because you can't do politics without developing conflicts and alliances - walking between friends and foes - which inevitably leads people into power struggles. Power is negotiated with the influence of ghosts from the past, and aspirations about the future, so it is always relational in both a social sense but also a temporal one. The more politicians turn up the social dial of democratic engagement - listening to constituents, lobbyists, journalists, each other - the more they have to deal with contradictions, exposure and risk. This sounds beneficial but then leads to a turning up of the second dial too - one of political and emotional intensity. To nurture our democracies in ways appropriate to our own nation, we need to pay more attention to these democratic dials.

I will return to how I came to these conclusions in the final chapter. I make this claim about anthropology: our approach has rigour and can discover parts of parliament that other disciplines can't reach. We can be politically savvy enough to do research in ways that uncover the hidden transcripts, meanings and possibilities for change. Our research methodology means we learn with people rather than merely turning them into objects of study. I end trying to point to what we don't know about parliaments and suggest that when beginning new inquiries it is always useful to approach the desire for knowledge with uncertainty.

Welcome to the wonderful and terrifying world of parliaments.

\section{Parliaments and legislatures}

Why should scholars mind about parliaments? Rai and Spray point to an answer with both local (Indian) and global significance at this particular point in history:

should we care about this institution? ... it is flawed and at times weak and even corrupt - the vernacularization of its politics is often represented as its decline. Women remain marginalized within its portals. At the same time, however, it is an institution that makes claims for India's democracy, which is increasingly valuable in a context of the dangers of increasing populism, of executive predominance, and of narrow nationalism even as neoliberal India faces challenges of increasing inequality. 


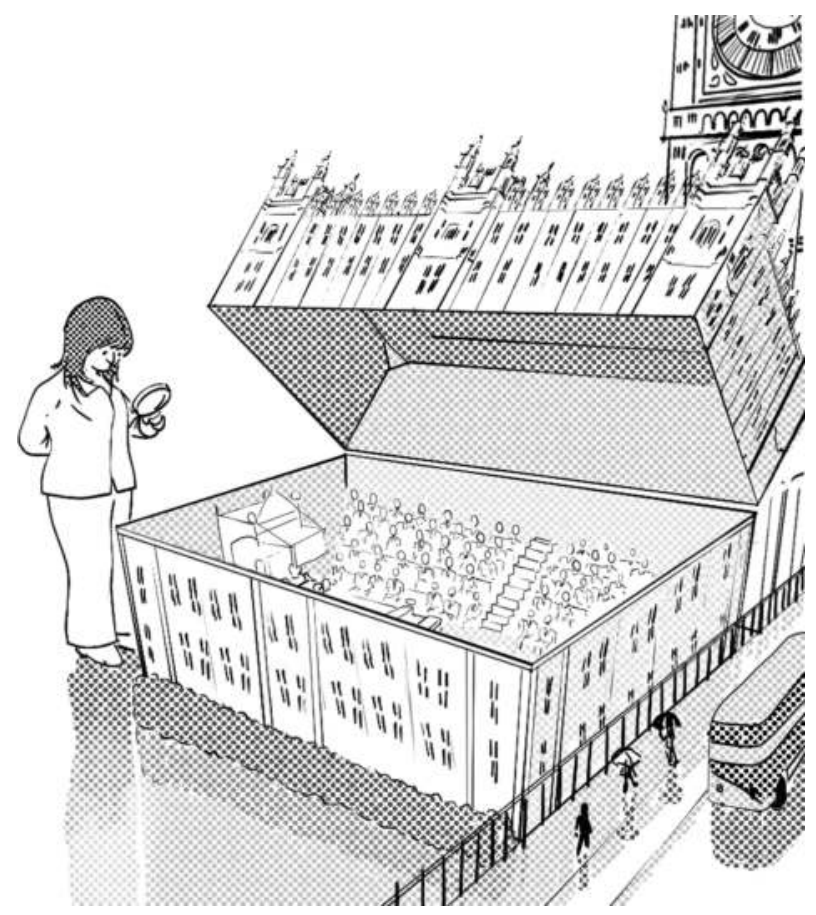

FIGURE 1.1 An anthropologist lifting the lid on the UK Parliament.

Parliaments are the embodiment and expression of democratic politics in concentrated form (it is hoped): an idea, a process, a place, a building, a time and a symbol. They are an idea-in-action in the sense that they are the "what, where and when' - the parliamentary laws and motions, in the house of parliament, during parliamentary terms and sessions - and so constitute the means for elected politicians to do the work of representation. The nation is usually but not always divided into constituencies, so parliaments are the meeting of those travelling from all over the country to talk (parler in French), scrutinise governments and make laws. Some of the business of political decision-making takes place in parliament. Solemn decisions are made in them about the laws and administration of a country or about going to war; the more serious the decision is viewed by those who control the rules, and the more it might be difficult to reach agreement, the more it tends to be ritualised. These rituals that allow laws to be made and motions passed depend on both formal and informal rules and conventions and hierarchical relationships between those who police and either obey or disobey them.

Parliament is a place designated for the work of politics, located in the political centre (or capital) of the nation, region or locality. It is also the name for a building of state in most countries. These buildings can be forbidding, inspiring discomfort and awe, but in different ways. In the case of Westminster - towards which I am biased not because I think it is the most important but merely because I have 
studied it for over 20 years - it is a gothic-style royal palace with 1000s of corridors, rooms and staircases, no one knows quite how many, that most find either entrancing or disturbing. The Palace of Westminster is one of the world's iconic buildings; it is also collapsing, with faulty electric wiring and pieces of masonry falling from the ceilings. If you are a visitor, you are confined to a few public areas - the important ones being the chambers, the committee rooms and the central lobby. Westminster's central lobby is where you can send a message to your MP as a constituent and ask to have a word with her, and although they are unlikely to be available to see you then and there, you do have the right to ask. In practice people rarely do.

How do other parliaments draw the public in or shut them out? The Lutyens buildings of state in New Delhi, India conjure grandeur but also a colonial past, while the modernist Bangladeshi Parliament designed by Louis Kahn looks like a fortress with its huge walls, few windows and brutalist architecture. Some newer parliaments are designed to encourage public participation. The Deputy Presiding Officer of the Scottish Parliament marked their 5 millionth visitor in 2019 by saying: 'The Scottish Parliament has always prided itself on being an open and accessible place, where the public should be welcomed and feel at ease. ${ }^{2}$ Parliamentary buildings, and their public's reaction to them, reveal how a nation wishes to present itself. But different groups within any population respond differently to each parliamentary space. The national Parliament in Myanmar has a 20-lane boulevard approaching it, large enough to land a plane, and a clear military presence. On 4 March 2020 I visited Naypyidaw with a colleague from SOAS, Bethel Worku-Dix, and while I felt intimidated - remembering other militarised zones in Sri Lanka and Israel/West Bank - Bethel saw it as showing-off, sending a message of strength to the outside world, including us. Our three Myanmar colleagues, scholars from different Burmese and non-Burmese parts of the country, replied when asked for their reaction ('how do you feel being here?'):

'Very good, it shows what we can do as a country.'

'Magnificent but lonely.'

'It's practical - it avoids traffic - but it is excluding, it is about showing a strong state. We should have a university here beside this road.'

I don't have the space to explain these reactions as they arise out of complex, diverse individual histories but I mention it because I want to emphasise that parliaments evoke multiple responses not only as a group of politicians, but as buildings, spaces and ideas.

A parliament is also a period of time between one general election and the next - so you might refer to the 2010-15 parliament - during which parliamentarians meet to make laws, pass motions and hold the government to account. This period obviously varies depending on how often elections are held and the duration of terms in that place. Within a parliament you have sessions (signified by the opening and proroguing of parliament) and sittings (daily meetings that often start and end with processions) (see Chapter 5 for more on the rhythms of work in parliaments). 
Parliaments often operate as both an insular bubble, creating a small town-like political workplace for politicians, journalists, lobbyists and staff where you can also drink, eat and get your hair done, but also a forum at the centre of a web connected to others across the country and the world. To describe all the connections comprehensively would be impossible. To research parliament, you have to study it locally, nationally and globally - to have the world in view - with a sense of culture, theatre, geography, history and the imagined future. The continual dynamism means that the study of any parliament never stops: as soon as you have finished writing about a specific parliament, at least some of your observations are out of date and you have to prepare to start all over again. As the pace of change accelerates, in part as a consequence of the digital revolution, some statements about politics are out of date almost as soon as you have committed them to paper or the web. But other observations endure in their relevance, so like any inquiry about people the researcher needs to consider both the stable and unstable, the continuities and the dynamism, the patterns at different times, places and scales.

Parliaments and legislatures are different: although both pass laws, in a UK-style parliamentary government the executive is constitutionally accountable to parliament whereas in a US-style presidential system there is a separation of powers between executive and legislature (Laver 2008). In presidential systems, such as the US and Brazil, the upper and lower houses or chambers are jointly called Congress. In other places parliaments are unicameral rather than bicameral - having only one house. Accountability or separation are the ideal but they only work effectively in democracies with a functioning opposition. (Some of what I write may apply to regional level assemblies within countries but anthropologists have given them less attention.) In this book I use 'parliaments' (with a capital when it is a specific parliament) as the umbrella word because I find it more beautiful than the technically correct 'legislatures'. (This is not a trivial matter - beautiful words help with intelligibility and writers, even academics, have a duty to avoid alienating the reader where possible.) Parliaments are any national, regional or local body in which elected politicians sit and within which people are represented, laws are made and/ or governments are held to account.

\section{What is anthropology?}

Anthropology is a discipline that studies with people and teaches about them and their social worlds. Ingold describes anthropology as a form of philosophy but with the people still in and even central to the inquiry (Ingold 2014). Ethnography is a way we approach learning with people and documenting what we find while the main method for doing this is participant-observation. Ingold explains distinctions in a helpful way:

Anthropology is studying with and learning from; it is carried forward in a process of life, and effects transformations within that process. Ethnography is the study of and learning about, its enduring products are recollective 
accounts which serve a documentary purpose ... participant observation is a way of knowing from the inside ... There is no contradiction, then, between participation and observation; rather, the one depends on the other.

(2013: 3-5)

Anthropologists tend to begin an inquiry by following, watching and talking to the inhabitants of the world in their sights. But that is only the beginning because we aspire to be thoughtful about how we produce knowledge out of our relationships with those we hope to understand. Ingold explains that anthropologists don't study people - they aren't objects of study - but they learn with people, it is a participatory form of research:

Anthropologists follow their noses, sniffing out promising sources and lines of inquiry. They are like hunters on the trail. To hunt, you have to dream the animal; get under its skin to perceive as it does; know it from the inside out.

(2018: 118)

To do anthropological research well, you have to have an open mind and to approach conversations, observation and encounters with a willingness to learn. If it is a world you have never been to before, you have to learn to become an insider - a strangely infantilising experience. If you are learning about what you assume to be your own culture, the process begins with unlearning - making yourself a stranger even to yourself. Learning is impossible without the possibility that it may change you so anthropology entails transformation and relies on resonance. As Rosa writes about interaction in general, 'Encountering the foreign commences a dialogic process of (always only ever partial) adaptive transformation that constitutes resonant experience' (2019: 185) (see Chapter 3 for more on resonance).

During fieldwork anthropologists are often drawn to narratives that explain puzzles, disconnections and the messiness of everyday realities so that ethnography is not just data collection and interpretation, it involves writing about people evocatively and with imagination. The people are the focus because anthropology tends to be empirical, starting with guesses about what is going on, proceeding to people's everyday experiences, meaning-making and relationships, and building up more certain theory from the bottom upwards. It is partly our interest in epistemology that makes anthropology philosophical, but it is also the nature of the questions we ask, whether about politicians or anybody else. How do people create and contest meaning in their lives? What are they doing when they do their kind of work? What motivates people to act in the way they do? What is the source of their morality or immorality? And what is the relationship between individual freedom and social constraint? In asking and answering such questions, seeing and then describing is never just about the activities seen on and from the surface. At the same time, good interpretation doesn't take you away from empirical description, just to advertise the cleverness of the author, but revels in it: 'cultural analysis 
is (or should be) guessing at meanings, assessing the guesses, and drawing conclusions from the better guesses, not discovering the Continent of Meaning and mapping out its bodiless landscape' (Geertz 1973: 20).

Geertz advises that this means that anthropologists will neither abstract away from everyday reality nor necessarily reach a perfect consensus, for example about what is really going on in parliaments, but will aspire towards refined debate and better precision with which to vex each other. Anthropologists studying parliament (or any mini-world for that matter) investigate the everyday concerns of people the mundane and dramatic, the logical and puzzling, the soothing and jarring - but keep in view the complexity created by pluralism, connections and change. Whether anthropology confronts these as a science, social science or an art is a matter of dispute, depending partly on how you view science. In the US the idea of science tends to be far broader than its European conception. US anthropologist Geertz described the 'interpretation' piece of any inquiry as relying on the 'power of the scientific imagination to bring us in touch with the lives of strangers' (ibid: 16). Clearly, he does not mean to imply that he relies on quantitative measurement, valid sampling or replicability of results - or equivalent associations with positivist scientific method. But rather he is claiming science as a systematic inquiry with a focus and depth. The problem with this broad conception is that it creates a great deal of work, in the sense of communicating to win the support of other scholars. Since many scientists (including social scientists) will complain that anthropological inquiry is not proper science, then the terminological decision will lose us allies. Is it worth investing time and pages making the case that science encompasses anthropology or is it more profitable to describe anthropology as a humanities discipline, and demonstrate how it establishes rigour more like other humanities, such as history, literary studies or philosophy? In the end I find myself more comfortable in Ingold's humanities camp because I find the investigation into philosophical rigour, with its inevitable focus on processes, more interesting than a battle over defining the rules and boundaries of science.

If we portray anthropology as a humanities discipline, and we want to be taken seriously by other disciplines studying politics, then we need to explain how we conceive of rigour. Since anthropology used to position itself as a science, has mostly been defined as a social science, but is (in my view) more like a humanity, anthropologists are right to obsess about rigour - both methodological and theoretical. At least three elements in anthropological inquiries are critical to rigour: reflexivity, interdisciplinarity and plurality, and it will become plain how these are as much about theory as method, as I muse on their place in anthropological research. (In the final chapter I will return to the processes involved in doing ethnography as anthropologists.)

\section{Reflexivity}

This entails thinking about how we think and respond to each other - what we know or claim as knowledge and how this changes during an inquiry as researchers 
encounter others. What anthropologists find most significant during an inquiry may be taken for granted by the people they study, the 'silent traditions' that seem so natural that they are scarcely noticed by those recreating them (Bourdieu 1977: 167). This is a good example of how method and theory are entangled. Bourdieu explains how culture is partly about people navigating rules and making implicit assumptions about what is true, morally proper or politically desirable, without noticing that they are doing this. Insiders often can't see their own traditions. As outsiders, or detached insiders, anthropologists can usefully see what tends to be invisible to those too involved to perceive their own cultural practices. However, doing anthropology means shifting from the position of outsider to insider (although you can never be just one or the other), and back to detachment again, so as research progresses your relationship with your informants transforms. Rigour depends on the anthropologist investigating their own silent traditions, and what happens when these traditions meet other values, bodies of knowledge and assumptions, and then converse, clash, merge, alter or remain stuck. An anthropologist's own dispositions, and relationships with informants, influences what she/ he finds when studying others, so it is important that the specificity of these processes become part of the inquiry. If you agree with Bourdieu's theory of culture and knowledge - that much of it is silent or at least quiet - then you need reflexivity in your method.

Consider this example of encountering difference with some colleagues in Ethiopia. During a methodological experiment in 2014 four of us interviewed Ethiopian women MPs to test out whether our own identities influenced the research. We went into the interview: me (a middle-aged white British woman), a younger white British man, a middle-aged Ethiopian man and a younger Ethiopian woman researcher. By prior agreement, towards the end of the interview the two men left the room to see if this influenced how the women MPs spoke to us. This is what happened:

While all the researchers were present, the MPs were determined to stress the strength of their party and government and their successful efforts at promoting gender equality. The impression given was that women politicians were tough, dynamic and invulnerable. When the two male researchers left, the conversation changed abruptly. The women MPs became far more candid about the hostility of some male MPs, quoted as typically saying: 'Why do you always cry?' and 'The constitution already reflects the interests of all. Women's issues are already discussed so do not always talk about women'. One of them tellingly said when asked what it was like being a woman MP: 'When a woman gets up to speak in the parliament she is always fearful, thinking "can I do this?" whereas a man never worries'. Whether this was true or not - perhaps men are just as nervous but refrain from saying so - it was clear that this would not have been said in front of the men, and especially the senior national scholar leading our research in that country who had taught several of them at university. This encounter made it clear to us that women MPs in this 
country struggle with confidence but are under pressure to appear invulnerable in the presence of figures of authority or those they are competing against. Such a pattern may be generalisable as there is plenty of evidence to suggest similar dynamics elsewhere.

(Crewe 2018: 23)

Although I have presented this example as gendered, the context being that I wished to convince colleagues that it was important to have women involved in any research team, other identities also shaped the interaction. Ethiopia was never colonised, but the country is locked into aid relations with Europe (including the UK) so this was a postcolonial encounter nonetheless. When talking to me, the Ethiopian MPs only opened up after I stressed that we (the two Brits) were not there to imply that they should copy Westminster; the UK House of Commons can be a place of misogyny, with women silenced and derided by colleagues or the media, I told them. At the same time, racialised identity wasn't necessarily the most important feature in the encounter between the MPs and my two male colleagues; it was the Ethiopian man's former status as lecturer at the university, and former teacher to several of the MPs, that was intimidating and constraining, probably more so than my British male colleague's whiteness. So, gender, race, age and a past teaching relationship all played their part in highly specific ways (no doubt along with other aspects that I did not notice). Different forms of difference have various and often unpredictable effects; patterns can be hypothesised but to ascertain what they are in particular situations with rigour, empirical investigation in context can't be evaded.

Too often researchers claiming to be reflexive used to treat it as a rather superficial listing of identity characteristics (I include myself, writing in my methodology sections: 'as a white middle-class women from London my bias is ...') rather than grappling with the meeting of cultures and individual histories as an endlessly complex process of morality, assumption and communication. But fortunately contemporary anthropologists rarely resort to such simplicities. We have moved a long way since the days of postmodern identity determinism - a period when anthropologists seemed to imply that your specific identity inevitably led to particular kinds of blindness or perception. Tilche and Simpson make an important point when they write about returning to Pocock's fieldwork site in Gujarat, India; they remind us that ethnography does not lead to a product that fixes our knowledge of 'the other' as truth for all time, but also it is far more than merely an idiosyncratic view. It is a process of education: 'Anthropology is not only a personal account of the world but also a kind of apprenticeship that can itself (and beyond the self) be transmitted as a knowledge in and of the world' (2017: 704). Tilche did not portray Pocock's fieldwork site as an entirely different place six decades after he lived there; in fact her findings strongly resembled Pocock's in form and content despite expecting the opposite. Despite the changes in researcher and site, the continuities were more interesting than the divergences. An approach to reflexivity that investigates how relationships generate knowledge in specific ways paves the path for a subtler approach to accounting for our participation in research as open-minded researchers. 


\section{Interdisciplinarity}

Bourdieu wrote that the separation between sociology and history is disastrous; great historians are also great sociologists and vice versa (Bourdieu and Wacquant 1992: 90). But anthropology goes further, it takes on whatever discipline dominates the field under investigation: if looking at development, anthropologists argue with economists; when writing about organisations you react to management literature; when researching parliaments a scholar can't avoid reading history, political science, legal studies and public administration. But parliaments are at the centre of more than politics, law and administration because politics is entangled with everything it touches and it touches everything. You can't study parliament without a sense of architecture to fathom the building; geography to consider how people navigate space and place; history to see what unfolds over time including movements in power, relationships or values; linguistics for perusing speechifying and written texts; legal studies if tracking law-making; psychology to uncover the pressures people face and how they respond to them and so on.

So what is our focus as anthropologists? Anthropology is often, and more than most other disciplines, looking at connections and entanglements rather than separations created by classification, whether typologies, lists or ranking of categories. So, in the social life of a community, organisation or theme we might consider the kinship between people, the circulation of money, hierarchies or the importance of music, and how these are related, depending on what bubbles up in observing and interacting with people. We once referred to anthropology as a holistic study. But in practice it is impossible to study a whole society, culture, group or organisation across time and place with attention to all the individuals and groups within it and how they are moving and changing. We now aspire towards a holistic sensibility, meaning we are open-minded to the possibility of anything being both important and connected to anything else and to the influence of the dispositions we arrive with, our own history, our identity, our previous research on the topic and our theoretical inclinations. To achieve this sensibility, and stand on the shoulders of others scholars wherever they come from, we have to be interdisciplinary.

\section{Plurality: who to listen to?}

Anthropological researchers are continually worrying about inclusion and exclusion, who they are (and are not) observing and talking to when doing their research. Aside from the ethical imperative of being inclusive, in the sense of listening to the inevitably diverse views of any group, research will suffer if the views reflected are excessively partial. Who you talk to, and to what depth, will influence how far, and with what degree of certainty, you can generalise your insights to whole groups or populations.

I began to learn about plurality, exclusion and excessive partiality in India. In 1983, when I was 21 years old, I arrived in a hill village in the foothills of the 
Himalayas to look at the rules governing relationships between castes to see if they were changing (for my MA dissertation). I set about talking to my neighbours. I discovered that the order of caste ranking depended on who you spoke to, with both Brahman and Rajput families in this particular Himachal Pradesh village claiming the top spot in the hierarchy. The rules stipulated that to avoid pollution you shouldn't eat with, marry or even touch a Dalit person's shadow. This presented a problem for Brahmans. They could avoid Dalits most of the time but their seat in the State Assembly in Shimla was reserved for a Dalit politician, so interaction with him/her was unavoidable. When I asked about this they told me that the caste rules only applied to 'the village'. But the new government buildings just beyond what they told me was the periphery of the village were, therefore, outside the rules. By investigating where this boundary was in the past, I began to realise that they had redefined the geographical periphery of the village so that meetings could be held in new government buildings with Dalits without fear of pollution. I suggested in my dissertation that this creativity with the rules was a way of preserving the status quo and maintaining caste hierarchy.

Influenced by structuralists, like Rodney Needham and Louis Dumont, and the post-structuralist Bourdieu, who were all interested in how ideology, rules and practices of social institutions create continuity, I wrote about how ideology tends to be taken for granted, which explains why structures persist. I outlined the cultural rules - divided into prescriptive rules (which are difficult to break and often explicit) and preferential rules (which are implicit, more like patterns or norms that people can't or don't necessarily articulate) - and the practices (which are what actually happens between people, as much shaped by ideology as they are by rules). It was a classically tidy post-structuralist account. Contradictions often get thrown up in everyday relationships - such as the caste rules versus the anti-caste discrimination law - so people have to find a way of resolving these, in this case by redefining the village limits, so went my explanation. I now look back and I see one terrible flaw in this research: I did not speak properly to Dalits. They did not speak English and my landlord and interpreter was a Brahman so he wouldn't go inside their houses because 'they were dirty'. As we stood awkwardly at their front doors with me asking them questions through the translator, he sometimes answered on their behalf and they couldn't speak freely. If I had found a way of talking to them alone, then the processes of exclusion and bonded labour that I only glimpsed could have been a serious part of my study, essential if I was serious about writing about inter-caste relations. When writing this up, I shouldn't have implied that I was writing about all inter-caste relations when I was only conveying the perspective of Brahmans with depth. Not only did I exclude half the village, but excluded the half that are endlessly excluded by the other half. Intimidated by my Brahman hosts no doubt, but I should have been at the least more modest in my implied claims about representing the whole village in my account of caste.

So, if we need to be aware of who we are excluding in our anthropological representations of the realities of others, then who should we listen to when studying parliaments? Since the whole population of any democracy is connected 
to parliaments via their elected representatives, researchers have to make selective judgements about who to include (and therefore exclude) from their research. This judgement will be informed by research goals and themes, opportunities for access and our own politics.

I hope I have said enough to introduce the preoccupations of anthropologists when they embark on ethnographic research. I will return to method and theory in the final chapter because it will make more sense after I have explained my insights and those of other anthropologists. Before I discuss these findings, I will explain why I leapt sideways in 1997 from working as an NGO activist into studying Westminster.

\section{My own entry into parliaments}

After a decade of frustrating work as an NGO activist and consultant in international development, in 1997 (aged 35) I noticed that the new Labour government intended to reform the House of Lords. The prospect of entering such an exotic fieldwork site, and watching the eviction of hereditary peers, was irresistible. I spent my teenaged years arguing with my father about whether the House of Lords, or at least the peerage, should be abolished. The more practical reason for avoiding foreign travel was that I had a two-year-old daughter and did not want to miss out on her childhood. Through a family contact, I managed to get an appointment with the Clerk of the Parliaments, Michael Davies (later Sir): the clerk in charge of running the House of Lords.

At noon I shuffled shyly into his wood-panelled room and accepted a glass of white wine. 'Where shall we sit?' he asked. I chose the high-backed red leather chairs near the window overlooking Parliament Square - it gave me the feeling of possible escape from what was mounting terror. Would I mess up this one chance of talking my way into this alarmingly grand and awe-inspiring place? Hoping he couldn't see my hands shake, I explained my idea for studying the House of Lords; I had some vague notion that I'd research culture and power but did not confess that I expected misogyny, racism and other heinous forms of prejudice. He told me later that he wasn't entirely sure what anthropology was, presumably not the study of evolution, ants or chimpanzees, he thought, but then what? Still, he seemed pleased that an academic proposed to study his neglected house of parliament.

As I was leaving he asked if I knew any peers as he planned to put my proposal to the 'usual channels'. I had no idea what that meant and must have looked puzzled, so he reeled off the names of the party leaders (Lords Richard, Cranborne, Rodgers of Quarry Bank) and Crossbench (non-party) Convenor (Lord Weatherill).

'Yes, Cranborne is a friend of my grandmother's,' I exclaimed. I rushed home and phoned my grandmother, 'Gran, did you have an affair with Cranborne?'

'No, but I did have a fling with Cranbrook. Is that any good?'

'No, no, no - no good at all,' I thought. In a terrible panic, I phoned my father.

'Dad, I need to find someone who knows Cranborne.' 
'Sure, Robert Cranborne is a cousin of your uncle's third wife.'

I wrote to Michael explaining that I was mistaken - Cranborne was a distant cousin via an aunt not a friend of my grandmother's. (I tell this story with a sense of embarrassment but it still makes me laugh and I'm trying to be honest about how I began with both ambivalence but also a significant advantage in the difficult game of getting access to elites.)

After a few days, a Conservative peer (an academic) telephoned me at home. $\mathrm{He}$ said that my research proposal had come before him as a member of a House of Lords committee and that they were considering whether to give me access. He snapped a question at me with considerable irritation: 'What is ethnography?' I blurted out something like the study of the culture of a self-identified bounded community, which seemed to take the wind out of his sails of annoyance. He explained that he was perplexed by the way that the Clerk of the Parliaments had put it because after ethnography he had written: 'the scientific study of the races of man'. He asked me why I thought he had done that. I suggested that he had probably looked it up in the dictionary or was being humorous. The peer replied that the Lord Chancellor had tried being humorous (about decoration) ${ }^{3}$ and that backfired. By this time, I was alarmed - tempted to beg for forgiveness for being so presumptuous - but he suddenly said that I had greatly reassured him as I obviously did not adopt an old-fashioned view of ethnography, and put the phone down.

Michael Davies asked two other sets of people for approval in addition to that committee. He asked the two other most senior clerks, the Lords still being managed at that time by an oligarchy of three clerks. One expressed reservations, arguing that they should reject the proposal, but Michael over-ruled him. Then finally he went to the usual channels - the three party leaders and the Convenor of the Crossbenchers - to ask them to give permission for my research. They consented but soon afterwards Lord Richard (Leader of the House) changed his mind (or never thought it was a good idea but did not want to say in front of the others) and told Michael to stop the project. Michael told him it was too late, I had already started. He issued me a pass (bright yellow with a red stripe, to indicate that I was a temporary member of staff in the House of Lords) and I started tiptoeing around the corridors.

I borrowed some posh frocks from my mother, as trousers were deemed too casual for women in those days, and summoned the ghost of a well-mannered and well-spoken persona from my past. Every morning that I visited the Lords I went to Michael's outer office, hung up my coat and gossiped with his personal assistants, giving me a sense of belonging from which I derived the courage to gradually treat the House of Lords as familiar. Writing about it some years later involved a huge effort of mental detachment, to try and see it through the eyes of a visitor once again:

To enter the House of Lords is to be translated from the gritty urban pavement to a serene and comfortable palace, where there is time for laughter, 
letters are often handwritten and a drink at eleven o'clock in the morning does not necessarily mean tea.

(Crewe 2005: 1)

That book was tortuous to write. I had my second baby in the middle (2001) so my brain became foggy and my body reluctant to leave home. As the first anthropologist in the UK Parliament I did not want to mess it up for others to follow by alienating my informants to the point of hostility. But most of all, because I had far too much data. For four years (1998-2002), ${ }^{4}$ but most intensively during the first year, I visited the Lords somewhere between once and four times a week. I carried out formal unstructured interviews (for 30 minutes to 4 hours) with 119 peers (I interviewed more later), 63 House of Lords staff, and 26 others (advisers, former staff, secretaries, police officers, postal workers, academics, peers' spouses/relatives, journalists, Commons' staff, civil society organisation staff and visitors). But that constituted only a small fraction of the conversations I had snatching political gossip with peers in the lobby before they went into the chamber, and in the office within which crossbenchers kindly gave me a desk, talking to clerks and other staff over lunch in the Lords cafe or bar, and joking during every visit with the doorkeepers.

The doorkeepers alarmed me initially, then all retired armed services men of a certain age, with their unparalleled standard of British banter. I couldn't do it at first. Their teasing, sharp observation and word plays were too quick for me. But I learned over time the skill of doorkeeper banter - not to take offence at teasing ('Emma, you can't wear brown shoes in town') and to tease back but not in front of peers; to judge how and when to rib peers or flip back into respect if not reverence; and not to banter with the one doorkeeper who always frowned at me. I became addicted and never visited the House of Lords without lurking in Lords' lobby with these avuncular figures. Alongside the banter, they were an incredible source of gossip about everything from the timings of votes to who was quarrelling with who and what was likely to happen next. When I tracked the legislation to exclude the hereditary peers I watched every public debate and even assisted the clerks in running the election to choose those that stayed behind. I accompanied the Staff Adviser, Derek Dunn, when he interviewed staff as part of his continual process of reviews. I became obsessed by the place and by parliament. In the words of the Principal Doorkeeper, Mick Skelton, I became part of the fixtures and fittings.

Some peers treated me with suspicion, either because anthropology was mysterious or, in one case, because it wasn't. One crossbencher (peers with no party political affiliation) who had studied anthropology several decades earlier questioned my right to portray them. A good question but not one to be paralysed by, I decided; my answer was to promise to work as hard as possible to come up with a persuasive portrayal. Some male peers flirted, many women communicated materteral solidarity; most revelled in telling me their life stories, a few were uncomfortable being questioned. What I shared in common with all those 
prepared to talk to me was a relish in political talk. Whether hearing their tales of triumph or failure, gossiping about backroom deals or discussing how parliament works, it was a conversational pleasure almost without exception. Only the most narcissistic peers, only interested in themselves and their own greatness, failed to be delighted to talk to an obsessed outsider.

It was during this study that I came to realise how thoroughly obscured the full story about our Parliament is from public view. When my book on the Lords was published those working there were surprised by some of the insights: they discovered about some habits, perspectives and events for the first time. This was partly because although it is like a village in its intimacy and small population, relative to the Commons in any case, nonetheless there are groups across the House that rarely meet. If you encounter relative strangers, or even people you work with regularly, you can't normally ask them, 'Why did you do that? What are your feelings about $x$ ? Tell me your whole life story', whereas an anthropologist can get away with a position of ignorance and absurd curiosity. Everyone understood that my topic was so broad, that I might ask about anything, even if they were initially surprised to be interviewed by an anthropologist, as former Foreign Secretary Geoffrey Howe clearly was:

Five or six years ago I was astonished to find myself being interviewed in the House of Lords' Royal Gallery by an engaging young woman anthropologist. Surely, I thought, there must be more rewarding places for her to work amongst Samoan tribesmen or Kalahari nomads, for example. I could not have been more wrong. For Emma Crewe has now produced a uniquely perceptive, thought-provoking (and often entertaining) study of the most undervalued component of Britain's unwritten constitution. All the more so, because she has been gathering her (often fly-on-the-wall) evidence from a vibrant variety of sources - from displaced dukes to all-observant doorkeepers.

(2006)

The Lords of Parliament: Manners, Rituals and Politics (2005) was a rather conventional post-structuralist account of culture, elegantly written (because it was edited by my husband Nicholas Vester and he is a better wordsmith than I am) but slightly old-fashioned in its presentation of information. I was trained to write more in an ethnography than you need for your argument, in case other anthropologists may find it useful for developing alternative arguments, but I should have made the significance of my findings more explicit.

As an aside on post-structuralism, since completing a book with Elizabeth Harrison (1998), strongly under the influence of Bourdieu and feminism, I had been wrestling with the structure versus agency debate. In our final chapter of Whose Development? we explained that the development 'industry' is not a cohesive machine but a complex mess in which constraining ideologies or rules and individual agency are in a dialectic relationship. But what was this Hegelian 'dialectical relationship' exactly? Were all, some or a few people alternatively constrained and then free to create some room for manoeuvre? I returned to it but was unable to 
resolve this in the book about the Lords. The biggest missed opportunity was in my discussion of rituals. Following the line taken by philosopher Stephen Lukes, I argued that rituals and symbols mobilise consent in the House of Lords. Their titles act as symbolic capital that can be converted into power elsewhere and their ethos of equal independent-minded influence reduces their incentive to challenge existing power hierarchies. So far so good, but I failed to write adequately about individual history and agency. Very occasionally individuals can have some success at revising policy or law in the House of Lords, in fact more easily than in the Commons, so backbenchers have the feeling that they are transcending their individual powerlessness, even becoming influential in the vital process of revising law. But it depends which political party they belong to, whether they are government, opposition or crossbench, and how many allies they have elsewhere. But then I stop. I do not explain how individuals navigate the Lords as individuals rather than as members of various groups and never directly grapple with the paradox of politicians' experience being both individual and socially constrained at the same time. I finally hint at this when writing about the House of Commons (2015a), and expand on this in Chapter 8 of this book, but I am getting ahead of myself.

In 2010 I turned my attention to the House of Commons. ${ }^{5}$ This time I made an appointment with Malcolm Jack (later Sir), the Clerk and CEO of the House of Commons. I knew him slightly because I had invited him to a conference in Hamburg, jointly organised with Marion G. Müller (with whom I later edited the conference proceedings, Crewe and Müller 2006). For several decades Malcolm had advised politicians as a clerk and, luckily for me, he had reached the top of the hierarchy just as I was ready to study the Commons. His advice to me about doing research on politics reflects his immediate grasp of how the anthropological method is a social and political process: 'Don't get too close to anyone - if you do you will alienate others' and, 'If a group of MPs came into this room and we sat at that table, they would all notice where they were sitting in relation to each other, you and me.' He counselled me to be attentive to these status struggles. MPs are in competition; status preoccupies most people but MPs have the dial turned up higher than others. There is much at stake for them, and closeness is also marked by party allegiance, so I took care to avoid revealing any views that might place me close to any one of the political parties or factions. Malcolm issued a grey pass with a green stripe - indicating a member of staff of the House of Commons - and sent an email to all staff encouraging them to co-operate if I asked to talk to them. I launched into research with another piece of advice by a former MP and Government Chief Whip (then in the Lords but since died) ringing in my ears:

If I learnt one thing when I was Chief Whip in the Commons about politicians, and that is a politician has, by and large, an infinite capacity to absorb flattery ... They can be persuaded of virtually anything if it's skilful enough. If they see it and think you're just flattering then, then it's no good at all. But if you can actually find the key to making them feel really loved and good, they'll do it. 
My Commons inquiry was influenced by a sense of puzzlement on reading scholarly literature on MPs' work. The cataloguing of politicians' work into separate roles by political scientists and sociologists created tidy abstractions that did not seem to reflect the messy patterns of their working lives (Searing 1985, 1994, Rush and Giddings 2011). Systems of classification are useful if you want to measure variables and create models with the aspiration of prediction. But this was not my agenda. I wanted to observe, interrogate and draw conclusions about the political significance of what MPs actually do when they are doing politics in the various sites they navigate. My project remains one of finding meaning, rather than measuring or predicting, not only in relation to the Commons but also by drawing on the work of anthropologists in other parliaments.

My methods in the two Houses can be charted in a superficial way as seen in Figure 1.2.

I have already made it plain that feminist post-structuralism was my position during the Lords research, interlaced with an interest in history (influenced by Jonathan Spencer, Pierre Bourdieu and Maurice Bloch). Clearly whatever you find

\begin{tabular}{|c|c|}
\hline $\begin{array}{l}\text { Interaction } \\
\text { - Over } 356 \text { formal interviews (incl } 59 \\
\text { MPs, } 30 \text { former MPs, } 98 \text { peers, } 35 \\
\text { parliamentary clerks, } 80 \text { parliamentary } \\
\text { staff, } 24 \text { MPs' staff, } 11 \text { journalists, etc.) } \\
\text { - Group discussions with clerks, staff \& } \\
\text { constituency MP/staff } \\
\text { - Informal conversations/gossip + } \\
\text { 1000s in Westminster and constituencies } \\
\text { - Shadowing staff, peers and MPs } \\
\text { - Attending meetings and policy } \\
\text { forums, workshops and conferences to } \\
\text { advise or participate }\end{array}$ & $\begin{array}{l}\text { Mini-histories } \\
\text { - House of Lords Bill } 1999 \\
\text { - } \quad \text { Selection of a parliamentary candidate } \\
2013 \text { (with candidate) } \\
\text { - } \quad \text { Eastleigh by-election } 2013 \\
\text { - Children's and Families Bill } \\
2012-14 \\
\text { - History of expenses scandal } \\
2016-19 \text { (with Andrew Walker) } \\
\text { - MPs in constituencies } 2018 \text { (with } \\
\text { Nicholas Sarra) } \\
\text { - Chairs of select committees } 2019 \text { (with } \\
\text { Nicholas Sarra) }\end{array}$ \\
\hline $\begin{array}{l}\text { Literature review \& outputs } \\
\text { - Review of biographies, diaries \& } \\
\text { parliamentary studies literature } \\
\text { - } \text { Five books (including two } \\
\text { ethnographies) } \\
\text { - } 15 \text { chapters and journal articles } \\
\text { - Radio programmes, podcasts and talks } \\
\text { (e.g., with Mark D'Arcy, Iain Dale and } \\
\text { Rafael Behr) } \\
\text { (www.emmacrewe.com for details) }\end{array}$ & $\begin{array}{l}\text { Observation } \\
\text { - } \quad \text { Chamber \& Select Committees meetings } \\
\text { (F2F and Parliament TV) } \\
\text { - } \quad \text { Staff meetings, staff/MP meetings } \\
\text { - } \quad \text { APPGs \& other meetings } \\
\text { - } \quad \text { Media (press, radio, TV, web, } \\
\text { twitter) } \\
\text { - Nine constituencies: interviews, } \\
\text { surgeries \& meetings }\end{array}$ \\
\hline
\end{tabular}

FIGURE 1.2 My research in the UK Parliament 1998-2020. 
in parliament has its tentacles in the past. I had some vague sense that I needed to make better decisions than I had previously about which tentacles to look at and how to discern what shape they were and what processes they were creating.

My thinking shifted between studying the Lords and Commons in various ways. As a decade passed between the two studies, my experience of fathoming organisations took a double leap. First, I managed an NGO and was mentored by two unusual management specialists (2005-11). Richard Livesey-Haworth, my first Chair of Trustees, taught me much about political ethics and the tactics of management. The first time I asked him whether he thought we needed to take an issue to the board he replied, 'probably but the timing depends on whether you want to ask for approval or forgiveness'. I learned from him that to be politically savvy in an organisation, every day continual research is needed to work out motivations, power struggles and incentives. Second, the next Chair, Chris Mowles, invited me to join the faculty teaching management at the University of Hertfordshire, supervising students to get their professional doctorates by research. This faculty group shares an interest in specific interdisciplinary strands of theory: process sociology or anthropology (e.g., Norbert Elias and Bourdieu); American pragmatism (especially George Herbert Mead and John Dewey), to understand how individuals gesture and respond to each other through improvised practice rather than rule-bound 'systems'; complexity science to help explain the unevenness of history and unpredictability of the future; and finally, group analytical theory (e.g., Foulkes 1948). This teaching has had a significant influence on how I undertake research (as I explain in Chapter 9).

The final source of influence in my study of parliaments has been to return to Eastern Africa and South and South-East Asia to work on comparative studies of parliaments. In 2014 Ruth Fox (Director, Hansard Society) and I secured funding to enable scholars from anthropology, policy studies and public administration to look at their parliaments in Bangladesh and Ethiopia. ${ }^{6}$ We all agreed that a healthy democracy needs researchers to take a close look at the claims, relationships and performances of politicians. The Hansard Society scrutinises not only parliament as an institution but how it is seen by the public and it occurred to us that this project could bring together the interests of parliamentary studies (usually considering the institution) with those of development studies (looking at citizens, civil society and the private sector). Along the way, as Ruth and I co-ordinated this project, we learned about the conflicting demands for rigour created by the different disciplines that study parliaments.

We then scaled it up with a larger programme in 2017 and gave 46 grants to scholars in Myanmar and Ethiopia to study the relationship between parliaments and people. Under the auspices of the Global Research Network on Parliaments and People, we went further in making the argument that all healthy democracies need scholars, breaking down boundaries between disciplines, researchers/artists/ activists and scholarship/advocacy. ${ }^{7}$ These entanglements have demonstrated the incredible potential and value of national researchers to conduct the highest quality research on parliaments if given the opportunity to design and direct it themselves. 
Amongst them are anthropologists, and other ethnographers, who deserve more opportunities to reshape the study of parliaments in their respective countries. These scholars are finding that making institutions more inclusive is not only about changing them on the inside; it is about improving the relationship between politicians and people in society, including in NGOs, creative industries, constituencies, in the private sector and so on. Investing in individuals and research organisations to produce knowledge about parliaments and scrutinise politics is vital for deepening democracy.

I will draw heavily on my own research in Westminster in this book - because I know it best and I have touched on so many themes in my research on UK politics - but also on the anthropology of parliaments located elsewhere. I will refer to anthropologists, and other anthropologically inclined ethnographers, who have written about parliaments, councils or politicians in Argentina, Bali, Bangladesh, Botswana, Brazil, Canada, France, Ethiopia, Europe, Fiji, Germany, India, Indonesia, Israel, Madagascar, Myanmar, Nepal, Nigeria, Norway, Pakistan, Pacific Islands, Portugal, New Zealand, Russia, Scandinavia, Senegal, South Africa, Tanzania, Trinidad, Turkey, Uganda, the UK, the US and Wales. By referring to ethnographic insights from parliamentary democracies from across Europe, the Americas, Asia, the Pacific Region, the Middle East and Africa, the well-worn geo-political categories of parliamentary studies are transgressed. Any theory about parliamentary democracies needs to take account of both global patterns and local specificity. Anthropology is uniquely placed to respond to this need.

\section{Notes}

1 Dadabhai Naoroji, HC Debates, 12 February 1895, col. 571.

2 https://www.parliament.scot/newsandmediacentre/112636.aspx, accessed 5 January 2020.

3 Lord Chancellor, Derry Irvine, had his official residence in the Palace of Westminster redecorated at a cost of $\{650 \mathrm{k}$. When he joked that it wouldn't collapse, like products from the DIY store B\&Q, it did not go down well. The huge cost was partly the result of asking the authorities to aim for an historically authentic standard, for example, in handpainted Pugin design wallpaper.

4 This was funded by an Economic and Social Research Council Grant (R000237788) under the title, 'An Ethnography of Culture and Power in the House of Lords'.

5 From 2011 to 2013 this was funded by a Leverhulme Trust Research Fellowship entitled 'Navigating Multiple Roles'.

6 The programme was 'Parliamentary effectiveness: public engagement for poverty reduction in Bangladesh and Ethiopia' funded by an Economic and Social Research Council Grant (ES/L005409/1).

7 This programme, 'Deepening Democracy', was funded by the Arts and Humanities Research Council (AH/R005435/1), and its findings can be found on www.grnpp.org, accessed 22 June 2020. 
$\because$ Taylor \& Francis

Taylor \& Francis Group

http://taylorandfrancis.com 


\section{PART I}

\section{The sociality of parliaments}

The study of parliament has traditionally been cautious, conservative and judgemental. It has been dominated by historians surveying politicians' biographies and attempts at reform; political scientists evaluating parliaments' performance or predicting outcomes; and legal scholars assessing constitutional problems, legislation or scrutiny and who influences these. This is all useful but leaves much unsaid. Some scholarship on parliaments suffers from a surfeit of judgement and dearth of theory; by rushing to judge, it is as if it has warped our capacity to understand. In Lords of Parliament (Crewe 2005), my final chapter was weakened when I succumbed to the temptation to make recommendations for reform (not all of which emanated from my findings) rather than theorising in sufficient depth about what I had found. Writing is a process of learning through mis-steps/takes like most endeavours so I resist the assumption that all research has to judge; in this book policy recommendations are scarcely made as the emphasis is on trying to understand.

In the literature on parliaments, most scholars tend to portray them either as an abstraction (institution, system, culture) or a collection of individuals. To investigate MPs' behaviour, most scholars rely on explaining and predicting the aggregated interests of individuals. Various versions of rational choice theory remain popular (especially in the US, e.g., see nearly all of the contributions in The Oxford Handbook of Legislative Studies, Martin, Saalfeld and Strøm 2014). This approach allows comparison between 'well-structured' parliamentary systems with empirically testable assertions, so goes the argument (Saalfeld 1995). The following basic assumptions influence rational choice theory: individuals are the basic unit of society; their goals reflect their self-interest (not just income but other stable preferences); and given options, they will go for the one with the highest expected net utility (ibid: 35 ). But few rely entirely on rational choice theory any more. It is sometimes combined with institutionalist theory, whereby individuals are constrained by the rules or norms of groups or organisations (e.g., political parties or parliaments) (ibid: 41). The only other alternative is (allegedly) ad 
hoc romantic ideas and interpretations of parliaments, say, about the theatrical nature of debate, which get in the way of finding fault and optimising performance. Martin, Saalfeld and Strøm critique 'micro-political' or in-depth studies of parliaments for their lack of potential for generalising and making causal links, claiming that it is US political science that offers the most useful research innovations (2014: 9-11). Their assertion misunderstands the basis of rigour for anthropological (and other forms of qualitative) research. This book is in part a response to this claim; I'm offering a counter-claim, aiming to demonstrate that anthropology has the potential to generalise persuasively, albeit in a different way.

In the last few years political scientists in Europe have begun to argue for innovations in methodology by adopting ethnography (Bevir and Rhodes 2010). The political scientists Marc Geddes and R.A.W. Rhodes (2018) have written about an interpretive approach to the study of legislatures influenced by their own experimentation with ethnographic methods, by my work in parliament (Crewe 2005, 2015a, 2015b), and by ethnographically inclined politics scholars Shirin Rai and Rachel Johnson (2014) and Cristina Leston-Bandeira (2016). Recognising that their colleagues are poised to burst out of rational choice theory and new institutionalism (or combinations of the two), Geddes and Rhodes invite scholars of parliament to turn their attention to beliefs, practices and traditions. Inspired by Geertz, they already understand that ethnography can be rigorous. As Geertz explains, the rigour of thick ethnographic descriptions of culture are based on interpretation whereby 'the analysis of it to be therefore not an experimental science in search of law but an interpretive one in search of meaning' (1973: 5). This book is also a response to the invitation of those political scientists - as well as ethnographers in other disciplines including anthropology - because we are agreed that there is more to discover about the nature of sociality in parliaments. Teasing out our divergent understandings of sociality could be generative as well, however, but that may need to wait for another book.

My starting point is that politics is always both individual and social. What do I mean by 'social'? If you treat the social and the individual as if they are opposites, then you tend to find yourself conceiving of the social as an entity, a structure (rather than a process), as anthropologists used to as a reaction to individualistic functionalism. In the days when structural functionalism dominated anthropology, the political 'system' served a social function. Take the work of the British anthropologist Edmund Leach. In the 1960s anthropology tidied up reality with abstractions, in part to establish a reputation for theorising and to go beyond merely describing endless specific cases as if classifying butterflies. Leach also wrote about political continuity and change - his analysis of 'systems' in highland Burma offered conceptual stability: 'while conceptual models of society are necessarily models of equilibrium systems, real societies can never be in equilibrium' (1954: 4) and 'it is necessary to represent the system as if it were stable and coherent' (ibid: 63). In reality political units in the Kachin Hills are inherently unstable, he acknowledged, and history shows that the size of political units continually shifts, often with violence, while the Kachin political system oscillates between feudal and 
egalitarian tendencies (ibid: 6). However, his conceptual equilibrium is artificial; it removes history from the theory and consigns it to the mere messiness of real life. He also divorces culture from the way people organise themselves socially, dismissing culture merely as the way people 'dress' a social situation (ibid: 16-17). Taking his area of the Kachin Hills, he finds that the cultural diversity doesn't fit with the political diversity so assumes they are unrelated, leaving his theory underestimating the significance of culture.

So if we give up on the search for either a social system or the social function of politics, then what kind of 'sociality' are we looking for? Rather than jump to an abstraction, let's consider empirically which social actors and what social processes we find in parliaments. The central actors are Members of Parliaments (MPs). In any parliamentary democracy they navigate complex, dynamic socio-political worlds in ways that have to accommodate dynamism - with every day developing with some familiarity but also variation. As individuals the specificity of their political and social performances arise in part out of their diverse identities because they are social beings as well. Identity is continually formed, and then cuts across the various social groups created by MPs based on gender, age, place of birth, residence and origin, language, nationality, ethnicity, profession (past or sometimes present), education, class, race, sexuality, relationships status, dependents and so on (Bellier 2002, Wodak 2003). When the MP representing the Kunama, a small group living in the far north of Ethiopia, is in his own village in the constituency he 'dresses up' completely differently to when in Mekelle or the capital Addis Ababa, explains Ethiopian anthropologist Mitiku Gabrehiwot (pers. comms). 'Dressing' entails putting on clothes that symbolise belonging to that group but is a metaphor for a wider social process of fitting into the cultural norms. Dressing is both social and political.

This may sound obvious but since people (journalists, the public, even civil servants) make crass generalisations about MPs all being the same, it is worth pointing out that even if they seem similar (and they are in some of the pressures they face), in many important senses they are not. To give an example from the administration of Parliament, in a bid to ensure fairness even the officials in the Westminster Parliament once provided induction and training to MPs based on assumptions of equality (in the sense of sameness) rather than diversity. When I was asked to give advice about how to improve induction (first informally and then to a select committee), I pointed to how the differences between MPs create entirely different imperatives and preferences for training so it was vital to inquire into the differences. After a series of conversations with the now Clerk/CEO of the House, John Benger (who was head of Service Delivery at the time), we co-designed a new way of doing evaluation. The House of Commons stopped the annual survey (carried out by an external marketing organisation), which provided little more than a ranking and occasional comments about malfunctioning toilets, as an example. I suggested that they use their own staff, rather than consultants, to interview MPs and MPs' staff, not only in Westminster but also in constituencies, to find out about existing services but also elicit ideas for new ones. I recommended that it 
would be hard for the most junior staff to conduct interviews, and that the most senior officials would intimidate MPs, so middle ranking officials would be the most appropriate interviewers. I briefed the interviewers about how to handle the delicate process of talking to MPs, they were trained by the Social Research Association in interviewing techniques, and they set off in pairs, armed with a checklist of questions. As a result, officials discovered precisely how different MPs found the various services provided by parliament, but also realised that there were gaps. ${ }^{1}$ Constituency staff felt isolated and one of the many innovations that came out of the project was an expansion in services provided for them. But as importantly, officials understood far more about the diverse needs of MPs. Since 2012 the approach to induction, training and evaluating services has reflected this diversity, with a new 'buddy' system for new MPs arriving in Parliament for the first time meaning that each MP is linked to an official who can respond to their individualised requests for assistance and advice. When given training, you also have to take account of the socio-political relationships between MPs - they are more likely to join courses with their trusted friends and allies and with those from the same political party. MPs navigate the world through relationships, just like any other social beings, so it is only by looking at how they relate to others that we can begin to understand who they are and what they do. The sociality of MPs has to be understood even when administering parliaments.

Within democracies three social processes of interaction are central to MPs' work and, therefore, how their worlds are configured:

- Winning votes, support and money

- Representing people

- Scrutinising the state

In each case it will become clear that these entail more than narrow political work in the sense of achieving goals. Each involves forming alliances, antagonistic factions and cross-cutting cleavages with social connections and disconnections, and various cultural meanings emerging out of them, which go far beyond political aspirations. When people vote in India, they are not merely choosing an option that promotes their self or group interest - they know that in most of India's vast constituencies they will not have any effect on the result as an individual. It is social (as well as cultural and symbolic) considerations that come into play, taking part in an event that connects them to the rest of the nation (Banerjee 2014). When politicians promise to represent a constituency in the US, it is a sense of trust and belonging that matters to those who lend their support rather than evidence that the representative is promoting voters' goals (Fenno 1978). When civil society organisations try to influence law-making, Mosse concludes that disputes 'are about how "the social" is made available for public debate and especially for the law" (2020: 26). It is important to his argument that he tells us enough about the social worlds (in this case created by caste in both India and the UK) so that we can appreciate that law is always entangled in conflicting social relations. I elaborate on 


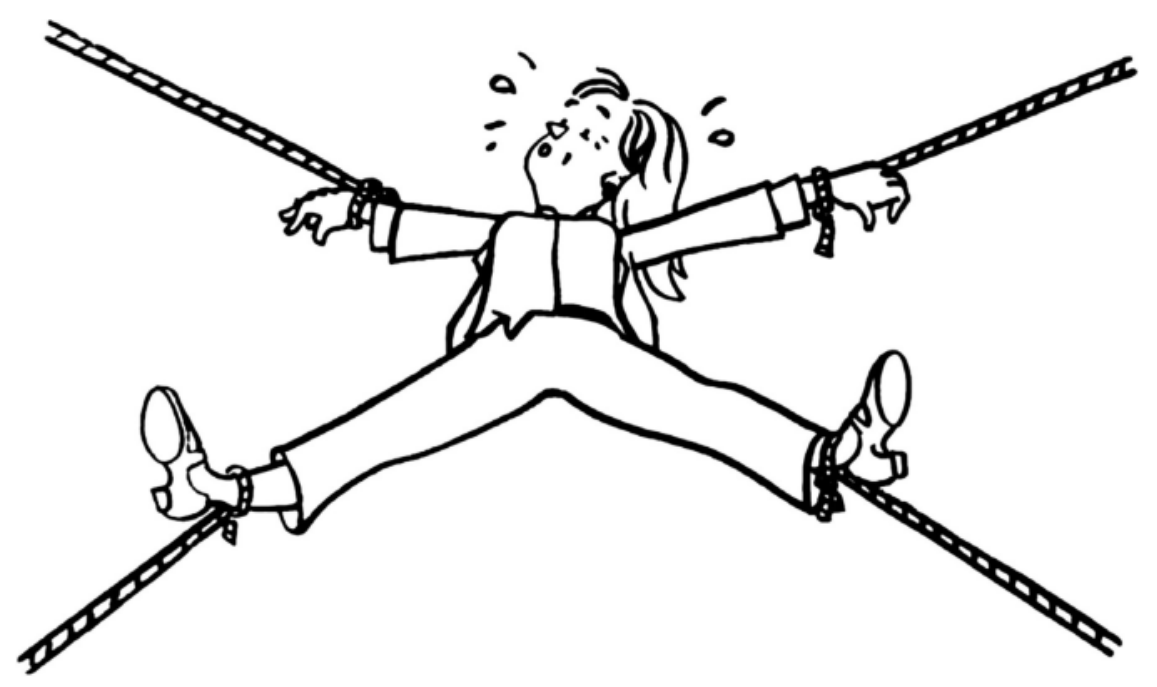

FIGURE I.1 The contradictions of political work.

these three processes in Chapters 2, 3 and 4 to explore what anthropologists mean by sociality in politics.

In Part I I am writing about the nature of everyday political work and what is involved when politicians are electioneering, representing, governing and scrutinising. According to one Conservative MP, 'It feels like Genghis Khan attaching four horses to your limbs and you are pulled in four directions' (see Figure I.1). And yet when contradictory demands are thrown up by these different kinds of work, with their various audiences and pressures, most politicians find ways of dealing with this without breaking down. The resulting inter-subjective cultures of parliaments accommodate multiple social entanglements without which democracy would die.

\section{Note}

1 https://old.parliament.uk/documents/commons-committees/admin-committee/Mem bers-and-Members-staff-interview-project-doc.pdf, accessed 13 October 2020. 


\title{
2
}

\section{THE ALCHEMY OF VOTING}

\begin{abstract}
Elections are 'a happy synthesis of liberation and revenge, secured in the ideal case without either bloodshed or massive public disorder; all the conveniences of revolution, without any of the inconveniences.'
\end{abstract}

(John Dunn as quoted by Banerjee 2014: 173)

To understand parliaments, you have to think about how parliamentarians got into the position of winning and taking their seats. Democracy means that the people, rather than Monarchs, choose their representatives and in most places this is organised by political parties trying to get their members elected. The rituals that create, renew or break the relationship between party, elected MP and represented citizens (and others) involve people casting their vote for the preferred candidate(s). Voters and preferences change, so their views have to be regularly retested through a process that will be trusted. As Spencer writes, 'the mysterious link between representative and represented is established and renewed in ritual form: through elections' (2007: 76). It is not the only way that people get into parliaments. Some houses contain appointed members (e.g., the Canadian Senate), and two also have members who inherit their right to a seat (the upper houses in Lesotho and the UK). But in by far the majority of democracies politicians have to win their seats through selection by their party and then in a public election, unless they are indirectly elected (e.g., in the Netherlands Senate, which means the individual candidates are selected by parties after the public vote). In most cases elected politicians have a specific locality as a 'constituency', but again there are exceptions: some seats reserved for women in the Bangladesh parliament have the whole country as their constituency. Fiji has no constituencies at all. Some countries have several members representing the same constituency. Weirdly, hereditary peers in the UK are elected (but only by other hereditary peers), but have no constituency outside parliament. Once they have taken their seats in parliament, MPs need to make decisions about 
law, policy and administration and in the face of inevitable differences of view, again they need a process that ensures the losers accept the result and the agreement sticks. Just like elections, voting in 'divisions' by parliamentarians is also ritualised and carefully surveilled so that no cheating is possible.

Political scientists focus on what influences people's votes or choices, or predicting and analysing results, but there is also much to be said about what voting means and does to relationships between people. It is not just the result that matters, it is that the expression of the will of the people is treated as sacred that is worthy of inquiry. What kind of magical process takes place between casting a vote as individuals and the momentous decision made by collectives that follows? What is it in the rhythm of the process of voting that makes it either so dramatic or so mundane?

\section{Elections: socially, historically and technologically embedded}

Citizens tend to assume that the most important vote in a democracy is cast by voters for a politician or party to represent you. However, you could argue that the candidate that political parties select in the first place is as influential on the process of securing a seat in parliament. As in any ritual, transformations happen in voting that are supposed to ensure that the 'will of the people' (or of the political party) are expressed in ways that are seen as legitimate. So, in an election a voter travels to a designated place, is identified, enters a private space within the room and puts a tick or cross on a piece of paper which is then turned into a 'vote' once it is counted. Ekaterina Melnikova points out that this voting process shares in common with other rituals that,

the prescribed parameters of time and place provide an understanding of the event as an event in result of which a certain activity is recoded and acquires a new meaning. What unites the actors is their participation in the very act of miraculous transformation; what divides them is their understanding of what is turned into what.

Voters in St Petersburg, Russia in March 2012, and especially older pensioners, got dressed up, bought pies or buns (which are often sold in the foyer of the polling station) and took photos of the event. Those who are unable to vote often invite members of the polling station election commission to drink tea and eat sweets. Elections have an element of festival and celebration about them. But they are also solemn events with strict rules that aim to ensure that the results are seen as legitimate. For example, the polling stations must fulfil certain criteria so that voting can be observed in general by the electoral commission but secret in the sense that individuals' choices among the electorate are not seen. The mix of tea, cake, music but also observers and police ensure that, as Melnikova puts it, 'the disciplinary space is combined with the celebratory one' (ibid: 142-3). If the polling station is 
where the voter meets the state, then the meaning of discipline will be different in Russia from other places due to its totalitarian associations.

Kimberly Coles has pioneered looking at the technology of elections from an anthropological viewpoint. She points to the social underlying democracy and as far as elections are concerned, argues that the social can be gleaned by studying the technical aspects (2004: 552-4). This technology is not merely instrumental, it is part of the social practices and artefacts that are essential to the process of doing democracy, a vital way of bolstering societal solidarity and translating the choices of people into political authority. Seeing elections as rituals is only part of the story. Democracy has to be continually remade by practices and actions of both humans and non-human objects: electoral rules, polling stations, officials, ballots and so on. In contrast to Melnikova, Coles argues that elections are more like a socially constructed scientific laboratory than a religious event. I don't see why they can't be both, in which case the task becomes one of explaining the nature of the entanglement - which is more important, for whom, when and why. It is revealing to make visible the technicalities to see how authority is established and remade in social terms.

The interweaving of the social, technical, cultural and political in voting is one of the many entanglements I will consider in this book. This question is, as always, not whether they are entangled, but whether one becomes more prominent and why or how they are part of one and the same process. Like all good anthropology, the devil (or the virtue) is in investigating the detailed practice. This entanglement is only clarified if you look with a forensic intensity at the practices involved in voting, whether dealing with errors in recording the number of ballots or arguing over how ballots should be transported. These practices mean hiding the uncertainty, ambiguity and error in any election so that the result can be trusted and deemed legitimate (ibid: 574). For example, a mistake Coles made on the 'daily accounting form worksheet' was obscured by a work around (redoing the form); so, creativity within the technology of elections reveals how social action can be part of making politics work.

Mukulika Banerjee has written about the political, sacred and technical aspects of voting, wrestling with the following puzzle: given that for many in India their vote will make no difference to the result, and the state neglects the majority whoever wins, why do they bother to vote? She finds multiple reasons and differences on the basis of class but shared incentives between them as well. The most neglected social group vote to gain a sense of empowerment and out of fear that they might lose their entitlements; those better connected to the state vote to maintain ties of patronage; while the elite vote out of a sense of civic duty and/or to protect their position (2014: 168). At the same time all Indian voters 'understand that unless they come together and participate in elections, the whole edifice of political democracy will collapse' (ibid: 169). Those are the political reasons. But elections are socially significant too. They are carnivalesque; festive occasions where people get dressed up in new or best colourful clothes, embroidered chadars and flowers in their hair, as if getting ready to do puja at the temple. The special biscuits laid out 
on best china (ibid: 139, 124) remind us of the Russian pies and buns that Melnikova told us about. Elections are rituals when normal rules get turned upside down and the social order is reversed - creating some of what Turner called 'communitas' - as powerful people beg for votes in stark contrast to everyday hierarchies when poor people beg them for goods or help (ibid: 172). The usual hierarchies of caste and class are inverted during voting while the result is to transform a candidate into someone god-like. And elections provide a rare opportunity for people to participate in politics as individual citizens, when their citizenship is, therefore, remade, and so voting acts as one of the processes that mediate between citizens and the state (ibid: 182). In the moment of voting, divisions based on gender, caste or class can be transcended.

Banerjee offers a story, related by Mekhala Krishnamurty, one of the researchers in her project, to encapsulate what voting means in India. An elderly woman in Madhya Pradesh was distraught when she lost her voting card, and when researchers tried to console her by saying it was only one vote she replied:

You see me? My work is to sweep up all the grain that falls from the sacks and the weighing scales on the floor. At the end of the day, I sell what I have collected and I am allowed to keep half the money. That is my income. So you see, I understand the value of each grain of wheat. On the floor they look insignificant, just one isolated grain of wheat, but each grain that is added to the heap determines what I earn. My vote is like those grains of wheat.

(ibid: 2)

Writing anything about such a vast continent is always incredibly ambitious. It is not surprising then to find exceptions to these tendencies. Jelle Wouters reports that voting in Nagaland in India's remote Northeast offers a rather different picture (2015). Representative democracy and party politics were seen as an interference to communal harmony in Nagaland, the 'Naga way of life', so that two Chief Ministers went as far as to suggest abolishing elections (Wouters 2018: 214). People's experience in the run up to election is that the competition between candidates causes rivalry and division. 'Our memories are long. If a fellow villager contests and we do not wish to support him, he and his relatives, even his entire clan, take it as betrayal and grudges grow', one elderly resident told Wouters (ibid: 199). So, in 2013 they had a consultative meeting in his village and decided on a commitment to one 'village consensus-candidate', a common practice in Nagaland. When the two candidates defied this order the elders of the village rushed around reassuring everyone that the election would soon be over and normal neighbourly relations would return. Historically authority in village republics was based on wisdom accumulated over a lifetime, so age had prestige and power, especially for men, and the naivety of youth was kept in check (ibid: 122-3). Naga intellectuals complain about competitive elections and people's practices embody a critique by adapting electoral practice not to reject democracy but to create their own way of doing it. Just as we know from anthropologists that people develop their own vernacular 
ideas about what 'development' consists of (e.g. Pigg on Nepal 1992), they also tell us about how old and new forms of vernacular democracy emerge. The new forms emerge out of history with politics and culture entangled. A former politician in Nagaland provides an illustration of this, explaining how his candidacy was hindered by the conduct of past relatives:

They were well-built, strong, and excelled in village wrestling. Those days, 'might' often meant 'right' and they became somewhat domineering in their behavior and got themselves landed into disputes. Much has changed since, but the villagers remembered this. Many therefore felt reluctant to cast their vote for me. I was held accountable for deeds done long before I was even born.

(Wouters 2015: 131)

The significance of all this is that we need to investigate historical and localised interaction (the vernacular) in any part of the world to see how democracy plays out. We can't assume consistency can be found within the sometimes culturally arbitrary borders of nations - so it is safer to make an assumption of diversity rather than homogeneity within and between countries until proved otherwise.

\section{Vernacular election games in the UK}

You can't understand democracy without looking at elections and you can't fathom the importance of elections for politicians unless you look at how they perform them socially, politically and emotionally. The performance of politics involves putting on a show (Goffman 1959), both as individuals and in groups, because getting things done in democratic politics means endlessly winning support from allies (whether temporary or permanent) and outsmarting your opponents (Crewe and Sarra 2021). The putting on of a show is also a 'show' of affect or a performance of emotion. Paradoxically, the 'show' has to be perceived as authentic in order to appear plausible but this authenticity is also performative. The inevitable competition and enmity involved in democratic politics creates a magnification of normal human experience, making it a rich and complex domain for the study of power, identity and emotions.

It was only by participating myself that I appreciated the drama and addictive quality of selections and elections. An opportunity arose when a friend and colleague, who I will call Roxanne, decided to stand to be selected as a Labour candidate for the election due in 2015 and submitted an application in her neighbouring constituency within a large English city. Armed with the list of Labour members in the area, we went canvassing (Crewe 2015a: 21). In this affluent city area, members probed to find out where she placed herself. 'I'm on the left of the party with Old Labour, I agreed with our current MP - so where do you stand?' asked one, to which she replied, 'Oh yes, I am Old Labour in the sense that I am very strong on civil liberties and a great defender of the NHS ...' At one house we met the local ward Chair. Roxanne did not know anyone in this ward, 
so she did not recognise him or know who he was. He looked at her with undisguised disdain; 'Who are you exactly?' he asked. She was committing the greatest sin in UK politics - she was a total stranger locally to the party even though she lived only a few miles away.

I advised Roxanne to stress her local connections in her publicity. Unlike most job applications, which focus on individual skills and experience, I stressed that she needed to convey her commitment to the local party and its demands. She wrote this:

\section{Putting people at the heart of politics again}

Fighting for Labour, Fighting for $\mathrm{x}$

\section{Dear Labour Party Member}

Weren't you relieved when $x$ challenged the legacy of Thatcherism and reminded us of how she undermined education, health and support for those in need, setting the context for a get-rich-quick culture where the individual was more important than society?

I have lived locally for over 17 years and I am passionate about representing $x$, speaking out on issues that matter to you and putting people at the heart of politics. This desire is driven by an increasing sense of frustration with the Coalition and their policies, which lack insight, compassion and care and give relentless support for private contracts. My career so far has taught me how to give voice to the most vulnerable, especially on issues linked to health, environment and human rights ...

As the candidate for $x$, I would relish working with the local party to win the seat and campaign nationally for both local people and concerns that are close to their and my heart.

Others advised her that a photograph and strong design were essential. Nothing was untrue in her leaflet but she left out various aspects of both past and present that she once worked for a former Conservative Cabinet Minister, finds a sense of humour essential to everything she does, and runs a foundation for an oil company. She was all set except that the three front-runners, as written up by the local newspaper, all had extensive party political experience and large numbers of 'endorsements' by senior party leaders, MPs, peers and party supporters. They were local Labour councillors with decades of experience of campaigning and winning elections. We thought about canvassing more regularly but what with holding down a job, and the pressures of normal life, Roxanne did not have time in the brief gap between application and the next stage - the shortlisting. 
One chilly Sunday afternoon we joined members of the local party in a church hall for the shortlisting ordeal. Roxanne and I split up to work the room, but I had realised by now that she was competing against three candidates who started fighting for this many years earlier and who were, therefore, far ahead in the race. The Chair of the Constituency Party called the meeting to order once over 100 people had arrived and the ten candidates were on stage ready to speak to the assembled crowd. The Chair asked the first to start and each was given strictly three minutes only. Candidate 1 had only managed a few sentences when a member interrupted on a point of order, complaining that the speakers should proceed alphabetically. The Chair explained with considerable tetchiness that lots had been drawn and members should not interfere with the process. By the time the first candidate fired herself up again, the mood was charged with a suspicious current. Each spoke nervously about why they were standing, what they could offer and why they would make a good candidate; my heart was beating fast with nerves on their behalf. The old hands stressed that they would win at the General Election and work with the local party; those new to politics treated it like a normal job application and talked about their motivation, experience and talent. The woman next to me complained that one of the novices talked too much about themselves; the performance of selflessness was obligatory from her viewpoint.

The candidates then moved from table to table being questioned by party members for 5-10 minutes each. On my table they asked the candidates questions about their politics, gauging where they stood on the symbolically important issues: 'What would you do about the privatisation of the health service?' 'How would you pay for the reversal of cuts?' 'What would you do about free schools?' To the latter one of the front-runners replied: 'I don't like free schools and I wouldn't have supported them but now that we have them, I don't think there is any point getting rid of them.' A member shot back with a look of fury: 'So you would just let them be?' When the table decided the process was at an end, the candidate turned to me panic-stricken to explain her position on education in more detail, as if I would in turn explain it to others when I had a chance. It helped me realise how nerve-wracking it was to be judged on your views, and your performance in conveying them, at the same time. (It was this candidate who argued that free schools should stay who finally became an MP.)

A few days later the party members met and selected their shortlist. All three of those chosen were the same front-runners who were identified by the local newspaper some weeks before. They shared in common: snazzy personal websites, endorsements by senior party figures, a track record as local councillors, and experience of elections. One was a journalist, stood for the Westminster Parliament in 2010 and had the backing of many party figures (including a shadow frontbench spokesperson); one had worked for Labour MPs for her whole short career and had a string of endorsements (including one from a former party leader); and the third was special adviser to a senior MP with 20 years of campaigning for the Labour Party. The proportion of MPs perceived to be young generalist professional politicians, rather than older specialists who turn to politics as a second or third career, had been increasing (Crewe 2015a: 28); so this result was completely unsurprising. 


\begin{tabular}{|l|l|}
\hline Area of concern & Brief comments \\
\hline Campaigning & $\begin{array}{l}\text { We thought you have the potential to be } \\
\text { an excellent candidate in the future given } \\
\text { your extensive public sector experience. }\end{array}$ \\
& $\begin{array}{l}\text { However, we would like you to get } \\
\text { involved in the voluntary and campaign- } \\
\text { ing aspects of the local Labour Party }\end{array}$ \\
before standing for public office. We \\
would also like you to research and learn \\
more about local government structure.
\end{tabular}

FIGURE 2.1 Assessment of a local government candidate.

Roxanne was told that she hadn't made it. She realised that to have any hope of being a parliamentary candidate she needed to be a councillor first, so she applied to stand for local government. The assessment panel turned her down for lack of experience of campaigning and knowledge of government (see Figure 2.1 for the reasons).

Eligibility for public office from the perspective of officials in that Labour Party constituency means connections of a certain kind: to get onto the shortlist you need to be part of the local and national party network. If you study any local party list of activities it is clear that this means, at the least, an exhaustingly timeconsuming commitment over many years of canvassing on doorsteps, stalls and marketplaces - challenging for anyone with dependents and/or an existing demanding career. For the local party members it means being known, in relationships with other members, but also sharing their loyalties - in this case to unions and the welfare state in opposition to the private sector - as signalled by shared rhetoric.

What conclusions can we draw from this narrative? Patronage from well-known figures in the party helps you get into the UK Parliament and you are unlikely to win unless you have contributed enough labour (in the sense of political work) to the party through meetings, canvassing and leafleting, for other candidates as well as for yourself. The performance of selflessness and commitment to the common cause were both essential. In Conservative, Labour and Liberal Democrat parties, MPs and activists have talked about how connections in the party and the patronage of big players in the party helps. ${ }^{1}$ Those big players want to build up their support base; the presence of indebted, bright young new MPs can be extremely useful when pursuing their own ambitions to get a ministerial position. This is especially true if you are a woman or part of a minority, because you tend to start with an in-built disadvantage, so mechanisms of inclusion have to be seen alongside exclusionary processes. As one former Lib Dem MP put it: 'Usually the problem for women getting into Parliament is not the electorate but the selectorate', that is, not the voters but party members. ${ }^{2}$ Gendered inequalities show up in various competitive political processes and selections are no exception. Betty Boothroyd was told in West Bromwich: 
'Well I don't think I'm going to vote for you because you're unmarried, you don't know anything about life, you don't have any children or know what it is to make ends meet on a low income. You don't know how to run a house. I'm certainly not going to vote for you' (McDougall 1998: 30). It is as if women are not trusted if they don't have children but if they have them (or other dependents), then the pressure on their time is (and is seen as) problematic.

Even today women are still asked as candidates how they will cope with managing two homes if they have children, or what their husbands will think about them running off to Westminster. A woman candidate in 2010 was not unusual in being told: 'I think you are evil. Your children will suffer.' ${ }^{3}$ Selectorates have created barriers for women across the world historically, with some notable exceptions in recent years created by quotas (Kenny 2013) or party policy (e.g., in Ethiopia, Ayenew et al. 2019). But hostile policies and attitudes are not the only reasons that women hesitate to stand. In the UK it is clearly extremely difficult to work as an MP, running two homes and workplaces if your constituency is outside London, and especially if you have children or other dependents unless you have an additional income or a spouse or relative who takes care of the family. Some do the sums and conclude it is not financially possible because childcare costs are extremely high if you need care at any time of day or night at short notice. Partly because it is less likely for women that their co-partner will be willing or able to step in, the consequence was in 2013 that only 55\% of women MPs had children, while $72 \%$ of men MPs were parents (Campbell and Childs 2015: 489).

To return to the question of patronage in selections, I have mentioned that in the UK having well-known senior politicians as 'patrons' helps a candidate's campaign to get selected within the party. This favours those who are already well-connected. Publicising a close relationship with a party VIP means that the candidate improves their chances, while the patron anticipates the benefit of new MPs who are likely to support their causes. However, patronage is usually associated with financial benefit and in some places this is clearly a part of the reciprocal support. Bueno de Mesquita et al. claim that selectorates, that is, the group that chooses a country's political leadership, have to be 'bought', whether by private goods like favourable contracts or by public policies that they agree with (1999: 149). But the potential for paying out private goods to win over potential supporters in the UK is far lower than other places, the US for instance (Bull and Newell 2003), and even rarer in countries with high political competition and media scrutiny such as Sweden (Svaleryd and Vlachos 2009). To understand how patronage works in contemporary Bangladeshi politics you have to look at the history of the two main political parties and how they operate in what has become a weak state but a strong society (Lewis 2011: 103). The patron-client relations are organised around the Awami League versus the Bangladesh National Party who took turns to form governments until 2014 (when the latter boycotted the election), using their power to build up state structures with their supporters (Lewis 2011, Ahmed 2020). But the details of everyday patronage between politicians, and between them and their potential supporters, from the 
beginning to the end of people's careers, remains partly in the shadows (Piliavsky 2014: 14). The anthropological work in Piliavsky's edited volume reveals that it is important not only to understand the political economy of these relationships but also how they are infused with morality. As Piliavsky concludes, wherever and whenever you study, 'Political giving is never only a matter of redistributing resources, it is necessarily a rhetorical act that conveys largesse as a politician's virtue' (ibid: 19), which is partly why patronage is so often expressed in the language of kinship.

It is when candidates move from selection to election that processes get seriously showy. Once selected by your party, or deciding to stand as an independent, elections require relentless intelligence-gathering and making socio-political connections, especially during by-elections. I witnessed this at a by-election in Eastleigh in 2013. For three weeks the nation's eyes turned to this Hampshire town in the South of England to watch the Liberal Democrats and Conservatives battle it out on the doorsteps. Labour aimed to come in as a respectable third. Only two years from a General Election, a poor performance would reflect badly on the leaders. They only remain at the top of their parties as long as their colleagues view them as an electoral asset so David Cameron (then Prime Minister and leader of the Conservatives), Ed Miliband (Leader of the Opposition and of the Labour Party) and Nick Clegg (Deputy Prime Minister and leader of the Liberal Democrats) poured staggering amounts of their time, and demanded it from their MPs and even ministers, into the campaigns in Eastleigh.

I began my campaigning with the Lib Dems (Crewe 2015a: 30). I walked into their headquarters in a Business Park as one of a constant trickle of volunteers. They sent out calls for volunteers by emails, blogs and twitter and 100s were arriving daily from as far as Aberdeen, 400 on one day. A friendly activist immediately slapped a white sticker onto my lapel - I had to choose 'Driver', 'Clerical', 'Canvasser' or 'Deliverer' - alongside another orange one saying: 'I like Mike' (the name of the candidate). On the first floor I found virtually the whole party's media machine shipped from London to Eastleigh, working the phones, producing materials, connecting with journalists, party people and activists in a factory-like election production process. The excitement of it still crackles in my memory.

The point of sending canvassers out to knock on doors is not to convert the voters - most activists don't have the skills to do that - but to find out voters' intentions and priorities and then convert the waverers into supporters with leaflets. This is true of all the political parties but especially Lib Dems, who have to fight harder to win elections. They couldn't rely on traditional banks of support; they needed to use clever political tactics. Canvassing has become a form of intelligence-gathering through conversations, analysed alongside opinion poll and survey data, and the LD operation is highly sophisticated. Some of this intelligence was done by phone and some by visiting people's homes in Eastleigh. On the day I went, volunteers were tutored at lightning speed by a US election strategist, who explained that they had slightly different questions on the doorsteps each day: 
(1) Do you plan to vote LD? If no, forget the other two - they don't need literature. If yes, then ask the next two; (2) Do you have a postal vote? Have you sent it? (3) Are you willing to help? If they say no to (1) then you record their intentions - not only which party they might vote for but what mix of affiliation they may tend towards, so LD leaning Tory is a yellow Tory, for example.

Once we returned our forms, the Clerical workers would put them in the database, allowing them to produce lists to be handed to the Deliverers so they knew which letterboxes needed leaflets. The media team had already produced specific leaflets, different versions for different communities and for voters with different intentions. In addition to leafleting, every five seconds a Lib Dem activist phoned an elector. The scale and efficiency was matched by the grit. One of the LD councillors was in hospital for an operation to remove a cyst on Tuesday and was back out canvassing by Wednesday, not wanting to let down his colleagues.

A vital aspect of an election campaign is to perform to the media. One evening I was at the HQ, chatting to MPs and activists in a festival mood, waiting for Mike Thornton (the candidate) to arrive with the Leader, then Deputy Prime Minister Nick Clegg. A young woman stood on a platform of boxes and began to whip up an atmosphere with accomplishments punctuated by cheers. 'We are up to 1000 calls in 90 mins, 320 volunteers through the door today, 1500 for the week, distributed 70,000 leaflets, 5,000 phone calls, and knocked on 10,000 doors.' She thanked and thanked and thanked colleagues for their hard work and success. The core campaigners were working from 8 am to midnight every day but somehow at the required moment they drummed up a buzz of anticipatory camera-ready excitement. And then suddenly Nick and Mike appeared to give rousing speeches about more achievements, surrounded by euphoric organisers in a tight gaggle, vital for galvanising their support but also for giving the impression on Sky News that the campaign had momentum and huge numbers of people at the core. Such a mood is normally confined to party conferences or General Elections, so it seemed to me at this point that a by-election is an unusual opportunity to create some precious communitas among the troops. I can still easily conjure the memory of jangling emotional excitement, both embodied as an individual and shared with a small crowd.

I also canvassed with the Conservatives beginning at their club, an impressive mansion with cornices and plush carpets, thronging with MPs on the day I visited. I met up with Sir George Young MP, the then Government Chief Whip, who was one of the few MPs I stalked regularly (with his consent). We were given our forms, leaflets and a map and set off with a woman MP. George and the other MP handed me the canvassing printouts and we whizzed from door to door at a cracking pace, far faster than the LD canvassers. The printouts had names and addresses but less information than the Liberals about voter intentions in this constituency. If he had an opening, George's patter was: 'I hope you will consider voting for the Conservative candidate. Maria Hutchings is a local girl, I have 
known her for 4-5 years and she will be a marvellous MP.' Then, like many MPs, he would glance at the house and garden and work out what they might be interested in: children's toys, he would talk about education; posh cars he would talk about the fuel price freeze; an affluent house he might talk about tax. All Tory MPs were asked to do three stints but some were skiing or shooting, so one Conservative MP told me, and they were short-staffed. With a shortage of money and volunteers, winning elections has become hard graft. We bumped into a Secretary of State so I asked him why so many MPs and even cabinet ministers were knocking on doors. He said that the local party needs the resources and it is important that the voters don't think you are taking them for granted. I wondered whether their presence was also partly to win support from colleagues in the party. Whether seen by fellow activists, or photographed by the media, perhaps when MPs, ministers and even the PM are seen backing the party this egalitarian business of electioneering is a rare opportunity to engender a shared party spirit and loyalty.

Finally, with strictly equal enthusiasm I campaigned with Labour. As is often the case with by-elections, the shortlist was drawn up by Labour National Executive Committee rather than the local party. They knew that they were going to lose so they picked a candidate who would at least get them some good press attention, the writer John O'Farrell. He braced himself for the strangeness of being a candidate: 'you can't just be your normal everyday self in democratic politics. You have to put on clothes you wouldn't normally wear - metaphorically and literally' (2014). He did not lose his sense of humour, tweeting mid campaign that when a voter told him: 'I'll vote for you if you pay for a boob job,' he replied: 'Not sure if that is an actual spending commitment, we'll look at economy in 2015.'

Canvassing with Labour was relaxed. I travelled down on the train with my own MP, Andy Slaughter, who had tolerated me as an occasional shadow, and a colleague of his, a woman MP. I asked them why MPs canvassed so much at byelections. They said it was partly tradition, shortage of activists in Eastleigh, and whips asserting their authority for the sake of it. At the Labour HQ, a small Victorian red brick house with worn carpets and peeling paint, I was greeted by elderly men with Yorkshire accents and young women with brightly dyed hair. As we tramped the streets of Eastleigh - getting lost, cold and with sore feet - the Labour MPs gossiped about their time in government, past whips and leaders. Canvassing is an opportunity for consolidating party loyalty through rallies, walking the streets together but also swopping stories about shared political experiences, people repeatedly told me. The prospects for winning affected the parties but the cultural and aesthetic differences between them were obvious too. In the Conservative club I was offered a glass of wine or beer, with the Lib Dems I drank water, while the Labour activists handed me tea. This matters because such habits play a part in creating a sense of belonging or alienation for those participating.

On the day of the election I canvassed one last time with the Lib Dem Simon Hughes MP. He took me 'knocking people up' and gave me a crash course on election day canvassing. I was the Driver. When you knock on doors, you must 
take care not to wake babies or, in rural areas, chickens. You should not talk too much and take care with direct questions: 'Do you have children?' would be tactless to a childless couple desperate for offspring; 'How do your parents find the health services?' would upset those whose parents were dead. (You should use an indirect approach by asking about local schools or the generation above.) But the performative aspect of talking to people when they open their doors is not only in using your imagination to discern difference and taking care with emotional sensitivities. What is harder to explain is the effect Simon Hughes had on the intensity of the engagement: his unusually potent charisma gave him an ability to create intimacy with strangers in moments. In contrast to other canvassers, who appeared to have minimal impact on those opening the door to them - or even faced complaints about the quantity of campaign literature and had doors slammed in their face - Hughes connected with total strangers within 5-10 seconds. He fixed them with an intense gaze and the hint of a smile and said in an intimate, confiding way, 'I will be the last person to pester you tonight', and they would almost instantly tell him what they were thinking about the election, how they voted and why. One man voted for the Conservatives so he gently teased him and slapped him on the side of the arm quite hard. But he did not seem to mind; he looked tinkled pink. At one door he met a Labour voter:

'I'm a Labour girl, have been all my life. Normally I vote LD tactically but this time I couldn't bring myself to. Because of the coalition.'

'Do you mind me asking how you did vote?' Simon added.

'You won't believe me.'

'Try me.'

'Peace party.'

'Ohhhhh. You obviously know that is a vote for the Tory party.'

'I know, I know ... I agonised.'

'At the next election will you consider voting for Mike?'

'Yes, to be honest if you had been here 30 minutes ago I might have voted for him. I will.'

This may have been partly his celebrity but even those who hadn't heard of him seemed entranced, acting as if they had known him for years rather than moments.

Talking to people on election day itself is also about finding out who has voted. When the potential voter answers whether or not they have already voted it is essential to send the information back to HQ so that they can be taken off the lists and won't be pestered again. In Eastleigh the LD did four sweeps on election day of the whole constituency, each time minus people who had voted as they were struck off the printouts. Meantime activists from around the country were phoning LD voters to encourage them to go to the polling booths. At ten minutes to 10 $\mathrm{pm}$, the close of the vote, party members (including extremely senior ones) were still phoning like crazy. In the final minutes they 'knocked up' residents within five minutes' walk of polling booths and checked that they had voted. 
At the Count, in a soulless Leisure Centre, people sat at lines of trestle tables counting votes. Each party's election agents doubled up as scrutineers, checking no mistakes were being made, but also counting how many votes their party had received in a sample. The LDs crunched the sample vote in a laptop and came up with the result well before it was officially announced. The technology of counting the vote was obscured by the ritualised performance of celebration. Once again, the political parties and the cameras colluded to make sure that the performance was festive; everyone knew what had to be done. The TV needed some drama, so the political parties arranged some. First came a small gaggle of Liberal Democrats waving orange 'I like Mike' banners, cheering as loudly as their exhausted beings could muster, and crowding around the candidate as tightly as possible. The cameras descended on them, urgent and close up, giving the impression of a massive and spontaneous crowd. The spectators looked on with wry amusement at this tiny huddle of showy supporters in a large mostly empty gym, providing some entertainment for the cameras, starved as they were of action and relying mostly on talking heads in studios with nothing new to say. The others followed with their own band of supporters at five-minute intervals. Diane James for the UK Independence Party came next with supporters in purple, looking equally buoyant and noisy. A gap and then John O'Farrell breezed in with an air of weary sophistication and his Labour crew in dark long coats and red badges looking like a unionised mafia. Finally, Maria Hutchings, the Conservative candidate, appeared dressed in dark navy blue, surrounded by anxiety as their impending defeat was becoming clear.

Canvassing for elections entails a heady mix of order and disorder - the mechanical work of intelligence-gathering and counting, on the one hand, and theatrical performance to engage people's attention (in conversation or through cameras and mediators) or outwit your opponents, on the other. Bad press for a good MP can ruin a good party campaign so the devil of negative campaigning tempts some. One Labour Party activist told me that in one general election he couldn't resist pointing out to a journalist that if he took a photo of a candidate in his Speedo swimming trunks from a particular angle then it would read, 'peedo'. The swimmer lost at the election. One of the most famous mudslinging campaigns took place in Bermondsey in 1983. A Lib Dem leaflet described the election as a straight choice (misreported as 'the straight choice'). ${ }^{5}$ Lib Dem canvassers walked around with badges saying: 'I've been kissed by x' (that is, the gay Labour candidate) badges and an anonymous leaflet asked: 'Which Queen Will You Vote For?', even supplying Mr x's phone number and address. Candidates will go to incredible lengths to get into parliament: trying again and again despite failing to win a seat, giving up their jobs, enduring vicious attacks from opponents (prospective politicians and countless others), attacking or even lying about opponents in their turn, and spending huge amounts of money. In a survey carried out by journalist Isabel Hardman she found that MPs spend an average of over $f 11 \mathrm{k}$ of their own money on electioneering to get into the Westminster Parliament (i.e., 12.5\% of their annual salary if they become MPs) and 11 spent over $\mathcal{E}_{100 \mathrm{k}}(2018: 19)$. Less is spent that it was on leaflets and more on digital advertising, but it is still expensive. 
Elections draw people in not just because they are the most participatory way to choose our representatives - conferring greater democratic legitimacy than any other method - but the solidarity and competitiveness are intoxicating. Democratic politics is like sport with ideas, UK politicians are keen on pointing out, as party members are drawn together by values in common but also a sense of social belonging. Former MP Natascha Engel describes this when worrying about whether MPs meeting on Zoom (during Covid-19) may erode team spirit:

Breaking the whip feels like a terrible act of betrayal, and in our Parliament, the disloyalty is physical. The hours building up to it, friends coming and sitting next to you in the chamber to try and dissuade you, the moment the division bell rings, standing up and walking into the other lobby - the one filled with MPs not from your party - how hard that is in person and how easy it would be online. Some might think that is a good thing, that MPs need to be more independent-minded. They certainly would be in a virtual parliament. But we would lose the reason why those party ties matter. For one thing, most people vote for a political party at elections rather than for the local candidate. Almost no MP would get to parliament without the party ticket on which they stood. It is what makes politics a team sport, and like any competitive game, it is always better live, cheering and groaning close-up with your tribe, because at heart, politics (like sport) is about actual people and their lives - a reality that is easily lost in the tiny heads and tinny voices of the virtual world. ${ }^{6}$

Whether politicians or ordinary party members, people often talk about joining and staying in or leaving parties because they share a moral and aesthetic sensibility. However, since parties change abruptly with new leaders, their support base of party members and voters shifts as well. Gone are the days when people have reliable allegiances to parties - they consume politics, and swop loyalties in the flash of an eye, rather than belong to one political 'tribe' (as they refer to them) for decades or even life. Loyalty is still a powerful inspiring and constraining influence on political relations, bonding some and excluding others, but these ties loosen more easily than they used to.

\section{Quiet rebellions: voting shifts as an indicator of social change}

In the UK the Monarch used to take the advice of his nobles until burgesses began to be elected and sent to 'Parliaments' from the thirteenth century (Crewe 2015a). Until the nineteenth century landowners or other wealthy individuals controlled over half of the seats, meaning candidates needed their favour to stand a chance. When power is concentrated in so few, with no opening to change the rules, it is common to find that elites resort to corruption. In this case it wasn't just that the controlling landowners bribed or blackmailed the voters to back his (or very occasionally her) candidate but also that the boundaries of constituencies ossified 
despite sizeable population shifts. Even though Manchester and Birmingham had huge populations by the nineteenth century, they sent no MPs to Westminster; Old Sarum in Wiltshire and Gatton in Surrey had only seven voters but two seats each. With the redrawing of boundaries and the secret ballot in the great reform acts of the nineteenth century, corruption was stamped out of UK elections, although only men were allowed to vote until 1928.

This brief snapshot of UK electoral history, and the equivalent from other Western democracies, is partly to blame for common universalising assumptions about how democratising is twinned with lower levels of corruption. But history is not that simple. Sylvia Tidey tells a tale about two mayors in Indonesia that disabuses us of such evolutionist tropes (2018). The post-Suharto drive to democratise entailed the stamping out of clientelism and corruption on the grounds that this is the only route to democracy. But voters had other ideas. Although an anti-corruption mayor was voted in during a 2007 election, five years later he was replaced with a known 'corruptor' (ibid: 125). Tidey points out that while voters might tolerate some kinds of stealing, they will not put up with a candidate who ignores the 'small people'. So, it is the betrayal of promises, and failure to recognise the intelligence of the voters, that provokes them to have a change of heart.

Aaron Ansell also found that people in Northeast Brazil were voting on the basis of anticipating loyalty versus betrayal, rather than assessing whether a politician would represent their interests or rise above a narrow liberal conception of corruption:

A good politician is one 'for all seasons' (de todos os tempos) and one who 'always walks around here' (sempre anda por aqui). A bad politician is one who 'only wants your vote' and 'only gives you value (valor) during the political period.' While politicians may boast of the enduring loyalties they have earned from village families who vote for them in sequential elections, they know that they need to do their part to secure these loyalties against the shifting sands of familial and neighborhood obligations (e.g., work partnerships, love affairs, and land disputes) that alter people's thinking about whom to vote for during the next election. Each subsequent 'proposal' visit implicitly affirms that a voter who was once captured in their numerical individuality has returned to live as a socially embedded person whose particularity awaits rediscovery.

(2018: S133)

So, voting reveals much about the relationships that people have within their communities and how politicians' connections with the community are viewed, at least in some constituencies. In larger cities, and places with huge constituencies, this may be less relevant. But it is certainly resonant of the UK where politicians in all constituencies, even in London, are expected to sustain their relationships with constituents by being present in the community and serving those who ask for help. They are far more likely to be trusted to maintain this connection if they are 
local. Campbell and Cowley's research indicates that while voters will not be strongly influenced by the gender, age or class of the candidate, they are far more likely to vote for someone who is seen as part of the community - preferably a resident in the constituency (2014).

Aside from the distinction between being an outsider or a local, politicians are seen as 'all the same' in the sense that they are lying, power-hungry and venal. The only route for them, as Robert Halfon MP suggests, is to recognise that:

the pure science of political campaigning will only have a limited degree of success - unless it is buttressed by a deep understanding of the most important ingredient - the building up of human relationships ... Human relationships, and a level of emotional intelligence, are a prerequisite to ensuring that voters don't see you as just another politician.

(quoted by Crewe 2015a: 40)

But you need both. The UK's Conservative MP Nicola Blackwood won a seat from the Liberal Democrats by finding out the intentions and concerns of $10,000 \mathrm{~s}$ of voters and sending out a million pieces of literature. Here are the ingredients of modern electioneering: nurturing relationships, gathering intelligence, making promises that respond to demands in your constituency and sustaining your connection between elections. Indeed, in the UK elections reveal a shift from patronage through a Burkean form of trustee representation towards the current more intimate connection whereby the politician is a delegate for his/her constituency. In the last few decades this has intensified with politicians being even more exposed by the 24-hour digital revolution, transforming the way that politics is performed, observed and participated in so that MPs have no rest from the endless pressure to please their supporters and potential voters.

The importance of dynamism in relationships doesn't stop with the seeking of votes to get into parliament but extends to a different form of voting once MPs take their seats: whipping to get party members to support 'divisions' (i.e., votes) as 'business' (usually law-making) goes through parliament. Both voting in elections and in divisions involves a process of alchemy. In both cases individuals express their view by casting their vote - in elections by a cross on a piece of paper and in divisions by electronic voting or (in the UK) by walking into one of the lobbies beside the debating chamber indicating yes or no. These many subjective viewpoints expressed through votes get counted up to produce a result that is seen as objective - yes versus no - turning the base elements of many subjectivities into the democratic gold of a decision that is beyond question. As if by magic, the argument stops, violence is prevented and a decision is created by the alchemy of voting. It is no surprise then that when the preparation for the voting changes, for example with new forms of massaging of the individual subjectivities, then the result is affected.

Once MPs have been voted in, voting for or against motions is a key part of their work. The pervasive scholarly view of whips - those politicians disciplining their members into obedience so that they vote with their party - is that they 
forcefully bully or bribe their members and politicians comply out of self-interest (Kam 2014). Many political scientists, and even people working in parliament, contrast the iron-like grip of UK House of Commons' whips with a feeble whipping operation in the House of Lords (Crewe 2015b: 7). All peers have a seat for life, and most have reached the pinnacle of their profession so lack career ambition, which means there are few threats or bribes at the whips' disposal in the House of Lords. So why then do the gentler whips in the House of Lords achieve relatively high levels of obedience while their Commons' equivalents deal with increasingly rebellious MPs who have so much more to gain and lose? Philip Cowley's work on divisions reveals that MPs have been more rebellious each parliament since the 1950s (2005). The Public Whip website produces figures by counting the number of times that peers and MPs vote against the majority of their party. The average for rebellion is tiny. ${ }^{7}$ Although double the number of more-than-average rebels can be found proportionately in the Lords, this raises a perplexing question: why do peers (like MPs) vote with their party the vast majority of the time even when they disagree with their leaders and whips?

To answer this puzzle you have to look at the social, cultural and political differences between the two Houses and how these are shifting. Then it becomes clear that obedience to the party's instructions in the House of Lords is only partly achieved by the whips. Three subtler social processes are at play. First, the experience of being a peer is socially all-encompassing. Elevation to the peerage, stimulating conversation, the charm and comforts of the gilded end of the Palace, \&323 a day for attendance (in 2020) ${ }^{8}$ and, above all, a sense of moral and political purpose make them humble to a collective of which they are equal members and share in its symbolic property. The deference to the will of their own House of Lords, and ultimately to the other House, is taught to peers within the rituals of lawmaking and scrutiny. They regulate their own proceedings with long-established peers encouraging restraint and punishing breaches with surprising ferocity ('selfregulation' in the words of peers); it is literally peer pressure. The seduction and deference only work effectively thanks to a third process: belonging. Belonging to political parties for life is mostly a dying pattern in the UK, but belonging has as much potency for politicians in the Lords as in the Commons, despite an ethos of 'independent-mindedness' among peers. A sense of belonging is unsurprising for former MPs, of which there are many in the Lords, especially as the MPs appointed as peers by party leaders tend to be especially loyal to party. But party loyalty stirs first-time politicians too. The late Earl Russell explained what loyalty meant to him: 'My loyalty to my party is one of the strongest emotions that I possess ... I had been here 10 years before I voted against the party Whip. ${ }^{9}$ To vote against the whip in either House can feel like a betrayal of colleagues you have taken sides with for years. Or, as one woman peer put it, when I asked about where her loyalty is directed: 'It is not to Britain, not the abstract idea of the Labour party, or to beneficiaries, it is to party members - party people. It would be very difficult to be disloyal to party people. I can't bring myself to go into the division lobby with the enemy. ${ }^{, 10}$ The key sanction for peers voting against party - shame - is extremely effective. 
Commons whips have more weapons than Lords whips. For the 140 MPs on the government 'payroll vote' in 2017, that is, with a paid or unpaid job in government, or on the Opposition frontbenches (with a position as whip or 'shadow' to a minister) you have no choice, you have to vote with your party or you will lose your job. For the rest - the backbenchers - your obedience will be rewarded with one of the following: support if you get into trouble (which MPs seem to manage rather often), 'slips' (permission to be absent for an important event like a football game or play at your children's school), a good office, an overseas trip or, most importantly, promotion to the frontbench. When government backbenchers' support wobbles, the whips arrange a meeting with the relevant minister and that often brings them around. Persistent offenders are threatened with denial of support at the next election, but since many local party associations can have a grip on this decision-making in the UK, this warning on its own can often ring hollow. Withdrawal of the whip, effectively expelling them from the party, is a serious threat, however. It was used only sparingly until recently, because it can dent party loyalty among those close to those punished. But the UK's PM Boris Johnson showed his desperation towards rebels in his own party by evicting twenty-one from his party in September 2019 with the consequence that many lost their seats in the General Election a few months later.

What does this intolerant post-rebellion approach reveal? Johnson's punitive act may have been merely a blip in a pattern in the Commons whereby increasingly whips rely on pressure exerted between MPs rather than the authority of the party leader. Most loyal party members in the Commons, like the Lords, deem defiance of the whip to be arrogant individualism or even morally suspect. They rely on this moral pressure because although whipping still constrains MPs, for a host of social, cultural and political reasons whips (and the party leaders they serve) have been losing authority. As MPs spend more and more time in constituencies, visiting at least once a fortnight in contrast to the annual trip that they tended to make a century ago, they listen to local party members and constituents more often than they used to, especially if in a marginal seat. In the UK local parties in constituencies often take less notice of the central party managers and so do their MPs. For many years defiance went almost unpunished and especially during the Labour Blair/Brown governments (1997-2010) when they had large majorities and could afford more rebellion than usual. The Labour Party's leader from 2015 to 2020, Jeremy Corbyn, was the second most rebellious MP during Labour's Blair/Brown governments; his Shadow Chancellor John McDonnell defied the whip more often than any other Labour MP.

Since 2010 whips have had even fewer bribes or threats at their disposal. They no longer choose select committee members or chairs since the whole House elects them, ${ }^{11}$ thanks to reforms brought in post the UK expenses scandal in 2009 to restore the reputation of Parliament and increase the power of the backbenchers. Stories about physical violence meted out on wayward backbenchers are also losing their intended deterrent effect; it is no longer socially acceptable to squeeze someone's balls (for those who have them) or shout verbal abuse to enforce their 
obedience; and backbenchers relish going straight to the newspapers or Twitter with tales of abuse by whips. Even deference itself is going out of fashion so the whips have less authority.

Whips rely on party loyalty but it is fracturing in the Commons. Belonging to political parties is sustained by social relationships between members, which continue in the intimacy of the village-like House of Lords, but not in the cityscape of the House of Commons. MPs spend less time with each other than they used to. They all have offices with two or three members of staff, sometimes in distant outbuildings, and they work fewer evenings in Westminster since the hours were shifted to earlier in the day. In general people support each other in politics because they like and trust them, not only because they agree with them. With hierarchies in decline and the loosening of social bonds, parties can no longer rely on loyal voting either outside or inside parliament. So whether researching people voting for politicians, or politicians voting with or against their parties, the relationships created before or after the vote are as interesting as the vote itself.

\section{Fetishising the vote}

We need to understand elections to make sense of parliaments, so I have written about what they mean to people in Russia, Brazil, India and the UK and how changes in voting reflect wider social and cultural change. Voting is so central to our idea of democracy that the latter could not exist without the former. You cannot be for or against elections; they just exist like trees or mosquitoes, argues Russian anthropologist Melnikova (2013). But I would go further: critical judgement is also necessary - not in the sense of questioning whether to be for or against voting, but to consider whether we have lost our sense of proportion about what voting can and can't do.

Voting is seen as an expression of the will of the people; the secret ballot is seen as emancipatory and connotative of a universal philosophy of individual choice, freedom and self-expression (Wouters 2018: 115-16). At times democracy is even equated with voting, as if elections fuel, drive or even constitute democratisation. As evidence of this, US overseas aid has become conditional on the establishment of 'democratic institutions'. Comaroff and Comaroff point out that this usually means regular multiparty elections with democracy being reduced from 'the substantative to the procedural, from social movement to electoral process' (1997: 125-6). Democratising, which usually focuses on elections and the rule of law, became the panacea for Africa's development ills at the end of the Cold War (Hagman and Reyntjens 2016). By equating elections with democracy donors gloss over gaps. They are inconsistent in their insistence on elections in practice, for example, when they prioritise electoral technical assistance for those countries that they deem to be 'weak' states. Donor darlings like Uganda, Rwanda and Ghana receive far less interference in the running of their politics on the one hand (Pommerolle 2016: 119, 127-8); in the Cameroon, on the other hand, various bilateral and multilateral donor workers got involved in 'electoral assistance' to 
maintain stability in the country. Since free and fair elections were seen as a symptom of success, and were vital for sustaining their aid budgets, foreign development workers repeatedly validated successive elections even though they were unable to offer proof. Their impact on Cameroonian politics was, Pommerolle argues, mainly to confuse matters.

I would argue that our pseudo-magical trust in the results of elections as the driver of democracy, and our fetishising of voting, can also lead to neglect of the other processes that are necessary to make democratic politics work. Just as technology is seen as the driver of development, fetishised to such an extent that people scarcely notice the harm it causes (Crewe and Harrison 1998), so too elections are seen as so sacred that we don't notice when they cause chaos, still less acknowledge their limitations. The architect of the Indian constitution, Ambedkhar, warned that democracy has to be cultivated - it can't work unless we transcend divisions, such as those created by class and caste (as cited by Banerjee 2014: 181, 171).

A painful example of fetishising the process of voting and the failure to overcome divisions (both new and old) was on display after the UK Brexit Referendum of 2016. The Conservative Party in the UK was plagued by division over our membership of the European Community and then Union since we joined in 1973. A large minority of Conservative MPs and members campaigned against the EU ever since and they persuaded the then Prime Minister, David Cameron, to hold a referendum to decide whether we should leave or remain as a member. To his shock, the leavers won the vote on 23 June 2016 and he resigned. For years afterwards the UK was paralysed by this vote. Our inexperience at holding and responding to referenda was partly to blame: it was advisory in law, so we did not have a threshold which would often be the case for a constitutional decision if binding, and the politicians failed to underline this before and after the vote. The government was entirely unprepared for the possibility that the 'leave campaign' might win and triggered Article 50 prematurely, the mechanism for leaving, without knowing on what terms we might exit. A mixture of indecision about those terms among Brexiteers, and an aspiration to thwart Brexit altogether among Remainers both inside and outside Parliament, made resolution impossible for years. The normal factions created by the main parties fragmented and new alliances formed, across Parliament and with those outside, to create paralysis. The referendum may have been merely a starting point from which debate and discussion might have found a way to leave the EU based on some kind of consensus or at least agreement. But politicians relied too much on the ritual of a vote, treating the result of the referendum as sacred and turning to elections twice (in 2017 and 2019) to find a way through the impasse, before finally leaving the EU in January 2020.

We take democracy so much for granted we have forgotten how it came about. As Graeber points out, 'We create things, and then, because we don't understand how we did it, we end up treating our own creations as if they had power over us. We fall down and worship that which we ourselves have made ... A fetish is a god under process of construction' (2005: 411, 427). Athens gave democracy its name 
with a system in which citizens governed themselves, but it took the French Revolution 2000 years later to turn it into an aspiration for transforming society into equal citizens (Dunn 2005: 16-17). John Dunn's story of democracy and how it became about choosing your leaders rather than self-rule, helps us understand the present. Today, the word democracy has become 'saturated with emotion, irradiated by passion, tugged to and fro and ever more overwhelmed by accumulated confusion. To rescue it as an aid to understanding politics, we need to think our way past a mass of history and block our ears to many pressing importunities' (ibid: 39).

How did this happen? Greek philosophers were fiercely critical of Athenian government by the multitude, and democracy was still a pariah word at the beginning of the eighteenth century, but by the time Tocqueville wrote Democracy in America, the idea had taken on an utopian character (ibid: 71-4). What is significant about the shaping of early democracies in North America and France is not just the integration of all citizens into the system but, in contrast to Athens, the fact that their participation was severely restricted to irregular elections. Voting their leaders and representatives into parliaments or legislatures - through the institution of representative democracy - was as much a way of excluding citizens from the exercise of power through government, as it was about including them. As Dunn puts it, the political leaders of capitalism's amazing advance embraced the idea of democracy, with elections at the core, as a highly effective way to appropriate and tap into a deep reservoir of political power (ibid: 134). You can recognize citizens as equals in theory but fail to treat them as such in the everyday practice of government, allowing obscene inequalities, injustices and harm to minorities to persist. To make sure citizens comply with the limits to their power, it is no surprise then that elections need to be highly ritualised, fetishised and made sacred (see Chapter 7 for a discussion of political ritual). It is not only authoritarian political worlds that need ritual to sustain them.

We are so dazzled by the idea of Western democracy being inclusive, and the other political systems being elitist, that we fail to see the opposite operating at the same time. The postcolonial meeting of different political aspirations in different nations around the world reveals much about the limitations of democracy. Comaroff and Comaroff point to the contemporary history of Botswana to illustrate how it can be entirely rational to take a critical position on the risks of democracy if reduced to mere election and no more (1997). Rather than assuming that politicians should be elected on the basis of their promises, people view a political party as credible if it has established its track record for engaging in recognisable forms of participatory democracy. So while electoral processes did not mimic earlier forms of political processes, they were embedded in long-standing expectations about how leaders should perform. When some even argued for a one-party system in Botswana, it wasn't a harking back to a traditional way of doing politics, but it was a critique of the superficiality of reducing democracy to one choice every five years.

The argument that democracy takes different forms with vernacular meanings in different places, depending on its history and culture, should not be taken too far 
or over-simplified. Jonathan Spencer, in his seminal work Anthropology, Politics and the State, cautions against the search for democracy Lankan-style for two reasons (2007: 93-95). He finds similarities in the way people engage in democratic politics across South Asia (high levels of participation with low expectations of politicians), but also threads that run through all processes of representative democracy wherever they are found in the world. One of these is the carnivalesque mood of elections, fuelled by a sense of possibility for a better future, and another is the threat of violence. So, we need to keep both the vernacular and the global in our mind's eye.

To come down to earth, and listen to the implied critiques from elsewhere (like India, Botswana and Cameroon, as explained above), we need to work hard at other aspects of democracy rather than merely revere its defining sacred process: the vote. It is voting that allows democracy to distinguish itself from other forms of political leadership, but it is processes other than voting that will enable people to make democratic politics work well or badly. Other democratic processes have been analysed in different ways by philosophers since ancient times. In re-imagining democracy we need to avoid universal recipes and allow for the emergence of vernacular and shared forms. There is no shortage of ideas, both local and global. For Arendt, politics is about debating diverse opinions created by the plurality of humans in public spaces, so she has plenty to say about how democracy needs to engage with the diversity of human experience in the public realm:

The more people's standpoints I have present in my mind while I am pondering a given issue, and the better I can imagine how I would feel and think if I were in their place, the stronger will be the capacity for representative thinking and the more valid my final conclusions, my opinion.

(1977: 241)

Writing after the tyranny of Nazism, Arendt counsels that participating in the public realm is a moral responsibility, necessary because important differences will always be found between people in any group, however homogeneous they may appear. She has influenced Hermut Rosa, who wrote about the plurality of voices in his book Resonance: 'Modern democracy is rather fundamentally based on the idea that its form of politics gives every individual voice and allows that voice to be heard, such that the politically shaped world thus becomes an expression of this productive polyphony' (2019: 217). Unlike Habermas, who implies that consensus can be reached, Rosa is interested in how we find resonance across separation, difference and alienation. So he goes deeper into the question: how can democracy accommodate plurality without foreclosing rule by the people? I will return to this in the next chapter, when considering how elected politicians make the claim to represent hugely diverse constituencies containing 1000 s or even 100,000 s of people.

To return to the issue of how democracy needs to develop, we need to expand our understanding of leadership. While politicians can be brilliant at some aspects of politics - adapting to different audiences, finding compromises and agreeing 
laws, as examples - their record at administration and government tends to be far weaker. Dunn warns that modern political theory focuses too much on intention and gives inadequate weight to practical skill. Part of the practical skill is about deliberating on the plurality of interests affected by policy, law and administration directly or in its shadow. Since what is good for some will be bad for others, reading the runes - imagining the future on the basis of the present - is fraught with danger for politicians. Their decisions will always be distasteful to some and in this sense we might even be grateful to politicians for courting inevitable unpopularity.

The very purpose of political society itself is precisely to stand in - by clear and predictable legal and judicial arrangements, backed by effective powers of enforcement - for the erratic and dangerous conditions generated by the collision of institutionally unrestrained human partiality.

(Dunn 2000: 84)

President Trump's neglect of administration, failure to accept the results of the November 2020 election, and encouragement of supporters to sabotage the orderly transfer of power in January 2021, all illustrate Dunn's warnings with poignancy. According to one of his aides, when he became President in 2016 Trump found it difficult to adjust to the business of discussing policy options. He often interrupted meetings to ask the aide to bring the election maps depicting his victory to explain how he won, state by state. ${ }^{12}$ During his term it was as if he never stopped campaigning, endlessly making claims about America's greatness and his own, seeing the two as intimately connected. His unrestrained partiality - including a sympathy for white supremacy - and emotional and intellectual inability to accept defeat, were his downfall as a politician.

In Chapter 4 I will look at the scrutiny of government - by parliament but also by media, civil society and academics - and suggest that this is an especially important role for researchers, including anthropologists. But next I'll turn to the claim to represent the people.

\section{Notes}

1 For example, http://labourlist.org/2012/11/labours-selection-process-a-word-of-pra ise-a-word-of-caution/, accessed 21 April 2013.

2 Interviewed by Emma Crewe, 4 September 2012.

3 Interviewed by Emma Crewe, 14 November 2012.

4 John O'Farrell, tweet, 17 November 2013, 15:09 pm.

5 On this issue, see, for example, Grice (2006).

6 https://thecritic.co.uk/the-zoom-parliament-is-here-but-hopefully-not-to-stay/, accessed 24 April 2020.

7 The average is $1.44 \%$ of this type of rebellion for all Westminster politicians; 154 MPs (about one quarter of the total) and 245 peers (roughly half of party political peers) rebel more than the average, http://www.publicwhip.org.uk, accessed 4 February 2015. These patterns are confirmed by the House of Lords Library, House of Lords: Party and Group Strengths and Voting, LLN 2012/026, 27 June 2012. 
54 The sociality of parliaments

8 https://www.parliament.uk/business/lords/whos-in-the-house-of-lords/house-of-lordsexpenses/, accessed 13 October 2020.

9 Earl Russell, HL Debates, 13 October 1998, col. 1324.

10 Interview with Emma Crewe, spring 2000.

11 To be more precise members are elected within parties and then approved by the Committee of Selection and then the House itself whereas Chairs are elected by the whole House.

12 Madeleine Westerhout, Personal Secretary to Trump, in 'Settling into the White House', The Trump Show episode 1, 12 October 2020, BBC, https://www.bbc.co. uk/programmes/p08v2sq0, accessed 14 November 2020. 


\section{3}

\section{REPRESENTING}

This is a wonderful place, filled overwhelmingly by people who are motivated by their notion of the national interest, by their perception of the public good and by their duty not as delegates, but as representatives - to do what they believe is right for our country. (John Bercow speaking in the UK House of Commons, 9 September 2019) ${ }^{1}$

\section{What is political representation?}

When the Speaker of the UK House of Commons announced his resignation in 2019 he referred to MPs as representatives and not delegates of the public - elected representatives who should use their own judgement in deciding what is best for the country. He was referring to what has become a sacred text for the trustee approach to representation, the words of former English MP Edmund Burke:

It ought to be the happiness and glory of a representative to live in the strictest union, the closest correspondence, and the most unreserved communication with his constituents. Their wishes ought to have great weight with him; their opinion, high respect; their business, unremitting attention. It is his duty to sacrifice his repose, his pleasures, his satisfactions, to theirs; and above all, ever, and in all cases, to prefer their interest to his own.

But his unbiased opinion, his mature judgment, his enlightened conscience, he ought not to sacrifice to you, to any man, or to any set of men living. These he does not derive from your pleasure; no, nor from the law and the constitution. They are a trust from Providence, for the abuse of which he is deeply answerable. Your representative owes you, not his industry only, but his judgment; and he betrays, instead of serving you, if he sacrifices it to your opinion.

(1854: 446-8) 
Burke famously listened to his constituents and then ignored them, for example in his support for free trade with Ireland. When politicians in the UK wish to argue that it is legitimate to depart from their constituents' demands or preferences, then they reach for Burke with predictable regularity. But this is beginning to sound out of step with contemporary popular riffs on representation in democracy - the now more familiar claim that MPs will represent the wishes, views or interests, as a delegate of a community or collectively as a parliament of the nation. It is a regular refrain to hear demands from constituents that politicians should present their views, sound like them in attitude and respond to their demands, not to do the best for them in their own individual judgement.

A representative being a delegate of a group was articulated by one of the architects of the US constitution, James Madison, in the eighteenth century, although its historical roots have been traced back to the Magna Carta (Rehfeld 2009: 217). It remains unsettled in democracies as to whether we want our representations to aspire towards trusteeship or delegation. But it may also be the wrong question. Rehfeld points out that this binary choice obscures three processes that will affect the represented and representer relationship: the law-maker's aims, the source of his/her judgement, and the degree to which he/she is responsive (ibid: 215). I might add that the trustee versus delegate binary ignores the complexity of representatives working within political parties and factions, or trading votes and doing deals across parties, to promote their causes. It also ignores places where MPs don't represent constituencies but the country as a whole, such as Portugal (Leston-Bandeira 2004). And the binary of trustee versus delegate fails to consider other alternatives beyond needs, demands and interests, to ask what representer and represented might mean to each other in symbolic, psychological and emotional senses.

The first political scientist to address this question in both depth and breadth as an ethnographer was Richard Fenno. He writes of US representatives that trust is the magic ingredient. 'If people like you and trust you as an individual, they will vote for you', members told him (Fenno 1978: 56). So, conversations between politicians and their constituents are not only (or at least as much) about policy or political ideology but about whether the representative can be trusted. It takes time to win the moral approval contained within trust and it means getting close to people or giving the illusion of closeness. One US representative told Fenno that no one will vote against you if you are on a first names basis and if you chew their tobacco, then they will even fight for you. Another representative put it: 'the best way to win a vote is to shake hands with someone. You don't win votes by the 1000 s with a speech. Very rarely will anyone ask you about how you stand on anything' (ibid: 64, 85).

Communication involves a subtler process whereby US politicians spend time in their districts to measure and enhance their voting leeway. Representatives know that they will be required sometimes to vote against the wishes of their constituents. To do this without losing too many votes they have to be trusted; the more a politician is trusted, therefore, the more leeway he or she has (ibid: 14051). Again, this quality of trust is not abstract but an embodied experience of 
emotion requiring mutual affirmations of identity. So, it is not policy agreement that voters demand, according to US Members of Congress, it is a feeling of belonging to one another. They continually talk about the shared streets, the characters and the churches, stressing their commonality, understanding and affectual resonance. They vary their presentation to different groups within the constituency. When voters do see the Member as the same as them, perhaps if their identity overlaps, then he or she becomes a symbolic representative; for example: 'Almost anything I do makes them feel proud. They know I'm a black man standing up for the black man' (ibid: 120). To what extent representatives are able to create this sense of shared space and resonance with different groups on digital media is worth studying, especially since digital communication is increasingly consuming so much of politicians' time and, in the face hate speech and abuse, emotional labour.

Political scientists have even undertaken participant-observation as politicians themselves (e.g., Price 1992 and Lee 2006). Mordecai Lee, who has been a member of both the Wisconsin State Assembly and Senate, wrote about how both constituency casework and legislating for special interest groups are viewed with relish by most legislators as ways to secure both appreciation and support in the next election (ibid: 373). However, there is, of course, the risk that it will alienate other special interest groups but the anticipated damage is less than failing to look responsive. Katherine Cramer, another US political scientist, offers another rare example of ethnographic research into democracy, again about Wisconsin (2016). She spent years conversing with groups of citizens in the rural areas of this swing state, interpreting their attitudes towards politics and politicians. She found that rural consciousness is partly constituted by a resentment towards city-dwellers. They feel ignored and neglected in ways that do not translate into automatic support for either Republicans or Democrats. They distrust all politicians: 'support for small government can come from something more visceral, though certainly not less serious, than political principles: our sense of who is on the side of good and who is on the bad' (ibid: 211). But such complex ethnographic research, based on many years of observation or even participation, remains rare in recent political science literature.

More conventional political scientists face a pressure to create universalising causal links and classifications to explain what goes on (e.g., in parliament or constituencies) and quantitative methods are seen as the gold standard. As Cramer explains, positivist approaches have their limits:

The positivist model set-up assumes that values on one explanatory (or 'independent') variable move independently of the other variables. Or, if claiming an interaction between explanatory variables, it assumes that people with particular combinations of these characteristics exhibit a significantly different level of the variable we are trying to explain (the 'dependent' variable). However, the object of my study, or my dependent variable, to put it in positivist terms, is not a position on an attitude scale but, instead, the perspectives that people use to arrive at that position. 
While Cramer's focus is on the entanglement of attitudes and identities, ethnography in the hands of anthropologists is often even more ambitious - probing into social relations, rituals and so on. The result is not only that positivist approaches struggle to inquire into such complex entanglements but there is a widespread misunderstanding of the epistemologies underlying anthropological (and philosophical, sociological and historical) theories/methods that depend on, as examples, logic, narrative, interpretation and abduction (which I return to in the last chapter).

When more conventional political scientists address the question - What does representation entail? - they tend to generate useful data, but have more to say on outcomes than processes and relationships. They sometimes look at the coexistence of (a) constituents' preferences and (b) how politicians vote, and then deduce a link between these based on a rational calculation of interests (Best and Vogel 2014). In this case they deduce that the coexistence of these two factors must mean that the elected representative has calculated that it is in his/her interests to please their potential electors by following what they want. The data can get complex in its detail when other variables get pulled into the mix. When considering how this is affected by electoral systems, apparently they found that proportional representation (PR) causes greater congruence with all voters while majoritarian systems do this with party voters (ibid: 71). Brack et al. agree that it is extremely rare for political scientists to find out what MPs actually do in their constituencies and why, offering a rare example of research into this from France, Belgium and Germany (2016). However, when they hypothesise that MPs' activities are influenced by institutional constraints, normative ideas of representation, perceptions of citizens' expectations, environmental considerations and the context of 'culture', this begs further questions. The two main variables - institutional and individual - are explained with further long lists: institutional characteristics include the electoral system; culture might involve the state, conflict or image; and the individual level brings in perceptions or the impact of electoral rules on MPs' incentives. Representation is about rules and activities in this perspective, which can be quite easily listed, but we never discover how these endless variables influence each other in the everyday relationships and practices of real people working together. Much political science research about representation - especially on preferences (of voters) and behaviour (of politicians) - tends to be abstracted from everyday experience, relationships and contradictions. It is difficult to probe the plurality of meaning or intention in quantitative surveys (we can't easily ask 'why?'), to inquire into the impact that the researchers (and their assumptions) have on the process, or to code the most revealing responses. The normative work of trying to classify and improve representation, before we have really understood it, can distract scholars from getting under its skin and from working out its history, meaning and plurality.

It is worth remembering that the idea of representation in Europe was paternalistic until the Enlightenment - that is, it was assumed that elites would take account of the interests of all, as far as morally required. But this changed in the UK in the seventeenth century, as recorded during the 1647 Putney Debates. It was revolutionary when Thomas Rainsborough argued: 
For really I think that the poorest hee that is in England hath a life to live, as the greatest hee; and therefore truly, Sr, I think itt clear, that every Man that is to live under a Government ought first by his own Consent to put himself under that Government; and I do think that the poorest man in England is not at all bound in a strict sense to that Government that he hath not had a voice to put Himself under. ${ }^{2}$

The idea that everyone needs their own voice took hold but it was 100s of years before the radicals' demand for universal male suffrage was met and it was only in 1928 that all adults got the vote in the UK, including women. To understand representation in the UK then, you have to know how we got from Rainsborough to where we are now. A UK history of representation is beyond the scope of this book, still less a global history of developments in different nations, but one aspect of this idea of 'voice' deserves particular attention in part because it has dominated global debates on representation by parliamentarians for the last few decades: women's political representation. The Sustainable Development Goals commit governments to gender equality and the empowerment of women, and one of the key indicators is the number of seats held in parliaments by women (indicator 5.5.1). Only $32 \%$ of parliamentarians globally are women, only three countries have parliaments with over $50 \%$ female - Rwanda, Cuba and Bolivia - and three have no women at all. ${ }^{3}$ Feminist theories about representation help us understand why progress has been so slow in promoting not only gender equality but also representative democracy more generally.

\section{Feminist theories of under-representation}

Central to feminism is the question of alignment or divergence between the interests of those representing and being represented. In recognition of women's political subordination to men, and lack of access to education, from the middle of the nineteenth century early feminists in the English-speaking world (notably Mary Wollstonecraft) pointed out that their interests were negated, marginalised or neglected entirely. In the UK, inspired by Wollstonecraft, the first wave of feminists argued for political representation. The impact of their fight for votes for women, and the on-going campaign for equal representation within political institutions (and the equivalent struggles elsewhere), was to transform parliaments. (Both the UK and the US were slower than the first country to give women the vote - New Zealand in 1893.) On the other side of the relationship - the representers rather than the represented - feminists assume that the differences between women and men mean that the latter will tend to (or even will always, according to some) overlook the interests of the former so self-representation is the most effective way to work towards equality. It is now widely accepted that women should have equal representation in political institutions for that reason or because it is their human right.

Shirin Rai, one of the world's leading scholars on gendered representation, explains the twists and turns with a unique grasp of its historical and geo-political 
complexity. She is a politics scholar whose interdisciplinary approach breaks through various boundaries by combining humanities and social science (2000). Despite democracy being such a powerful motif, its message of political parity is not translated into practice because liberal democracy has privileged a 'public man' as the default political actor and excluded women from becoming fully engaged citizens (ibid: 2-3). The work of feminist activists and scholars has been to shift the focus from individual rights towards identity-based politics. Hanna Pitkin's Concept of Representation (1967) was influential in helping people rethink what this relational, rather than merely individually based, representation work might entail. She argued against choosing between a trustee and delegate model of representation, proposing that the representative should be accountable but able to take autonomous decisions on behalf of the group. Her classification of four meanings of representation - formalistic (the institutional arrangements), descriptive (shared identity or interests), substantive (taking actions that are in the interests of the group), and symbolic (the meaning evoked) - reveals where our attention is still drawn in terms of intention several decades later. Most of the scholarship and political work on representation continues to focus on formalistic and descriptive, rather than substantive and symbolic. However, Pitkin's classification tells us little about what actually goes on between people who are representing and being represented.

Jane Mansbridge offers a more empirically based four-fold categorisation of forms of representation that is based on empirical findings: promissory (whereby representatives are evaluated for their promises), anticipatory (taking actions that seek rewards in the next election), gyroscopic (looking within to decide what is in constituents' interests), and surrogacy (representing those outside their constituencies/districts) (2003). This is a helpful advance on Pitkin's work as it injects a sense of time into the relationship, not just past time but future time, that is, people's anticipation of the future. But it still leaves us with old and difficult questions about evaluating 'interests': who should decide what is in the interests of some or all women? If you ask women we will always disagree between ourselves (like any group) and we don't always have the full picture of possibilities or, as Appadurai puts it in another context, 'the capacity to aspire' for our rights or resource entitlements (2004). Maxine Molyneux's distinction between strategic versus practical interests addresses this difficulty. She offers an attempt to acknowledge that it is the most subordinated who can be the least ambitious for change because they have the poorest access to the resources required to make demands. Women's practical interests address their immediate needs (e.g., for access to services or childcare) and this is what resource-poor women will often focus on. Strategic interests challenge women's subordination by addressing those conditions that reproduce it (e.g., fairer pay, better political representation or stopping gender-based violence) (1985), and that can only be achieved in collectives. But can we generalise across cultures about the conditions that reproduce gendered inequality?

Since the 1980s white feminists have been criticised by 'Third World', black ${ }^{4}$ and LGBT + feminists for simplistic generalisations, portraying women as 
homogeneous, denying their diversity (based on age, class, sexuality, nationality, ethnicity ...) and privileging the views and experiences of white, heterosexual, middle class women. Western feminists often assumed that the 'victimhood' of women around the world mirrored the European experience of patriarchy. Chandra Talpade Mohanty was one of the first to point out that the portrayal of Third World women as passive victims was a symptom of widespread postcolonial racism - some women are far more powerful than others (1986, 2003). Child rights activists point out that feminist generalisations are often adult-focused (Crewe 2010). Demands for the representation of women leaves out the pervasive abuse and exclusion of girls, despite the commitments that states have made via the Convention on the Rights of the Child that all children will be consulted about laws and policies that affect them.

The Eurocentric 'globalised' generalisations about women that we find in some Western white feminism spill into some donors' initiatives to increase women's representation in parliaments. Women lack voice, access to resources and contacts, so since the 1990s many donors and UN bodies have invested huge amounts of energy into increasing the parliamentary representation of women so they could argue for equality. Better representation in parliaments is perhaps less contentious than addressing women's unpaid work as carers and their unequal pay, which are far higher priorities for many women but require complex social and political change (Sawar 2000). Nonetheless, feminist-inspired representation does entail complexity too. Anthropologists have pointed out that women's interests, and therefore the representation of them, are inevitably different according to context and can confound both expectations and assumptions. In Botswana's stable and multiparty democracy you might expect women's representation to rise but actually it has been falling (Bauer and Burnet 2013). In Rwanda quotas have achieved one of the world's majority female parliaments, but limited progress has been made by government towards a feminist agenda, partly because the space for the women's movement in civil society has shrunk (ibid). Ugandan feminist and lawyer Sylvia Tamale's innovative work with women politicians also probes connections between their experience inside the Ugandan Parliament and how it is connected with broader social relations, embedded as it is in a long and specific history of patriarchy (1999). Cultural socialisation orientating girls and boys towards different ambitions - ideas about 'feminine' mothering in the domestic arena versus 'masculine' aggression in the public realm - influences their experiences when they become MPs. The male dominated government can never quite shrug off gendered assumptions and interests when confronted with feminist action so women MPs face a backlash from men and are often blocked in their efforts. There is general agreement that to make progress, and resist the temptation to get involved in patronage politics themselves, women MPs need to work with those beyond the state in civil society.

Much feminist work in the last 20 years has argued for going beyond numbers. Another feminist who has reshaped debates on representation in profound ways is Anne Phillips in her Politics of Presence (1995). She makes the argument for the 
presence of diversity in political institutions to ensure diversity of skills in the name of justice, to guarantee a range of interests and to deepen participation. But she also points out that numbers are not enough. The next challenge is for representatives to be more accountable. Anthropologists, and other ethnographers, who have listened to politicians talk about this have explained how this is even more fraught for women than men. Ethnographically inclined political scientist Jack Corbett writes about women's experience of representation in a way that echoes across contexts: politicians in the 15 countries of the Pacific Islands reflect that once elected, your constituents own you and for women it is a form of dual ownership. They represent their constituents and all women at the same time because their total number in all Pacific Island parliaments is extremely low (2015: 72-73). Even in 2020 women are proportionately only $7 \%$ and three of the four countries in the world with no women politicians at all are in the Pacific. ${ }^{5}$

I too found that accountability was especially complex for those who are underrepresented or from minorities. While white men feel more easily entitled to be our representatives, women and, especially those who are black, Asian or minority ethnic (BAME), can be treated in subtle ways as if they are 'space invaders' in Parliament, as Nirmal Puwar puts it (2004). When Dadabhai Naoroji, a Parsi from Bombay, stood for Parliament in 1886 and was defeated, Lord Salisbury later commented that England was not ready to elect a 'Blackman'. Naoroji became the first Asian MP to sit in the UK House of Commons, winning a seat by only five votes in 1892, hoping to represent the interests of the whole Indian subcontinent. Three more Indians sat as MPs up to 1929 but then no one of Asian origin sat in the Commons until 1987. Dawn Butler, a black woman and MP for Brent Central, was told by a white MP: 'This lift really isn't for cleaners', while in 2019 Abena Oppong-Asare MP was handed a bag to look after as if she was staff by another MP (Whale 2020). Black MPs are especially abused and stretched in different directions; they are mistaken for each other, treated as an homogeneous group, and expected to represent endless other groups. Diane Abbot, a longstanding black MP, received almost half of the abusive tweets sent to female MPs in the year before the 2017 election. Chi Onwurah, MP for Newcastle upon Tyne Central, told the journalist Sebastian Whale: 'I get racist trolling whenever I open my mouth to say something vaguely controversial ... I get tweets from Nigeria telling me to stand up for Nigerians. All BAME MPs end up being seen as representing or not representing different groups' (ibid).

In Westminster one British Asian MP (let's call him Deepak) was particularly articulate about how his identity affected his work of accountability (Crewe 2015a: 96). His 30-year involvement in his constituency, and in its Borough council, meant that it feels as if everyone knows Deepak. It has given him a good knowledge not only of the sizes of the different communities in his constituency - white, Indian, Pakistani, Tamil, Afghan, Somali, Eastern European and so on - but what they mind about. Although some Asians trust Deepak, others disapprove of him because he speaks out against caste and domestic violence, infuriating traditionalists who think he has been too influenced by 'Western thinking', as they put it. From 
when he wakes till the moment he sleeps, he is on call - just as his father was (as a former politician in an Asian country). Deepak has three offices, including one at home staffed by relatives, and each accumulates invitations, requests and obligations. If the invite offers an opportunity to speak and exchange views, he will not refuse. He goes to a disproportionately high number of Asian functions, perhaps three or four weddings each weekend, because if he turns them down, they will not forgive him, whereas a white person will assume the MP is just too busy and will not take it personally. He wasn't complaining, just explaining to me what it is like to do representative politics British-Asian style.

When you consider such everyday tales of accountability, they show up the failings of classificatory schema, or at least relying on them too heavily. Schema miss a sense of proportion and what it is like to be on the extremes of a pattern. We also fail to get an explanation of the ways in which different uses or forms of representation are entangled - contradict, reinforce, undermine, get magnified and so forth. The most influential scholar to challenge such rigid schema is the philosopher Judith Butler, famous since her book Gender Trouble (1990) was published, with her theory of performativity. She subverts the systems thinking approach, and other rigid typologies that are blinkered to process, by looking at how gender and sex are not given by nature or created by an abstract thing called culture but performed through processes of people interacting. Performance entails endless judgement and if you transgress expectations or assumptions as you recreate your gender, then you can face moral censure or punishment. Those expectations about how women should relate to women, women to men and men to men, are culturally or locally specific so gender doesn't create stable identities, but a repetition of acts, which over time leads to sedimentation of ideas about what is, as examples, an impressive male parliamentarian or a good mother. We all perform gender but the content of the performance emerges out of specific cultures (and sub-cultures), endlessly changing with the movement of time and place and negotiation of power.

Butler's perfomativity has been taken up in depth within parliamentary studies by Shirin Rai and Carole Spray in their book Performing Representation. Although they suggest a schema - a framework for researching the performance of politics they use it to open up the debate by probing assumptions, spaces and patterns rather than closing it down with definitions (2019: 21). This important merger of ethnography with political theory explores how the claim of representation plays out in practice in the Indian parliament - offering a radically different way of understanding representation in contrast with many scholars in political science. Michael Saward's idea of representation as a 'claim' is one of their starting points and it is worth explaining this first (2007). Representation is not a one-way formal mechanism provided simply by an institution or a person; it is process created by a claim, a two-way relationship between representer and represented within which the represented choose their politician in an election and the representer portrays the represented in particular ways. It is something that happens within relationships that continually change. The claims made by politicians - about themselves or their 
constituency - tend to be more compelling when they resonate with current cultural understandings. While the conventional question is whether MPs are responsive to those they represent, as if their interests can be known, political theorist Saward stresses a different aspect of the relationship: does the MP manage to silence or evoke the represented? Re-presentation of other people is not usefully seen as a mechanical articulation of the interests of a group but as a changeable relationship between a constituency and the person symbolically creating it, within which claims are made, contested, accepted (including partially) or thrown out and remade. So, it is not only anthropologists who understand that representation is a process rather than an event or activity.

As Rai and Spray point out, what is badly needed, but remains rare, is research about what this claim means in practice as politicians perform representation in the sense of re-making identities and relationships (2019). While contemporary feminists of parliament coalesce around institutionalism, over-focusing on rules and norms in my view, in contrast this tour de force by Rai and Spray reaches into architecture, embodiment, anthropology, theatre, materiality and symbolism to analyse the performativity of politics not only through speech but also non-speech acts. Methodologically, it is innovative because they make eclectic use of statistics, narratives, interviews and observation, and then inquire into these with careful attention to the rhetoric, discourse, rules or practices generated by these different techniques of inquiry. They don't take what people say as literal statements of truth; statements are the starting point for interrogating plural claims and experiences. Empirically they provide us with a treasure trove of material about who women MPs are, what they do, how they relate to others and what this all means for representation. Theoretically, it matters because their interdisciplinary-informed explanations offer both complexity and a challenge to received wisdom on politicians' work of representation.

What are the implications? First, they are writing a whole monograph about a nation in that area of the world (the 'Global South') that is normally confined to a footnote or, at best, a few chapters on the 'rest of the world' in parliamentary studies (e.g., Martin et al. 2014), as if only countries in the 'Global North' are in the centre of the globe and can be compared when writing about legislatures. Second, they elucidate findings with subtlety by treating what informants say as only the beginning of the inquiry. To take the issue of representation they point out that asking whether women represent other women is problematic because it essentialises the category, glosses over women's different ideological positions on feminism, and underplays how institutions (including parliaments and political parties) and hostile men constrain women's ability to pursue feminist (or womanfriendly) agendas (Rai and Spray 2019: 336-8). They make this argument in relation to India (and potentially in principle therefore beyond) by substantiating it with rich and varied data. Gender can only be fathomed in conversation with other inequalities in any political institution, and in India specifically you have to also consider class, age, caste and religion at the least. Most women MPs are largely middle-class professionals, middle/upper caste and mostly Hindu (ibid: 125) and 
when Aparupa Poddar was elected from a constituency reserved for lower castes, her win was contested by the losing candidate on the grounds that she had married a Muslim man so had lost her Dalit status (ibid: 143). When her claim was challenged in this highly competitive environment, a mix of her gender, caste and religious identity were used against her.

Women's experience of being politicians is influenced by being surveilled and judged more than men for how they dress, speak, tweet or seek support. For women politicians both the content and impact of judgement is magnified, even if the substance of these evaluations will vary across place on the basis of diverse cultural norms and taboos. So, we need more research about how representation is gendered in different places. We should not assume that progress is being made; women's position can also go backwards. Despite the promising signs of better representation of women in Myanmar, after the supposed end of military rule a decade ago (Minoletti 2019), gendered, ethnic and religious forms of marginalisation and dispossession have become entrenched and even more severe for some (Maber and Aung 2019: 407). Meanwhile the party in government, the National League for Democracy (until the military coup in February 2021) discouraged its own MPs from engaging with its own civil society, distrusting NGOs and overrating their own capacity to reflect plural interests and knowledge of the population without consultation. Civil society space for action contracted after Aung Sang Suu Kyi became State Counsellor, with the exception of the ultra-national Buddhist movement Ma Ba Tha (which has huge assets, 270 offices and over 150,000 members across the country), with punishing effects on women's groups and feminist causes. So, we also need to know more about how gendered representation is entangled with religion, ethnicity, race, class, sexuality and other differences within past and imagined relationships between politicians and different groups of people.

\section{The anthropology of representing and ignoring}

The claim to represent is easily made; to accomplish it literally for all electors in a specific moment is impossible. My own district councillor told me after a year of representing our ward: 'I can't please everyone. I try to provide a sense of community leadership: I'm a conduit between our locality and the local authority. But some will always disagree with what I do. ${ }^{6}$ Elected politicians are usually connected to localities by the aspiration to represent residents of their constituency, and through those constituencies they collectively connect to the whole nation. The number of residents can be substantial. The MP for Malkajgiri in India was elected by over 3 million voters in 2019. One of the MPs elected in São Paulo, Brazil received 1.8 million votes in 2018. The largest electorate in a UK constituency was in the Isle of Wight at almost 110,000 in 2017. The numbers of nonvoters, who also expect to be represented, pushes up the numbers even higher: the total population of the Isle of Wight was over 140,000 only one year later. ${ }^{7}$ The largest constituency geographically in the world is Kalgoorlie in Western Australia: 890,000 square miles in total and from north to south it covers the distance 
between London and Moscow. Apparently on average humans tend to maintain close ties to around 150 people at any one time, but one UK MP estimated that most politicians regularly interact with about 2,000 constituents (Dunbar 1996: 69). An anthropologist is bound to ask, given these substantial numbers, what does this process of representation mean in practice within different places and from different viewpoints?

Politicians' relationships with citizens were a focus of attention for Marc Abélès, the first anthropologist to study European parliaments. Politicians stress their local roots in France: a politician is above all the representative of a territory with all its traditions, even a living symbol of a locality; 'it is more or less obligatory to occupy local and national office simultaneously' (Abélès 1991: 268). So, relationships in politics are not merely about interests, kin connections or viewpoints; politicians have to tap into people's imagination. Politicians who ignore the sacred - the ritual, symbolism and drama of politics - and merely try and impress voters with their views, will find it harder to secure support. Representation is not just putting up a mirror - politicians need to do more than listen and repeat what people say, or appear like those they represent. Even the leader of the nation has to evoke her or his locality. In his article about President Mitterand's visit to the department he represented for 30 years, Abélès relates how he continually reminded people of his local connections (with the past, with people) and their shared belonging: 'we comprise some sort of community' (1988: 394-5). When he bestowed investitures on local government dignities, or inaugurated a railway station, there was a quasireligious aspect to it. Like many rituals, this 'constructs a historical form of legitimacy, an image of the elected person which is reflected, in inevitably distorted form, in the mirrors of the mass media' (ibid: 398).

The work of representation is so much more than a 'role' carried out by an individual as if following prescribed duties set out in a Job Description. Several anthropologists have taken a closer look at politicians' relationships with constituents and other citizens, depicting this work as more performative than prescribed. One pattern across these relationships is a combination of promising, shifting to adapt to different audiences and privileging certain groups, but the intensity of these processes varies dramatically. Since 2014 I have been supporting anthropologists in Bangladesh, Myanmar and Ethiopia to research the relationships between parliamentarians and individuals, groups and organisations in society. In Bangladesh politicians' interactions are weekly, in Ethiopia some MPs only visit twice a year and in Myanmar it varies from one extreme to the other depending on the MP.

Let's take the case of Bangladesh. In my work on the Commons I challenged pervasive assumptions about how acting as a representative is about the fulfilment of a role by looking at how these interactive processes play out in different constituencies within contrasting areas (Crewe 2014b) and encouraged my colleagues in Bangladesh to do the same. ${ }^{8}$ What is meant by 'roles' in parliament? This relationship between representative and represented is often analysed as one of MPs' functional roles. Searing classifies UK MPs' representation work as 'Welfare 
Officers', or 'Local Promoters' (1985), while Norton's taxomony offers seven types: safety value, information provider, local dignitary, advocate, local benefactor, powerful friend and promoter of constituency interests (1994). ${ }^{9}$ But conceiving this work in terms of 'roles' glosses over critical ingredients - identities, relationships, power and emotions. As Goffman pointed out in his study of how individuals present themselves in social encounters, the idea of roles can miss the point that people are responding to different audiences through performance and power struggles (1959).

Taking up my point that representation has to be performed in contradictory ways within relationships with diverse groups of constituents as a form of improvised shape-shifting, Ahmed looks at how MPs are involved in this endless selfadjustment in Bangladesh to build up their reputation and win support with very different groups of people (2019). They do so selectively, influenced by operating within a profoundly conflictual and distrustful contemporary Bangladeshi political world. When Ahmed finds that a particular MP colludes with a group of his own constituents to humiliate a religious minority teacher, an act that amounts to a violent abuse of power, any potential idealisation of him representing his whole constituency breaks down. Young people across the country showed solidarity for the teacher on social media, clearly expressing their sympathy and even symbolically identifying with him by repeating the act of humiliation and posting it on Facebook and Twitter. This MP, who is dispensing patronage and favours to some constituents and abusing others who are rescued symbolically by total strangers, is engaged in a process of 'representation' for which the label 'role' (as a way of describing work) seems inadequate. In this example the politics and emotions are amplified and abusive, but it is indicative of the general pattern of relational work in representing any group of people. Other examples could be subtler and benign. Representation is a complex, messy and dynamic process of relating, which can only be explained by richly describing the history, politics and social world of the specific place and seeing how it is different from other worlds.

I found a similar pattern to Bangladesh in Myanmar when I visited one constituency in Mon State in 2019 with their MP who was born and bred in that area. ${ }^{10}$ I could not find a constituent who did not know the MP (or at least of him) reasonably well. The constituents I spoke to uniformly described him as reliably present: 'he is one of us', 'he delivers', 'he's here, can give the time.' They told me he represents them abroad, mediates in disputes, organises nationalist celebrations, makes development happen (e.g., got funding from government to develop their infrastructure), and is always at the end of the phone - answering 520 calls a day and replying on Messenger, Facebook and WhatsApp. He confirmed he visits his constituency (also his home) every day after $4 \mathrm{pm}$; 'they are my friends, I am very close to them, they call me brother.' Contrast this with research in the same country but in Chin State (by the Chinbridge Research Institute) where researchers found that $74 \%$ of those in a large survey did not know the name of their MP. ${ }^{11}$ This is more like Ethiopia, where according to Ayenew et al. 93\% of MPs only visit their constituents twice a year, only $7 \%$ 
visit more than twice and they almost never get involved in individual cases (2019: 33). It is also telling that over three-quarters of the Ethiopian MPs interviewed reported that it was the local party secretary who organised the schedule and only $2.3 \%$ said that they had spontaneous meetings with constituents (ibid: 38). The party discourages too much interaction by the MP, as it might generate local demands that interfere with the government's national plans. So, these meetings are formal, theatrical occasions where speeches are given and the politician speaks about the achievements of government. The result is, unsurprisingly, that citizens in most parts of Ethiopia complain that they never see the 'face' of their MP.

It is clear that variations can be found both between and within countries. Consider the different findings of anthropologists working in West versus North India. Ruud's research on how people view politicians in West Bengal, India reveals that people see them as unprincipled and corrupt. As the business of politics itself is so dirty, by getting involved 'anyone was bound to be tarnished by unsavoury decisions, shady actions and odorous alliances' (2001: 117). But Michelutti found in North India that Yadav leaders see themselves as a martial race, with an historical link to Krishna fighting for social justice, born to be politicians acting for their caste when necessary in muscular ways (2008: 178-83). People locally have a far more favourable view of these representatives and even support these (allegedly) 'criminal' politicians because they defend the poor.

One way to research representation is to look at the social distance between represented and representer and how the former judge the latter. It is rarer for anthropologists themselves to assess the impact of MPs on constituents, but there is some research of this kind. A Swiss anthropologist, Kathrin Wesendorf, compiled work by lawyers, historians and anthropologists to look at how indigenous peoples relate to parliaments in the Arctic region and found neglect (2005). In this region participation in democracy has not halted their dispossession or marginalisation and they face opposition from politicians and the public when discussing their collective rights, including to land (ibid: 12-13). The generalisable message is that parliaments are failing to represent indigenous peoples, even if indigenous peoples are developing different strategies for strengthening their political clout in either existing or alternative parliaments (ibid: 20-1).

Meanwhile in other places citizens expect their MP to rectify problems and find that some do deliver in strange and diverse ways. In the words of a Marshallese politician:

Your constituents don't expect you to only be their senator in the parliament. They also expect you to be a counsellor in a marriage fight, a psychologist in a suicide attempt, to bankroll a first birthday party or a wedding or a funeral.

(Corbett 2015: 75)

In the UK I have begun to inquire into what MPs do to, with and for those they represent by visiting 9/650 constituencies and listening MPs' reflections - thinking about not only how they view each other and how often they meet, but what they 
mean to each other. Since the answer is different for each MP, and the sample is small, this research is at an early stage. Nonetheless, patterns are emerging.

\section{In UK constituencies: the collective MP}

MPs try to represent constituency interests during the various processes entailed in making law. For example, Stephen Lloyd MP explains that he voted against his own party's introduction of tuition fees because 'for me, the promises I made to my constituents will always come first. ${ }^{12}$ But interwoven with the representation of their constituents, the MP is in the business of self-presentation so this also shapes their interaction with their constituency. MPs represent themselves and others at the same time; attention to self and other are thoroughly entangled. The political performance of representation by MPs takes place in many sites - in Parliament's debating chambers, committee rooms or meeting rooms, television studios, Twitter, local party offices, and in offices, streets and meeting venues within constituencies. UK MPs are well-known for name checking their constituents in Westminster (Crewe 2015a: 84-6). The then Minister Eric Pickles MP mimicked other MPs by saying that Stockport was close to his heart, a gem and a magnificent town, Formby a wonderful place to invest, and Rochdale was the apple of his eye, all within the space of an hour. ${ }^{13}$ Even the lesser-known parliamentary rituals provide opportunities for constituency name checking: 'Points of Order', when an MP can ask the Speaker to take action regarding rules being broken, have been harnessed to the constituency cause occasionally. As the then Speaker Bercow pointed out, they can act like a press release: 'It is part of the choreography of Parliament that this is tolerated to some extent. ${ }^{, 14}$

At the same time these days no MP ignores her/his image or appearance. Photos and reports on how MPs have raised constituency issues bloom all over MPs' websites, their campaign literature, in the local press and on Twitter. As soon as MPs ask a question in Parliament's debating chamber, they rush back to their office and instruct their staff to put out a press release or call the local paper. Paul Flynn advises other MPs:

Be ubiquitous and ever present in the constituency. The drip feed of blog, tweets, early morning radio interviews that are repeated throughout the day, widely advertised surgeries, and attendance in the Chamber in a cameraexposed position, all propagate the message 'Busy MP'.

If you follow MPs around to meetings in public places - churches, community centres, universities, business parks, housing associations - you will see that they take photographs and email them to their staff or put them on Twitter themselves (Crewe 2015a: 99).

MPs are encouraged to look busy by media and civil society organisations peddling various superficial ways of measuring of success. For example, during the general election of 2019 change.org published 'the People-Power Index' ranking 
MPs according to whether they are 'good' at their job. They had three indicators: (1) MPs' availability (judged by their online presence, whether they hold surgeries and whether they are 'distracted' by an additional job outside parliament), (2) voting record in parliament and raising issues in parliament 'from the constituency', (3) how much the MP listens to their constituents. However, the problems with their methodology were multiple. Where they couldn't speak to MPs' staff about frequency of advice surgeries, even if they have a caseworker or legitimate absences, they put a default 'no'. So, MPs were penalised if their staff decided that answering the survey was not the best use of their time. They rated those poorly who do not have a constituency office, but MPs can save money if their staff are all in Westminster; this doesn't stop them spending half their week in their constituency, which may be in London. Second jobs that are a 'public service' were scored differently from other jobs, but who defines what is in the interests of the public? Strangest of all, listening to the public was measured by how often MPs mention petitions or constituents sign change.org petitions. ${ }^{15}$ Despite these flaws, local newspapers all over the country reported on their MP's ranking - this was easy, timely and cheap copy, requiring journalists merely to consult a website. The presentation of results as if they were rigorously gathered glosses over contested assumptions about what representation means.

MPs' interaction within their constituencies has intensified hugely with rising expectations and cuts to public services. Constituency work doubled between the 1970 s and the end of the 1990s and over half of MPs claimed that they spent more than 40\% of their time in their constituency by 2012 (Judge and Partos 2018: 268). As its significance grows, it is worth scrutinising this work. Pundits, political scientists and MPs themselves tend to view their close and frequent interaction with constituents as either: (a) work that should be done by local councillors and a waste of resources merely invested to please the public and get the MP re-elected, or (b) useful political work that deepens the MPs' knowledge of their locality and the impact of politicians' decisions. However, some completely ignore this aspect of representation work and some journalists even complain when Parliament closes and MPs go 'on holiday', ignoring the fact that they spend most of the time in their constituencies when not in Westminster. Isabel Hardman is a rare exception as a journalist who has not only asked MPs about their constituency work, but even shadowed them into chilly church halls, community centres and library basements as well as bread throwing rituals and, most significantly, their 'surgeries' (2018: 62-79). She found that MPs often solve problems for individuals facing disasters and raises two important questions. Since the problems constituents face are often created by MPs - poor legislation, for example - and they are rarely qualified to deal with people's crises, is this the best use of their time? This seems to me an interesting question for MPs to debate with their constituents. In the meantime, I have been trying to understand more about what happens in these surgeries.

Surgeries have scarcely been studied by scholars and yet MPs or their staff spend a huge amount of their time in constituency 'surgery meetings', mostly either 
listening to lobbyists or individuals expressing political views or to constituents asking for help. The latter involves invisible and neglected encounters with those constituents who present with urgent problems. Between 2011 and 2013 I observed surgery meetings in six constituencies and found almost half were 'urgent', meaning that either the constituent or an immediate family member was: (a) destitute, (b) about to lose their income, house or right to stay in the UK, (c) dealing with a serious mental illness (Crewe 2015a: 92). Cases were almost never about only one issue; they were complex, with many strands of difficulty, which constituents pointed out were never adequately dealt with by one local service. The MP or caseworker listening to him/her was invariably respectful and polite. Of course, the MPs who allowed me to visit may have been more serious about these processes and my presence could have affected this courtesy. But during and after these meetings with constituents, many of whom had visited the office multiple times, they often mentioned the way they were treated with respect in the MP's office without any prompting. In contrast to local government officials or staff in companies dealing with their challenges, constituents talked about having their dignity restored when the MP or staff member - someone important - was taking them seriously and appearing sympathetic. They felt recognised in their struggle. One said about a DWP worker, they 'were rude and never apologised. They don't have any standard of courtesy. I have never had a pleasant reply. We pay our taxes. Why can't they be more receptive?' (Crewe 2015a: 94). Even when the MP or their caseworkers were doubtful that much could be done, the constituents usually went away full of praise and gratitude. Although much of the rest of their work impels MPs to speak at people, to be (or at least appear) thick-skinned, and to feel oblivious to the feelings of their opponents, in the privacy of surgeries MPs who do this work - which is the majority of them - become patient but also surprisingly good listeners.

MPs and their staff develop an in-depth knowledge of the characters, agencies, rules, resources and latest changes in social security; compiling a socio-political, institutional and economic ethnography of the local state. Research is an integral part of the work of MPs and their staff. They aim to treat all constituents, irrespective of whether they are supporters or even voters, as equally deserving of attention and usually take care to avoid assessing the merits of the case explicitly in their conversation with the constituent. Refusing to take any action at all is extremely rare. But when writing on behalf of a constituent an experienced MP will give hints about the severity of the case, putting 'we ask that this be looked at in a timely manner' (meaning don't rush) all the way to 'this is extremely urgent', as appropriate. Constituents get a copy of these letters but since they can't compare with the letters sent on behalf of others, they can't easily interpret the meaning of these hints. MPs would destroy the goodwill of government and voluntary agency contacts if they gave the impression that fast and time-consuming responses had to be made equally in all cases. So they signal the level of urgency without making it explicit to the constituent.

This mediation by MPs (and staff) between constituents and the state inevitably privileges some above others - and there is no avoidance of this - so representation 
is uneven however much politicians strive to act otherwise (Crewe and Sarra 2021). But when seen within wider processes in society - whereby people with a substantial income pay for lawyers, accountants or doctors, and it is those more dependent on the state who go to their MP as a last resort - representation by MPs, it could be argued, colludes with rather than addresses these inequalities. Unevenness and inequality are found between constituencies too. More established MPs have a huge 'bible' of useful services, contacts and resources while newer ones may not (especially if they have taken over from an MP in a different political party). The political position of the MP's party will make a difference. An MP whose party is in government can't blame their own ministers for their constituents' problems and, if their party controls the council, then they have to defend their record locally too. On the other hand, if their party governs either locally or nationally then you have the advantage of better access to decisionmakers who can make something happen more easily.

MPs' own identities influence whom they listen to most closely but also how people react to them. British women MPs seem more comfortable than male counterparts with 'glorified social work', as some observers call the process of listening and then responding to constituents' reports of suffering (Crewe 2015a: 88). I did not find a simple pattern. The MP who looked most at ease was a man who had been an MP for decades, so he was the most experienced among my small sample, but I found no women looking uncomfortable while several men did. Several male MPs in my wider sample delegate all (rather than most) casework to staff but I only discovered one woman in the House of Commons who did this. In a familiar gendered pattern of women's work receiving less public recognition and value, this invisible political work enhances an MP's reputation locally but counts for nothing in the eyes of the whips when trying to get promotion onto the frontbench.

So, interaction between MPs and their constituents reveals the wider social and political patterns in society. When the Covid-19 pandemic hit, MPs' staff had to work from home - like everyone else - navigating the difficulties of caring for small children or lack of work space while communicating with constituents via email, phone or online video. They dealt with a flood of requests in the first few weeks, according to one staff member five times more than normal. Initially they did not know the answers to completely new questions - about lockdown, people stuck abroad or government assistance - so they had to learn fast about a new pandemic-struck world, one created in a matter of weeks. ${ }^{16}$

If we go back into the past, we find more normal gradual change: during the 2010-15 coalition (the time of my first bout of fieldwork in the Commons) we were beginning to witness the direct impact of austerity and cuts in public spending. This showed up in the meetings between MPs and constituents with huge numbers of questions about benefits and housing in particular. During more recent fieldwork with Chris Law (MP) and his staff in Dundee West over a few days in late 2018, by collaborating with Nicholas Sarra (a psychotherapist and group analyst), we were able to make sense of the psycho-social interaction within 
constituency offices in more depth. The over-riding impression was that the work of the constituency office is always suffused with affect and emotion (Crewe and Sarra 2021). Constituents present their cases with the hope that the staff will identify with their concerns and difficulties. To 'identify with' is to feel a sense of alliance with and to find one's own experience in the experience of another, as if I am like you and you are like me. These ongoing processes of identification in the MPs' office appeared to us as psychologically demanding on constituency staff, required as they are to engage with disturbances and challenges in the community. For example, we heard a rough estimate that $50 \%$ of presentations to the constituency offices were mental health related. (The week we visited the caseworkers reported that they were dealing with 125 live constituency cases.) This work is not just about dealing with the turbulence of others, but navigating the emotions summoned up for the MPs' constituency staff too. So, the 'mood' in the office corresponds with the 'mood' presented. The office can feel sad, angry, anxious, grateful, happy or disturbed according to who walks through the door or what comes through the screen or phone. In effect this means that wider individual, family and sociological disturbances, embodied in the constituents and their individual histories and concerns, express themselves through the conduit of the constituency offices. Political representation is a politics of affect.

All staff working in this Dundee West constituency office recognised the construction of a collective MP through their own collaboration in representing the latter (ibid). The endless demands by letter, email, tweets and people walking in through the door need a response as if it were the MP himself responding. The MP will come to represent a community symbolically as they come to stand in the public's eye for something larger than their own individual self even if that individuality may well express both party and personal political ideology and its branding. She or he can't do this alone. As the social psychologist G.H. Mead wrote:

Consider a politician or a statesman putting through some project in which he has the attitude of the community in himself. He knows how the community reacts to this proposal. He reacts to this expression of the community in his own experience - he feels with it. He has a set of organized attitudes which are those of the community. His own contribution, the ' $\mathrm{I}$ ' in this case, is a project or reorganization, a project which he brings forward to the community as it is reflected in himself. He himself changes, of course, in so far as he brings this project forward and makes it a political issue. There has now arisen a new social situation as a result of the project which he is presenting. The whole procedure takes place in his own experience as well as in the general experience of the community.

(1934: 187)

The MPs' office is constituted as if it were a mini-community within the larger constituency. An ongoing process of imaginary anticipations and identifications 
takes place and is embodied affectually, in which the constituency staff are able to form a collective: 'We' and 'I' become fused both through the persona of the MP and the personae of their staff. Each member of staff may respond slightly differently - after all, they each have their history, professional experience and performative style - but they are part of the collective 'We' (represented in this case by Chris Law MP) at the same time. How does this relate to representation? The MP evokes the social object of representation and by extension his staff do the same by their active work in performing the collective 'We'. Representation is linked with identification, the latter of which is partly an emotional process involving as it does an acute sensitivity to issues of belonging or the processes of inclusion and exclusion which concern their constituents. The more an MP can extend this sense of 'We' identification, the more successful they will be at creating the idea of a community which they symbolise and represent.

The reward is not merely better prospects at the next election. MPs tend to be loathed as a collective in the UK, but in their constituencies they are still VIPs, often even loved. UK MP Paul Flynn's constituents knew everything about him, he told me, and they think, 'He is a mad bastard, but he is our mad bastard. ${ }^{17}$ They are certainly local heroes, but whether their social work is glorified or respected is a matter of political judgement. It is a judgement that needs to be made by each individual and group within any constituency, not merely by looking at superficial measures of participation, but by finding out what MPs actually do in their encounters and holding them to account for that work.

\section{Resonance and alienation}

It is obvious that representation is about more than numbers. Demands for proportional representation of different groups in society is complicated by the multiple identities of representatives and those they represent. I have already mentioned that one British Asian MP was particularly articulate about how his identity affected his work: although some Asians trusted him, others disapproved of him because he spoke out against caste and domestic violence, infuriating traditionalists who thought he had been too influenced by Western thinking. Former MP Dame Anne Begg, who uses a wheelchair, did not want to be pigeonholed as a disability activist so rather than working on disability as a separate issue isolated from context, she considered the interests of disabled people in the course of all her work as an MP. As former Chair of the Work and Pensions Select Committee, she thought

about how disability related to pay, pensions, benefits or whatever came up. ${ }^{18}$ The question of whether or not people are best represented by those with a shared identity becomes problematic when you consider that there can only be overlapping identities, rarely identically aligned ones. Furthermore, plenty of women felt ignored by Margaret Thatcher; plenty of black people were disappointed that Barack Obama did not do more for their rights. Identity is always co-created in relationships, dynamic and, therefore, provisional. While a parliamentary chamber should be representative of the wider population, because they are then more likely to consider a range of interests and the electorate will have more faith in 
them, an overlapping identity between specific MPs and constituents is no guarantee of truer representation.

The relationship between representative and represented is too complex to be captured with mechanical metaphors; they tend to ignore the emotional, hidden, symbolic and sacred. As Graeber points out:

any system in which one member of a group can claim to represent the group as a whole necessarily entails setting that member off in a way resembling the Durkheimian notion of the sacred, as set apart from the stuffs and substances of the material world, even, to a certain degree, abstracted from it.

(2005: 421)

Flynn described the relationship between MP and constituent as:

that of a priest and parishioners, solicitor and clients, shepherd and flock, shop steward and workers and friend of many friends. The MP should be the living embodiment of the constituency, tirelessly promoting and defending the territory with the ferocity of a mother protecting her offspring.

(2012: 138)

We have seen that MPs extol the virtues of their constituency - its beauty, variety or warmth - and develop an affinity with the place they represent. MPs can champion their locality, at least in general terms, without incurring anyone's displeasure, so this process has a performative quality achieved through their interactions with their constituents. This fosters the sense of an expanded 'We' identity of which he or she is the embodied representative. Without our elected representative, we would not exist as a constituency - a political entity reaching up to the nation. So, the representative creates us as a group and we create her/him as a symbol of that collective. This means far more than the representation of our interests or views as an aggregate of individuals with preferences, as it involves the shared belonging to a locality within which the representative champions our area as a space and an environment as well as the diverse organisations, families and individuals within it (Crewe 2014b).

Political science rarely acknowledges the importance of symbols and yet culture and politics rely on them existentially. MPs are not just women or men of actions, ideas and policies, they are symbols with the power to evoke. This power of evocation is essentially the capacity to evoke an emotional and cognitive response and in particular, a response which affirms a mutual or collective identity. These identificatory processes are experienced as feelings of belonging and 'we-ness'. To identify with an MP's gestures is to affirm their authority to represent. Being seen as 'local' is the most important identity marker when people elect their MP in the UK (the evidence is summarised by Judge and Partos 2018: 207). All MPs symbolise the link between local and national government, and even political locality and nation, succinctly conveyed to me when one MP presided over the celebrations for the Queen's birthday in England in 2012 (Crewe 2015a: 104-5). This event 
involved residents in a constituency assembling to watch a parade by cadets (the military), vicars speaking about the importance of community (the church) and the MP (Parliament) concluding the speeches by encouraging us to drink a toast to the Monarch. The MP symbolised the embodied link between community, Parliament and the Monarch reigning over the nation, an example of how identities are constructed through performance and ritual at a local level (see Chapter 7).

But any community involves both fission and fusion - the fission is created by differences, factions and conflicts, the fusion by commonalities, alliance-building and other forms of co-operation. Dewey grappled with the problem of fission and fusion in the process of political representation long ago. How can representatives mirror the interests of a huge group as individuals? Since he was interested in participation - or 'self-organisation' of citizens - the trustee model of representation puts them in too passive a situation and the delegate still makes them spectators, he argues. ${ }^{19}$ To be more deeply democratic, representation would have to involve the representative being willing to be changed by the process of seeing the world from the viewpoints of those they are representing. Viewpoints, or preferences, would have to be understood as neither just individually held, nor culturally determined for whole groups, but emergent through processes of interaction. If representatives are serious about acknowledging pluralism, and being open to change, then this is hugely demanding, as the sociologist Hartmut Rosa explains:

democratic will formation and decision-making are inherently time-consuming, as - in the language of resonance theory - they are based not on a logic of attunement through the mere casting of votes, but rather on a responsive process of deliberative, argumentative encounter. The more pluralistic a society becomes i.e. the more circuitous its chains of interactions and the more complex the issues it must negotiate - the more time-consuming this process becomes.

In this negotiation, effective representatives will be continually attuned to the possibility of resonance or alienation. Resonance is a metaphor for how people relate to other humans and the world around them; a process that happens between minds, bodies and the environment. Rosa's most concise explanation in his epic tome is as follows:

It describes a specific relationship between two vibratory bodies whereby the vibration of one body prompts the other to itself vibrate in turn. If you strike one tuning fork in close proximity to another, the second will begin to vibrate at its own frequency. We can speak here of resonance, however, only when the two bodies in question are not so interconnected that the movement of one necessarily elicits a mechanical or linear reaction from the other (e.g. because the two tuning forks are glued or clamped together). Resonance is produced only when the vibration of one body stimulates the other to produce its own frequency. 
This might be useful for helping us move beyond a numerical or mechanical view of representation that portrays the relationship as either the aggregation of individual interests or the mirroring of collective interests. Representing others is both an individual and social process of relating, requiring a resonance of more than material interests or social identity or emotional states, but all of these at the same time. The subject and the world need to be consistent enough to be able to speak in their own voice, but open enough to have influence on each other (ibid: 174).

So political representation is partly material, but it is also affectual. Affect is the physiological resonance between interdependent bodies and the meanings we ascribe to these patterns of physiological resonances are communicated through the vehicle of emotion. Emotion communicates the qualities inherent in the processes of identity formation ubiquitous in political work:

Our view is that emotion and its performance are fundamental to political life and that we miss something important if we fail to recognise this and the connection with how identities are constructed through political processes. The presence of emotion is not only discernible in exceptional circumstances or when 'feelings run high' but an omnipresent quality in all human relating and thus through all political work. Therefore, we argue that it is erroneous to separate rational from emotional process and more helpful and pragmatic to view them as mutually constitutive and arising at the same time in political life.

(Crewe and Sarra 2021)

How are the social, emotional, cultural and material entangled in the work of representation? The first point to make is that they are not evenly so because people's material circumstances are so unequal. At the same time, as Mosse puts it, all economic relations are social relations but not all social relations can be reduced to economics, so people living with poverty are every bit as emotional and engaged in culture as richer people (2010: 2). To be poor is not to lack social contacts or networks but to engage with them in adverse ways because you owe your patron money, or are exploited by richer landowners, or are a woman who can only be 'married off' with a dowry. Poverty is both an individual and a social experience, a form of structural violence embedded in culture; ignore any of these elements and it is all too easy to perpetuate the status quo.

If you look at poverty as social relationships that could be changed, then you have to wonder, why does anyone tolerate such suffering in their communities? To relate this to this chapter's theme of representation, why don't politicians do more to challenge poverty or climate breakdown? As Appadurai suggests (2004), people's ideas about the future, and whether or not their priority is poverty eradication, are embedded in culture not just material circumstances. He challenges the idea that economists are the ones we need to help plan the future while anthropologists study culture, which is associated with the past. Anthropologists are interested in culture, and culture is about the future and present as much as about the past. He points out that economy and culture are not opposed in people's lives; economies 
themselves are embedded in cultural and, I would add, emotional processes. Thus, both your economic experiences of life, and the meaning and emotion you attach to them and to your future, are culturally produced and nurtured.

Has our disposition towards the suffering of others changed with Covid-19? What are the prospects of returning our attention to what Robbins calls the good value, imagination, well-being, empathy - which might make it easier for politicians to be influenced by what people are already doing to make a better world for themselves and their neighbours (2013: 450)? Politicians have seemed indifferent (or ineffectual) in challenging poverty - no doubt in part a product of their social and geographical distance from the poor: a form of alienation - and this translates to what Keith Hart calls inhuman principles:

Compassion and similar human qualities are unlikely to be influential in economic life when power seems to be concentrated in remote, faceless centres. The normal response to problems is to let 'them' (the powers that be, les responsiables) get on with it. When confronted with the consequences of their own actions, people shrug their shoulders: it is nothing really to do with us.

(2002: 33)

To move beyond this alienated stance, perhaps what is needed is an emotional transformation; it may be that the trauma of the Coronavirus pandemic could inspire such a change. We have had agricultural, industrial and digital revolutions, perhaps it is time for an emotional revolution based on resonance and empathy? Is Extinction Rebellion, the movement based on the idea of action for future generations, and the state response to Covid-19, the sign of things to come? Might it even be possible to envisage a world where civil society, governments and parliaments address emergencies in critical collaboration?

\section{Notes}

1 John Bercow, HC Debates, 9 September 2019, col. 497.

2 http://www.putneydebates.com, accessed 30 November 2019.

3 https://data.ipu.org, accessed 1 December 2019.

4 The language of race is fraught with problems, often a symptom of the racism underlining the way people are classified. I have tried to use the terms used by people themselves - Mohanty referred to herself as a Third World feminist, for example - but all of them are problematic for some. 'Third World' disparages huge tracts of the globe, BAME (black, Asian and minority ethnic) is clunky and only makes sense in predominantly white countries, Global South vs Global North homogenises difference within each category, Black (as a political term for non-white or those facing racism) is seen as privileging those of African origin, and people of colour implies white people don't have colour. I have at least tried to alter the language partly to fit with the context but also to avoid the impression that any of these terms is satisfactory for all.

5 These are Vanuatu, Federated States of Micronesia and Papua New Guinea, https:// www.pacwip.org/women-mps/, accessed 24 April 2020.

6 Steve Hogg, Councillor for Wrington, interviewed by Emma Crewe, March 2020. 
7 https://commonslibrary.parliament.uk/local-data/constituency-statistics-population-byage/\#compare_constituencies, accessed 8 November 2019.

8 This research was part of a coalition directed by Emma Crewe and Ruth Fox and was funded by the Department for International Development and the Economic and Social Research Council (2014-17), co-ordinated by SOAS with the grant reference ES/ L005409/1.

9 Norton's more recent work, including an article about the importance of informal space for understanding what goes on behind the scenes, shows an open-mindedness towards other disciplines (2019). It possibly also reflects the depth of his everyday experience of the Westminster Parliament, gleaned by being an insider as a member of the House of Lords since 1998.

10 This research was part of a larger programme funded by grants awarded by the Global Research Network on Parliaments and People, supported by the Global Challenge Research Fund and the Arts and Humanities Research Council (2017-21), co-ordinated by SOAS and directed by Meheret Ayenew, Emma Crewe (PI), Ruth Fox, Niraja Gopal Jayal, Cristina Leston-Bandeira and Myat Thet Thitsar, with the grant reference AH/R005435/1.

11 This was also part of the Global Research Network for Parliaments and People, see note 10. See also, https://chinbridge.files.wordpress.com/2019/02/p4p-leaftlet-confirm-english-version.pdf, accessed 1 December 2019.

12 http://stephenlloyd.org.uk/en/article/2010/453897/lloyd-votes-against-rise-in-universitytuition-fees, accessed 28 June 2013.

13 Eric Pickles MP, HC Debates, 12 March 2013, cols 12, 15, 20.

14 Interviewed by Emma Crewe, January 2012.

15 https://www.change.org/l/uk/the-people-power-index-methodology, accessed 5 December 2019.

16 Emma Salisbury, Coronavirus and constituents: working for an MP during a pandemic, 1 May 2020, UCL Constitution Unit blog, https://constitution-unit.com, accessed 1 May 2020.

17 Interviewed by Emma Crewe, November 2013.

18 Interviewed by Emma Crewe, May 2012.

19 https://www.academia.edu/37946758/Political_Representation_from_a_Pragmatist_ Perspective_Aesthetic_Democratic_Representation?email_work_card=interaction_paper, accessed 22 June 2020. 


\section{4}

\section{SCRUTINY OF THE STATE}

Scrutiny of the state, in the sense of critical examination and questioning, is seen as vital to a healthy democracy, but what exactly is being scrutinised? The state is one of those words with many meanings. Going back to the idea of the 'estates of the realm' (noble, common, clerical), it is also often used interchangeably with the nation, but while a nation has geographical and political boundaries, the state is both an idea and a network of governing organisations with no clear lines between it and society. Whether defined as the political means or ends, and separable from the private sector, civil society or family (e.g., Lazarus-Black 2001) or not, and whether you wish to see its reach extended or contracted, all depends on your political viewpoint. Within a state you find various political institutions: government, the judiciary, parliament, local authorities ... that fit together in different ways depending on the country and its history, geography and culture. A government is a group of people who rule a politically defined area, but while some entities are clearly governmental others are hybrids (e.g., 'quangos' which are usually funded but not run by government). Some national or regional governments are part of wider structures - the United States of America, the European Union or the Federal Democratic Republic of Ethiopia - meaning that you can only understand how they work by looking at the larger unit. In parliamentary systems (such as the UK) the ministers of government are chosen from among the MPs, so parliament contains both the legislature and the executive. In a presidential system (such as the US) the executive is separate from the legislature. In the former the civil service tend to be permanent and apolitical, in the latter they tend to be political appointees. Some parliaments have one house (unicameral), while others have two (bicameral) - a lower (usually primary) and upper (usually secondary).

My point here for the anthropology of parliaments, seen within the context of states, is that we begin with an unsettled sense of what states are and what they do. If drawing the boundaries around the state is complex, then we can logically 
assume that scrutiny of the state is probably difficult as well. The most promising anthropological theory of the state in recent years was proposed by Jonathan Spencer (2007). His starting point is that states are much more than an apparatus or process of disciplinary power. On Foucault-inspired anthropological work on the state he writes, it can be 'a very predictable world, a feel-good dystopia, where external power meets local cultural resistance, and the last surviving remnant of Foucault's bracing capacity to shock is drowned in a sea of sentimentality' (ibid: 111). He takes us into new directions by pointing to neglected avenues in political study - to history, emotion, performance and ritual - offering an approach that gets us beyond merely deconstructing rigid typologies and lists towards exploring the movement of and within entanglements, a task that is always incomplete. People's tendency to use the idea of the state to dream about happier futures, and their collusion with state authorities in the meantime, tells us something about our deeply unsettled ambivalence towards the state. To inquire into how people move between collusion, blaming and dreaming tells us much about their relationship not only with the state but with politics more generally as well.

In the last 20 years anthropologists have been rising to this challenge - writing about state violence (e.g., Das and Poole 2004), corruption (Blundo et al. 2006), and the everyday practices of state bureaucracies. For work on bureaucracy in Africa see Bierschenk and Olivier de Sardan (2014), for the UK we have Koch (2018), for France see Fassin (2015), and for a special issue in the Political and Legal Anthropology Review on bureaucracy, see Bernstein and Mertz (2011). But there is a marked dearth of research on important processes within the political world: scrutiny by and of parliaments. The Handbook of Political Anthropology has a chapter on the state but none on parliament and only a few mentions in passing (Wydra and Thomassen 2018). Greenhouse's entry, 'Political Anthropology', in The International Encyclopedia of Anthropology alludes to existing anthropological work on the impact of the state - privatisation, outsourcing, austerity - and the response of political movements, encouraging us to study how states, law and regulation are both coercive but also culturally reproduced subjectively for citizens (2018). But again, parliaments/legislatures are absent as objects of study.

While anthropologists ignore parliaments, political scientists tend to ignore culture in favour of science. Political scientists, and their sub-branches, tend to be tempted to create taxonomies and typologies of states and parliaments, or activities that take place within them - identifying their common ancestor or features and trying to group them into separable categories as if they are like plants. As Paley points out, they do the same with democracy: advanced liberal, parliamentary, electoral and socialist (2002: 471). This scientific-like classification can generate insight but it can also obscure more than it sheds light, making the world appear more wellordered and stable than it is. It can even have troubling effects. The 'Westminster' model of government describes most political systems around the world, according to many political scientists, even half a century after the end of British imperial power. Apparently, the Westminster model offers efficiency, ambiguity and flexibility but weak accountability (e.g., Kumarasingham 2013: 580-1). In the use of this model 
in other parts of the world, the absence of some elements of the model and/or the gradually evolving unwritten rules you find in Westminster, have made it easy for the executive to evade some aspects of (including informal) forms of accountability. Efforts to correct this have been made, for example, New Zealand aspired to have a better version of the Westminster model, but the executive wielded even more power over the state than in the UK so they introduced PR in the 1990s (ibid: 584).

To return to typologies, in other postcolonial nations, the export of the Westminster model is seen to have failed and the apparent backwardness of those places is explicitly or implicitly blamed. In a search for features to blame: their 'dictators' are unconstrained, politicians lack incentives or a system has been inadequately influenced by the West. These apparently explain why some countries drift towards authoritarianism rather than democratisation (e.g., Schuler and Malesky 2014). Such an approach entails finding features shared between commonly labelled systems, creating a typology and calling it a theory, without looking at the assumptions lurking beneath the claims. This is problematic if you accept the anthropological premise of taking specific national and local histories seriously and rejecting an a priori assumption of Western superiority. Some politics scholars agree. Barry Munslow, who has researched and lived in Africa and clearly understands the history of the places he writes about, offers a convincing account about the perceived failure of the Westminster model in postcolonial settings:

The first is that the models and institutional framework established by a particular country in Europe is the product of its own history. They cannot easily be transposed to a society whose social, economic and political tradition has been extremely different. Parliaments would have to face different problems. Regional rather than national splits are still represented in Nigerian politics, for example. The intensity of the conflict was such in this country in the mid-1960s that civil war broke out between the Ibos of the east and the rest in the Biafran war. The Westminster model was the creation of Britain's own history, with its unwritten constitution based on long tradition and precedent. It emerged after its own bitter civil war and the long struggle for popular emancipation which only in recent times fully enfranchised the adult population. The legislature is far from being the sole source of power; there are firmly established interest groups like the Trades Union Congress and the Confederation of British Industry, powerful economic institutions like the banks, newspaper chains and well-established health and educational systems. Power is diffused within the society. The newly independent states of Africa lack these established patterns of power and the borrowed institutions exist in an altogether different environment. Much stress has been laid on the 'preparation' for independence which colonial rulers are supposed to have carried out, but on closer inspection this appears to have been a hollow claim. 
Even though he challenged the ethno centricism of mainstream political science in its depiction of 'failing' states over 35 years ago, and others with deep knowledge of places have echoed this since, the importance of history is often still ignored in the taxonomy of states. Russell and Serban have recommended that the term 'Westminster model' should be dropped as the contradictions within it, even if only aiming for family resemblances, muddle the aim of comparison (2020). Some even argue that Westminster itself doesn't conform that well to its own 'model' (ibid: 12).

The political failure of states is given labels - failed, failing, emerging, weak, fragile, authoritarian - to indicate that those places are in need of assistance from the West (including from Westminster or Washington). Even though this taxonomy has its scholarly critics in political science (e.g., Nay 2013), this classification has created an economic incentive for aid agencies to collude with the hierarchical ranking of states so it has become entrenched. Since the account of failure and prescribed solutions are both flawed, it is unsurprising that governance assistance (or more specifically 'parliamentary strengthening') usually fails too in the sense of achieving little change. ${ }^{1}$ But for the moment my main point is to question the utility of the commonplace classifying of parliaments in both academia and international aid discourse. If you do follow anthropologists by going beyond taxonomy to history, processes, relationships and effects in countries around the world, then a far deeper understanding of scrutiny becomes possible. By presenting some of the threads of anthropological inquiry on the state in more detail in the next section I hope to show you what I mean.

\section{Anthropologists on the shape of the state}

Anthropologists point to the blurring and entanglement between the state and other parts of society, as well as other states (see Mitchell 2006: 170). The state is not the discrete system sometimes portrayed by political scientists or policy / public administration scholars: it is entangled, dynamic and unpredictable. Whether in relation to service delivery, human rights regimes or collaboration on security, states are conceived of as single entities in well-ordered typologies but in practice operate in concert with other entities and each other. As examples, states privatise and outsource service delivery to the private and voluntary sector from their own nation and others; while government departments are clearly part of the state, there are 'quangos' that are hybrids; people cross from one state to another and live in several, so responsibility for their welfare and tax is complex; transnational and multi-lateral organisations (such as the UN), networks and movements operate across national boundaries; and so on. If globalisation challenges two ideas underlying the idea of the national state - territoriality and sovereignty - then for Sharma and Gupta the question is, 'How can an anthropological approach further our understandings of the state as a multilayered, contradictory, translocal ensemble of institutions, practices, and people in a globalized context?' (2006: 6).

To understand the relationship between state and society, we have to look at what Sharma and Gupta call the cultural moorings of the state. Since anthropologists are 
interested in the everyday practices of both making culture and statecraft, this means turning our attention to people's ideas and action rather than abstraction away from practice. So, anthropology invites us to get beyond definitions and taxonomies, because they rarely generate understanding of practice (in Bourdieu's sense, 1977), to ask what the state actually does, or, to be more precise, what do people who are seen as part of the state do and with who else? What cuts across from one state to another? And what is created or destroyed through these processes? What changes over time and why?

The banal practices of bureaucracies - mapping, collecting taxes, filling out forms, receiving complaints - can be highly significant when you look at them closely. For example, Sharma and Gupta noticed that they have the effect of reproducing the primacy of the state and its superiority over other institutions (2006: 11-13). 'Proper procedure' is part of the performativity that confers legitimacy on the authorities and claimants, while subversion and rule-breaking expose the inter-bureaucratic conflicts. The activities of the state are geared to creating the impression of predictability and order but in reality its work is always messy, even when it achieves tasks:

By lending to the state a veneer of consistency, systematicity, centralized control, and wholeness, and by thus eliding the messiness, contradictions, and tensions that states congeal, statist representations play a crucial role in entrenching the borders and vertical authority of the state and in shaping resistance to the state.

(ibid: 19)

The anthropologist Michel-Rolph Trouillot writes about the tension between simultaneous state encroachment and decline. Millions of daily encounters between individuals or groups and the state reveal how it regulates, denies access or rewards but also how social movements and transnational companies bypass state power (2003). He, in turn, was influenced by one of the best-known scholars of the state, James Scott, an anthropologist and political scientist, who interrogates processes of state control. Scott outlines four processes that lead the state towards harm. Unlike typologies that merely classify, these point to patterns about the workings of the state in action over time that have explanatory power. First, modern statecraft involves processes of classification, mapping and simplifying complex human and environmental phenomena into categories that make it easier to organise. 'These state simplifications, like all state simplifications, are always far more static and schematic than the actual social phenomena they presume to typify. The farmer rarely experiences an average crop, an average rainfall, or an average price for his crops' (1998: 46). Second, the ideology of high modernism - the belief in scientific and technological progress to create order - means that making the organisation of people look ordered is symbolic of being advanced. These two tend to be characteristic of most states. Their capacity for lethal harm increases with the two final processes: third, using the 'full weight of its coercive power' and fourth, 
obliterating the possibility of resistance by opposition, within the state or in civil society (ibid: $4-5$ ).

Scott did not dream up these processes and then apply them to examples. He explains that his inquiry began with a question about why the state is seen as the enemy by people on the move (pastoralists, travellers, refugees etc.) and morphed into a wider question about state power. He developed his ideas in response to thinking about real life encounters between people and the state; for example, he retells the history of ujamaa, a campaign to permanently settle the population of Tanzania in the 1970s (ibid: 223-61). Five million Tanzanians were relocated. The aim was to make it easier for the state to deliver services, such as education and water, but it was also about making it easier to enforce state policies (e.g., communal farming). Although clearly not found on the plans, Scott argues that a third less tangible dimension was at play - the aesthetics of modernity. The aspiration was to transform people's disorderly traditional living arrangements into efficient, orderly, intelligible modern ones. The scheme failed - economically, socially and environmentally - due to the 'destructive conservatism of the people', according to a Tanzanian civil servant (ibid: 241). Scott's version, after considering how it looked from the viewpoint of various people, was that a mix of ill-informed politicians and planners (influenced by colonial and aid 'experts'), canny elites determined to secure a bigger share of the benefits, and resistant peasants contributed to the disaster. The peasants' resistance was highly rational. The politicians and planners ignored the peasants' complex, delicate adaptations to make the most of their environments, misunderstanding their rational caution for traditionalism; in fact, their foot-dragging and flight made the scheme less destructive, not more so (ibid: 246-7).

This combination of politicians'/planners' ignorance, elite capture and the rational resistance of peasants is a familiar story in the anthropology of aid and development, not only in the processes controlled by states but also by international donor agencies (we summarised this literature in Crewe and Axelby 2013). So, governing as a process - or even Foucault's broader governmentality - it not just in the hands of states; it takes place across sectors and within and across borders, locally, regionally and globally. The 'aid industry' is a clear example of government across borders, administered in the name of 'development', about which anthropologists have much to say. In many parts of the world aid-receiving governments are entangled with the aid industry to such an extent that it is difficult to separate them conceptually as sovereign states. Aid-giving nations continue to have incredible influence on aid-receiving ones, and compete against each other for influence, either directly or via multi-lateral agencies (such as the Bretton Woods institutions and the World Trade Organization), and through aid, foreign policy, trade or security. International aid receives even less formal scrutiny than national development, even though aid agencies often behave as if they are governing, so both national and international scholars of aid and development play a key role in scrutinising. If you were to take this view of scrutiny (or lack of it) seriously then aid-giving countries might consider two policy shifts. First, they might invite 
national scholars and experts to give evidence more systematically to the body that the aid-giving government is ultimately responsible to (e.g., in the UK it is the International Development Select Committee [IDSC]). Second, they should involve them in developing strategies for governance programmes including for parliamentary strengthening. (I have found the UK IDSC and government officials sympathetic to these ideas in theory but they continue to rely heavily on UK academics to make the connections.)

Can we apply this kind of anthropological approach to researching the state, and more specifically, to the study of parliaments? In the next section I offer two narratives on evidence and conflict in processes of scrutiny, before seeing whether this might advance our inquiry into the anthropology of the state, as well as the relationship between knowledge and politics more broadly.

\section{Reading the runes: making law in the UK}

Legal scholars and political scientists frequently observe that the Westminster Parliament is moribund, burdened by arcane rituals and responsible for a leeching of power from legislature to executive. Anthony King and Ivor Crewe offer an example of such despair about the Westminster Parliament in The Blunders of Our Governments, 'the parliament of the United Kingdom is, much of the time, either peripheral or totally irrelevant. It might as well not exist' (2013: 361). I have no interest in quarrelling with their list of government failures, except to warn by that by focusing on domestic topics they gloss over some of the most critiqued areas of UK government policy in recent years: the invasion of Iraq and Brexit. However, my problem with this book is that their critique of Parliament's role in the failures is too unspecific and ignores valuable but less visible aspects of scrutiny. The parliamentary scholars who have forensically studied what Parliament actually does to legislation - such as Russell and Glover (2017) who tracked twelve bills over 2005-12 - conclude that government backbenchers, the opposition and civil society have significant influence on the process of making laws. So, what is this influence and why does it get overlooked by some, including King and Crewe?

The making of law (or policy) begins with a political claim - usually to promote national (or sometimes local or global) interests in the future. Inevitably what really goes on in law-making as it is implemented either complies or departs from this (or both) to different extents depending on the example and your own politics (e.g., what you thought of the law in the first place). Governments privilege the interests of one group above another but often try to conceal how these choices involve taking sides. There are also more specific claims that gain credibility and respectability in a particular time or place. For example, the prevailing rhetoric in contemporary law-making in the UK (and elsewhere but in this narrative I'm focusing on the UK) asserts that any new Act will modernise the country and reshape the future based on evidence. My narrative challenges this rhetoric, showing how evidence is always entangled with politics and arguing that the future can't be predicted. It is in the hands of many groups and organisations, so in practice 
governments are reading the runes and anticipating the future rather than reshaping the nation in a predictable way. It is a case study, or to be more accurate a minihistorical ethnography, about law-making in Westminster.

For almost two years part-time (2012-14) I followed one 250-word clause about parenting as it made its journey through the two UK Houses of Parliament while being transformed from text (a 'bill') into law (an 'act'). If you merely glanced at the texts produced by government and parliament, ${ }^{2}$ you might think this minihistory concerns MPs on a committee championing the interests of families in tandem with one venerable Baroness Butler-Sloss, a giant of family legal matters as the former President of the UK family court, rising above politics to improve draft legislation on the basis of evidence. So, text-based research might validate the politicians' claims that decent non-political law, and especially good law about children, is driven by evidence. But a more rigorous inquiry over a long time and across space into the less visible sites reveals that the story is messier and more political: a huge cast of individuals and groups, including some influential ones in civil society, arguing over evidence and, therefore, entangled with politics in ways that show scrutiny of law-making is about far more than one committee and one person holding law-makers to account (Crewe 2017).

The clause I followed was a response to the transformation of family life in the UK during the previous 50 years, which has witnessed the greater involvement of fathers in parenting, as reflected in custody arrangements for children on divorce or separation. In response to fathers' rights groups, such as Fathers4Justice and Families Need Fathers, constituents and even male backbench MPs, the government decided to direct judges to encourage 'shared parenting' when parents or carers bring their disputes about custody to courts. However, feminists, family lawyers and child rights' groups were worried by this because 'evidence' from Australia indicated that such legislation had inflamed conflict between parents and failed to protect children from domestic violence. The scene was set for a struggle over the wording of this clause to promote what was conceived of as a contest between fathers' and children's interests. (Feminists decided to frame their views in terms of child protection for political reasons, calculating that championing children would always trump a campaign in favour of adults.)

During the course of scrutiny, the government made three significant changes to this 250-word clause:

1. comments from citizens on proposals for legislation. The government absorbed concerns about the risk of abuse to children in their wording of the first draft of the clause by changing the wording from, 'children should see both their parents if safe', to 'children should see their partners unless there is a risk of harm' (see $3 \mathrm{a}$ of the clause, Figure 4.1). So, children's rights advocates made a small victory as a result of comments by the public.

2. the recommendations of a Select Committee. The Justice Select Committee undertook pre-legislative scrutiny on this clause. Select Committees make a tactical claim to be evidence-based and above party (or 'tribal') politics, so 
* The changes mentioned in the text are underlined.

Welfare of the child: parental involvement

(1) Section 1 of the Children Act 1989 (welfare of the child) is amended as follows:

(2) After subsection (2) insert -

'(2A) A court, in the circumstances mentioned in subsection (4)(a) or (7), is as respects each parent within subsection (6)(a) to presume, unless the contrary is shown, that involvement of that parent in the life of the child concerned will further the child's welfare.'

'(2B) In subsection (2A) "involvement" means involvement of some kind, either direct or indirect, but not any particular division of a child's time.'

(3) After subsection (5) insert:

"(6) In subsection (2A) "parent" means parent of the child concerned; and, for the purposes of that subsection, a parent of the child concerned -

(a) is within this paragraph if that parent can be involved in the child's life in a way that does not put the child at risk of suffering harm; and

(b) is to be treated as being within paragraph (a) unless there is some evidence before the court in the particular proceedings to suggest that involvement of that parent in the child's life would put the child at risk of suffering harm whatever the form of the involvement.

The circumstances referred to are that the court is considering whether to make an order under section $4(1)(\mathrm{c})$ or $(2 \mathrm{~A})$ or $4 \mathrm{ZA}(1)(\mathrm{c})$ or (5) (parental responsibility of parent other than mother).'

FIGURE 4.1 Final version of section 11 in the Act.

they tend towards assumptions that (a) unanimous reports will have more influence and (b) consistency with past reports protects their credibility. In that respect they become like mini-political parties. Since the Justice Select Committee's earlier inquiry on this issue was clearly child-centred, they recommended a change in the title of the clause from 'shared parenting' to 'Welfare of the child: parental involvement'. They wanted to emphasise that the courts should put the welfare of children above the rights of parents. The government accepted this; another triumph for children's rights.

3. $2 B$ was added by the House of Lords. From the documents it looks as if this amendment was crafted by Baroness Butler-Sloss, revising law on the basis of evidence accumulated during decades of experience. However, this amendment was originally drafted by a paralegal called Hazel Kent (with help from her colleagues Kirsten Anderson and Professor Carolyn Hamilton), all based in a children's charity (Coram Legal Centre) in Bloomsbury (Crewe 2015a: 199ft27). Hazel was part of a coalition of children's charities, academics, lawyers and social workers; I attended the coalition's meetings for almost two years. They put this amendment to the Labour Party and their Shadow Minister moved it during the public bill committee when the clause went through the Commons. Of course, it was rejected because the government almost never accepts opposition amendments in the House of Commons unless forced to to do so would be a loss of face. The coalition then met with child rights 
campaigners in the House of Lords from all parties, with me observing discreetly from a corner, and they agreed that an amendment should be moved by Baroness Butler-Sloss because she had the best chance of winning it. As a crossbench (i.e., non party) peer and former judge, she could appear as if she was above politics. Sure enough, she won and she then made an agreement with the government to ensure that they wouldn't reverse it in the Commons.

On a quick appraisal of Bill documents, the Clause 11 changes could have looked like the influence of one committee and one crossbench peer, but were really a process of far greater complexity involving significant numbers of people, conflicts of interests, contested evidence and networks of both competing factions and alliances communicating through phone, meetings, documents and emails. In short, messy politics. The Children and Families Minister, Edward Timpson MP, told me that 'it is as much about tapping into the human element as it is about getting into the nitty gritty. It is a very human process, it's about relationships, not just texts. 3

I tell this story elsewhere, so will not repeat the detail, but will restate what this political scrutiny did and did not involve. It was not above politics; it was not a cool, detached look at the facts as if free from the contamination of what is seen as the polluting processes of political conflict. Law about children in particular is often talked about by politicians and officials, and written about by legal scholars, as ideally free of politics. The legal scholars Maclean and Kurcezewski claim the more political the process of law-making, and the more controversial the content of the bill, the lower quality the result (2011). But this clause was unusually carefully scrutinised because it was political (and at times party political) so in this case scrutiny was more detailed and keenly fought over precisely because it was intensely political and controversial (Crewe 2017). Politics, far from being a nasty form of pollution as often portrayed, usually requires adversaries and conflict in order to work effectively. Chantal Mouffe points out that, 'a well-functioning democracy calls for a vibrant clash of democratic political positions', clarifying that this needs to take place both in Parliament and outside (2000: 104). It will inevitably entail the exclusion of some people - the challenge is that political processes need to be designed, and people need to respond to this design, in ways that make it possible for that exclusion to happen with justice and without violence.

Illusions that this parental involvement law might be (or even could be) simply 'evidence-based', does not stand up to examination either. The idea of 'evidencebased policy' can give an impression that expert opinion or research consists of incontrovertible facts that can be turned into solutions irrespective of politics. My colleague Chris Mowles, influenced by American pragmatism, argues that evidence is always contestable and so likely to produce a paradox: 'the more evidence is collected, the more contestation, so rather than creating greater certainty, the search for evidence may only create greater uncertainty and ambiguity, i.e., multiple meanings with no necessary connection between them' (2015: 10-12). So, 
the more evidence we have, the more we know about conflicting interests, then the more complex the decision. This was clearly the case with the 'shared parenting' clause.

Whether this clause was catching up with cultural change, or attempting to provoke it, the politicians were listening to a mixture of fathers and those representing children. They scarcely consulted those most affected - children themselves - although others had and they reported to politicians that children's demands were clear. They want to be involved with both parents if they get along, but not if they have a poor relationship with them (Mooney et al. 2009: 16). Researchers working with children conclude about their welfare on separation that they are better off if parental conflict is low, they have a good relationship with at least one parent, their main parent is not suffering from mental health problems and their family is financially secure (ibid: 10-13). The logic of taking children's perspectives seriously might be a huge investment in family therapy and eradicating child poverty, but in the context of austerity, this was hardly suggested within Parliament; the opposition knew it was impossible in that historical moment.

The contestability of evidence is far more complex than the articulation of interests in straight lines. Different groups of people in society produce truth and knowledge, and therefore what they see as 'evidence', in different ways so people argue about what is reliable as much as they disagree with the substance. Political work involves undermining your opponents' arguments; in the face of hierarchies of knowledge, and what is seen as expert versus personal opinion, this contest is unevenly fought. The French anthropologist Bruno Latour compares how lawyers and scientists produce knowledge or what they both call 'evidence' when asserting knowledge as truth (2010: 229-43). When lawyers establish truth or falsity in a court they use documents, images and speeches to make claims about a specific context even though the events were in the past and the subject can't necessarily be seen. Scientists establish truth completely differently. They aim to create universal generalisations by interviewing, observing or experimenting on subjects and then deducing predictable laws that do not depend critically on context. Form matters in the law - how you present evidence - whereas content matters in science - how you collect your data. So, assertions about scientific versus legal objectivity are based on different epistemologies, rituals and audiences. Politicians make use of both legal and scientific knowledge in speeches, debates and documents, to rationalise their arguments in seemingly dispassionate ways. But they also believe that their colleagues are not usually swayed by the knowledge produced by scientists or lawyers, despite the credibility and prestige it confers on the person using it, so then they resort to other rhetorical or political devices to persuade their own audiences. They rely on close allies for support, reassure everyone that this is 'modern' and well-intentioned, appeal to the emotions of waverers by telling heart-rending stories, and make deals with potential opponents ('if you support this, I'll back you on that other matter'), to win others over to their causes. Obviously law-making is political: those who pretend it is not, just because the people involved don't fall into the usual party political-based groups when creating alliances and divisions, court 
the danger of a specific form of manipulation. A stance of anti-politics allows lawmakers, and other politicians, to find excuses for evading accountability.

This narrative about parenting was about how evidence was handled in the context of conflict, how it constrains and enables politicians in scrutinising government as backbenchers and while on select committees. In my second narrative about scrutiny I consider the shadowing of parliament by the media, and how and why scrutiny can tip over into attack, before deriving general observations from these two cases of scrutiny.

\section{Crocodiles and snakes}

In the 1960s Prime Minister Harold Macmillan and his colleague Selwyn Lloyd walked off a plane after an overseas trip. A BBC journalist greeted them with: 'Prime Minister, have you got anything to say to the BBC?' Macmillan replied: 'No, I don't think so. Selwyn, have you got anything to say to the BBC?' 'No, I don't think so,' Selwyn replied. ${ }^{4}$ For the PM to have nothing to say to the BBC today would be unthinkable, political suicide. Although some say Bernard Ingham was the first Press Secretary and spin-doctor, Margaret Thatcher was the last PM who did not obsess about media reaction, according to former Cabinet Secretary Robin Butler. ${ }^{5}$ She listened to the Today programme while having her hair done but did not pay too much attention and used to say she planned to lead not follow. Since around that time, the relationship between politicians and journalists has descended further into a polarised combination of collusion and hostility and it is not always clear to outsiders which is at play and to what degree. The aspirations for accountability and scrutiny persist in theory, but traditional investigative journalism by newspapers is in a decline while political spin for TV and online audiences has been professionalised. As Matt Chorley of the Times 'Red Box' summarises:

Every time a paper closes, lazy MPs, corrupt councillors, dodgy police chiefs, rip off businesses, and anyone in the dock can relax a little. This isn't just nostalgia. The great and the good didn't stop behaving badly because we all got Snapchat and iPlayer.

(as quoted by O'Toole and Roxan 2019: 194)

And we are still living in the new world of political communication partly reshaped by Tony Blair's press secretary, Alastair Campbell, who took spinning to a new dimension, managing 1000 s of stories every day. ${ }^{6}$ He was in turn responding to the digital revolution, which brought with it 24 hour news and social media. As a consequence, you have a revolution in politicians' relationships with MPs, journalists and various forms of mediated communication (Crewe 2015a: 167-78).

The press has traditionally or ideally had a vital role in holding politicians to account. A healthy democracy needs an energetic, free and courageous press. But the relationship between politicians, and celebrities more broadly, and the media 
has taken a darker turn partly for economic reasons. Newspapers have been shrinking for two decades: in the US print circulation has almost halved and, according to Pew Research, the number of journalists employed by newspapers has decreased by 39\%, 126 newspapers have closed between 2006 and 2016, and 20,000 journalism jobs have been lost (O'Toole and Roxan 2019: 195). The Canadian government has even commissioned a report asking what will happen to democracy in a post-newspaper world (McLennan and Miles 2018). As online media has exploded in use, print is dying; compare Sheffield's main daily newspaper's readership of 16,000 print copies and 130,000 unique web users (O'Toole and Roxan 2019: 143). According to the Media Reform Coalition, this has left more than two-thirds of local authority districts with no local daily (ibid: 89). Larger publishers have been taking over, and merging or closing down less profitable local papers, with the five largest publishers owning just over $77 \%$ of all local newspapers by 2017 (ibid: 88). Editorial budgets of local newspapers have nosedived; Chris Walker (Senior Managing Editor for Reach, formerly Trinity Mirror) reports that his budget halved in the last ten years to 2017 (ibid: 140). Local journalists find it more difficult to talk to local government officers, press offices can be more obstructive and they have to use Freedom of Information requests more often. Another weakening of local accountability has taken place within local councils; their attempts at communication with citizens faced serious hostility with the new coalition government of 2010-15. The first Communities and Local Government Minister, Eric Pickles, was determined to stop local councils spending so much on what he called 'propaganda' (ibid: 184). Cuts to local government budgets since 2010 have led to a reduction in broader consultations with citizens as they focus on more specific issues (ibid: 58-64) - and as much as 50\% cuts in spending on communications (ibid: 39). Taken alongside the drastic fall in local newspapers, it could be argued that scrutiny of local democracy is in trouble.

The warning signs were obvious during one of the last important pieces of investigative journalism in the UK in recent times led by campaigning journalists and The Telegraph - the expenses scandal of 2009. That this was followed by a tawdry explosion of inaccurate articles in a host of other newspapers is an indicator of a weaker print media. It is a story worth telling as it reveals much about cultural change in Parliament, and UK society more widely, but also a shift in how we understand scrutiny and accountability. Between 2017 and 2018 I pieced together the story of the expenses scandal with the official then in charge of resources (and therefore MPs' expenses), Andrew Walker. We trawled through 1000s of documents and interviewed the key protagonists and what we discovered surprised us both.

Even Andrew, who lived through the whole sorry saga, hadn't realised how it looked from the viewpoint of the different people involved - MPs, officials, those brought in to clean up the mess and so forth. The public assumed that:

greedy MPs dipped deep into public funds to pay for a lavish lifestyle and that officials in the House of Commons colluded to assist by maintaining a corrupt 
system. They bought duck houses to decorate their ponds, cleaned their moats and improved their homes with flat screen TVs because they were greedy; so goes the crude version. While the rest of the population suffered pay freezes, MPs enjoyed increased benefits. Even the most thoughtful accounts blame either the greed of individuals or the flaws of a system. MPs' explanations are often one-track minded in their telling as well. Many of them felt wrongfully accused of embezzlement when the vast majority were following the rules and fraud was only proved in a handful of cases. Few asked why it occurred and how its repetition could be prevented. This is bad history partly because the cartoon version begins too late and reduces what was a complex scandal into one inaccurate riff. To understand the expenses scandal we have to go way back in time.

(Crewe and Walker 2019: 3)

In our complex history of the expenses scandal various declines have to be appreciated. I have mentioned the newspaper industry already, but mix that in with a combination of the financial crash of 2008 (so that people's declining incomes meant that any hint of corruption was especially resented) and (more positively), an acceleration of the erosion of deference towards figures of authority (including MPs) since the 1950s. MPs' salaries lost value relative to other public sector pay awards, so their party leaders agreed that expenses and pensions would act as a form of compensation.

In the uneven way that history tends to unfold - with the 'butterfly effect' evident at critical moments - several seemingly small (or tangential) events grow into huge ones over time. When Andrew Walker shifted from the Inland Revenue to Parliament and decided to tighten up the regime, he found an ally in Liberal Democrat MP Archie Kirkwood. Archie, a member of the House of Commons Commission, came up with the idea of insisting on receipts for MPs' expenditure in a bid to improve accountability. Without those well-intentioned receipts, the scandal would not have happened. The introduction of the Freedom of Information Act, a piece of legislation that required public bodies to provide information on request if it was reasonable, was also an essential ingredient. This attempt to enhance government's transparency had all kinds of unintended consequences. One of them was to allow a campaigner and journalist, Heather Brooke, to ask awkward questions about how much MPs were spending on their second home allowances. Finally, the House of Commons was forced by the courts to make this information public, and was preparing redacted copies without personal data about MPs when a leak handed over millions of pieces of information to The Telegraph.

As newspapers published the information about MPs, the public were horrified by both extraordinary claims for moat cleaning and ordinary expenditure on items like bath plugs and toilet paper. Ever since then the media obsession with expenses has continued. The new Independent Parliamentary Standards Authority, and some MPs themselves, publish all claims on the internet, which provides ammo for the local press to write scurrilous reports and make fun of MPs in a formulaic fashion 
(Crewe and Walker 2019: 164). So, journalists persist in a form of auditing of MPs that once had a purpose, but is long past serving a useful function. Taking a closer look more often at the additional sources of income of some MPs, including their involvement in and relationship with lobbying companies, or the kind of cronyism and clientelism reported by Peter Geoghegan during Covid-19 (2020), would be more revealing but would require more serious and costly investigation. Expenses now provide cheap weapons for media attack. The immediate result was that while $30 \%$ of people in a survey were dissatisfied with MPs in 2001, after the expenses scandal it was $71 \%{ }^{7}$

Alongside media attacks we find collusion. Alliance-building between journalists and politicians starts with lunch and is sustained by regular contact, whether phone, WhatsApp or whatever other means necessary. As one MP explained to the Spectator journalist Isabel Hardman:

hacks will want to have lunch with you to build a good relationship before you enter a ministry. If you're good company over lunch, they will warm to you and write you up as "effective", even if this only means "effective at gossiping and eating pudding'.

(2018: 123)

If you fail to be noisy to the media about your achievements as a minister, then you can get into serious trouble:

impressing the right journalists with good chat (and, as already mentioned, good pudding-eating skills) means that you are able to create a reputation for being an effective minister, one that is sustained largely by writers who haven't got a clue whether any of your policies are actually working.

(ibid: 131)

If you go quiet then the Prime Minister might suspect you of plotting or being lazy, a Special Adviser (SpAd) told her.

Jack Straw, former Cabinet Minister, pointed out to the Leveson Inquiry that politicians always want to get close to the press because the media is the prism through which the public see them (Crewe 2015a: 169). When in opposition MPs' communication with journalists is designed to attack the government but of course this changes once the MP gets into government. Then he or she relies more heavily on special advisers to brief journalists privately but they no longer find the media as co-operative once they become a minister or even a government backbencher. After all the job of the press is to hold the powerful to account and that often means government (or occasionally Parliament), rather than the opposition, which is relatively powerless. Whether journalists do that effectively or not is hotly contested. In the UK 2019 general election high profile journalists were criticised by the Twitterati for reporting what 'senior sources close to $\mathrm{x}$ ' claimed as if it was more than spin, thereby abandoning their scrutiny function. 
The media play a ferocious role making kings and queens out of politicians, although they can be created without their help, so some MPs are bitter when they don't get enough attention. A group of backbenchers complained to Hardman that journalists were ignoring them (2018: 123). But seeking attention is risky. In 2007 Rebekah Brooks, then editor of The Sun, called John Reid when he was thinking about running in the leadership contest and suggested he should think again. He went ahead anyway and they ran an eight-week campaign to trash him, saying he had no brain (Pascoe-Watson 2007). So the journalism that makes and breaks politicians is not only scrutiny - it is MPs and journalists colluding with or against each other to do politics, making friends and breaking foes, to gain support for their own ideas, groups and leadership. Anonymous briefings from colleagues, or increasingly their special advisers, are difficult to rebut. Apparently former SpAd Damian McBride was annoyed by Labour MP Ivan Lewis having ideas about tax policy. When he refused to be bullied, Damian then planted a story in the News of the World about how he pestered a young civil servant (Crewe 2015a: 171).

'Plebgate' was another example of politics by and through the media: journalists, the police and probably politicians (either opposition or rivals in his own party) colluded to bring down a minister. In September 2012 the newly created Chief Whip, Andrew Mitchell, was trying to leave Downing Street with his bicycle and asked a policeman to open the main gate. The officer told him to use the pedestrian gate. Mr Mitchell says he muttered: 'I thought you guys were supposed to fucking help us', while the policeman logged that he called him a pleb and threatened that there would be consequences. ${ }^{8}$ Gossip circulated shortly afterwards that someone in the Labour Party tipped off the Police Federation that Andrew Mitchell MP was not that popular so they might be able to oust the new Chief Whip. The Police Federation may have relished the opportunity for revenge at a government that was cutting police pay at the time. The police officer's version was leaked to The Sun and another policeman pretended to be a witness, sending in a false email to corroborate the story. ${ }^{9}$ Five weeks after the incident, when it was clear that the various forces ranged against him were not going to back down, Mitchell resigned. In December 2012 a Channel 4 Dispatches investigation reported that the police had fabricated evidence, with the collusion of various journalists, but by that time it was too late for Mitchell to reclaim his Cabinet post. Once again Andrew Mitchell's story is about collusion between journalists and his political opponents hell-bent on his scalp (Crewe 2015a: 171-2).

This relationship is important because politicians' reputations are critical to their success in the game of politics. Honour is so central to politics in Brazil, it is even recognised in the legal framework under the 'right of personality' (Teixeira 2004: 33). If your honour is violated - for example, by a journalist - you are entitled to compensation. It raises questions for any democracy: when does valuable critique transgress into a violation of rights? What should be done when both happen simultaneously? If honour is translated into money, through compensation, asks Carla Costa Teixeira (ibid: 38), then doesn't honour merely become 'a misplaced shadow of the world of egalitarian individualism'? 
It is as if journalists mimic the politicians, taking sides and elevating the reputation of their own side by bringing down the villains in the other gang. Politicians are bound to do this; it is inherent to the way representative democratic politics works. There is fierce competition between them, which has the benefit of galvanising action. But when journalists join this antagonism and compete against each other, to reach more readers and pursue their own political causes, then they can lose their effectiveness as critics. The scrutiny by citizens of politicians on social media might surely face the same risk. Abusive tweets on Twitter during the 2019 election reached 138k as opposed to $31 \mathrm{k}$ in 2017 and increasing numbers of politicians have attributed their decision to stand down to abuse on social media. ${ }^{10}$ Is media scrutiny tipping over into the undermining of politics? This is surely a vital question for future research.

The relationship between the state and the media of course varies hugely around the world. In Ethiopia, to give just one example, the media environment consists of a mix of private and state-owned enterprises, but the latter dominate and are tightly controlled by government legislation and warnings (Skjerdal 2011). Selfcensorship is common as a result. In 2008 the government produced a 'development journalism' policy document reviving the idea (that prevails in other parts of the region too) that journalists should contribute to development. They were even expected to work towards Ethiopia's national goal to rise to a middle-income country within 20-30 years (ibid: 65-6). Private media were accused in the policy of being driven by a mix of profit motive and hatred, and were instructed to focus on positive success stories in the future. Until recently, most Ethiopian journalists complied, hardly ever reporting on government in critical or oppositional ways, with the rare exceptions dismissed by the government as hostile and 'political' or even imprisoned as a threat to security.

The relationship between government and media has shifted again with the advent of Prime Minister Abiy Ahmed in 2018. Government capture of media communication once inadvertently limited hate speech within Ethiopia (Workneh 2020). But the Ahmed-led reforms - release of prisoners, repeal of restrictive law, the return of exiled politicians and activists and the creation of a new national Prosperity Party - have created new unintended tensions. The government has been struggling to control ethnic-based hate discourses, violence and displacement, passing a Proclamation to combat hate speech in February 2020. Communications scholar Téwodros Workneh explores the arguments for and against new legislative frameworks to control this rampant expression of hate in Ethiopia, listening to a range of people talking about the tensions between peaceful co-existence versus freedom of expression (2020). Although Ethiopia's history of state-media relations has its own unique history, with its long tradition of incarcerating journalists, and it will need to work out specific solutions to reduce hate speech in its own way, Workneh's warnings have global significance. Legislation against the incitement to violence is open to abuse and on its own can't curb hate speech - 'it is one player in a cast of several actors' (ibid: 136-7); social media companies are a key one. But he also presents ideas for a longer-term strategy for reforming education in formal and 
informal settings involving government, civil society, religious organisations and media outlets, and even the hate-speaking offenders - who have responsibilities and should be part of the solution. It is this kind of nuanced and critical scrutiny of the relationship between the state and its critics seen from many perspectives that offers theoretical but also practical insights of great value.

\section{Critique as scrutiny}

If you contrast the performances involved in law-making versus court proceedings, much is revealed about how they are accomplished and scrutinised. Ilana Gershon has compared the anthropology of courts and legislatures in the Anglo-American system, pointing to their different constraints: legislators by their claim to represent others; judges by the pressure to perform objectivity in the cause of justice (2011: 157). Courts use analogies to set precedents while legislatures focus on equivalences, that is, imagining the qualities of people who might face a problem. People can embody culture in both settings but in courts people become a vehicle for understanding different cultures, while in legislatures law-makers speak for people belonging to various cultural groups. As law moves from legislatures to courts, one of the many shifts that take place is that explicit compromises move to the background, thereby hindering their transformative potential (ibid: 169). To make her case Gershon refers to Lazarus-Black's work on legislative debates in Trinidad over the Domestic Violence Act 1991. She raises questions about how to define family and whether to challenge beliefs about masculinity in contrast to how cases were handled in court, where the law's transformative potential was closed down.

Lazarus-Black's research has in common with my parenting case study an argument about how the impact of law has to be researched in society (homes, offices, streets ...) not only in parliamentary chambers and the courts, where their claims about impact are partial and conflictual respectively. It was in the shadow of the law', in these cases of violence and parenting, that the relationship between the state and family were at stake. In the case of domestic violence, the issue was transformed from a private to a public one and the Trinidadian state gained the power to interfere, but while criminalising violence changed people's attitude to what was seen as 'disciplining' women, it provided little relief to the majority of women facing abuse (Lazarus-Black 2001: 400-1). In relation to parenting by separated carers in the UK, custody was already a matter for the state and so in the public domain when parents were in conflict. The bid to give the courts more power to promote fathers' rights failed and children's welfare remained 'paramount' in the courts. The most thorough assessment, by Felicity Kaganas, a law professor, concludes that this clause failed too: fathers' rights group remain angry that the courts are biased against men; the higher courts ignore it; and in the lower courts (and informal dispute resolution processes) women are under more pressure to accept more contact with fathers against their wishes. She concludes that this has probably put a greater number of women and children at risk of violence in society 
(2018). In both cases, despite the best intentions and high quality scrutiny of lawmakers, including by the civil society organisations engaging with them, the law failed to protect women and children as much as intended. The reason for this in both cases was not too little evidence and too much politics, but not enough transformative politics to challenge inequalities based on age and gender.

Another narrative of inequality surviving the failed efforts of law-makers was recently told by the anthropologist David Mosse. Caste discrimination gets less attention than other forms of inequality despite affecting 100s of millions, including the South Asian diaspora in the UK. In 2013 the UK government put in law the requirement to add caste to pro-equality legislation. Following a backlash from 'Hindu organisations', who labelled this move postcolonial racism and even a 'hate crime against Hindus', the government abandoned its plans in 2018 by repealing the established duty (2020: 11-13). Hindu organisations claimed that caste discrimination was reinvented as a creation of colonial missionaries, in contrast to the benign equitable form of it in Hindu scriptures. The objectors diverted attention from the experience of Dalits. It was only by excluding Dalits, and their arguments about the prejudice they face, that Hindu organisations managed to present their case as anti-racist. Ironically it was the practice of excluding on the basis of caste, and protecting upper-caste community spaces in everyday lives, that was being defended through the cancelling of the UK's commitment. Although scrutiny and public participation sound politically good, it is clear from Mosse's research, and the other narratives in this chapter, that it is far from inevitable that it results in less inequality. Scrutiny and advocacy spaces are often dominated by the more powerful groups in society. So, scrutiny is a vital part of democracy but, like voting and representation, should be nurtured and inclusive rather than idealised, as if assumed to work by magic rather than hard work.

The UK select committees and US congressional committees respectively inspire awe (mostly) while the free presses in these two democracies were once the envy of the world. But alongside these impressive looking structures, troubling patterns are emerging. Scrutiny of government by politicians and journalists appears to be waning in the wake of other more emotionally and politically potent processes of exposure, blame and conflict. When storms flooded and bashed the UK in early 2014, Ed Miliband blamed the government, Secretary of State Eric Pickles MP blamed the Environment Agency, Lord Smith (Chair of the EA) blamed the Treasury and those affected blamed anyone in authority. As the journalist Simon Jenkins observes:

We now have a new form of accountability, to an 'inquiriat', a cackle of inquisitors and lawyers jumping to the bidding of public opinion, flapping round every executive's head and piling accusation on every error. This can only lead to ever more defensive behaviour in every sphere of public life. It is the paranoia of the modern state. Every document is 'open', every conversation 'on the record' and your friend today is tomorrow the witness against you. ${ }^{11}$ 
Haridimos Tsoukas makes a related argument by pointing to the alarming side of transparency (another idealised democratic goal), predicting that the obsessive production and collection of information could reduce people to bald facts, numbers and images, making it even easier to monitor them. When the context and meaning of information has become distorted, the less we understand its complexity and the more distrust it generates; it may well 'constitute a new tyranny' (as quoted by Crewe and Walker 2019: 200).

Both transparency and scrutiny have to be understood within the context of the ubiquity of audit as a new form of accountability that has spread across the globe, as various anthropologists have explained (e.g., Strathern 2000, Shore and Wright 2015). The all-encompassing regime of audit is influenced by New Public Management, which has permeated all sectors (Gulrajani 2011). One aspect of this is that 'performance' (in the sense of effectiveness here) is measured by narrow metrics, often of a financial kind, and there is a presumption of predictability and control whereby organisations (including governments) are only deemed effective if they anticipate the future. Many of the managerial tools adopted for planning and measuring success were originally developed in project management disciplines of bridge building in a military context (Mowles 2010). Mostly they are assumed necessary for incentivising and monitoring organisational performance, with surprisingly few politicians asking what harm (and occasionally benefit) they cause.

Claims about following scientific evidence can be a political strategy of evasion. We observed an example of this during the Coronavirus crisis. PM Boris Johnson made sure he was flanked by scientists when he announced to the country the strict measures to tackle the spread of the Covid-19 virus. He stressed that he was 'following the science', as if it was singular and as if that absolved him of excessive scrutiny, despite the usual entanglement of evidence with politics (Grey and MacAskill 2020). To give just a few examples, when scientists did their initial modelling of the likely spread of the virus they assumed that the UK public wouldn't tolerate a curfew so did not even include that scenario. They made political assumptions that affected their production of evidence that the politicians failed to question. On the side of the politicians, the government flipped from a strategy of testing and tracing to lockdown when it became obvious - guided by scientific advice - that the spread couldn't be contained. But they could have done both. They also missed eight conference calls or meetings about the Coronavirus between EU heads of state or health ministers and missed a deadline to take part in a common purchase scheme for ventilators, which were later in short supply. Whether for political reasons (the UK was exiting the EU), or a mere administrative error (as Johnson's spokesman claimed), it is clear that the response to Covid-19 was about making political judgements. 'Following the science' is useful as rhetoric, but should not be taken literally.

When Trump was asked questions by journalists about whether the US government was acting fast enough to respond to Covid-19, in his replies he insulted the journalists, telling them they were 'bad people' for sounding negative. In the middle of the crisis he withdrew funding to the World Health Organisation because they criticised his response to the virus. By April 2020 it was widely 
reported that the US states were competing rather than co-operating to deal with the huge surge in virus cases. When criticised for speculating spontaneously that scientists might test whether people should inject disinfectant, he later pretended he was just being sarcastic. In the country with the second highest number of cases, Brazil, President Bolsonaro claimed that Covid-19 had been exaggerated by journalists and he undermined his own state governments and Health Ministry's efforts to control the pandemic by encouraging people to ignore regulations. ${ }^{12}$ Trump and Bolsonaro could have saved lives if they took some notice of journalists' questions, but they increasingly reframed scrutiny as anti-patriotic, fantasy and 'fake news'.

Critical scrutiny of the state by journalists, academics and other politicians is vital for holding officials and ministers accountable for their actions. It is part of the duty of elected representatives to engage with this - marshalling evidence to answer questions - in ways that deal with the inherent contradiction in democratic accountability. Elected politicians in government are expected to be honest and transparent, including about their mistakes, but to appear competent at all times so that they don't lose support for their party. When backbench politicians are the scrutineers in the chamber or committees, they are told by their whips to back up the party line and by their constituents to demand more for their locality. Scrutiny is yet another highly contradictory form of political work.

\section{Scrutiny as part of shapeshifting work}

Political scientists tend to divide political work into idealised roles and categories. The impression given is that MPs are doing representation or scrutiny or policy or party work or government and that they vary in how they prioritise these, which allows the observer to slot MPs into ranked categories. In practice, MPs are often performing these roles - campaigning, representing and scrutinising have been the focus on the last three chapters - simultaneously; speaking in a debate, for example, about hospitals to influence policy in a shared cause with other MPs, while both opposing the government and pleasing some of their constituents (and displeasing others) all in the same moment. There are other strands of political work that I know less about: governing, lobbying and working with the media. Like anyone else, politicians also do other kinds of work beyond the political realm: earning money at other jobs, caring for dependents, even love involves a kind of work. These all deserve urgent anthropological scrutiny from the viewpoint of both politicians and those they affect.

I have argued that underlying all political work is sociality in various forms, whether social relationships or socially produced knowledge shared by social groups. To show how profoundly politics is entangled in sociality, remember the Marshallese politician who dispenses marriage guidance counselling, therapy and loans (Corbett 2015: 75). Or the UK MP who does a pub quiz with local party activists or listens to constituents talking about mental health problems in their surgeries and then talks about that in a debate. A politician needs to respond to endless requests from constituents, whips, interest groups and local supporters without having enough time to do justice to any of these demands; these interests are unknowable, dynamic and open to endless contestation. 
We all do this adaptive shapeshifting to some extent as humans, just as we all mind about status and absorb praise easily. For example, academics change their language, style and emotional sensibilities between talking to students, university committees and attending seminars with fellow scholars. But politicians do this more often, more quickly and with more exposure than academics because they are in the public realm almost constantly. Even when recklessly having an affair with a stranger, a politician risks courting media interest and therefore public censure. The consequences of successful or disastrous shapeshifting are more serious for a politician than for most of us, so the torture is more intense. Adapt to your different audiences too little and you will be seen as remote and failing in your role as a representative. At the same time, the more inclusively you listen, the more directions you will be pulled in and the more you sink under the weight of many voices and demands. Some improvised shapeshifting may be a universal pattern of human relating, but the extent to which politicians have to do it, and the rapidity of their reactions, means that they are a concentrated form of socially shifting being.

How do MPs deal with this confusing array of strands of political and social work? Across the world the work of politicians entails endless shapeshifting but continuities are created by meeting spaces, rhythms and ideological riffs. The performance of politics requires rituals, mediated communication and a claim of representation. In Part II I elaborate on these cultural processes in parliaments.

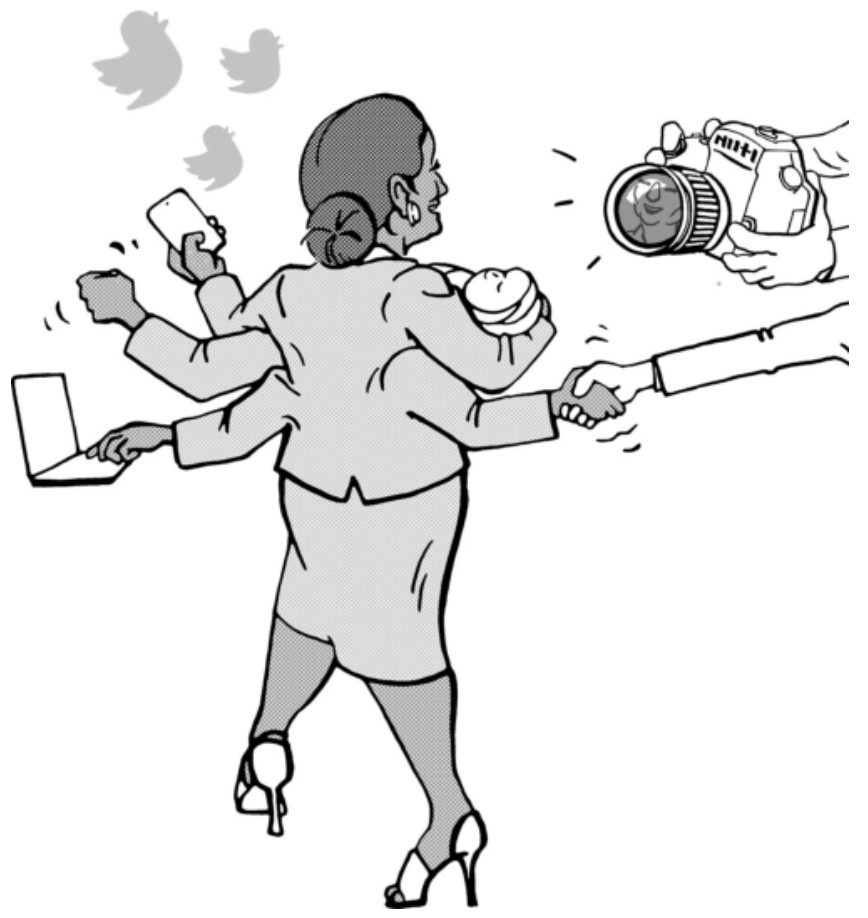

FIGURE 4.2 The shapeshifting work of politicians. 


\section{Notes}

1 Ayenew et al., SOAS and Hansard Society Evidence to the International Development Select Committee's Inquiry into Parliamentary Strengthening, HC 704, January 2015, http://data.parliament.uk/WrittenEvidence/CommitteeEvidence.svc/EvidenceDocument/ International\%20Development/Parliamentary\%20Strengthening/written/13915.html, accessed 24 April 2020.

2 Bill documents - Children and Families Act 2014, https://services.parliament.uk/Bills/ 2012-13/childrenandfamilies/documents.html, accessed 9 December 2019.

3 Interviewed by Emma Crewe, 8 April 2014.

4 As told by Sir Malcolm Rifkind, interviewed by Emma Crewe, 4 September 2012.

5 Interviewed by Anthony Seldon, http://www.cabinetsecretaries.com, accessed 15 May 2014.

6 Leveson Inquiry, 14 May 2012, http://webarchive.nationalarchives.gov.uk/2014012214 5147/http://www.levesoninquiry.org.uk/hearing/2012-05-14pm/, accessed 15 May 2014.

7 House of Commons, Rebuilding the House, House of Commons Reform Committee, First Report of Session 2008-09, 12 November 2009, HC 1117, p.7.

8 Mitchell's resignation letter quotes himself saying this, see http://www.independent.co. $\mathrm{uk} / \mathrm{news} / \mathrm{uk} /$ politics/government-chief-whip-andrew-mitchells-resignation-letter-infull-8218906.html, accessed 11 February 2014.

9 Keith Wallis was prosecuted, found guilty and imprisoned for one year in January 2014.

10 https://www.polimonitor.com/polimonitor-research-uncovers-increase-in-twitter-abusereceived-by-candidates-in-2019-general-election/, accessed 2 January 2020.

11 http://www.theguardian.com/commentisfree/2012/oct/23/jimmy-savile-witch-huntparanoia?cat $=$ commentisfree\&type $=$ article, accessed 30 May 2014 .

12 https://www.hrw.org/news/2020/04/10/brazil-bolsonaro-sabotages-anti-covid-19-efforts, accessed 14 June 2020. 


\section{PART II}

\section{The cultures of parliaments}

To fathom the contradictions and entanglements in MPs' work the spotlight needs to be turned onto culture. I can only write about culture on the back of understanding sociality (or vice versa), rather than jumping entirely from one to the other. The sociality/culture entanglement becomes clear only when you look at innovation: 'the mark of distinctly human sociality is not the possession of one culture or another as such but the capacity to change and create new cultures' (Carrithers 2005: 57). Anthropologists have been making the argument for decades that culture is something you do, create, reproduce and contest, not something you have or live in (Carrithers 1992, Street 1993). But culture often remains a more static concept in political science as well as among those working in parliaments, whether MPs or officials. Whether seen as a variable or a black box into which to put the unexplainable, culture is often conflated with tradition. So, for the next three chapters I will try and describe with brush-strokes, and sometimes minute detail, how culture gets made, remade and displaced through the everyday interaction between people. People thinking, walking and talking in private and public parliamentary spaces create and are created by cultures.

I'm interested in what social interaction and cultural processes by MPs reveal about their work. MPs are not just individuals, any more than the rest of us; their belonging to different groups with diverse interests and huge webs of relationships with others demands complex social and political navigation. In that navigation they are moved by dynamic and often contradictory motives, constrained by cultural habits but also enabled by imaginative possibilities. They face continual shifts as they encounter different configurations of people, requiring them in turn to respond to the endlessly changing demands thrown at them (but also created by them) as they move from relationship to relationship: at times antagonistic, at other points as allies, sometimes both and often moving between the two. Politics involves processes 
of (a) seeking support for oneself, one's cause or party or nation, (b) backing the causes of one's allies and/or (c) undermining opponents (and opponents' allies).

How do MPs cope with this changeability? In the UK, many don't. Alcohol consumption and divorce among MPs seems to be relatively high and reports of bullying of their staff are troubling. ${ }^{1}$ In Portugal drinking alcohol is part of a 'cult of masculinity' among politicians (Mineiro pers. comm), so caution in universalising causal connections is always wise. Divorce may be partly associated with the unique pressures of work but also with separation - many MPs live in the political capital while their partners are at home in the constituency - with MPs finding new socio-political networks, friends and even lovers in London. So, alcohol and divorce may not necessarily be symptoms of a failure to cope. On the whole, most UK MPs do cope, enough to keep trying to return to Parliament multiple times. But stability of the self matters, not only for the MPs' well-being but their capacity too. Ricoeur wrote about how self-constancy is vital to be recognisable, counted on and accountability - to act and perceive MPs as moral beings we need to see some constancy in their identities (as cited by Larsen 2020).

Many politicians do cope with changeability, judging by the skill with which they adapt their performances to multiple sites, audiences and demands. Learning the skill of adapting to individuals (and groups) through endless daily practice reveals something about how they do this work. But we are still left with the problem of how they retain any sense of stable self that travels across all these relationships. I suggest that there three processes that provide some continuity for MPs between and across this chaotic dynamism. These processes enable MPs to maintain or rupture relationships, sustaining or breaking either alliances or enmities.

1. The first are the rhythms of performance that organise the work of MPs by creating repetition in time and space but allowing for variation at the same time (Chapter 5). The detail of these depends on the context but most parliamentarians organise their time through repeated patterns as well as departures from fixed schedules. The meeting spaces around which the bodies of MPs and others move - whether debating chambers, surgery meeting rooms or TV studios - and position themselves together do not determine how they behave but they have a bearing on how they relate.

2. The second continuity is the riffs of meaning that MPs develop to make sense of ideology and communicate as policies and arguments, each improvised for different audiences (Chapter 6). The communication of these within many legislatures, and especially in the digital sphere, is becoming more antagonistic and distrustful.

3. Finally, these rhythms and riffs work in conjunction through rituals and symbols (Chapter 7). MPs navigate these processes of relating through various rituals - as examples, debates in parliamentary chambers, press or party conferences, or more formal meetings - which punctuate the daily routine with riffs and rhythms of particular political, social and cultural significance (for details on an earlier version of this, see Crewe 2015a: 225). The more 
events are significant, the more they tend to be ritualised. This usually means they will be charged with symbolic meaning, regulated by rules and involved in reproducing or challenging a socio-political hierarchy. The credibility and plausibility of politicians, and even the parliament as a whole, is constructed through a variety of performative rituals, artefacts and settings with the aim that they will be taken seriously by the wider parliamentary community and the general public.

This may be a more generative way of conceiving of MPs' work than the reliance on a typology of roles or functions, because the musicality of riffs and rhythms emphasises the performative, changeable and relational nature of what they do when they are doing politics, while the idea of rituals allows us to investigate politics with a sense of proportion. After all, rituals, and especially well-established ones, reveal which work is trivial and what is politically, socially or culturally significant.

This approach is a way of encouraging multi-disciplinarity by bringing in history (what action unfolds between people over time), geography (how bodies move through space), theology (what people believe or at least what they say they believe), and culture (how people discipline each other and make or contest meaning). A focus on these processes invites consideration of politicians' arguments and performance of ideology; where bodies go, when, with whom, why and with what consequences; and how encounters are ritualised, regulated and performed, revealing what is contested, what is taken for granted, the power hierarchies and struggles, and what matters socially, culturally and politically in a specific time and place. If you were researching parliaments during Covid-19 you would have to analyse what happened to rhythms, riffs and rituals when mediated by the technology of Zoom and its equivalents. This allows us to study both what individuals do differently but also how the processes create continuities and cultural patterns, avoiding both methodological individualism and crude structuralism. Whether researching a bill, or the relationships between MPs and constituents, or the workings of a select committee, my contention is that you have to look at the individual and shared rhythms, riffs and rituals to understand the political work involved in any depth.

A thorough investigation of these in any parliament might assist in working towards a rigorous ethnography because rhythms, riffs and rituals can only be understood if the researcher looks behind the front of stage with its most public performances, to investigate private and less visible encounters. In the next three chapters I will explain what I mean in more detail about the continuities in parliamentary cultures and inquire into whether this perspective might work in different contexts around the world.

\section{Note}

1 Alcohol Concern carried out a survey in 2013 and one quarter of the 150 MPs who responded believed that there is an unhealthy drinking culture in parliament. According 
106 The cultures of parliaments

to Conservative MP Charles Walker around one sixth of the 2010 intake of Conservative had divorced, separated or had long-term relationships break down by early 2013 (Hellen and Grimston 2013). Bullying has been reported in an independent inquiry, https:// www.parliament.uk/documents/Conduct\%20in\%20Parliament/GWQC\%20Inquiry\% 20Report\%2011\%20July\%202019_.pdf, accessed 25 April 2020. 


\section{5}

\section{RHYTHMS OF PERFORMANCE}

A good anthropologist (including of parliaments) has to be in part an historian; history and sociology depend on each other (Bourdieu and Wacquant 1992: 90). But we also need to have a sense of geography. Without doubt history and geography are enriched by each other; it is hard to imagine how you could write about time without keeping place in mind and vice versa. But this goes beyond enrichment and elaboration on insights into one parliament or many. You can't understand what it is valid to generalise about beyond a highly specific moment and space without working out what endures and what changes through time and across place. The rhythms of parliamentary life need an inquiry into seasons, diaries and appointments observable in offices, streets and parliamentary buildings.

Winston Churchill famously said that we shape our buildings and thereafter they shape us. Buildings matter deeply to those inhabiting them as their affective response confirms. In an article about the political aesthetics of the nation, Shirin Rai writes about how the Lutyens-designed Indian parliament was originally created to meet the needs of the British imperial state and continues to be an expression of power:

social and political relations are reproduced through a variety of modes in specific spaces - narratives (verbal and written), ceremony and ritual, symbols, paintings and sculpture. Together, this forms the aesthetics of politics as well as of power ... through these imaginaries we can reflect upon the processes through which they become hegemonic - how the dominant modes of power are reproduced and how the marginalized are kept outside the spaces of performance of power (Bourdieu 1984), in the shadows, 'out of place'.

(2014: 2)

It is hardly surprising that PM Narendra Modi announced that the buildings were in need of a facelift and that they would be replaced by a new modern building 
within a few years. ${ }^{1}$ But how buildings inspire such emotion, and how culture is entangled with power in space, can be enigmatic. One of the world's most famous buildings, London's Palace of Westminster, soars in some people's imagination as a symbol of Britain's glorious past:

The past is everywhere: soaring arches, the luxuriance of sculpted dead kings sprouting from mouldings, painted historical tableaux on the walls, marble statues of deceased parliamentarians. The ceremonies seem of another era, binding the everyday to ancient splendour ... The Lords presents a seductive version of the nation's history, apparently unfolding in perfect continuity from the place in which one stands. For its devotees, the House is a shrine to this beloved, majestic, patriotic saga, conjuring endless genial associations, while still being thoroughly alive in the present.

(Crewe 2005: 9) ${ }^{2}$

At the same time, for many it doesn't. It can be a reminder of historical global vandalism, class privilege or even the UK as a colonising and occupying superpower creating havoc, displacement and dispossession. The public-school appearance is as alienating for some as it is resonant for others (see Figure 5.1).

The iconic image of the Palace of Westminster may represent clichés of symbolic significance - magnificence or alienation - but the building is falling apart. The roof is leaking, pipes and cables are in a tangle, mice scurry across its green and red carpets, and bits of stone regularly crumble and crash to the ground. MPs and peers are due to move out to allow the Palace to be restored but they have been procrastinating for years. Despite officials warning that the edifice could collapse entirely, politicians are reluctant to tear themselves away from this alienating or

\begin{tabular}{|l|l|}
\hline $\begin{array}{l}\text { 'When I am coming down in the train } \\
\text { from Manchester, I write these revolu- } \\
\text { tionary speeches. I take the tube to West- } \\
\text { minster and as I walk through the portals, } \\
\text { my speech seeps away. Then I rewrite my } \\
\text { speech. When you are away from it, you } \\
\text { have glorious thoughts.' (Peer interviewed } \\
\text { in 1998) }\end{array}$ & $\begin{array}{l}\text { When a Scottish nationalist first arrived in } \\
\text { the Palace he saw the lion, symbol of } \\
\text { England, and the unicorn, symbol of } \\
\text { its neck. He loves architecture, and the } \\
\text { building is extraordinary, but he does not } \\
\text { belong. 'This is someone else's place. I } \\
\text { just want to get out of the place as soon } \\
\text { as I can.' (MP interviewed in 2018) }\end{array}$ \\
\hline $\begin{array}{l}\text { 'I don't want to get comfortable ... You } \\
\text { can see how in this big grand building } \\
\text { people get moulded to serve the institu- } \\
\text { tion. I never forget the people who sent } \\
\text { me here - I am here to serve them not this } \\
\text { place.' (MP interviewed in 2011) }\end{array}$ & $\begin{array}{l}\text { 'I'm not a real Clerk', one state-school } \\
\text { educated House of Commons Clerk told } \\
\text { me, 'and this doesn't really feel like my } \\
\text { building. I'm only part English so it is not } \\
\text { my history.' (Clerk interviewed in 2015) }\end{array}$ \\
\hline
\end{tabular}

FIGURE 5.1 Feeling out of place in the Palace. 
exhilarating political Hogwarts. The officials responsible for restoration despair of the politicians' aversion to change and the impossibility of bringing about radical transformations in the Palace. But this disposition towards the building, with its occupants clinging to it like limpets, may be more attributable to a craving for continuity and stability in the face of endless flux and uncertainty than a broader conservatism. In the endless shapeshifting of parliamentary work maybe the building offers one of the few stable continuities? In this chapter I will look into the possibility that space is as significant for people as time, and far more important than I have acknowledged in the past in my studies of parliaments.

Rhythms organise people in political worlds by creating repetition in time and space but allowing for variation at the same time (Edensor 2010). Edensor was influenced by the French philosopher Henri Lefebvre who suggested that to be serious about the everyday use of time, space and energy, we need to analyse the rhythms: rhythmanalysis he called it (2013). Lefebvre suggests we look at rhythms in all their variety - sequential ones where people follow each other (melody); action in concert when people perform at the same time (harmony); repetitive, cyclical and life-like patterns ('birth, growth, peak, then decline and end', ibid: 25); as well as eurhythmia (normal and regular), arrhythmia (problematic) and polyrhythmia (many rhythms in concert rather than conflict). This offers a way of being both thorough but also proportionate in our multidisciplinary investigation of how people in political worlds perform everyday political work, rather than merely fulfil roles in a mechanical way. One temptation is to pluck some features of a building or some events in an historical account and make claims that these are more important than other details simply because the author has that reaction herself. Another is to listen too hard to those who are easiest to get hold of or have a position of authority. But we can do more rigorous research if we attempt a more detailed description of how various inhabitants react - comparing and contrasting what different individuals and groups say and do. When we study contradictions between responses and these two types of engagement with informants, then we can eventually describe the different kinds of significant rhythm more rigorously.

To understand rhythms of political performance in parliament, we need to go beyond the famous people and publicly famous spaces. These magnificent/dreadful Barry and Lutyens designed edifices of the world's nearly oldest parliament and largest democracy respectively, contain the most famous political spaces globally, but parliamentary spaces extend far beyond these grand buildings that inspire both awe and frustration. Politicians navigate government buildings, committee rooms and constituency offices as well as schools, hospitals or factories; they meet people in media studios and in the street; they communicate via mediated channels (down the phone, on their smartphone or in Zoom meetings); and travel to political spaces in other countries. Politics happens everywhere and anywhere. Rhythm is created by visiting or revisiting familiar and new spaces, with the same or different people, at repeated or non-routine times.

People's everyday routines - where and when they navigate regular and new spaces and times, that is, the rhythms of their performances - make politics possible 
and reveal part of its specific and generalised character. Researching this character means asking what bodies are doing when they do politics, because it is impossible to divorce bodies from minds (at least when they have a healthy relationship). While the focus in this chapter is on bodies, that is, the embodiment of political performance, in the next I will shift to thinking about the ideological content of political communication: riffs and what they mean or do for different people. Finally, I will consider how rhythms and riffs are performed through ritual in Chapter 7.

\section{Agendas and diaries of time and space}

Politicians' minds and bodies have to navigate time (parliamentary calendar and seasons) and space (a parliamentary estate often with many outbuildings, government departments and the streets of their constituencies) by following routines and timetables. These rhythms create continuity and disruption in the work of MPs and their importance is revealed by the considerable status of diary secretaries: the more important the politician, the more influential the diary secretary. Although some do it themselves, MPs often have a secretary who arranges when, where and with whom they should place themselves, making decisions about who gets access to private spaces and precious time. Patterns emerge when you look at MPs' diaries both shared and individual. Groups of MPs share rhythms in common - mostly planned (e.g., attending a select committee), and others spontaneous (like sitting regularly with your mates in an informal meeting space), while many rhythms are idiosyncratic (e.g., visiting particular businesses in their constituency annually). In the everyday work of MPs rhythms provide some continuity in social relations and form, which makes it possible for MPs to navigate their changeable social world. It means they can develop and maintain key social relationships and have some continuous sense of self in relation to the world around them.

The shared rhythms are created by public space and fixed calendars. UK MPs' shared spaces each have their own history, character and habits. The main formal debating chamber, and a smaller one-off Westminster Hall, meet at the same time on a weekly schedule beginning with questions to a minister and followed by debates and motions, on Monday from 2:30 to 10:30 pm, Tuesday and Wednesday 11:30 am to 7:30 pm, Thursday 9:30 am to 5:30 pm, and Friday (when sitting) 9:30 am to $3 \mathrm{pm}$. Hours have moved around; Commons' sittings used to start in the afternoon and go into the evenings until they were changed in 2002 and 2012. But before 1570 they met from 8 to 11 am or 12 noon and even at 6 am in 1604 (Rogers 2012: 122). These days one of the few events that all MPs try and attend is Prime Minister's Questions (PMQs) on Wednesdays at 12 noon. Committees tend to meet weekly at a set time (often on Tuesday or Wednesday mornings), and then on an ad hoc basis in addition, either in a room on the committee corridor of the Palace or in the far newer Portcullis House. These fix some of the shared rhythms for all MPs, in the case of PMQs and important votes, or more often a significant number of them according to their interests or instructions from the whips. Whips 
demand the presence of their members (or flocks as they are sometimes called) to ensure that the session is quorate, their frontbench get support in debates or, most importantly, they are ready to vote with their party. Whips are both people but also instructions; so, the whips issue a 'whip', an instruction stating how their members should vote, indicating how serious it is by the number of lines.

Political parties have a huge influence on the rhythms of MPs, whether through whipping, electioneering (see Chapter 2) or party conferences (as well as politicians in local government, Spencer 1971). In the French anthropologist Florence Faucher-King's fascinating work on party conferences, she explains how the organisation of these regular rituals reveals both continuities and shifts in UK politics. Party conferences emerged 100 years ago in a time when political parties inspired lifetimes of loyalty and dominated UK politics. As loyalty to party is seeping away, and conferences have been professionalised, the audience is becoming sceptical about their spontaneity and authenticity (2005: 10). She tells us what they are for in contemporary times:

conferences are an integral element of British democracy: for a month every year, the main political organisations hold their national gatherings by the seaside. Thanks to the considerable attention that they receive, conferences act as reminders of the existence of political parties, whilst at the same time, taking them temporarily outside of Westminster. They are an opportunity for parties to address the electorate outside an electoral campaign and for politicians to be seen meeting 'real people'. The conference city, be it Brighton, Blackpool or Bournemouth, becomes for a few days a microcosm of the nation and a symbol of the 'accessibility' and representative function of politicians in a democracy. Photo opportunities are organised for instance at local schools or at the racetrack. Thus, politicians are presented as 'in touch' with the common citizen, mixing with 'ordinary' people. The 'conference season' marks the end of the summer recess and the beginning of the new parliamentary year. It draws attention to the inner workings of political parties and also restores the political structure after the interruptions of the 'silly season'.

(Faucher-King 2005: 11)

'Silly season' is the period between parliamentary terms during the summer when the media suddenly have to cope with a dearth of political news. Newspapers are filled with human interest stories while they wait for the politicians to return. The party conference returns us to the seriousness of politics, a rare chance for parties to distinguish their groups from each other for the public and to create some sense of communitas internally.

So, some rhythms are partly controlled by the 'usual channels', the political party managers, but others are in the hands of individual MPs or their factions. Usually factions are within parties but after the 2016 referendum was won by those wanting the UK to leave the European Union (or 'Brexit'), factions - and therefore rhythms of participation in the chamber - were utterly disrupted. Backbenchers 
had been getting progressively more rebellious but Brexit precipitated disobedience to new levels. Semi-private plotting between politicians often takes place away from the public gaze behind the Speaker's chair in the corridor off the main debating chamber or in the Tea Room where parties sit on different tables. Rebellion against Brexit required deep secrecy. When private plotting across parties requires space undetected by other politicians (as it did to defy May's and then Johnson's attempts to get Parliament's agreement to do a deal with the EU), then closed meeting rooms, MPs' offices and, increasingly, social media channels are employed. WhatsApp is transforming politics in ways we are only beginning to understand. It means politicians and their allies can communicate instantaneously to a huge number of differently configured groups to share knowledge and agree tactics. While the UK government planned how to Brexit, backbench MPs from across the political parties (Conservatives, Labour, Liberal Democrat, other small parties) joined a 'Rebel Alliance', as they called themselves, but when they communicated by WhatsApp they did not want to give their group that name in case it was spotted by a Brexiteer looking over one of their shoulders. So, the profile of their WhatsApp group was: 'Buses and Trains'. Digital transformation also means that the processes of inclusion and exclusion shift around even faster, partly beyond our gaze, than they did pre-digital media, obscuring even more of the alliances in our political worlds from view.

While it is relatively easy to observe MPs' shared patterns by watching them in public spaces and checking their websites, ${ }^{3}$ tracking the secret movements of factions and compiling individual patterns is far more complex. Some rhythms are idiosyncratic to individual MPs. But if you investigate one, you don't know what they share with another, so you have to consult many people and sources: the research task becomes extremely time-consuming. Politicians' published diaries reveal that rhythms are wildly different depending on party, personality and where their constituency is. The most amusing political diaries I have read are by former MPs and Ministers Alan Clark (Conservative) and Chris Mullin (Labour) - humorous because they are written with honesty and a sense of the absurd. Mullin's diaries contain endless references to the places he occupied - whether meeting in the library corridor or committee room 10, having lunch in the House of Commons Tea Room, getting on the phone to Gordon Brown or dealing with asylum cases in his Sunderland constituency - and it is a repeated theme on routines that he argued that Parliament should sit in September otherwise it would look as if MPs are shirking (e.g., Mullin 2010: 132). Clark, writing 15 years earlier, moves from the Commons' despatch box, to the smoking room, to his gentlemen's club (Brooks), his castle in Kent and only occasionally to his constituency of Plymouth by sleeper train for meetings rather than surgeries (2003). The portraits of the rhythms they conjure are starkly different - products of their time, their class and their political party - only explicable if you contrast across contexts and tease out contingent factors.

There is no shortcutting the painstaking business of charting individual rhythms, comparing them and finding the patterns. In my writings on parliament so far I have tried to outline some of these patterns, including some typical days in the life of different types of MP (Figures 5.2, 5.3, 5.4). 
This MP's constituency is in London and she is a junior minister in the Health and Social Care department

8:30-10:00 Constituency Opening of a new school with both the Leader of the Council and the Mayor of the Borough. Short speech (off-the-cuff) during ceremony then discussion of school-related issues. Must leave at 10 a.m. sharp.

10:00-10:30 Travel to Ministerial Office, Health Department, Richmond House, Whitehall.

10:30-11:00 Minister's Office Go through the diary for the coming week with all her Private Office. Decide on communications strategies with Private Secretary and Special Advisers (SPADs).

11:00-11:30 Minister's Office Preparation for BBC World at One interview

11:30-12:00 Minister of State's Office Weekly forward look at speeches, events and issues over the next month and relevant political/communication strategies with ministerial team.

12:00-1:00 Secretary of State's Office Review of the forthcoming week including Weekly Communications Grid, allocation of Commons Health Questions for regular four-weekly slot on Tuesdays at 11.30 and tour de table so each minister and SPAD can update team on major issues of concern. (First half of meeting with officials, second half is 'political' i.e., no civil servants). Secretary of State knows that minister has leave for studio at Millbank at $12: 45$.

12:45-13:00 Whitehall/Millbank Walk to BBC studio, 4 Millbank, briefing on the way by Press Secretary and SPAD.

13:00-13:20 4 Millbank Interview on the World at One with the BBC.

13:20-14:15 Commons Meeting Room Sandwich lunch with backbench MPs and peers in her party to discuss the upcoming health legislation to win their support.

14:15-15:00 Commons Ministerial Office Meeting with Chair and some cross-party Members of the Health Select Committee to seek their views on the upcoming legislation.

15:00-15:45 Minister's Departmental Office Box Time - chance for Minister to do some of her box work - policy submissions for decision, correspondence with public or MPs/ Lords, answer queries from the office or any other issues that arise.

15:45-16:00 Minister's Departmental Office Quick review of speech for event tonight.

16:00-16:30 Minister's Departmental Office Meeting on questions allocated for Health Questions officials will have prepared initial response to each question and briefing on followup questions by either the MP asking initial question or others.

16:30-18:00 Minister's Departmental Office Back-to-back meetings with interest groups and professional groups affected by the forthcoming legislation.

18:00-18:30 Minister's Departmental Office Policy development meeting on mental health in the North East with officials and SPAD.

18:30-19:30 Minister's Departmental Office Deferred policy development meeting about prioritising and budget planning for next year.

19:30-20:00 Commons Catch up and cup of tea with MP colleague - vote if votes come early.

20:00-20:15 Travel to Association of Community Pharmacists annual dinner at the British Medical Association.

20:15-10:30 BMA, Tavistock Square Attend dinner, give speech at around 9:30 - in between courses. 11:00-12:30 Minister's Home Do 'Red Boxes' - especially anything time sensitive. Each submission will have covering or 'box' note from the relevant private secretary explaining what the minister needs to do. Normal routine - at least 30-40 submissions marked for information or decision, correspondence, Commons Questions briefing to review following earlier meeting, drafts of forthcoming speeches, copies of other ministerial diaries, invites to make decisions on, request for future. She will also have constituency matters, urgent and routine, to deal with.

FIGURE 5.2 A Monday in the life of a junior minister.

Note: Adapted from Committee on Standards. MPs' Outside Interests, Chair Lord Bew, July 2018, pp. 24-7, https://assets.publishing.service.gov.uk/government/uploads/system/uploads/attachm ent_data/file/721697/CSPL_MPs_outside_interests_-_full_report.PDF, accessed 14 June 2020. 
This government MP's Scottish constituency is 4 hours travel from Westminster. Her constituency is a mix of rural and urban. She stays there from Thursday afternoon until Monday morning, returning to London to attend Parliament from Monday pm until Thursday am.

9.00-10.00 Meeting in a local hospital to discuss possible closure of one department.

10.00-12:00 Surgery in MP's office:

six meetings with individual constituents facing severe and multiple problems and challenges when accessing local services; one meeting with a group of environmental campaigners; one meeting with a group of parents complaining about a local school.

12:00-12.30 Meeting with MP's staff to make decisions about follow-up on individual constituents' cases and phone calls to council for the most urgent case.

12.30-13:45 Walk to meet local party officials to review tactics for campaigning for local elections and eat a sandwich along the way.

13:45-15:30 Canvass for local government elections (also reconnecting with constituents by knocking on doors), meeting up with neighbouring MPs from the same party, and giving a speech to party workers.

15:30-16:30 Interview with local journalist about the possible hospital closure.

16:30-17:00 Meeting with staff in MP's office to discuss latest developments in a campaign to raise funds for a local charity.

17:00-18:30 Walk to and then visit a housing association to discuss complaints received from tenants.

18:30-19:30 Opening a new social enterprise, creating jobs for adults with learning difficulties; giving speech and meeting those involved.

19:30-20:45 Back to office to go through emails, postbag and Twitter and respond to requests from constituents, journalists, other MPs and party workers.

21:00 Home to catch up with family who live in the constituency.

FIGURE 5.3 A Friday in the life of an MP in her constituency.

These patterns are mere tendencies. Since MPs spend increasingly sizeable chunks of the week in their constituency, especially if their majority is slender and they don't have a frontbench position, their rhythms are hugely affected by the distance from Westminster to their constituency (until Covid-19 interrupted all patterns). If outside London, most MPs have two homes or at least two regular places to stay - one in Westminster and one in the constituency. If they have dependents, then decisions about where and when to travel will be influenced by their responsibilities to those children or elderly relatives. Some leave their children in the constituency while they visit Westminster during the week; others put them in nursery or school in London during the week and travel all together to the constituency at weekends. Whatever their pattern, 'it is a constant juggling act on a giant scale for those with childcare responsibilities' (McDougall 1998: 135) and it remains the case that women in UK society still bear a greater responsibility for household care than men. In any parliament, if an MP has dependents and no partner or care-giver to share the work (e.g., grandparent), then the complexity of dealing with workloads is inevitably immense.

The organisation of political space in the UK has rendered it more difficult for those with dependents to find a bearable rhythm to their work. It is not just that increasingly 
His constituency is in the North of England, too far from London to visit during the week.

9:30-10:00 Spoke in a debate in Westminster Hall about 'Children Missing from Care Homes'.

10.00-10:30 Interviewed by a journalist about why children go missing from care homes.

10:30-11:00 Discussed with staff in his constituency office about various urgent constituency issues on the phone.

11.00-12.00 Spoke at a meeting of the All Party Parliamentary Group on Children about children accessing social care services.

12:00-13:00 Met with other backbench MPs to discuss abuse on social media.

13:00-13:15 Grabbed a sandwich.

13:15-14:15 Met with a group of representatives from children's charities to discuss improving the educational prospects of children in care and strategies for responding to upcoming legislation.

14.30-15.30 Attended as a member of the International Development Select Committee an oral evidence session on sexual abuse and exploitation in the aid sector.

15.40-16.30 Participated in the Urgent Debate: Learning Disabilities Mortality Review in the Main Chamber of the House of Commons asking the Minister a question.

16:30-17:00 Met with his whip to explain why he plans to vote against the party in an important vote next week.

17:00-17:15 Went to his office in Portcullis House and discussed commitments for the week with his Westminster office staff.

17.30-18:30 Opened a charity function in one of the House of Commons function rooms for raising funds for a children's charity with a brief speech about their work.

18.30-19:30 Went to the House of Commons to collect some research findings they had compiled for him and wrote his speech for an important debate the next day.

19:30-21:00 Dinner with colleagues in the party; discussion of campaigning tactics for the local elections in their region (and how the leadership is doing). After dinner caught up with emails

1:00 am Home to his rented flat.

FIGURE 5.4 A Tuesday in the life of a backbench MP in Westminster.

politicians are expected to live in two places, which makes it difficult if they have school-going children, but the very architecture of Parliament can be excluding. Nirmal Puwar takes us on a feminist walking tour of the Westminster Parliament, a Palace built for specific sorts of masculinity (2014: 234). Women and racialised MPs are bodies out of place - even 'space invaders' - while the norm of an MP is assumed to be male and white (see also Chapter 3). This has been mostly reproduced by the design of the place and its rhythms of communication but occasionally disrupted, most notably by the suffragettes. In 1908-9 suffragettes padlocked themselves to the grille of the Commons' ladies gallery, ${ }^{4}$ handcuffed themselves to statues in St Stephen's Hall and hid in a cupboard on census night (so that Emily Davison could claim her address as the House of Commons). Puwar draws our attention to how their invasion into a masculine space underlines the profound exclusion of women (ibid: 237-9). Women 
may have fought their way into Parliament as both voters and representatives but as MPs they remain a minority and are still a challenge to our idea of a 'normal' parliamentarian. Unsurprisingly, Labour women MPs, and increasingly those from other parties too, console and support each other in both Houses. I was often told that when women are seen sitting and talking in a group without men, they are assumed to be plotting. Again, the rhythm of meetings, conversations and communication, and whether they happen in public, semi-public or private, tells us much about differences and relationships between politicians, including how they are gendered.

If you watch MPs' navigation of time+space, and see who is investing more time in travelling, juggling and fighting their way into spaces, you learn about political work and inequalities between politicians. But we haven't really analysed what the navigation consists of in depth - I will unravel a few more layers to see what goes on in both routines and breaks in rhythm.

\section{The emotional gestures of minds and bodies}

Two aspects that have been neglected in many existing studies of parliament, including in my ethnographies of the House of Lords (Crewe 2005) and Commons (Crewe 2015a), are emotions and the sense of self. To find out about these you have to shift attention away from activities and outputs and into the minds and bodies of the participants. As the anthropologist Andrew Beatty points out, emotion isn't just important as an extra dimension; if the researcher can't read emotion (his own as well as those of the people around him) then how can he relate to his informants and do research at all (2019: 3)? In the early twentieth century anthropologists assumed that it was only in so-called 'primitive' societies that mind and body are inseparable and that supernatural and mystical beliefs take precedence over rationality and logic. But most would now argue that despite the vital importance of understanding local cultural specificity, mental, emotional and bodily processes are entangled, just as rationalities and magic are, in every culture around the globe. Let's get up close to find out how politicians navigate time and place socially, politically and emotionally in more detail in a specific place. Lefebvre points out that 'Everyone knows from having seen or appreciated this that familiar gestures and everyday manners are not the same in the West (chez nous) as in Japan, or in Arab countries. These gestures, these manners, are acquired, are learned' (2013: 47). But it is easy to take for granted familiarity with the gestures of our 'own' culture - in my case cultural habits found in London. Once I had a closer look, and realised parliamentary culture has habits all of its own, I was as mystified as I might be in foreign country. I did not realise what was going on until I looked with a greater intensity than usual and with the assistance of a psychotherapist colleague, Nicholas Sarra.

In January 2019 the then Clerk of the Committees in the UK's House of Commons, Paul Evans, asked me to do research about chairs of select committees. At the time, I was working with Sarra, a psychotherapist / group analyst from Exeter University, in a Scottish constituency (see Chapter 3), so we agreed to jump sideways, observing and interviewing chairs and their clerks during the first half of 
2019. We wrote an article on the basis of this collaborative mini-ethnography about how committee work is embodied:

Committee chairs, members and staff are constrained by the architecture, rules and rituals in their bid to achieve plausibility, but at the same time find the room to express individuality in the ways that they manage emotions and communicate with others through words, silence, bodily movements, or facial expressions. By embodying the committee, and mediating between those involved, the work of chair involves walking between friends and enemies forming alliances, dealing with disagreements and disciplining the unruly - to create the impression that select committees are above party politics.

(Crewe and Sarra 2019: 841)

First, to give a sense of the constraining political sociology of committees, we described their hierarchies. Within each committee mini-kingdom you find a flat formal hierarchy - chair and members, clerk, committee specialists and other staff but a more pronounced one between the members and staff. Second, departmental select committees have limited powers and are confined by specific spaces and allocations of time (ibid: 845). They can call, but not compel, any witnesses to come before them and give evidence by answering their questions; when Dominic Cummings refused to attend, there was no serious punishment available for the committees to impose. In 2018 he was invited to give evidence to the Digital, Culture, Media and Sport Select Committee, as campaign director of Vote Leave (arguing for the UK to withdraw its membership of the European Union), but refused. Even when ordered by the House of Commons, he did not comply. The Committee of Privileges concluded that he was in contempt, adding that they regretted his tone - 'this attitude did not serve the interests of civilised debate ${ }^{5}$ and recommended the House should admonish him. However, this did not stop Prime Minister Boris Johnson appointing him as a senior adviser three months later in July 2019.

Committees might expect government to consider and respond to their recommendations, but they can't demand that they are implemented and they can't freeze a contract, hold up a budget or stop a bill. When committees sit their room is set up in a rigid way - usually with the members' chairs arranged around a horseshoe-shaped table, the witness table forming a line to close the horseshoe and (a few) chairs for the public behind the witnesses. MPs' schedules are so full that it is not usually realistic for them to meet more than once or twice a week during parliamentary sessions. Thus, the scene is set for committees to perform.

Politicians sitting on select committees are both constrained (by hierarchies, limits to power, rules, routines ...) but also, and simultaneously, find ways to create room for manoeuvre or, to put it another way, breaks in the rhythm. These openings provide the leeway within which creativity becomes possible, and the driver for creativity is emotion. This is not necessarily how politicians themselves view political work. When one of us asked whether emotion features in the life of 
select committees a former chair replied, 'It doesn't. Not relevant.' But he was not a typical participant - an older man who seemed intent on conveying a tough, manly kind of leadership. How could political work be possible without emotion, if it matters to people? The vast majority of staff working on committees told us that emotional experiences are always present - both unavoidable but potentially and necessarily performative, often requiring discipline to avoid expression of them through bodily gestures such as frowning or laughing. When in the gaze of politicians and the public, for example if the committee is taking evidence in public, its staff in particular have to perform competence but also the appearance of political and emotional neutrality:

staff experienced a tiring relentless pressure to perform required emotions ('If you don't smile when everybody's smiling, there's a problem.' - clerk) or not ('When to speak, when to not to. When to stop admiring.' - clerk) ... In particular feelings of potential shame and humiliation frequently arise through the vigilance around mistakes, blunders and various faux pas which through the emergent politics may also be constructed to advantage, disadvantage, scapegoat or displace various positionings. There is, therefore, a perpetual excited feeling of insecurity which evokes a hyper vigilance about one's own and others' status movements within the wider community. There is a 'fear of looking like a dick', as one participant put it.

(Crewe and Sarra 2019: 852-3)

Emotions require bodies to experience and 'perform' them, and yet parliamentary scholars rarely take bodily communication seriously. Cheryl Schonhardt-Bailey is rare in arguing that facial expressions showing anger and contempt are more common in exchanges between politicians than between politicians (acting as committee members) and others in society (2017). We found that bodies often communicated in order to discipline each other. The late Quentin Hogg reputedly held back a proposal by Norman St. John Stevas (that the Lord Chancellor's Department should be scrutinised by a departmental select committee) with a single and pointed cough. Committee members, and especially the chair, often watch the clerk to see whether his/her face is expressing disapproval. The select committee in action constitutes an embodied affectual display of impression management in which the poker face, the smirk, the 'look', the frown, the appearance of engagement or disengagement, all play their part in managing the emergent situation (Crewe and Sarra 2019: 854).

Individual bodies and minds are not equally constrained or free; it is the rhythms of performance that reveal how the hierarchies affect the chair/members differently. Formally, the chair presides over the meetings by sitting in the middle of the table with the clerk on her/his left, representing the committee to the outside world and embodying it so that one MP who has been chair for many years claimed, 'I am the committee.' The clerk is responsible for the administration of the committee and is the manager of its staff, making their relationship with the 
chair key to how the committee operates. The rhythm of authority - who is leading the committee in practice - is revealed by what the bodies of clerk and chair do, especially at the beginning and end of meetings. During the formal 'sittings' of the committee, the chair is the authority, but in between meetings the clerk symbolically holds the committee in a parliamentary outbuilding in Tothill Street (pre-Covid), about 10 minutes' walk away from the Palace of Westminster.

The Committee might symbolically pop into the public domain in the guise of the chair giving an interview to journalists or talking to stakeholders, but mostly the intensive work is carried out by the clerks, committee specialists and other staff - speaking to the chair as and when necessary, so resides in Tothill Street. Just before every meeting of the committee, and after it has been concluded, the chair and the clerk confer - checking arrangements, discussing members or whatever is needed - as the committee is symbolically handed over from one to the other. When the clerk then takes it to or from Tothill Street, with the staff and often huge piles of paperwork, the Committee has a nomadic quality to it as it is moved around the parliamentary estate and even, very occasionally, on evidence-gathering trips to others parts of the UK or the world.

(ibid: 847)

Politicians in general, and select committee chairs and members in particular, face a continual psychological pressure to perform political competency. This vigilance is expressed not just by what they say, but what their bodies do. It means that during a session the chair especially can't do anything other than focus on their job - looking and listening to the witnesses, deciding when to move on, checking with the clerk, disciplining members who are not paying attention. Other members can look their iPhones/iPads or even leave the room. Clerks and committee specialists remain silent during the session - only communicating with gestures or notes (one passes a post-it with the word 'time' on it when members talk for too long), and whispering to the chair if unavoidable and when they can see the cameras are off them.

What does this tell us about the work of performing on select committees? The chair embodies the committee and mediates between all those involved through gestures/responses of her/his mind and body: walking between friends and enemies, reforming alliances, healing divisions and negotiating the tensions between difference and contradiction. The credibility of the committee is constructed through the rhythms of performance created by the staff and members through documents, disciplined enactments and rituals, hoping that they will be taken seriously by the wider parliamentary community, the media and the general public. The chair and members must be memorable and convincingly authentic in their public gestures, as if their personalities have the quality of being amplified through a loud speaker. They must appear to be pursuing the needs of the committee in a unified way, heart-felt but not too emotional - fierce with ministers but patient with experts - as embodied through the chair, in order to come across as moral and politically significant. 
Emotional communities are created by those who share ideas about feelings and values (Rosenwein as cited by Beatty 2019: 29). Part of the process of relating to each other emotionally is that we speculate about what others are feeling and don't always get it right, because feelings are partly interior to the body but also because they are entangled with values and always contested. Beatty's point is that 'emotions are often performative - intended to influence, persuade or repel. We learn how to feel anger by observing its behavioural contexts, how it is manifested and pragmatically used' (ibid: 54). So, emotions are part of rhetoric even more than the pervasive Western view of them implies, as if they are inner states that are beyond our control. For example, in the New Hebrides among the A'ara if you get anger reclassified as sadness or regret then you are closer to achieving reconciliation (ibid: 55). In fact, as Beatty suggests, there isn't a right interpretation of feelings because emotions are better conceived of as episodes rather than entities (ibid: 45), that can only be probed within their specific cultural context, which is why narratives rather than typologies are so good for conveying emotional experiences and interactions. So, we have emotions but they have us at the same time; we perform emotions rather than merely being in their grip. It is not so much that some emotions can be controlled while others can't but more that the intensity varies, so that it feels as if nothing else becomes possible if overtaken by, say, fury. This performance, or series of 'gestures', as George Herbert Mead puts it, isn't feigned or inauthentic just because it is performative but it is influenced by anticipating how others might react. Communicating is not so much a process of sending messages but making gestures that arouse responses in others that involve both mind and body. So, when people respond to each other - with each response to a gesture becoming a new gesture - we take account of our audience (a point I will return to in Chapter 7). The audience is both made up of individuals but also generalised in our minds:

The organized community or social group which gives to the individual his unity of self may be called 'the generalized other'. The attitudes of the generalized other is the attitude of the whole community. Thus, for example, in the case of such a social group as a ball team, the team is the generalized other in so far as it enters - as an organized process or social activity - into the experience of any one of the individual members of it. If the given human individual is to develop a self in the fullest sense, it is not sufficient for him merely to take the attitudes of other human individuals toward himself and toward one another within the human social process, and to bring that social process as a whole into his individual experience merely in these terms: he must also, in the same way that he takes the attitudes of other individuals toward himself and toward one another, take their attitudes towards the various phases or aspects of the common social activity or set of social undertaking in which, as members of an organized society or social group, they are all engaged. 
A narrative about performing in a select committee in 2014 will illustrate how Mead's way of understanding communication - as a social process rather than an individual activity or event - means taking account not only of one's individual interlocutor but the attitudes of the generalised others, in this case a complex configuration of different social groups in parliament. It will also substantiate Beatty's point that it is difficult to write about performativity; about how speech, thought, bodily movement and emotion emerge simultaneously and often in contradictory ways. In telling this narrative about giving evidence I need to convey this changeability. Katherine Ewing found in Pakistan that someone's idea of themselves can shift (e.g., from a good daughter to a devious politician), but that they have a sense of wholeness by selecting only those memories that relate to the prominent sense of themselves at any one moment. A selective memory and rhetorical devices help people in general deal with the simultaneous experience of consistency and contradiction (1990: 269-71). So here is a challenge to myself: can I write about performance (in this case to a select committee) in a way that conveys these entanglements - both consistencies and contradictions in simultaneous shapeshifting - without smoothing them over as we have to in everyday life?

I will try my best. In 2014 I noticed that an ad hoc governance committee was asking for evidence about running the UK House of Commons. I drafted written evidence in the expected format - numbered paragraphs so it is easy for staff and MPs to refer to extracts they may use in debate or reports - and submitted it via the parliamentary online site. This committee was set up to deal with a row about who should replace Robert Rogers (now Lord Lisvane) when he announced his retirement as Clerk of the House and Chief Executive Officer of the Commons. A recruitment panel chaired by the then Speaker Bercow, announced that they planned to offer the job to a parliamentary officer in the Australian Senate. Rumour had it that Speaker Bercow and his allies wanted to redress the elitism and male dominance of the clerks by appointing a woman; plus, they thought she might reform management practice in the House. Others were horrified by her lack of knowledge of parliamentary procedure (she wasn't a clerk). The consternation of clerks was leaked to the media, directly and indirectly by politicians who were allies, so the PM held back from recommending the panel's choice to the Queen, paused the recruitment process and set up a Select Committee to decide what to do.

After I gave my written evidence, I was called to speak at one of the committee's meetings (i.e., to give 'oral evidence'), so in preparation I watched or read all the words of the other witnesses. Clerks were often characterised by non-clerks as poor managers: backward looking, tradition-bound and opposed to innovation. Frank Doran MP argued:

I think one of the perennial problems of people who reach the top in this institution - and I say that advisedly - is that there is a lack of outside experience. That has been shown over the decades. We are very slow to move things forward and custom and deference are a big part of the problem as well. 
Meanwhile, Peter Hain complained about the clerks' culture of aloofness. ${ }^{6}$ Clerks had been a vital source of information, humour, reflection and friendship during my research; I recoiled at this attack on my colleagues. Like MPs, or perhaps even more so, they are often misunderstood. The idea of these procedural experts being no more than that, a view perhaps egged on by their seventeenth century legal garb (bob wig and court dress), was many decades out of date. They had been managing all aspects of the House of Commons for many years, albeit with an impressive anti-managerialist flexibility that was becoming unusual in modern British workplaces. I noted some of my allies. Sir Kevin Tebbit, who conducted a review of the management of the House of Commons in 2007, gave a soothing warning: 'there is an alchemy here - a curious combination of effects which produces a unique result - and you tamper with it, to some extent, at your peril. ${ }^{7}$

I braced myself, increasingly alarmed at the complexity of the issue and the debt I owed the House staff, including clerks, which I did not want to betray. My sense of injustice at their situation was fuelled by the knowledge that staff are not at liberty to criticise MPs or their decision-making publicly. I studied the reports and evidence, took advice from trusted colleagues and imagined my way into a mood of calm defiance. When I speak publicly, I play a trick on myself - 'I will now be the person others think I am, not the more hesitant and unreliable person I think I am.' When I took my seat to begin responding to the MPs' interrogation, nerves had me in their grip but I sat alongside them in an emotional place of steely focus and gave my evidence (see Figure 5.5).

After the session I stood in the corridor debriefing with other witnesses, bitterly regretting what I failed to say but relieved that I made no chronic errors. Valerie Vaz passed by and, to my amazement, thanked me for giving evidence. I was touched and suspicious in equal measure, thinking she clearly doesn't want to make unnecessary enemies longer term after our tense exchange. I could imagine how easy it would be for us to move into a different relationship, now that we were away from the public arena, making emotional adjustments just as all those who do political work have to do every day.

After deliberating on all the evidence, the Committee decided to keep the Clerk of the House as the most senior position but created a Director-General with a contradictory place in the hierarchy: below the Clerk but chairing the Management Committee. This resulted in the most senior clerk getting the top job and the new DG focusing on non-political management. So, the Speaker won in the sense that a non-clerk was recruited but lost because it was a clerk who was appointed as CEO. After giving evidence, I was afflicted by a dose of vanity, at the possibility that I might have had some influence on the decision, but also worry about losing access to my research site. I had just irritated the most important gate-keeper in the House of Commons - the Speaker, John Bercow. But if he was infuriated by my evidence at that point, he was magnanimous later, even assisting in a project that involved looking at the sensitive question of why MPs became embroiled in an expenses scandal in 2009 (see Chapter 4). Political work always involves risks when you alienate people but like politicians, any of us can weather chilly periods of exclusion if you have allies, patience and the readiness for making reparations. 


\begin{tabular}{|c|c|}
\hline Extracts of the transcript of oral evidence ${ }^{1}$ & $\begin{array}{l}\text { A Woody-Allen }{ }^{2} \text { style explanation of what was } \\
\text { going on in my head }\end{array}$ \\
\hline $\begin{array}{l}\text { Emma: 'Thank you very much, to begin } \\
\text { with, for inviting me. I am absolutely } \\
\text { delighted to have an opportunity to talk } \\
\text { about Parliament. Why? Because I am a } \\
\text { specialist in organisations, and I do } \\
\text { research, particularly on voluntary orga- } \\
\text { nisations and Parliament. I have been } \\
\text { doing research on the UK Parliament } \\
\text { since about 1998, starting on the Lords } \\
\text { and looking more recently at the House } \\
\text { of Commons. I am also looking at Par- } \\
\text { liaments in South Asia and eastern Africa. } \\
\text { I have just completed a three-year project } \\
\text { looking at the House of Commons. My } \\
\text { main focus was understanding the work } \\
\text { of MPs, which I think is undervalued. I } \\
\text { do not think the complexity of the work } \\
\text { that MPs do is sufficiently recognised. } \\
\text { People are extraordinarily cynical about } \\
\text { politics, and I think that spills over on to } \\
\text { politicians and Parliament. So, I am a } \\
\text { huge champion of Parliament, but also of } \\
\text { the officials in Parliament. My experience } \\
\text { of observing them is that the institution is } \\
\text { extremely well run, so in a way, I am a } \\
\text { bit puzzled by some of the evidence, } \\
\text { which seems to claim that it is not.' }\end{array}$ & $\begin{array}{l}\text { 'Eeeeek, I'm so nervous I feel nauseous - how } \\
\text { am I going to think straight. If I get this } \\
\text { wrong, if I freeze with stage-fright, I'll really } \\
\text { screw this up for parliamentary staff. Everyone } \\
\text { else in this room knows more than I do. I'd } \\
\text { better establish my credibility first by mention- } \\
\text { ing my research not only in the UK but else- } \\
\text { where. I'll flatter the MPs - my audience - to } \\
\text { soften them, but I must sound like I mean it } \\
\text { otherwise they'll think I'm being phoney. I'll } \\
\text { make it plain that I'm on the side of Parlia- } \\
\text { ment and its staff. OK I'm feeling a bit more } \\
\text { confident now. I'll come out strong in defence } \\
\text { of staff - thwack, hit them with a slightly } \\
\text { passive aggressive attack on anti-staff evidence. } \\
\text { I can feel my anger and indignation rising.' }\end{array}$ \\
\hline $\begin{array}{l}\text { Valerie Vaz: Okay. Perhaps you are talk- } \\
\text { ing to the wrong people - I don't know. } \\
\text { When are you publishing your report? }\end{array}$ & \multirow{3}{*}{$\begin{array}{l}\text { 'A verbal assault! Am I blushing? She's hitting } \\
\text { back - trying to undermine my research, imply- } \\
\text { ing I spoke to the wrong people or am out of date. } \\
\text { Hardly surprising. She's Keith Vaz's sister who } \\
\text { is a close ally of the Speaker, John Bercow, who } \\
\text { wants to appoint someone from outside who } \\
\text { doesn't know about UK politics. So, clarify I'm } \\
\text { up to date and ready to substantiate my claim.' } \\
\text { 'Phew, he smiled at me - I think he is on my } \\
\text { side. Anger abates.' }\end{array}$} \\
\hline $\begin{array}{l}\text { Emma: 'My book comes out in April } \\
\text { 2015. I could give a little more substance } \\
\text { to the claim that I think Parliament is well } \\
\text { run, if that is useful. Is that appropriate?' }\end{array}$ & \\
\hline Chair: Yes. You could also write to us. & \\
\hline
\end{tabular}

FIGURE 5.5 Evidence to a governance select committee 2014.

Notes:

$1 \mathrm{http}: / /$ data.parliament.uk/writtenevidence/committeeevidence.svc/evidencedocument/ house-of-commons-governance-committee/house-of-commons-governance/oral/15827. pdf, accessed 28 April 2016, Q648.

2 There is a brilliant scene in Annie Hall when a man and a woman talk to each other while their neurotic inner conversations appear as subtitles. I have re-imagined my thoughts here - some I do recall but I have also filled in the gaps - to convey a recognisable pattern rather than factual history.

32Parliament Office of Science and Technology. 
FIGURE 5.5 (Cont.)

Emma: 'In a way, it relates to why I think you need to have one clear person at the top who has experience of parliamentary business, which I define very broadly - not just as very narrow and fusty procedural work but as something much broader than that. I would include what people in the Library do, what people in Committees do, dealing with the media - we have not talked about the media very much. It is an incredibly complex organisation. What is puzzling is that the kind of complaints I have read have been about mice or about building projects going over budget, but they are not the core business of Parliament. Who claims that the Committee work is not absolutely outstanding? I have watched a particular Committee for two years. I could not do what those Clerks and specialist advisers do. It is not just the Clerks; the specialist advisers produce reports incredibly fast, in a way that, frankly, most academics would not be able to. How many mistakes are made in all the mass of documents that come out and relate to the Chamber? As far as I am concerned, the deftness with which the officials deal with the core business is very underappreciated. It is partly because they do not really blow their own trumpet. They are not really here to do that - they are here because they are serving Parliament, and, in a way, they are so busy defending MPs and defending Parliament that they sell themselves a bit short.'

Valerie Vaz: 'We have not heard evidence of that - in fact, we have heard evidence to the contrary, that Parliament is run quite well, and the Clerks and Committee section in particular. We think they are outstanding and we have heard evidence that they are absolutely outstanding. We could not do the jobs that they do. I do not know whether you are just looking at something slightly different or have heard something slightly different. The basic running of Parliament we think is good; the decision-making process and how that filters down to the rest of the organisation is the issue that we are looking at. Obviously we had certain terms of reference for that. We have heard from staff - we had a staff event, which obviously was not public. It is right that we should listen to the people at the bottom. It is at the top management layer that things seem to be going slightly wrong. I don't think we have ever suggested otherwise - I suggest you look at the evidence that has come out of previous sittings.'
'Feeling calmer now and Andrew Kennon, the clerk beside me, will definitely like what I'm saying. Be brave. I have less to lose than the staff. Right, sound decisive and get to the point. The person running Parliament needs to continue being an expert in politics. Establish your evidence for the idea that they are already doing a good job. Do they look like they are listening? Yes, my nerves are under control; keep going. Make the critics sound as if they have lost their sense of proportion. Put my case and undermine my opponents; sound quietly confident but not nasty.'

'Ouch, she's saying I'm on my own - I'm unreliable, panic ... heart beat rises as I reel from her oh-so-subtle dismissal, implying I'm "slightly" but fatally off the mark. I don't believe it! She's implying that I've only listened to the people at the top, while they've been paying attention to people "at the bottom". How dare she call people "at the bottom"? How rude! She's had one event - I've been talking to staff at all levels since 1998. My blood's up again resentment swirling - but I'll focus on keeping my mind sharp, unfazed by emotion otherwise she'll win the argument.' 
Emma: 'I have. I have talked to a lot of staff and I have talked to a lot of MPs' staff, as well, about how things are run. My experience is that there is some dissatisfaction. For example, as David was saying, people who are not Clerks should - this has already improved massively, but there is still room for improvement to open things up - be able to become Clerks if they choose to, and not necessarily permanently. It is about that interchange that David was talking about, and I think that there could be a lot of improvements with that.'

Valerie Vaz: 'You actually said in your written evidence that "any staff should be encouraged to develop expertise in the core of the House of Commons business". I was just a bit troubled by your next phrase, which was "if they demonstrate the capacity." Are you saying that it is only a few people - the anointed few?'

Emma: 'I am partly influenced by the fact that I come from the international development sector, where civil society organisations have appointed people to the top - to the chief executive role - who do not really understand the core of the business. If they have an opportunity to learn about it, great; but if they get parachuted in without necessarily understanding that business, then in my experience they have not done a good job. Not everyone is going to have the capacity to work, for example, as a Committee Clerk - I would not be able to do that job. Clearly you have to have the capacity and the particular skill set to be able to do that kind of job.'

Valerie Vaz: 'I do not know whether you have seen this, but they are developed quite well. It depends on the teams. The senior Clerk develops people within those teams. They do get there at the end. I am not sure whether you have looked at that. I will move on to allowing people to go across departments, as you say. It is not necessarily about giving people an extra qualification, but sometimes when you get into the civil service you have a course at Sunningdale. Do you think it would be useful, when people come into this organisation, to have an induction day - whoever they are, whether they go through the Clerks' section or anywhere else - or some kind of certificate or qualification? I am reluctant to go down that route, but, as you say, do you think everybody should know the core business?'
'Quick - defend my credibility and undermine evidence against my arguments. (God this is exhausting, how do MPs do this all the time?) Acknowledge discontent but twist it away from her superficial claims about problems to my more important agenda, i.e., that all staff should have equal opportunities for promotion. What a relief - I think I've surng back onto the higher moral ground.'

'Another blow - she's saying I think some people are too stupid to be clerks. She's taken it out of context. I'm so riled I'm getting hotter; now my reputation is really at stake. Now I'm really cross again, but need to keep calm.'

'Annoyance at my interlocutor is now mixed up with memories of fury at charities I love being taken over by CEOs from the corporate sector who introduce pernicious managerialist processes - taking the soul out of the work. I'm fuming equally at the arrogance of CEOs and MPs who think they know best. But I need to make sure everyone knows I'm not the snob as portrayed in her latest accusation.'

'Another hint at my deficient knowledge, eh? But I'm calm and steady now - I can see the other MPs are looking at me in a reassuring way. I refuse to be knocked down by her passive aggressive digs. Or misrepresented by her - I never said everyone has to know the core business. I can feel I'm entrenching a steely determination for myself. I'm calm now.' 
FIGURE 5.5 (Cont.)

Emma: 'I would not say that necessarily absolutely everybody should. I think that anybody who is interested should certainly have that opportunity, absolutely. There are hugely talented people working in the Library, for example, or in POST or whatever, who I think should be helped to get the qualifications to apply, for example, for a Clerk job. I think that would be brilliant. It would be more than being inducted. There might even be a course in procedure, say, available to them. That kind of opening up of opportunities would be fantastic.'

Later, in response to Jacob Rees Mogg,

Emma: ' . . . appreciation of what is already going on that is good is very important, and recognition of the complexity of Parliament would be useful, because there is a lot that officials cannot say publicly. They cannot be rude about MPs. They cannot talk about the inevitable conflicts that go on within organisations. They cannot take credit for things, because they are always giving credit to MPs. They cannot explain the delays that happen, which I know happen particularly between the House of Lords and the House of Commons. Also, when MPs get involved, they cannot blame the MPs for those delays; they have to take the blame themselves. So I think some recognition of all that would be helpful for morale.'
'I'll underline the importance of equal opps, while reaffirming that I know different corners of Parliament like POST - using acronyms shows familiarity. ${ }^{3}$ I'm rising above her antagonism. Maybe if I let my enthusiasm shine through, it will expose her miserablism.'
'Still smarting at how rude MPs have been to and about staff, I'll emphasise that staff are constrained so it is reasonable for me to speak on their behalf. I'll try and make it politically difficult for them to put negative things about staff in their report - it will make them look mean. I think we must be coming towards the end. I don't think I have majorly messed up but what have I missed I wonder? ...'

The point of this story is to highlight the complexity of researching emotions in politics and how they are always partially concealed and entangled in social relationships. Even explaining my own during one encounter is hard given the tangled circumstances, a huge cast of characters, different processes happening in public versus private, and the simultaneity of speech, movement, thought and emotion. Add to the mix that all those characters have their own contradictory interests and emotions, and you can see how much work is involved in telling narratives. Including emotion in the story has to be more than a list and less than the whole truth and nothing but the truth; it means revealing how and why people are relating to each other as they are. Rather than getting fixated on defining emotion in politics, let's look at how people relate to each other in a given emotional world. We have to be careful not to reify cultures - as if all participants in a place conform to ways of being - in fact, I'd argue that the emotional performance of MPs, clerks and witnesses in select committees is at odds, responding as they are to different relational pressures. 
Beatty contrasts emotions he studied in two places (Niha histrionics with Javanese discipline) (2019: 79), and we might do the same with different groups in parliaments, but we need to do this in a way that recognises that emotions are both an individual and social experience. Reading emotions, as difficult as that is, is a good way to study political worlds because emotions are a 'social commentary, a mode of politics' (ibid: 133) and politics always stirs the emotions. Maybe the really skilled politicians develop a capacity to withstand ambivalence and a dynamic sense of self - the paradoxical experience of being an individual with agency, but part of a wider constrained social group at the same time - as part of the identity shapeshifting that is essential in political work?

\section{Breaking rhythms: moving on or staying put}

I have written mostly about continuities: how rhythms create routines and welltrodden paths, thereby maintaining the status quo in people's relationships with each other. But anthropologists have become equally interested in disruption, resistance and breakdowns, grappling with questions about how change happens. Michael Carrithers has written about how rhetoric can bring about change. He tells us about an extraordinary moment in history when Willy Brandt visited Warsaw to lay a wreath to commemorate the Holocaust in 1970:

As is routine on such state visits, a wreath-laying was arranged according to the meticulous code of an internationally recognized diplomatic culture. The monument with its honour guard was approached by a motorcade of Polish and German dignitaries. In due, careful, and slow procession, the dignitaries stepped out of their cars and arranged themselves while the press crowded about to record the routine event. An elaborate wreath was produced for Brandt to place before the monument. He stepped forward to lay the wreath, arranged its ribbons carefully, then stepped back and, facing the monument, bowed his head solemnly for a while, obeying the tempo and code of such affairs. Then, suddenly, he fell gracefully to his knees and, still obeying the guiding tempo, remained there silently for perhaps a minute. As the present German Chancellor said (on a recent visit to Warsaw to join in naming a square after Brandt), 'we held our breath'. Brandt then rose gracefully and turned away toward the cars. It was done. A year later he was to be given the Nobel Prize for peace, not least because of what he did before the monument in Warsaw. He had achieved a masterstroke of political rhetoric and with it had created a new item of German, indeed international, culture ... So it became, to echo Goodenough's famous definition of culture, something that every German must know to count as a competent member of society.

(2005: 580-1)

Here we have the familiar routine of wreath-laying disrupted by an apparently small gesture; he added to the familiar style and tempo of a state visit and wreath- 
laying with another familiar move - one of kneeling to express remorse and repentance. Interestingly a poll in Germany at the time found that $41 \%$ deemed it appropriate, while $48 \%$ thought it inappropriate but later it became seen as a heroic act, paving the way for a new culture (or set of rhythms) of regret for Germany's crimes during the Second World War. It was an act of leadership, improvised he tells us in his memoirs because, 'As I stood on the edge of the Germany's historical abyss, feeling the burden of millions of murders, I did what people do when words fail. ${ }^{8}$ It turned into a huge gesture. Now let's try a thought experiment about this improvised leadership. Imagine if it was someone else who fell to their knees imagine if it was a woman, a young woman in the Green Party. Would she not have been seen as disrespectful to tradition, overcome by emotion and illustrative that women don't really know how to behave with dignity? She might have been accused of doing a stunt. Think again, what if it had been Angela Merkel (current Chancellor) in the present? She has such a reputation for calm, rational, leadership I think it might be applauded. So, to understand the act, you have to consider the historical time as well as the person's reputation, their age and gender, and what's at stake for them, because disruption is both an individual and a social act.

Spray et al. have compared disruption in the Indian, South African and UK parliaments and found that protests provoked by backbenchers, and the opposition, expressed rebellion at the dominance of the executive (e.g., grabbing the Chairman's microphone, a walkout and filling the well of the House respectively). This can lead to 'adjournments' where the Speaker stops the session so that MPs can 'cool off'. But when you survey the three sites in detail, it becomes clear there is huge variety in form, severity, frequency and response (Spray et al. 2014: 202). Disruption is found in all parliaments but to different extents; the mass violence that has erupted in parliaments in Japan, Ukraine and Taiwan is extreme relative to the norm elsewhere (ibid: 204). Disruption is always interesting but to discern its meaning you have to study the rhythms over time - the more serious the disruption, the longer the time.

The need for a longer historical view becomes plain when you try to fathom the causes and impacts of political coups. British anthropologist Jas Kaur has written about the rhythm of coups in Fiji:

It is not as if history implodes into the moment of the coup and emerges as something else on the other side; neither is it the case that history and identity politics simply remained the same. Rather, the coup changes some things, while other things remain the same. In essence, a coup offers an empirical and heuristic rupture to narratives which allow life and ethnic difference to make sense. At the same time, the momentum and the structures of that conjuncture allow the past to continue into the future.

(2017: 19)

And if you consider the build-up to coups you realise that what appears to be sudden might actually be very gradual: the plotting entailed in a coup might go on 
for weeks, months or even years beyond public view, but the pressures and tensions between groups is likely to have constituted a conflict that was busy brewing beneath the apparent peace. You can always find moments of peace in a feud and tensions underlying periods of relative harmony.

The juxtaposition of contradictions in sociality is a theme that Mead took up nearly 100 years ago, but still seems to have been overlooked by those in search of reductionist explanations. Reducing theory to one primary cause is useful if you are aiming to predict simple cause and effect patterns, but not if you are trying to understand and anticipate human thought and action. As Mead explains, the social character of the universe means that an emergent event arises out of history but also how the future is being imagined, thereby creating contraditions; so 'Sociality is the capacity of being several things at once' (1934: 75). The adjustment from routines to breaks in rhythm is what leads to the emergence of novelty. When Speaker Bercow allowed far more Urgent Questions - a process whereby the Opposition can ask government to make debatable statements on topical issues this brought about a significant change in the relationship between executive and parliament (see Chapter 2). When constituents became more demanding, changes in the rules of allowances meant that MPs could afford to spend far more time with them (see Chapter 3). When digital technologies enabled people in political worlds - politicians, journalists, activists - to communicate instantaneously, 24/7 and via smartphones in our pockets, the rhythms of lives, and how we engage with each other, was accelerated. When Covid-19 forced everyone to meet virtually, our rhythms were transformed: we lost face-to-face and, therefore, embodied opportunities for informal alliance-building and strategising. The emotional impact of the digital revolution and disruption by Covid-19 on our established and new relationships will be a vital area for future research for many years to come.

Herein lies the movement in the rhythms of life, including in politics: 'we are not just located in the world symbolically; nor do we experience reality purely through the text: instead, we are located in relations that transform the natural and social worlds in which we live' (Burkitt 1999: 2). Both changing the world, and being changed by it, whether as a result of a shift in people's values or habits, rules, or technology, new rhythms are continually emerging and that emergence is accelerating. It is hardly surprising then that UK MPs are not only procrastinating about when to move out of the Palace of Westminster to allow restoration but fighting to retain their private spaces rather than give them up to officials. A venerable backbencher, Conservative Edward Leigh, wrote to the House of Commons Speaker on 23 December 2019, complaining about a proposal to hand part of the MPs' library over to office space. He referred to it as 'a space specifically dedicated to MPs' needs', 'part of our rich cultural heritage', and one of the 'very few quiet places for MPs to work'. He was perhaps fighting to protect MPs' space because an attack on one's space, if you feel a sense of belonging to it, can feel like an attack on one's identity. But what is novel in contemporary parliaments is the increasingly public nature of power struggles over space, as this letter was posted online. ${ }^{9}$ 
What I have proposed in this chapter is a systematic (but not comprehensive) and comparative approach to the study of politicians' routines and rhythms. My contention is that rhythms should be taken seriously partly because they offer some stability and continuity for politicians, and even for the rest of us in a less pronounced way, in their chaotic, contradictory and shapeshifting work. It is important to point out that anthropologists have been writing about the complexity of change for a long time; there is nothing new in this. I am rejecting various either/ or theories - as if choosing between the idea that change is only internal to a society or imposed from outside; that it is only materially driven or culturally infused; that it is controlled from above or below. Anthropologists are interested in entangled explanations and would be in agreement that routines, and breaks in routine, have to be researched empirically.

\section{Notes}

1 https://theprint.in/india/governance/new-home-for-pm-a-triangular-parliament-modigovt-readies-delhi-power-corridor-makeover/342758/, accessed 5 January 2019.

2 This passage was word-crafted by my husband, Nicholas Vester.

3 https://calendar.parliament.uk and https://www.parliament.uk/about/how/occasions/ca lendar/, accessed 20 January 2020.

4 Parliament provides a little information and an image of this: https://www.parliament. uk/about/living-heritage/transformingsociety/electionsvoting/womenvote/parliamentarycollections/ladies-gallery-grille/grille-incident/, accessed 20 January 2020.

5 https://publications.parliament.uk/pa/cm201719/cmselect/cmprivi/1490/149003.htm, accessed 9 February 2021.

$6 \mathrm{http} / / /$ data.parliament.uk/writtenevidence/committeeevidence.svc/evidencedocument/ house-of-commons-governance-committee/house-of-commons-governance/oral/15556. html (Q319), and http://www.publications.parliament.uk/pa/cm201415/cmselect/cm govern/692/692.pdf, accessed 20 January 2020, pp. 32-3. Frank Doran is mistakenly referred to as Frank Dobson in the report.

7 Ibid, p. 44.

8 https://rarehistoricalphotos.com/warschauer-kniefall-1970/, accessed 5 January 2020.

9 https://order-order.com/2020/01/08/mps-stage-fight-parliamentary-staffs-library-takeover/, accessed 2 February 2020. 


\section{6}

\section{RIFFS OF MEANING}

Politicians create 'riffs' to communicate their ideas, perhaps seven or eight at any one time, according to Chris Bryant, a British Labour MP. In music riffs are a repeated chord or melody. It is in jazz that the word is used most commonly, usually meaning that although there is repetition, there is also the scope for improvisation. Riffs are a good way to think about not just the continuities and breaks in ideology, but also the performance as well as the meaning of acts of communication. When Chris Bryant was Shadow Social Security Spokesperson ${ }^{1}$ he had to mug up on pensions and so he developed a 90-second speech (or riff), which could be adapted or extended to several different lengths: two minutes, five minutes, 20 minutes, one hour. It is acceptable if your audience hear the same arguments in different contexts, but he adds, 'If you have a reputation for using formulas, then you are going nowhere. ${ }^{2}$ Riffs will be used on various occasions, whether in the chamber, in a media interview or in your constituency, so your style and tempo need to change completely in the different sites because different relationships are being formed or renewed. You need to have an awareness of specificity - the audience, the mood, the relationship - and to express a coherence of self and ideology that glosses over the fact that all human beings have ups and downs, changes of heart, a range of influences and so on. What makes the politicians' job especially demanding is that they deal with multiple audiences having different levels of interest and knowledge, not only shapeshifting between audiences but communicating to several simultaneously.

Riffs are part of the content of politics that has to be adapted to different relationships. It is full of risks - if you change your riffs too much, you will be seen as changeable and unreliable; if you don't change them enough, you will be deemed inauthentic and robotic. So the content and performance of riffs demand both authenticity as an individual but also a process of improvised shapeshifting to allow for loyalty to party and to the diverse preferences and demands of diverse 
constituents. In this, politicians are like everyone else. Anyone with a job that involves communication, and definitely academics who teach and talk about their research, develop riffs to convey what they are thinking about or arguing for. But politicians' riffs are more changeable and audible in the public realm; there is usually more at stake when an MP articulates a policy position than when a university teacher gives a talk. So politicians are also different: they are more exposed to censure. This chapter is about these riffs - what they consist of, how they are created and contested, what impact they have in different contexts - and which aspects of them are idiosyncratic to politicians as a group as opposed to generalisable to all humans.

\section{Ideology and knowledge}

Although the content of ideology - in the sense of your understanding of the world, your knowledge, how you attribute meaning to events, what you value, your judgements about what is good or bad and so on - is wildly different in (and within) different locations, the processes of creating and being created by it can be observed across the world. An individualistic view would mean you conceive of ideology as contained in people's minds as if separated pieces of information. The assumption would probably be that if they belong to the same culture, they ingest the same information, more or less, and transmit it from one generation to the next. Members of a political party are indoctrinated with an ideology to different extents, in this view, and it is shared ideology that keeps them in that group. In contrast to such individualism, anthropologists take a relational view, focusing on the social relations and group processes entailed in creating (and being created by) ideology, which become sedimented and disciplinary, but not fixed, as an important part of their culture. Anthropologists see ideology and culture as entangled, rather than deterministic in what people do and how they remake the world around them, but we may disagree about how to think about individual agency and cultural change. As examples, Bourdieu stresses the disciplinary processes and endurability of ideology and power structures while Ingold sees learning as a creative process that entails formation, reformation and transformation. But anthropology's starting point on ideology, knowledge and culture is that these are relational, changing, and are processes rather than commodities or positions.

For the benefit of non-anthropologists, I will briefly mention how we got from an individualised to a relational way of understanding the world and from dividing people into two categories (primitive versus modern) to seeing us as either one or a multitude of groups. Early anthropologists used to deem it possible to find out about the content of other people's worldview by collecting and classifying their beliefs as if they were a collection of mental artefacts. Non-Western beliefs were portrayed as irrational and primitive until Malinowski did fieldwork. He was the first anthropologist to immerse himself in another community (calling it participant-observation), in his case in the Trobriand Islands in the 1920s. He portrayed Trobriand Islanders as rational beings who used social institutions and technologies to maintain a stable society (Alaszewski 2015: 207). The need for social stability was a human universal 
in his view. Evans-Pritchard took this one step further, pointing out explicitly that what we might see as an irrational 'belief is experienced by the believers as knowledge. When he looked in detail at ideas about witchcraft, for example, he found the Azande of South Sudan rational in the sense that they were logical within their own terms of reference, seeking to predict and control the future (ibid: 209-11). What was the significance of this? Logical thinking is another universal feature of societies that can only be understood if you take account of local context. The assumptions underlying Azande investigations about how witches create misfortune are not so different from those of auditors in urban centres around the world - accounting for past deficiencies in bureaucratic procedures and projecting remedies into the future. When either the Azande diviners or auditors find their predictions don't come true, they both attribute blame to the process claiming that the way the divination or forecasting was conducted was flawed. Perhaps the client was not competent or someone interfered with the various steps required. So, all cultures operate with a mix of magical and other kinds of thinking even if the basis of logic or rationality varies, with some believing in the supernatural power of witches (to inflict injury), accountants (to predict financial health) or engineers (to solve the climate crisis).

The most famous French anthropologist of the twentieth century, Lévi-Strauss, put it like this:

magic still exists and all of us are magical in one way or another ... my objective in The Savage Mind [1966] was ... to place the thought of people without writing and that of so-called civilized people in some sort of equality, on the same plane.

(as quoted by Alaszewski 2015: 212)

Since this early anthropology, we have broken out of both functionalist and structuralist straitjackets but also shaken up crude classifications of the world (primitive versus modern) by acknowledging diversity in the way knowledge emerges in different places or, in the world of academia, disciplines, but also between dynamic factions and individuals. Fredrik Barth was influential by bringing back individual agency into our understanding of knowledge production, warning:

As academics, we have been marinated in Western philosophical discourse to the point where we might too readily accept its current parochialisms as universal premises. We want to be able to discover and be surprised by other lives and exercise the relativism whereby all of the traditions, bodies of knowledge, and ways of knowing practiced by people are recognized for our comparative and analytic purposes as coeval and sustainable, each on its own premises.

(2002: 3)

Barth distinguishes between three spheres of knowledge: ideas about the world; partial communication of those ideas in words, gestures and actions; and 
transmission of ideas through social relations. These distinctions are important because they make it possible for us to acknowledge some stability in ideology, while creating the space to discern erratic local innovation by individuals and, therefore, recognise people's agency.

That is enough of a detour into epistemology and, more specifically, anthropological developments in thinking about knowledge and classifying people and nations. It was necessary because one of the foundations of anthropology is that we assume processes of culture-making can be generalised while the substance might always be looked at afresh in specific contexts. So, to understand political communication in parliaments you have to look at ideas, rhetorical styles and what goes on between people as they relate to each other through conversation, ritual and various kinds of media in ways that account for generalisable processes and specific substance. To make use of Barth's useful distinctions, I will focus on ideas and knowledge (ideology) in this section, move onto communication and rhetoric in the next, and finally write about advocacy in the final section of this chapter.

Let's return to ideology and think about the kind of taken-for-granted thinking - or silent traditions in Bourdieu's words - that are implicit, and so only appear in riffs as assumption rather than rhetoric, and that are shared by all (or almost all). The idea of pollution is taken for granted in places where caste distinctions are made and this is a good example of how ideology is transferred to the young:

I was sitting on the veranda of a house near Elpitiya in Sri Lanka. It had just rained, and a boy of 2 or 3 years began playing intently in a mud puddle in the red laterite soil in front of the house. After a short while his mother shot from the back of the house and yelled, 'Stop that! You'll be as filthy as an outcaste!' He stopped, began to cry, but grew distracted and wandered off to the back of the house ... this is quite an extraordinary and highly concentrated slice of rhetoriccum-culture, for it conveys to the child, in one short hot virtuoso burst, at once a desired aesthetic of comportment (cleanliness), a classification of the social world (us vs. outcastes), and a negative evaluation of the others (dirty in nature, even if not in actual appearance). If one were to ask how people in caste societies come by the idea that humans are naturally and obviously divided into different and unequal kinds, then this would be a splendid illustration.

(Carrithers 2005: 578-9)

So, what is the equivalent to these South Asian ideas of caste and pollution? What ideas are shared by all politicians? Most obviously all UK MPs assume the need for 'modernisation' when trying to win support from the public. In the UK although traditionally Conservative philosophy tends towards conservatism and the protection of national institutions, since Thatcher's reforming zeal they have championed change almost as much as Labour. Now none praise British traditions or spurn modernity; it has become a taken-for-granted dominant riff for all politicians. Even Jacob Rees Mogg, reputedly the last MP who champions British traditions, conveyed his approval of change when he wrote this in his first tweet in July 2017: 
'Tempora mutantur, et nos mutamur in illis' ('the times change, and we change with them'). ${ }^{3}$

Even globally it is hard to find a politician who champions the protection of tradition without some pledge of renewal or change of some kind; their promises are about reform and transformation and possibly a return to past glory, but always with an innovative twist. (Of course this may change post-Covid-19 into a language of recovery, but as I write this book during and after a period of lockdown and then isolation, we are in a transitional phase.) In countries deemed to have emerging rather than advanced economies, the aspiration of modernity is translated into the language of development. For politicians in the world's 141 'Low and Middle Income Countries' (so-called by the World Bank), ${ }^{4}$ development, and the eradication of poverty and conflict, are the discourses they have to engage with when negotiating with aid-giving countries. The ambitions to reshape the world get more grandiose and encompassing, while the struggle to raise funds and navigate economic and political complexity intensify for governments and non-state actors alike. Whether by governments or NGOs, development is packaged as fundable 'programmes' and 'projects', and represented in policies, plans and evaluations, as if it is about achieving tangible outputs and impacts on beneficiaries (what it is really about is summarised by Crewe and Axelby 2013). The amount of time taken up with this representation of development in documents and speeches has become greater and greater as those investing in programmes bestow less and less trust on planners and implementers and give in to the temptation to claim credit for themselves. So, the realisation of the impossible ambitions recedes even further as resources are poured into claiming credit and winning support for development rather than into achieving results.

To give another example of shared taken-for-granted ideology among politicians entangled with people in society, but in a specific region of the world, take the dominant paradigm of Israeli political culture: Zionism. As Aronoff explains in his book Israeli Visions and Divisions (1989), Zionism emerged in response to the persecution of the Jews, on the one hand, and the threat of assimilation by the diaspora on the other. As soon as waiting for messianic redemption was seen as too passive, Zionists conceived the only rational position to be national liberation through the creation of the state of Israel. The overwhelming majority of Israeli Jews - politicians and people alike - support Zionism in contemporary times, but the two most significant groups who oppose it are some Orthodox Jews (who see it as blasphemy) and the vast majority of Palestinians (whether residing in Israel or occupied territories) (Aronoff 1989: xvii-xix). Even among Zionists, he explains, there is a lack of consensus on fundamental values and policy:

These divisions would appear to be linked to profound differences in a relative sense of individual and collective security, trust/distrust and amity/hostility toward outsiders, and temporal worldviews between types of Zionists ... What is shared appears to be very meagre. 
Aronoff offers us a persuasive history of the fractures in Israeli society, which are, if anything, more pronounced now - decades after he wrote this book. At the same time, his narration of arguments between Israelis (politicians and citizens) about whether/how to make peace (e.g., to give up the settlements in the occupied territories), obscures the view from the Palestinian side. For Palestinians inside and outside Israel the dispossession of their land and rights - the denial of the right of their return to where they were born and from which they fled during 1948 or 1967, for example - is against international law. In contrast, the dispossession is taken for granted as the new state of affairs by virtually all Israelis. Ascertaining public opinion - the riffs that circulate in society at large - is not an easy task. Framing makes a huge difference: an Israeli and Palestinian researcher found that when people were asked if they supported a specific solution to the right of return, Palestinian support dropped by half when the same question was presented as a compromise rather than a victory. In contrast, Israeli support increased slightly from 30 to $35 \%$ (Shamir and Shikaki 2005: 321). It can be easy to manipulate questions to get the answer you want.

In studying ideology there is no shortcutting the painstaking process of writing about agreement versus disagreement and how political alliances and hostilities have developed over time, often in fractured and contradictory ways. You can't understand politics in Bangladesh unless you consider the competing rivalries caused by ideological splits informed by Bengali nationalism, relations with India/ Pakistan, Islam, economic liberalisation and kinship. The bitterness between opponents, partly organised into the main parties of Awami League and Bangladesh National Party, has been fuelled by blaming each other for violence and assassinations of former leaders (Ahmed 2020). According to British anthropologist David Lewis, you need to go further back to understand Bangladeshi politics to see how its economy was shaped during the colonial era (2012). In Ethiopia you might argue that contemporary conflicts - including the displacement of 2 million people partly due to ethnic conflicts - can only be understood if you study PM Meles Zenawi's establishment of ethnic federalism after the Ethiopian People's Revolutionary Democratic Front (ERDPF) overthrew the Derg in 1991. Regional boundaries were drawn based on major ethnic groups and this created permanent ethnic minorities that are politically excluded in the sense of being inadequately represented in regional parliaments (Birhanu and Senbeta, forthcoming). If you take the case of Benishangul Gumuz, for example, the groups seen as 'non-indigenous' have been poorly represented in parliament, marginalised from the benefits of mega projects, and even displaced in huge numbers. It is possible to trace how the ideology of ethnic nationalism has emerged historically within Ethiopian federalism in ways that have created deep divisions and conflict within the politics of this region.

In the UK too you have to think historically to understand the strands of political ideology, but again the question is: how far back should you go given the turbulence of recent times? The rough headlines of party soundbites over the past 50 years are confusing: Conservatives once protected national institutions, the memory 
of Empire and a paternalistic version of helping the less fortunate. But during the 2010-15 coalition this shifted to a strong alliance with successful, aspirant, 'hardworking' people - exemplified by Grant Shapps MP (Conservative) saying to the House in 2012, 'we are on the side of aspirant people who wish to buy the roof over their heads. ${ }^{5}$ There were hints of this during Thatcher's time but they were surely also influenced by Labour Prime Minister (PM) Tony Blair (1997-2007) who pulled his party towards the right, championing aspiration and sounding pro-business, arguing that this was necessary for winning over non-Labour voters. He argued in his memoirs that aspiration was something natural: 'to help the individual gain opportunity, to let him or her overcome limitations ... That echoed and captured something deep within human nature: the desire to be free, to be the best you can be' (Blair 2010: 90). While it was a Labour PM, Clement Atlee, who created the Welfare State, and that party is associated with generosity in public funding, it was the Conservatives who almost nationalised the whole economy when coping with the Covid-19 pandemic. So classifying the ideology of the two parties is no longer as simple as it was.

The ideology of the smaller parties in the UK is more straightforward: most were partly created out of dissatisfaction with the larger parties (Liberal Democrats with their illiberalism, UK Independence Party [UKIP] with their pro-European sentiments, and Green Party with destruction of the environment) or nationalism in Wales (Plaid Cymru), Scotland (the Scottish Nationalist Party) and Ireland (Sein Fein). But what parties (or their representatives) put in soundbites and messaging reveals only a fraction of their ideological assumptions. The contradictions and dynamism in political parties deserves far more research - I have only really done so in depth in relation to one piece of law-making (see Chapter 4) - and our network, the Global Research Network on Parliaments and People, is embarking on such work in six countries. ${ }^{6}$

A comprehensive analysis of the ideology of UK political parties would require a book of its own, but it is worth pointing to how politicians themselves have to continually research their own party's riffs and how they are shifting. To influence your colleagues, and thwart your opponents (on your own side as much as in other parties), MPs need to know what others are thinking and what they are plotting to achieve. You need to know your own history - as examples, how and why did ideological minorities in the UK's two main parties gain such influence between 2010 and 2020, the Conservatives by the anti-Europe faction and Labour by the Corbyn-led left? Cameron was persuaded to have a referendum about Brexit because the anti-Europe party - the UK Independence Party - was gaining popularity. But also the anti-Europe campaigning within the Conservative party gathered steam and a large minority threatened to withhold their support for other measures unless he agreed to a referendum. After this was won by those expressing a preference for the UK to leave the EU in June 2016, until parliament brought this about in January 2020, the party was mired in bitter conflict about how, and even whether, to leave the union. This conflict can only be understood in the context of how the UK, and specifically politicians within the Conservative Party, reacted to various EU 
initiatives since the Second World War. In short, the Conservative Party has been painfully divided on its relationship with its neighbours for many decades. A small faction took advantage of the Party's weak position (a coalition and then minority government) and rising public popularity for the idea of more participatory democracy.

How did the left gain control of the Labour Party by electing Jeremy Corbyn as leader in 2015 despite his tiny number of supporters among MPs in his party? How did he continue as leader, even when 173 out of 230 Labour MPs passed a no confidence vote in him the following year? Again, you have to look at history. First, the former leader Ed Miliband changed the rules so that the membership had a far bigger say in choosing the leader. Then the membership of the Party increased from 198,000 in 2015 to 552,000 in 2018, in part encouraged by the socially media-savvy group Momentum, and Corbyn seemed to bring back members who had felt alienated by the Blair/Brown government (Whiteley et al. 2019). This pitted the Parliamentary Labour Party against the membership and consolidated Corbyn's position. However, there is some evidence that it was not so much ideological differences, as the perception that Corbyn was divisive, unelectable and lacking competence as a leader, that motivated lack of support for him among the PLP (Scott Crines et al. 2018). Parties are not formed on ideological agreement alone: before Corbyn became leader, Angela Eagle MP (former shadow leader of the House of Commons) claimed that it was likely that Labour Party members probably only agree with about $40 \%$ of its manifesto commitments (as quoted by Crewe 2015a: 56). Electability, and the promise of power, makes disagreement with a leader far more palatable. When Corbyn did better than expected in 2017, dissent quietened down, whereas when his party lost so badly in the 2019 election that he realised his position was untenable and announced that he would resign almost immediately. It seems to be another example of how minority factions in political parties in the UK can take advantage of a rising expectation for more participatory democracy. It looks as if this may be a sign of things to come.

But also, it is clear that loyalty is about more than a cold clinical assessment of your leader's policy positions. As French anthropologist Florence Faucher-King points out:

Values and ideology are often taken as the cement, the raison d'être of political parties. However, studies of party activism have shown that activists ignore the details of political and economic theories that form the ideological basis of their party and only the most sophisticated amongst them can maintain consistency between such an ideology and the needs of their organisation (Barnes, 1968; Faucher, 1999a: 39). Values are the outcome of interactions between individuals and relate to rituals in so far as these collective and performative events help connect us with identities larger than ourselves (Elias, 2001).

(2005: 7)

Loyalty to leaders is about far more than values and ideology in other countries as well. In 2018 a new young and charismatic politician - Dr Abiy Ahmed - became 
the first Oromo to be Prime Minister of Ethiopia. Perhaps Dr Ahmed's PhD in peace gave him an understanding and, therefore, powerful riffs about relationships in leadership. In the early days he talked about mobilising talent, capacity and creativity to foster collective action and in one of his early speeches he thanked his mother and then his wife. Apparently, no Ethiopian leader has acknowledged their family, and specifically the women in their family, in this way before. Women scholars told me that this speech was significant: they felt a slight edging towards the idea that women are part of the political world, a world they have been excluded from. At the end of another early speech he thanked god - not his specific Protestant one (his mother is Christian, his father Muslim), but god in general so that Protestants, Orthodox and Muslims could identify. Ethiopian leaders since former Emperor Haile Selassie have scarcely acknowledged the importance of god's role in peace; for decades people in this deeply religious society have had to pretend that god was irrelevant to politics. The possibility of reconciliation without god was remote, one Ethiopian political scientist colleague told me, so Abiy gave everyone hope. He recognised what is important to all Ethiopians - family and god - and spoke as an individual but to all in the nation. It is a good example of what Carrithers surely means when he writes: 'Sociality penetrates us through and through; thought itself is an argument with yourself, like an argument with others, and the stuff of thinking is also the stuff of persuasion' (2005: 578). Abiy was saying out loud what people were thinking, so they were persuaded that he was talking to them, even if tragically within a few years conflict and displacement plagued the country because in this case words were not enough. This takes us into the realm of rhetoric.

\section{Rhetoric: communicating riffs of meaning}

Looking at how politicians communicate requires consideration of a dizzying range of sites, at least before Covid-19: government departments, chamber, select committees, constituencies, overseas visits, media studios, rallies, party meetings, offices, streets ... ; modes of communication: mail, email, other social media, speeches, gestures, images, symbols, texts, gossip, lies, slogans, manifestoes ... ; and effects: alliances/divisions, winning/losing seats, violence and policies/laws passed. I can do no more here than indicate some promising lines of anthropological inquiry. As far as shared and contested knowledge is concerned, we can assume that a fission/ fusion of agreement and disagreement operates in most political arenas where rhetoric is concerned. Leach tells us that in highland Burma in 1939-40 there were endless squabbles over water rights. These were usually settled by the village headman but when outsiders (equivalent to other political parties) were involved, 'The Hpalang people dropped their differences and all told the same lies for the common good' (1954: 70). The main zone for this fission and fusion in parliaments is within political parties, as I have mentioned. The content of riffs is both individually created but also dictated by your party: politics is partly about getting your side to back your narrative and undermining the arguments of the other side. But 
factions or thematic groups can be as, or even more important; in Brazil Bolsanaro won in 2018 thanks to the 'bull, bullet and bible' bloc (agricultural, security and evangelical) lobbies in a Congress with over 30 political parties.

In a fascinating doctoral thesis about political communication in the Green Party of Aotearoa New Zealand, Jessica Bignell explains how statements are a vital part of the game for politicians and their parties. Politicians in political parties are not just aiming to get into government, they are in a power struggle to represent the world as they see it (2018: 2). She relies on Bourdieu to argue how 'what creates the power of words and slogans, a power capable of maintaining or subverting the social order, is the belief in the legitimacy of words and those who utter them. And words alone cannot create this belief (as quoted by Bignell ibid: 3). It is easier to study how words are produced than what happens when they are communicated. She explains the history of political spin and messaging coming out of the US since the use of propaganda during the 1914-18 world war (ibid: 35). The contemporary influence of political communication activists / academics, such as George Lakoff, has encouraged politicians and their spin merchants to speak in metaphors. He claims that when people hear words it sets off frames of reference in our brain (e.g., politics in the US is filtered through two ideas: a conservative strict father versus progressive nurturing parent) so the task is to ignite the frame that suits your goal (ibid: 39-45). Take this together with the pervasive idea in political marketing that you have to appeal to emotions not rationality and you have part of the explanation for why political communication both changed in style over the last 100 years but also, arguably, returned to the ferocious contestation of earlier times.

The 'message discipline' of parties is not just about making sure, as far as possible, that all members adhere to key content, and self-censor when off message, but that they follow communication styles as well. When Bignell immersed herself in the Green Party she found that they all agreed to convey statements that gave the impression of economic expertise and competence, and the ' $1+3$ rule' where 1 was the headline statement that would be used by the media in soundbites, and 3 were the supporting arguments that would grab attention and substantiate their claims (ibid: 144-53). Members are disciplined by their parties but at the same time individuals respond differently depending on their values, history and ambition. As one New Zealand MP explained:

any organization always has a tension between hierarchical control and freedom of thought and conscious thinking, I accept what I can accept but there is a certain line that if it's crossed, I will not change and I'll dig in very firmly.

(as quoted by Bignell ibid: 153)

Whether or not to dumb down a message on climate change, to make the Green Party more palatable to a potential coalition partner and the public, as well as the timing of declarations, became the focus of a disagreement. What then took place is what often happens in politics - a compromise with papers being distributed to a smaller group, having an impact but not the one anticipated by anyone (ibid: 161). 
Bignell's thesis is unique as an anthropological ethnography for its spotlight on political communication in parliament, specifically messaging by political parties. But another anthropologist has also forensically investigated communication by politicians at a local level. Heikki Wilenius researched how East Javanese regional councillors authorise their status (2020). His work is important as a warning to those tempted to sum up the political culture of place as creating singular modes of communication. Politicians in Malang have to use different linguistic registers, ossicilate between hierarchical and egalitarian sensitivities, respond to the need to dispense patronage but appear clean at the same time, and adjust to swopping from highly ritualised events to encounters with scarcely any ritualisation at all. Different publics require different kinds of persuasion and rhetoric can be both ambiguous and misrecognised (ibid: 256). In contrast to research that pathologises Indonesian politics, this fine grained ethnography reveals what is going on in the kind of rich complexity that characterises good anthropology: it makes one feel guilty when attempting to summarise.

Other anthropologists have written about communication by politicians as part of wider studies; for example, Faucher-King has written about how political party conferences are changing partly because they have become more visible to the general public, so are no longer serving merely internal functions (2005). These days voters can watch politicians' conference speeches on the TV or online which is partly why the leadership tightly control what happens in the public performances. The focus on the personalities of individuals, especially the leaders, increases year by year, with soundbites and images being used to boost their reputation as celebrities while the leader's speech is an opportunity to show her/his charisma (ibid: 10). These highly performative shows remain important politically: 'The conference season actualises the political map, frames ideological debates and clarifies the positions of the competing teams. It legitimizes political organisations and the ways in which social and political conflicts are mediated, displaced or relocated in Westminster' (ibid: 11-12). So then the differences between parties become vital so that viewers are able to weigh them up: 'Comparing these group styles points to the competing repertoires and ideologies articulated and promoted by different political parties' (ibid: 4). One of the areas of variation between parties is found in the role of the conference in developing its party's riffs. While the Conservative conference is an occasion for conveying the party's policies, the annual conference acts as the sovereign body of the organisation for the Labour Party. Kinnock's attack on the then far left, the Militant Tendency, and the rebranding of the party in 1995, took place at conference. Policies are developed at conference by the Liberal Democrats, but not all of them get into the election manifestoes, while for the Greens these events are the main mechanism for forging a common culture and a set of policies (ibid: 16-20).

British anthropologist Amy Busby writes about Members of the European Parliament and points out how central their management of information has become when playing the game (in Bourdieu's sense) of political work. All politicians receive huge quantities of information, including 100s of emails a day, so their staff 
have to act as a filter to decide what is important and what can be ignored (2013: 170-3). The invisible staff act as their eyes and ears, reply on behalf of MEPs and even attend meetings on their behalf, speaking for them: 'my member says this, that'. Those that get involved in policy wade through 100s of amendments and even draft amendments, reports or draft resolutions for their politicians. Some assistants end up knowing more about the policies or parliamentary procedures than the MEPs (ibid: 176), becoming the experts that act as intermediaries or brokers of knowledge. The more substantial the demands on politicians, the more their staff shift from communication into creating and using riffs to do political work on behalf of their employers. MEPs get their information from a range of places (party, NGOs, library, academics etc.) but it is revealing that the one they most trust is unofficial, informal contacts, and other MEPs' assistants are the most common source (ibid: 184, 188).

Gossip is a mechanism for communicating information that is as old as politics itself. Rhodes writes about this in his study of everyday government (2011), an innovative piece of ethnographic research by a political scientist interested in the interpretive approach'. Politicians, officials and journalists gossip about conflict, affairs and who might get onto/off the frontbench. Ethnographers achieve much of their research by gossiping with informants about what is being gossiped about between them. Promotion is a regular topic of gossip between officials, as confirmed by this conversation between a Permanent Secretary and Rod Rhodes (2011: 193):

RAWR: And are you looking forward to whatever the next promotion might be? PERMANENT SECRETARY: Yes and you are wondering what it is going to be. RAWR: You're discussing it furiously with all your peers?

PERMANENT SECRETARY: Yeah, yeah, it happens all the time. And you know, by now I know a lot of people around the departments and there is a lot of gossip isn't there, it's like a big family.

Gossip is a continual theme in my book on the House of Commons (Crewe 2015a). Gossip is an essential part of building alliances and outwitting opponents not only between politicians but with Special Advisers, party apparatchiks and journalists too. The habits of gossiping between UK politicians and the media used to involve expensive lunches, or a drink in one of the many bars in the Palace or nearby, but post the digital revolution the news is more likely to whizz around via Twitter (publicly or privately through direct messages) or WhatsApp. Journalists are becoming cut out of this process as politicians leak news straight to the public, but they remain especially useful when MPs seek anonymity as the source of information. The Chair of the influential Tory backbenchers group (nicknamed the 1922 Committee) wrote to his members to complain about leaking. It was immediately leaked as follows:

Dear colleagues, Earlier this year you elected me to serve on the Executive of the 1922 Committee. One of the reasons I decided to stand was my frustration, shared by a large number of colleagues, about the frequent leaks from 
1922 Committee meetings. These leaks, once unheard of, have now appeared to become the norm. However, I have been prompted to send this email after last night's meeting which was addressed by the Prime Minister. Details of this meeting weren't just leaked. It is clear that somebody was live leaking a minute by minute account of proceedings as they happened to journalists who then posted on Twitter whilst the meeting was still taking place ... These leaks are not just undermining the 1922 Committee. They threaten to make it completely redundant ... Kind regards, Graham Evans MP. ${ }^{7}$

Gossip, and now leaks, are constant: so what is new? Foret (borrowing from Balandier) makes an argument that political communication has changed not only because of the digital revolution but because society has transformed as well (2010). As sociality is becoming weaker, and social relations more fragile, so we are getting cut off from traditions, and symbols are losing their significance except in very specific arenas. Where once political leaders could dramatise their power by mobilising embodied symbols, they now have to express their mastery in other ways with new symbols expressed in a continual virtual performance:

public authorities cannot rely on traditional symbolic resources on a day-today basis to maintain their social control. They have to demonstrate constantly their ability to master change and deliver efficiently the results expected by citizens. Symbols still matter, but the construction of the political drama is radically altered (Balandier 1992). The purpose of symbols for political power is the same: to show strength and to express legitimacy. Technological means and cultural conditions are incongruent. Leaders and institutions have the potential to reach anyone at any time. They are under a continuous obligation to communicate, as silence would mean indifference or helplessness. Power is permanently on stage (Schwartzenberg 1979). It is no longer a distant center that appears at leisure in a carefully controlled ceremonial setting, like the triumphant arrival of a king in a loyal city. It must be an interlocutor, listening to citizens and responding to them. Mass media forbid the segmentation of the public a priori (even if new media tend increasingly to do so in practice). It creates the obligation to have a catch-all message with a neutral content that makes sense to the majority of the audience without alienating any minority groups. In short, technology is not only means of communication but also a communicative constraint.

(ibid: 59)

I will return to the question of which symbols are losing their significance in the next chapter, as Foret seems too sweeping on that point, but for the moment it is plausible that communication modes are shifting and legitimacy has become even more dependent on claiming results and dodging blame. Politicians have always done this: Caesar wrote The Gallic War to make claims about being a military giant. 
But being judged by results as an individual politician, or leader of any kind, has become even more complex in two ways. First, it is easier for detractors to disprove false claims, make counter claims and generally sow confusion. Second, ministers have little control of the impact of their departments and even if they did, change often takes place long after they have gone - whether positive or negative. The journalist Isabel Hardman reminds us that the Teenage Pregnancy Strategy introduced to the UK in 1999 took 15 years to have an effect. By the time the number of teenage girls falling pregnant halved not only had the minister left but the government had changed as well (2018: 135).

The pressure to seem in control, to claim results and to evade allegations of harm, is partly why politicians are drawn to both spin and secrecy like moths to a flame. Writing during the 2019 general election Robert Crampton (journalist and son of an MEP) asked why politicians shapeshift in their promises versus delivery of policy:

Consider the fate of an aspiring politician who made a speech incorporating the following inconvenient truths. You, the voters, simultaneously demand a low level of tax and a high level of public services. You don't want personally to look after your elderly relatives, as people do in Spain and Italy, but you'll be damned if you're going to pass up inheriting the parental home in order to fund state provision... We want more houses, wind farms, prisons and railways - only not where we live. We want unlimited free healthcare while greedily eating and drinking quantities of food and booze that will make us ill. And so on.

In contemporary politics in democratic states some hypocrisy is inevitable, but it is worth being discerning about the kind of deceptions that politicians get involved in. A 'mask of virtue' is inevitable in politicians, as Runciman points out, and those who think they are immune from it are deceiving themselves (2008). 'Knowingness about political hypocrisy is no more an escape from it than any other kind of inside knowledge, because it too can be deployed as a mask' (ibid: 71). The most dangerous forms of hypocrisy are in the hands of those politicians who pretend they are above politics, that their hypocrisy doesn't matter, that they never lie or that the game of politics is easy (ibid: $72-3$ ). This means that the real choice in political communication is not between sincerity and hypocrisy, but how you handle - and how honest you are about - the inescapable temptation towards hypocrisy.

I have written about ideology shared, for example within political parties, and how this is turned into rhetoric and communicated in ways that allow people and politicians to rise above the contestation and dissent. This is changing faster than anyone can keep pace with. I need to address the huge shifts in political communication as a result of globalisation and to do this it is important to think about networks. 


\section{Networked advocacy}

The handling of ideological conflict by politicians is powerfully influenced by how riffs are communicated. Communication has been revolutionised by globalisation, succinctly defined by Ted Lewellen as:

the increasing flow of trade, finance, culture, ideas, and people brought about by the sophisticated technology of communications and travel and by the worldwide spread of capitalism, and ... the local and regional adaptations to and resistances against these flows.

(2002: 7-8)

Two elements of globalisation - the digital revolution and action on climate change - happened to coalesce recently in a campaign I joined in my home area of North Somerset in the South West of England, within the UK. This narrative is about local politicians in a District Council deciding whether or not to allow Bristol airport to expand. Residents, civil society organisations and groups, politicians and the airport tried to control their own version of the narrative, developing riffs about technical materiality and community interests while conjuring fellow feeling across overlapping groups. What unfolded revealed much about how politics is both a continuing form of engagement but also changing into something new.

In August 2016 an email pinged in from the Parish Council of the Somerset village in which I live with my family about an application for a nearby pub to convert itself to a hotel. I knew from village gossip that this was a cover for illegal airport car parking. The owners of the pub had a reputation for intimidating local residents to let them use their fields to fill them with holiday-makers' cars at a cheaper rate than the airport's official car parks. So I went to the council's planning meeting to speak against the application. My neighbour and friend, a chartered surveyor, advised me that I must give them 'material grounds' to refuse the application that relate to council or national policy and planning regulations. A council officer strongly hinted on the phone that the public do well in these situations if they allow themselves to express emotion too. The meeting began in the pompous but mundane way that council meetings proceed and I spoke when invited, saying that it would clog up our single track lanes and that the design of the hotel was like an urban factory in a beautiful corner of Somerset. This was 'inappropriate development on the green belt' (the technical bit) and 'more residents would have spoken but did not for fear of intimidation' (the emotional bit). That sent a frisson around the room. The lawyers and agents for the applicant were at a disadvantage - they sounded dispassionate, as if they were just doing their job, and the councillors were clearly bored by their speeches. The councillors poured over PowerPoint slides of the design. 'Hmmmm, I agree with the public speaker rather than our own officer; it does look rather industrial', said one. Even though the council officers were recommending approval, their comment about how the 
applicants were being investigated for running illegal airport car parks, perhaps conjoined with the mention of the word intimidation, combined to put some off the whole idea. They voted and the applicant lost by 8 to 11 votes. My own local councillor and I glanced at each other from across the room and gave each other the smallest but most heart-felt smile. It was shockingly exciting for a mix of selfish and altruistic reasons. In political stories it is easy to overstate your own role, in a longing to be the hero of the story and in the 'struggle for recognition', as Honneth puts it (1996), and I can't pretend this was politically important to anyone outside our village. What was more significant from my viewpoint was that it pulled me into a network that became far more important to this region and alerted me to the potential for influencing planning decisions.

From that moment I met a few neighbours regularly to drink a glass of wine and complain about illegal car parking, occasionally haranguing the council to take action (which they mostly did not have the resources to respond to) and talking about how we might gain more influence. I met with our local MP and we agreed that the inadequacy of transport infrastructure to the airport (no rail or motorway), and monopoly on legal parking, were creating serious problems. We gave our then tiny community group a name - Bristol Airport Parking Community Action Group (BAPCAG) - and teamed up with the North Somerset Parish Councils Airport Association (chaired by Hilary Burn), experts about the damage caused by the airport with years of experience of campaigning against it. The need for advocacy abruptly stepped up in December 2018 when the airport put in a huge application to expand by $50 \%$ - from their then level of 8 million passengers a year to 12 million. Our airport parking group morphed into a major campaign 'Stop Bristol Airport Expansion' with a website, Facebook page and Twitter account. ${ }^{8}$ Our first meeting had already taken place in a village hall near the airport before the application was put in, because we had heard rumours about it, and nearly 100 people came ready to pledge support. This new group encouraged people to submit written objections on the council site and plotted a media campaign to make the arguments against expansion. We met with Liam Fox MP to discuss the argument that there wasn't the infrastructure to support an expansion. We wrote to our councillors to express our dissent to this expansion on grounds of noise, destruction of the green belt, traffic and climate change. Several of us wanted to be noisier about the climate crisis, but the majority said that the public would be turned off by such riffs.

On 20 August 2018 Greta Thunberg had decided not to attend school but to stage a protest outside the Swedish Parliament demanding action on the climate emergency. Within a few months schools in and around Bristol had joined her Friday climate strikes, including my own daughter Scarlett Vester, and Extinction Rebellion groups were springing up across the UK. In February 2019 North Somerset Council had declared a climate emergency and a goal to be carbon neutral by 2030. ${ }^{9}$ Then the man leading Stop Bristol Airport Expansion (SBAE), a Professor of Film John Adams, had a genius idea - a way of communicating our key riff. He and his film-maker wife, Cassie Farrell, made a film with four 17 year 
olds, including Scarlett, about the damage that airport expansion would cause. Entitled 'An Open letter to Ontario Teachers', because the airport was owned by the Ontario Teachers' Pension Fund, they uploaded it to Facebook on 12 April 2019, paying for ads to make sure that it was seen. ${ }^{10}$ It had over 60,000 views and 100 s of comments flooding in from teachers, horrified at what their pension plan was doing to schoolchildren in rural Somerset. It featured on several TV news programmes and Scarlett and one of her fellow students, Libby Scott, were interviewed on BBC radio. It was even reported on by the Chair of the Environment Agency, Emma Howard Boyd, in the Financial Times:

The North Somerset Times reported that 17-year-old Scarlett Vester got involved because of the consequences the expansion could have on the environment. The students did not just design placards, they followed the money. On discovering that the airport is owned by the Ontario Teachers' Pension Plan they contacted teachers in Canada asking if they really knew how their retirement savings were being invested. ${ }^{11}$

The airport executives were given their chance to reply and invited Scarlett and Libby to talk. So, Scarlett wrote to the airport and took up their invitation to meet, informing the BBC so that they could film it. I wrote a two page briefing for them with four riffs for objecting:

1. Contribution to climate emergency

2. Fields filled with cars and terrible traffic on small lanes and on A38

3. Noise pollution

4. Area of Outstanding Natural Beauty ruined forever

When Scarlett and Libby sat down with two executives, they brought out their phones to record the meeting but were told that was strictly not allowed. They remember clearly, however, that whatever they asked seemed to elicit a pre-prepared answer to a slightly different and less embarrassing question. For example, they asked, 'Why do you claim that you will be carbon neutral when you are not taking in account plane and car use and just referring to your site and building?' and were told that the airport is not responsible for that. The BBC were not allowed into the meeting by the airport executives but they interviewed Scarlett and Libby on a nearby field afterwards. Both sounded incredulous at the dissimulation of the airport representatives. Viewers were impressed by the students' poise, understanding of the issues, and ability to voice their anger with calm and journalists reported it widely. ${ }^{12}$ Now 100,000 s of people in the South West knew about the campaign against airport expansion.

The endless objections residents submitted to the council's planning website, ${ }^{13}$ and the concerns of the council officials, led to a huge amount of work for the council to assess the merits of the case. They spent the whole of 2019 assessing and negotiating with the airport to improve the application, uploading $100 \mathrm{~s}$ of 
additional documents. This meant endless delays to the planning meeting that would approve, reject or delay the application. During the early part of 2019 it is puzzling that residents were bothering to campaign, as it was clear that the overwhelming majority of councillors were pro-airport expansion. As one of them, I can say that my motivation was partly irritation at the complacency of the airport and the council. Rumours circulated that they were developing the site already on the assumption of approval. The council had a reputation for allowing the airport every application it put to the planning committee and even reneging on conditions that it attached to approvals.

However, the council elections in May 2019 changed the council's composition dramatically. After 12 years of holding a majority, the Conservatives lost 23 seats while Greens gained 2, Labour 2, Lib Dems 7 and Independents 11, with the latter taking control of the council. The new councillor in our ward, Steve Hogg, a former manager at British Telecommunications, was an Independent. Since the airport was in our ward, he was the local politician most affected by the application. We had absolutely no idea what the new Councillors thought about airport expansion and they were instructed early on by council officers to avoid 'predetermination' (that is, making their mind up before they had all the evidence). Open-mindedness was essential or they could give the airport (or its opponents) grounds to contest the process if they did not like the result.

In the second half of 2019 it was hard to keep track of the hyper-dynamic level of activity on the campaign side. Stop Bristol Airport Expansion, and various allies including Extinction Rebellion, co-ordinated by a joint WhatsApp group called Bristol Airport Action Network, held meetings, ${ }^{14}$ rallies and protests to get the media's attention. During one protest one rebel spent the whole night sitting on the top of a sculpture just outside the airport. ${ }^{15}$ Campaigning was not necessarily always perfectly harmonious: some found Extinction Rebellion cult-like, some disagreed within their various groups about how disruptive to be, others felt their contribution was not being adequately appreciated. Despite this, campaigners recruited more objectors who in turn wrote to their councillors and submitted further objections on the council site, all to get the local politicians' attention. And a core team kept marshalling the arguments against expansion, led by Hilary Burn and the Wrington Parish Council (the area most affected by the airport), knowing that the application could only be turned down if there were 'material' grounds. On 29 January 2020 the council released a 175 page report (with another 75 pages of appendices) stating that they were advising the planning committee to accept the proposal. Of critical importance, two days later Liam Fox (MP) wrote to the council's CEO (and posted it on his website) advising that problems of poor transport infrastructure, noise and parking should be addressed before a decision was made about expansion.

The Parish Councils Airport Association and Bristol Airport Action Network had already crowd funded to get legal advice, hiring a planning lawyer to form an opinion about the material grounds. She brought out her report on 4 February 2020, six days before the planning meeting, and it was sent to all the councillors. 
She explained the meaning of a 'material consideration' (i.e., grounds for refusal): it was a breach of council policy or regulations that when put on the decisionmakers' scales should tip the balance one way or the other. She found four ways in which the application failed to comply with 'the Development Plan' - all environmental impacts - and pointed to the airport's over-statement of economic benefit. Knowing that pro-airport councillors were likely to warn that refusal could lead to an expensive appeal, she pointed out that approval could equally precipitate a costly judicial review.

Once it was known that the planning meeting was set for 10 February 2020, the council received a flood of applications from the public to speak. They proposed that Hilary Burn, Chair of the Parish Councils Airport Association, should pick 10. Scarlett and I were included and asked to dwell on representation of youth and democratic engagement respectively. We had both been less involved than others during the second half of 2019, distracted by other study/work, but had kept in touch through rallies and odd meetings. We wrote speeches with a mix of technical and emotional riffs. As we tried out our speeches on each other the weekend before, knowing that we had a part to play in shaping the narratives that could influence the decision, nerves jangled our bodies. We discussed what was driving us: for Scarlett it was climate change; for me it had become about solidarity with Scarlett. The annoyance at local disturbance (cars in our lanes and fields, the noise of planes and traffic jams on the road to Bristol) was entangled with alarm at climate change, but also the campaign had the kind of emotional heat needed for me to pour time and energy into it because my daughter felt so strongly. For me, it was politics entangled with kinship.

In the wood panelled council chamber the speakers, councillors and observers drifted in to take their places. We tested our microphones and asked fellow speakers anxiously about procedure and technicalities, Scarlett and I smiling at each other tentatively to exude reassurance but sitting apart to disguise our relationship. The objectors spoke in turn for three minutes, each cheered by the public audience behind us, followed by pro-airport speakers, in their turn cheered by their supporters in the upper public gallery. I began with emotion: 'In the last year we have witnessed an incredible and diverse movement of volunteers - young and old spring up across the South West making arguments against airport expansion.' In the middle I focused on politics: surveying the objections from 8800 submissions to the website. I ended with technical materiality, drawing their attention to the independent barrister's report that gave them the material grounds to reject. Scarlett created a similar mix in her narrative but her riffs were about saving lives, representation of youth voices and asking the council to be consistent with their policy on climate change. Others made more emotional speeches (e.g., an Extinction rebel) or more technical ones focusing on familiar riffs - tackling inconsistencies with policies, illegal car parking, climate, noise and public transport problems.

We listened to the councillors debate for 3.5 hours without any idea about their positions until they spoke. Gradually we began to realise that many were doubtful 
about expansion. We knew for sure that our own councillor Steve Hogg was against it because he had campaigned to win his seat in May on that platform. When he spoke, he made the case against expansion, sounding authoritative and determined, stressing that approval would drive a wedge between the council and its residents. He warned that the council officers' report ignored the views of the communities and he detailed the material grounds for rejection. Despite the dryness of the topic, he held the rapt attention of his audience. Some councillors then reflected on the momentous decision before them. Councillor Westwood (Labour) said:

we need to be looking for the necessary materiality to turn this down, speaking bluntly ... the last briefing was from a barrister on some legal aspects of our decision today. One point he made to us, which I found very interesting, was that we were the politicians in this mix, we were here to - by some alchemy - reflect the interests of our constituents, whilst at the same time deliver a decision based soundly on the material issues of the application. He also said we should take no heed of what other locally based politicians might say. ${ }^{16}$

The council officers replied, defending their 250-page report and warning that the councillors should not be swayed by 'untested' claims and assertions. If information had not been filtered through the impartial and independent process of council officers 'testing it', then they should be wary, the officers warned. And yet the impartiality of the council officers was assumed. They had been locked into assessment and negotiation with the airport - close collaboration no less - for over a year but since planning decision-making has a bias towards approval, this wasn't seen as a compromise of impartiality. Just after 10:30 pm they voted in turn: 18 against expansion, 7 for and 1 abstention. We had won.

An airport executive was heard saying into his phone bitterly some minutes later, 'that's politics for you.' I suspect he may have meant something like: good sense and evidence was pushed out of the way in favour of residents being self-interested and emotional, while councillors responded by trying to please them. Some weeks later the airport's solicitor sent out a letter warning the councillors that their reasons for turning down the application were not proper or rational, threatening that they were likely to lose on appeal:

the reasons for refusal raise wholly artificial issues which are unsupported by the relevant policies cited or by any evidential basis on which to make such a decision, or raise issues which have been fully addressed by proposed conditions or planning obligations. Accordingly, the reasons for refusal do not constitute proper reasons for refusal ... we would remind the Council that examples, as set out in National Planning Guidance, where an award of costs may be made against local planning authorities, include failure to produce evidence to substantiate each reason for refusal on appeal and vague, 
generalised or inaccurate assertions about a proposal's impact, which are unsupported by any objective analysis.

Clearly the airport didn't recognise the politics - the claim that 'evidence' was entirely on their side, for example - involved in their threat.

The political tactic of denying that you are being political can be dangerous for democracy. The French anthropologist Bruno Latour challenges us to think about politics as one of the ways that we create society, so when people refer to a crisis of representation in democratic politics, they are undervaluing and perhaps taking for granted a process that is easy to misunderstand. When riffs are portrayed as false, fickle and corrupt in a political debate, we judge the conditions of one regime of talk by the standards of another; after all, he explains, 'political discourse appears to be untruthful only in contrast with other forms of truth' (2003: 147). For example, if you are conducting a scientific experiment about what subjects said in relation to a given question, truth depends on faithfully recording and reproducing what they said. If you are doing politics, the representative (whether elected politician, trade union representative or child rights protector) can't faithfully produce all her group's views; she has no option at times but to betray them in the sense of converting multiple views into one or two riffs, filtered through the lens of her own causes or those of her organisation or party. It is not possible to faithfully reproduce everything that has been said. In that process of conversion her interpretation of what is right, good and true is inevitably filtered through her own way of understanding the issues. Political representation, in contrast to science, always involves mediating individual difference and social commonality.

So to pretend that political talk can be guided by reason, straight talk and the literal representation of a multitude of interests is dark and dangerous. Latour ends with this warning:

By replacing distorted representation by faithful representation, impossible obedience by pedagogy, composition of new groups by rectilinear transfer of 'relations of domination', we may well finish off politics for good or, in any case, cool it down to the point of it dying of numbness, without even noticing, like a careless pedestrian lost in a blizzard.

(ibid: 162)

Let's take an example from the battle over the 'material' grounds to approve or reject expansion. The airport claimed, with council officers' backing, that in the calculation of environmental impact they did not have to take account of emissions caused by the planes or passengers' cars arriving because policies state that these can't be controlled by the airport. But as our councillor Steve Hogg pointed out, the airport could have some control over this by choosing to agree or disagree with the plans. He was stretching interpretation of policy to its limits but in doing so making the council more consistent in its policy about climate change. This politician was stretching but he wasn't twisting because he was taking advantage of a 
contradiction to recommend an environmentally ethical course of action. So contrary to widespread assumption stretching an interpretation can be ethical while the disparagement of politics itself can be politically manipulative.

This narrative reveals the complexity of ethics in politics but also how campaigning has changed in recent years. Digital media was a central ingredient in this story. Alerting 1000s of people to the campaign, raising funds and persuading them to join rallies and submit objections would have been impossible without Facebook, Twitter and WhatsApp. Herbert Richmond is quoted as saying about another form of technology: 'Sea power did not win the war itself: it enabled the war to be won' (Mawdsley 2019: 477). In a similar fashion, digital communication did not stop Bristol Airport expansion, but the use of digital media by the anti-airport movement played a crucial role in the rejection of a planning application. The key co-ordinators in that movement caught people's attention by marshalling technical riffs and inspiring a shift in emotion. Although members of the movement were diverse, and the methods, riffs and relationships used by them varied and kept changing, they all shared a common narrative about stopping airport expansion. The movement was more of a process than an organisation, as Latour clarifies:

politics as neither a type of procedure nor a domain of life. Politics is not some essence, it is something that moves, it is something that has a trajectory ... The radical departure pragmatism is proposing is that 'political' is not an adjective that defines a profession, a sphere, an activity, a calling, a site, or a procedure, but it is what qualifies a type of situation.

(2007: 4)

I have written in this chapter about how political communication has a role to play in that trajectory; it works in at least three ways - through culture, rhetoric and advocacy. To move towards a fuller understanding of the trajectory of politics, I need to explain how the communication of riffs relates to how people navigate time and place through rhythms, which brings me to rituals and symbols: the subject of the next chapter.

\section{Notes}

1 In the UK the government ministers sit in Parliament and opposition parties assign spokespeople to 'shadow' them, also sitting on the 'frontbench' to ask questions during Question Time and lead the scrutiny of that department.

2 Interview held by Emma Crewe, January 2012.

3 https://twitter.com/Jacob_Rees_Mogg?lang=en-gb, accessed 1 September 2017.

4 https://data.worldbank.org/country/XO, accessed 12 February 2021.

5 Grant Shapps MP, HC Debates, 12 March 2012, col. 13.

6 See https://grnpp.org/ethnographies-of-parliaments/ for details about this project.

7 http://www.huffingtonpost.co.uk/2012/07/12/tory-mps-told-to-stop-lea_n_1667229. html, accessed 15 February 2020.

8 http://www.stopbristolairportexpansion.org, https://www.facebook.com/stopbristolairp ortexpansion/, and @StopBrisAirport 
9 https://www.n-somerset.gov.uk/news/actions-to-tackle-climate-emergency/, accessed 29 April 2020.

10 https://www.youtube.com/watch?v=HwpB6aLOnVU, accessed 29 April 2020.

11 https://www.ft.com/content/16c15e67-8e5d-30b7-87a9-0b98a3d0d0ad, accessed 24 June 2020.

12 https://www.bbc.co.uk/news/uk-england-bristol-47948702, https://www.northsomerset times.co.uk/news/students-call-on-bristol-airport-backers-to-pull-expansion-funds-16032471, https://www.ft.com/content/16c15e67-8e5d-30b7-87a9-0b98a3d0d0ad, accessed 14 February 2020.

13 https://planning.n-somerset.gov.uk/online-applications/applicationDetails.do?activeTab= summary\&keyVal=PJML85LPMKI00

14 Just as one example: https://www.youtube.com/watch?v=b_C69rCTVEk, accessed 29 April 2020.

15 https://www.northsomersettimes.co.uk/news/bristol-airport-expansion-sparks-protest-16248572, accessed 14 February 2020.

16 https://www.youtube.com/watch?v=M_wOcBlnsKE, accessed 14 February 2020. 


\section{7}

\section{RITUALS AND SYMBOLS IN POLITICS}

Ritual is conceived of as indispensable to religious and royal occasions but tangential to politics by scholars and participants alike. In the 1930s Hocart told us that scholars misunderstand ritual as hocus-pocus, whereas they tend to view the state as founded on economic interests (1970 [1936]: 35). The situation has scarcely changed in political science. A few scholars have looked at ritual in parliaments but nearly all from a functionalist perspective, searching for its instrumental value in a narrow sense. Patzelt considers the value of symbols from within a new institutionalist paradigm. The guiding idea of a parliament, or 'value-oriented principles', need to be symbolically represented to create the necessary emotion for participants to feel committed to the institution, he argues (as cited by Crewe and Müller 2006: 164). He evaluates examples of parliaments symbolising 'guiding ideas': it works well in the French National Assembly where the liberties of citizens are symbolised effectively, but badly in both Canada and East Germany because their values are internally contradictory, so do not impress their publics. The problem with this theorising is that the foundations of the argument are divorced from people's everyday (or at least routine) practices and meaning-making. The theory that when values are aligned with symbols then a parliament is more likely to be effective begs too many questions about both alignment and who defines success. If you consider Patzelt's least contradictory example (France), even there the Assembly sometimes lived up to its ideals and sometimes failed to (ibid: 167). The work of understanding symbols can't evade inquiry into what people actually say and do (or avoid) and when you do this research, you find that the entanglements defy tidy conclusions and universal recipes for improving democracy, even if some common ingredients can be found.

Rituals tend to reveal what is of particular importance to participants as collectives. Some social encounters are significant to politicians even when not ritualised, for example, informal plotting in the corridors. And rituals and symbols of less 
political significance may persist even when less seems to be at stake. However, it is telling that participants start to question them if they find them trivial (or disturbing) and the continual adjustments to rules and rituals occur precisely because they matter so much. Former MP and Foreign Secretary, the late Lord Howe of Aberavon, told the House of Lords how he felt about ritual, mentioning in passing an anthropologist who had interviewed him some years earlier:

I can well understand the concern of people - I have felt it myself sometimes - at the over-elaboration of ritual and dress. On the other hand, I confess to having been attracted by it on some occasions. I designed a uniform for the Chancellor of the Exchequer in which to go to the Trial of the Pyx because I did not see why everybody else should be dressed up and not me. However, we ought to remember that, although we are rightly critical of particular aspects of these things, tradition, history and ritual can serve a real purpose. Emma Crewe, who is after all an anthropologist, goes a little far when she says: 'The rituals are the real stuff that politics are made of. That is an overstatement, but surely our language - the noble Lord, the right honourable gentleman in the other place, my noble friend - is a courteous way of reminding us to respect each other, instead of saying, 'You've got it wrong mate'. It is odd, but important. I do not stand up for every aspect of ritual, but dress is also important. People wear various degrees of strange dress from Annabel's to Butlin's, from the Quai d'Orsay to the Kremlin, for recognition purposes and to tell the staff from the visitors. ${ }^{1}$

Did I go too far when I claimed democratic politics can't happen without ritual? To see how much politics relies on ritual, Engelke suggests we consider what happens when it goes wrong (2018: 207-8). During President Barack Obama's swearing-in ceremony in 2009 the Chief Justice of the Supreme Court read out the words in the wrong order, causing Obama to stumble. His advisors worried that opponents may suggest he wasn't really president. So they re-ran the oathtaking the next day in the White House and significantly, the Chief Justice put on his black robes to signal that he had the authority to perform this less showy version of the ritual. In the competitive world of politics, where the undermining of rival people and causes is rampant, of course the marking of status through ritual matters. Whether signalling the authority of a new president, that a new law has been passed, or a parliament is sitting as a sovereign 'house', rituals communicate important messages to us in ways that are hard to argue with.

Shirin Rai is the only politics scholar to have taken rituals seriously enough to run a substantial research programme on what they mean and how they are gendered (in the Indian, South African and UK parliaments). With an exceptional capacity for interdisciplinarity, she combined a theoretical interest in gendered performativity, disruption and symbolic space with a commitment to rich specificity and broad comparison, to inspire her coalition of researchers to produce unique political science (Rai and Johnson 2014). Rituals show us the institutional 
claim-making, operation of hierarchies and the disciplining of members that is necessary to reproduce norms. But by examining the disruptions, the challenges to hierarchies and norms are revealed as well as the inevitable conflicts inherent in politics (Spray et al. 2014). For more about Rai's work, see Chapter 3.

Meantime, until the 1990s anthropologists sidestepped Hocart's plea for them to look at ritual, caught up in a scientific-like study of politics that impelled them to create taxonomies and systems. At the end of the last century Jonathan Spencer summed up the plight of political anthropology in a seminal article 'Post-colonialism and the Political Imagination', describing the sub-discipline as in a decline offering 'social facts at their most thing-like', the hard currency of anthropological comparison (1997: 3). In neither African Political Systems (1940), edited by Fortes and Evans-Pritchard, nor Leach's Political Systems of Highland Burma (1954), do we find much about rituals or even the relationship between politics, culture and history. Similarly, in research that relied on methodological individualism (e.g., Bailey's Stratagems and Spoils, 1969), the political was opposed to the cultural or symbolic. Few looked at how politics is entangled with culture - with Clifford Geertz (1973) as a rare exception - Spencer points out, doing so in a way that considers our specific historical moment as one of postcolonial dislocation.

Partly as a result of his article, British political anthropology's entanglement with culture has had a resurgence. As Spencer recommends, anthropologists have been writing since the 1980s about how the state is not only created by political institutions like parliaments but by political action within the polity. Taking the uncertainties in claims of representation - one of which is that elected representatives stand for or symbolise their area - means that symbolism can't be brushed aside as peripheral (1997: 11-12). The French anthropologist Marc Abélès points out that:

an elected representative is simultaneously a person and a symbol. Politicians are not only men and women of action; they have the power of evocation. Many rituals are intended to express in material form the continuing identification of elected representatives with their communities.

(2006: 21)

If you consider how the death of Tamil politician and former film star, M.G. Ramachandram provoked riots and even suicides in 1987, with over a million people attending his funeral, then the splitting of politics and culture becomes thoroughly unconvincing (Spencer 2007: 19-20). Spencer's embrace of uncertainty and connections in all directions doesn't take us into a chaotic mess because anthropology offers a rigorous way to study entanglements. We do so by focusing on Malinowski's obsessive empiricism - the study of what people actually get up to in everyday practices - and working out what seems to be significant (Spencer 1997: 15).

Following in Spencer's footsteps, this chapter will consider these neglected processes of huge significance - rituals and symbols. Kertzer argues, 'far from being 
window dressing on the reality that is the nation, symbolism is the stuff of which nations are made' (1988: 6). All political and legal institutions require rituals because all face the problem of securing the consent of those who lose out. The more that is at stake, the more danger there is that the decision might be contested. So, one of the reasons that ritual is politically so significant is that it:

helps societies deal with many kinds of interpersonal conflicts that threaten to poison social life and tear the community apart. Indeed judicial procedures, from the simplest societies to modern nation-states, are highly ritualised. Rites of the law court are not that different from rites of the royal court. In both cases the image of sacrality, of legitimacy, is fostered through ritual, while aggressive behaviour is sharply contained and lines of authority bolstered.

(ibid: 132)

How is this achieved? Kertzer writes about how the process is emotional and cultural; ritual creates an emotional state that renders the substance - the riffs of meaning that I wrote about in the last chapter - beyond contestation, 'framed in such a way as to be seen as inherent in the way things are' (ibid: 101). But this legitimising process, or what Stephen Lukes called mobilising consent (1975), is only one aspect of political ritual. We have to take a look at what happens in practice before concluding what rituals and symbols mean for participants.

Five distinct kinds of ritual tend be required to make politics work: elections, conferences, informal meetings, decision-making and ceremonies of state. I have already written about elections and conferences, and informal meetings are not particular to parliaments (see Brown et al. 2017 for a special issue on the anthropology of meetings), so in this chapter I will focus on parliamentary decision-making and ceremonies of state, before returning to broader questions about political ritual.

\section{Ritualised decision-making}

Ritual can only be studied properly by watching and, even better, participating, to get a sense of how the political, cultural and emotional co-exist. Plenty of anthropologists have done this and written about the rituals of parliamentary or council decision-making in varied cultural contexts - including parliaments in Ethiopia, Europe, France, India, Myanmar, Norway, South Africa, the UK and the US. I have observed ritualised debates in person in the House of Commons, House of Lords, Dutch Senate, both chambers in the Indian Parliament, and the North Somerset Council. I have watched many more via the internet but it is much harder to discern what is going on without being able to look where you wish (rather than just where the camera points), use all your senses and, more significantly, if denied the chance to discuss the significance of events with a range of participants before and after.

Developing the skill of performing in rituals is important for establishing credibility. Abram (2017) takes us into planning committees in Norway and some 
aspects echo my experience of the North Somerset Planning and Regulatory Committee (see the last chapter). In Norway the institution of the council was being produced with reference to an imagined internal and external world beyond the confines of its wood-panelled council chamber. In North Somerset too all the speakers made constant reference to how the councillors were bound by the rules of the council but also its obligations to the county. The Norwegian councils showed maps, charts and statistics, while the politicians invoked various trends, patterns and policies about the area - a constant reminder that 'their legitimacy lies in the notion that they relate not only to their own procedure, but that meetings are primarily about something else, somewhere else'; this is all part of bringing 'into being the council as authoritative agent, and as corporate body', as Abram puts it (ibid: 40-1). They had to learn how to navigate the meetings but also how to read the documents, which are significant for the internal political processes but also for how to relate those in the external world that they are trying to act on (ibid: 34).

The riffs in their planning decision-making rituals were partly to create the very institution that needed the legitimacy to ensure that its authority was seen as legitimate. This process also depended on the position of the officials in both places, as described by Abram:

The requirement to remain calm and appear disinterested is an essential quality for administrative staff, at least in this municipality (and, by all accounts, also elsewhere), and takes on the quality of a psychological trait required for the work ... Public servants must embody a quality of obedience to the council that is temporally marked ... The administration is seen to speak with one voice (formally the Chief Executive's) in relation to the municipality outside, rather than being an assemblage of individuals engaged in internal power struggles or debates. Appearing to be impersonal is thus crucial to the effectiveness of administrators' roles in council meetings, an essential performance of the Weberian separation of powers that helps to uphold the legitimacy of the political process.

(ibid: $38-9$ )

Like Norway, the officials in the North Somerset case had to speak as if in one voice and in prescribed ways and once either the public or politicians were engaged, they remained outside the discussion. They set themselves apart as impartial judges but intervened in the liminal space between public and politicians, and between debate and decision, to remind the decision-makers to discount information that had not been 'tested' by them. Whether leaflets distributed by activists, or speeches by residents, these were unreliable riffs, unfiltered by the impartiality of officials in North Somerset. Of course, the officials couldn't say the same about politicians publicly, even though many of the points made in councillors' speeches were identical to those made by the public, but those working for councils will continually complain privately about how politicians ignore their impartially produced evidence. It is as if in the power struggle between politicians and officials, an 
alliance between representatives and their constituents contaminates the rational process of planning being made orderly by regulations. It is no coincidence that the North Somerset committee is called the Planning and Regulatory Committee, as if to remind potentially wayward politicians to be mindful of the rules.

The rhythms of this planning committee meeting were tightly organised by rules about where different groups sit. This is always the case in parliamentary decisionmaking rituals. The seating reveals the status of the different groups so that politicians sit on opposing sides and the public are usually separated into a spectator area. During this ritualised political decision-making moment the public are excluded spatially by the impenetrability of the documents and assumptions about the unreliability and partially of their views. Officials in the council were elevated on a podium, to indicate their considerable authority during this specific ritual, whereas in the Westminster Parliament they are always tucked away into a box in the background and never allowed to speak. The more politically significant an event, the more officials tend to recede into the background but when it comes to planning sub-committees, they depoliticise it as much as possible in a bid to avoid losing control.

When politicians disagree, then the drama in a planning committee will be found in the performance of their speeches and in the final vote. Any representative politician is likely to mention their constituents in an important speech, partly to establish their authority as a symbol - standing for a specific group of people in a place of supreme value - but also to speak to those they are representing, to signal they are on their side, to apologise to those who disagree, and win further support. In the case of the airport vote, one councillor asked that the vote be taken by name, rather than a show of hands, given the importance of the occasion. This heightened the sense of drama, prolonging the vote by many minutes so that rising excitement (or presumably dread on the part of the airport) gave the final announcement far more theatrical punch. Tactically the councillor leading the debate asked for this knowing that it would be harder to raise their hands on their own in defiance of public opinion than it would if the show of hands was collective. And as individual votes were expressed in support of this motion in sequence, it might encourage the undecideds to follow the herd. It was not only the case that this planning decision could not have been made without ritual; the ritualisation of the decision reveals the moments of greatest political significance.

The main decisions that parliaments, rather than councils, make are to pass laws and this relies on rituals on every occasion. The way the process is ritualised sheds light on how that particular house of parliament functions. Usually the government and opposition parties disagree, at least in democracies where you have a vibrant opposition, so law is always a contest and a negotiation over the meaning and moral value of ideas expressed in a text. As Riles explains, such documents are not just ethnographic objects but in their turn reveal much about processes (in this case of law-making) as well as how ethnographers analyse what is going on in their fieldwork site (2006: 7). Rituals of debate ensure that in the endless series of collisions between different moral outlooks (or potential conflicts where they are not 
given expression) each skirmish has an outcome, usually a victory for the government that is accepted by the losers. The outcomes are usually determined by the party managers through whipping its members to accept both the message and the approval/rejection of the motion.

The performance of riffs and the rhythms of ritualising law-making vary hugely from place to place. The first to look at these events as rituals was Jack Weatherford who wrote about the US Congress as long ago as the 1980s. He portrays these appearances as empty of substance, merely a way of signifying that they are powerful legislators rather than an opportunity for debate:

The normal work day of a member of Congress is spent making series of cameo appearances in the various ritual arenas ... . The politician enters one scene, is coached by a waiting assistant for a few moments, and then performs the role. His particular performance may have no relation to that of the actors who appeared just before or after him, but the pieces will be edited together afterwards by the staff. The important point is simply that he should get his appearance on record. He voted, he came for the quorum call, he asked the question of the witness, he introduced the bill, he co-sponsored the amendment, he spoke the sentence. The staff can issue all the press releases and printed speeches to show that this made him a prime mover.

(1985: 206-8)

So, the rhythms of US politicians' participation indicate the highly individualistic way that they intervene. The point is merely to show up and convey their own words so that they can claim to have represented a position, but not to take part in a discussion. Weatherford concludes that it is the ritual that prevents substantive interaction: 'Congress preserves the format of legislative procedure - the appearance of debate and decision without any of the substance ... The greatest deliberative body in the world has become the greatest ceremonial body in the world' (ibid: 177, 266). Senators are merely aggrandising their position and consolidating their power, so that when they are given an account of their speech afterwards, they can correct it for the Congressional Record into what they should have said rather than what they actually said (ibid: 200-1).

Putting aside for one moment that ceremony is a misleading term in Weatherford's account, because it is usually seen as interrupting the everyday rather than constituting it, the rhythm of parliaments' performances seem to stretch along several continuums:

- from individualistic to intensely social;

- from highly scripted to spontaneous and improvised;

- from dull and cautious to dramatic and theatrical debate.

On individualism, both France and the UK are up the other end from the US. Abélès writes that in the French National Assembly words, acts and objects are 
manipulated in ritual to symbolise the relations between political power and civil society (1988: 393). I argued something similar in Chapter 4 when politicians and civil society activists were scrutinising a bill about shared parenting. Even if the individual peer, Baroness Butler-Sloss, was the hero of the hour as she led the final campaign to amend a clause, the reality behind the scenes was a substantial network of politicians, professionals and activists at work. The social processes of alliance-building and establishing obligations of reciprocity go on before, after and even during rituals. UK politicians in both Houses talk about reciprocity, the political advantage of supporting a colleague on their cause because it will increase the likelihood that they will support you later. Many resist electronic voting in the House of Commons because appearing in person is an opportunity to lobby colleagues and ministers, whether about the vote in question or another matter. Labour MPs were so keen on this process during the Blair/Brown government that they would place endless post-it notes on the lapel of the minister they wished to influence. At all-night sessions ministers looked like they were attending a Greek wedding - jackets fluttering with yellow messages with the exception of David Blunkett whose incredible memory needed no jogging (Crewe 2015a: 44).

In Samoa too politics requires a process of softening those who might oppose or delay:

One of the things that I used to do, because in the budget debate the opposition have their fun, so tactics and everything. I used to take the matters that they have raised and then I would discuss it with them in the lounge during morning tea, afternoon tea, and supper at night. When I would reply, there were very few interruptions because I had already discussed it with them. But some of the more senior politicians will say 'Okay, well thank you for that but just touch on it in your speech so that my district, my constituency who are hearing' (laughter). So, that was a tactic that I used. Samoan politician.

(Corbett 2015: 90)

Improvised spontaneity is unusual in most parliaments much of the time. But it is a feature of some almost all of the time (e.g., House of Lords) and in most parliaments at least a little improvisation is expected when the public are watching. In the House of Commons and the French National Assembly it is the most controversial issues that pressurise politicians into a performance that is especially unpredictable. Abélès tells us about how conservatives clashed with liberals in 1999 when members proposed a law to give legal status to homosexual couples (2006). They battled over the text in highly improvised ways - especially when it got heated, for example, about whether the new status should be an 'agreement' or a 'contract' - and shouted, insulted each other, even burst into tears and had to be restrained from hitting the Prime Minister. So ritual does not necessarily close down the possibility of improvisation; in fact you could argue it provides a structured process within which improvisation and dispute are possible without losing the element required to secure an outcome that is recognised by all participants as 
legitimate. I have tried to comment on the rhythms of parliamentary ritualisation but the riffs deserve just as much attention before I consider how these interweave.

In both the UK House of Commons and Lords politicians make moral arguments in ritualised parliamentary debates 'about how society should be ordered and governed, how resources are controlled and divided up, and what is deemed normal, natural and morally desirable' (Crewe 2006: 94). What they are communicating - their riffs of meaning - are cosmological, in the sense of how people, animals, objects, money and even gods should relate to each other. Again, it is when these become more controversial that both spontaneity, and with it heightened drama and emotion, enter into the arena. Unpredictability in politics is exciting, so the more closely stage managed the rituals are, the less gripping they become. While I was studying the House of Lords, it was the topics that were most connected to their identity that inflamed their passion, and made peers difficult to control for the whips (that is, secure their obedience in voting for their party). Identity was called into question when discussing homosexuality, animal rights and reform of their own house. It was as if traditionalists experienced (a) liberal attitudes to gay sex as an onslaught on Christian family values, (b) protecting animals as anti-countryside and (c) reform of their House as a rejection of their own worth; while modernisers were aspiring for a secular, urban, socially liberal, animal-loving and democratic nation. In recent years in the Commons, it has been nationalism and our borders - whether to let people through them and whether to split from the rest of Europe - that drove politicians into a frenzy. The votes on Brexit highlighted with clarity why these processes of decision-making have to be ritualised. But before I explain what I mean by that, I need to be more specific about the details of UK parliamentary ritualised decision-making.

When the Westminster Parliament sits, everyone in the debating chamber has to comply with a vast catalogue of rules about where to sit, how to move, speak or remain silent, and how proposals (or motions) can be approved or rejected. It is the routinised repetition of rules, the defined hierarchies between participants and the symbolic significance of its substance that make this a ritual. Describing the rules, and symbols within them, of just the Westminster Parliament could consume volumes; in fact the formal 'rules' of the House of Commons can be found online in its 'standing orders'. In 1832 there were only eight, but since then the ideological clashes engendered by universal franchise and the growth of national parties have led to over 200, mostly invented to clarify who wins and who loses in circumstances where attempts at consensus fail to contain the heat of politics (Crewe and Evans 2018). The bible of procedure, known as Erskine May after a former clerk, is guarded by his priestly descendants. It runs to over a thousand pages of close text, explaining the precedents for when rules are ambiguous. I wrote this with one of senior Clerks of the House, Paul Evans:

Erskine May ... sits on the 'Table' of the House as the Bible sits on the lectern in a church - a powerful presence, even when unconsulted. But the ultimate judge of what happens in the Commons is the Speaker, who is the high priest 
whose presence is essential to validate its rituals. As a presiding officer, the Speaker of the House of Commons is generally acknowledged to be an outlier in international comparisons in the degree of discretion and authority they have in interpreting the unwritten - and indeed the written - rules of the House; choosing who speaks (within the conventional ritual), what is debated (within the limits of other agenda-setters) and what is in or out of order. That is in part why so much ritual surrounds the office of the Speaker, from the ceremony surrounding his or her election at the beginning of a Parliament, their role in State Openings, the way in which MPs are required to bow to them whenever they enter or leave the Chamber, to the sometimes insincere politeness with which they are addressed by MPs in the heat of debate. MPs recognise the need to venerate the office of the Speaker, however much they may love or loathe the individual who holds it, because that position is a lynchpin on which the business of the House hangs.

(ibid: 45)

So that gives you an introduction to how proceedings are ritualised. Now I will turn to a narrative that I hope will demonstrate how rhythms and riffs are entangled within rituals.

It can be through the breakdowns in normal interaction that the habitual patterns become clearer. The politics of Brexit (leaving the EU) was one such breakdown for Westminster and the role of the pro-Europe Speaker - as the high priest of the rules of parliamentary ritual - was strained to its limit. When Boris Johnson took over as Prime Minister he did not have a majority to approve his Withdrawal Agreement to pave the way for our exit from Europe. So an antiBrexit alliance formed in the House across his own party as well as opposition parties, to thwart the whole plan or insist that it only happened with Parliament's approval (depending on your viewpoint). The PM tried to duck the need for Parliament to approve the plan by proroguing Parliament. The Supreme Court later ruled this unlawful and the Speaker was determined to protect Parliament's authority in decision-making on Brexit, even if it meant twisting procedural rules. On 12 September 2019 Speaker Bercow said in a lecture outside parliament, 'Not obeying the law must surely be a non-starter. Period. ${ }^{3}$ To make sure that the government abided by the motions passed by the anti-Brexit alliance (i.e., the law), he added:

if that demands additional procedural creativity in order to come to pass, it is a racing certainty that this will happen, and that neither the limitations of the existing rule book nor the ticking of the clock will stop it doing so.

He ignored the advice of the clerks both before and after this lecture (e.g., in his choices about allowing amendments) but the Brexiteers won in any case after Conservatives secured a majority in an election a few months later and voted Johnson's Withdrawal Agreement through Parliament. 
Contrast Bercow's 'twisting' of procedural rules with my narrative about the airport where my own councillor, Steve Hogg, merely 'stretched' them from my viewpoint. In both cases politicians were dealing with highly controversial political riffs - in one case leaving the EU and in the other expanding an airport - and a breakdown in the normal rhythms in part created by new political divisions. The perspective of the winners often shines through in historical accounts so am I being influenced by Hogg's victory versus the failure of Bercow's cause to remain in the EU? Or by my past relationship with these politicians (see Chapter 5 and 6)? Possibly another strand has more influence on my judgement. Bercow was the referee not a player. When politicians make arguments for change, they surely have to be allowed to question assumptions and take their interpretations into new directions. Hogg was testing out whether the airport could be held more accountable for its environmental impact. It might have been a rhetorical tactic, using the art of persuasion rather than a cold clinical statement of policy facts, but that is what political riffing consists of. Bercow needed to perform neutrality as Speaker of the House, to be showing no favour as he policed the rules. Even as an anti-Brexiteer it seemed to me and others that he favoured my side. The emotional problem with this is that my passion for remaining in the European Union was so intense, that if asked to acknowledge this at the time, I fear that I might have stayed quiet. So when a referee takes sides, we can all get implicated in a breakdown in the impartiality of the ritualisation of decision-making.

But it is not just rules that matter in rituals, and render the Speaker, as arbiter of the rules, the most important person in the process of decision-making (including how it is ritualised), but it is symbols that create meaning. Symbols are powerful partly because they combine clear messages but also ambiguity in meaning. The most important symbol in a democracy is the Member of Parliament as the representative of an area. In the UK this is indicated by their name - the Honourable Member for Hammersmith, for example - which has to be used when another member is addressing them in debate. The name of that individual (presently Andy Slaughter) is less important than the area that they geo-politically symbolise: 'a single person is entrusted with the powers of a whole crowd of people, that person can be invested with a power which transcends each of the individuals who delegate him' (Bourdieu 1991: 203). She or he can be an incarnation of the transcendence of the social, Bourdieu suggests, as if an act of magic transforms a collection of people into one body (ibid: 208). That move to speaking on behalf of a collective entails an act of violence upon individuals within the group because it means eliding differences. So, while the claim of representation sounds clear - the Member of Parliament (or Council) will speak for a specific group - what that means in practice is ambiguous. 'Speaking' can be a mode of vocal communication but it can also entail far more - using your voice to push for the interests of a group, a form of advocacy, on the pretence that they can be singular. Politicians are symbolic representatives who can claim that their voice (in the bodily sense) is an act of voice (in a political sense) when they engage in the ritualised decisionmaking and scrutiny within parliament. The Speaker symbolises the House of 
Commons, which makes her/him the most important figure in our parliamentary rituals, but their job is not so much to speak (ironically) as to ensure that others have fair opportunities to do so.

\section{Ceremonies of state}

The ritualisation of decision-making is the process for the alchemical transformation of an idea via a text into a policy, a regulation or a law. This is only possible because we, the public, consent to the authority of the decision-makers. This consent also requires ceremonies - interruptions in the decision-making - to confer legitimacy on different kinds of decision-maker. A leadership election, an introduction to parliament, a State Opening of Parliament: these ceremonies mark the transition of a person, or an institution, to move from one state to another - from citizen to politician for example, or from ordinary building into a sitting parliament. At the same time, ceremonies achieve many other effects too, so the search for a singular meaning is pointless. Some of the symbols and their effects are fresh, some long-standing, so ceremonies not only transport people in the present but they reunite them with cultural or political ghosts. To understand many ceremonies you have to consider their past. Maurice Bloch explains that rituals in Madagascar clearly demonstrate royal power as an important element in the cosmic social and emotional order but this alone does not explain the ritual (1987: 294). To do this you have to consider the specific logic of that particular ritual and how it constructs authority; in this case, the king is a violent conqueror, so the ritual is partly about how violence by the king is justified (ibid: 296).

Bloch is dissatisfied with Geertz's famous conclusion in his book Negara on nineteenth-century Bali that although culture and power were inseparable, ritual did not serve power, rather ceremony and symbolic action constituted the politics of Bali (Geertz 1980). Given that kings (or sovereignty) can use violence with impunity (Graeber 2017: 73) then surely Bloch has a point; if ritual as a performance of culture can't be separated from power, then we need to explain the relationship between them. Giesen argues in response to Geertz that the Balinese king and court are performing a ritual in which the hierarchical structure of the cosmos is recreated (2011: 168). In general, the king's power to do violence with impunity is communicated through ritual, as Bloch points out when writing about Madagascar. But kings can't inspire loyalty through violence towards enemies alone; they also give gifts. Burghart writes about how ritual gift-giving, including to gods, by Nepali kings was a way of constituting their authority until the late nineteenth century (1987: 267-8). That Nepal became more concerned with its citizens than gods, and the kings gave land to the public by endowing schools and hospitals, indicates shifts in power. For our purposes here I'm interested in why the gift-giving was ritualised, rather than a merely technical and practical process, and in his answer Burghart makes it plain how gifts connect to violence through ritual. The ritual representation was emotionally important, inspiring soldiers to bravery for example, in a way that a mere material transaction never could. 
So, let's turn from kings to democratic governments and parliaments. In various explanations of state ceremonies there has been a shift from singular functionalist accounts to more complex, entangled perspectives. Beginning with functionalism, Shils and Young follow Durkheim in seeing the social purpose of the coronation of the UK Monarch as creating social solidarity and an ordered society through an act of communion (1953: 67). The philosopher Stephen Lukes recoiled from their assumption of consensus and the idea that moral values are shared nationally when there is so much contestation about what is good or desirable (1977). For Lukes rituals make social relationships intelligible; they tell the participants and observers how society was, is and will be organised, enabling our capacity to imagine the future. The connection to power is critical in his view because rituals ensure acquiescence and mobilise consent. He even writes about parliamentarians that this is helped by their occasional rebellions: 'The occasional success of back-benchers in checking or even reversing government policies greatly enhances the symbolic effectiveness of Parliament as a mobiliser of consent' (ibid: 209, ftn. 75 and for more see Crewe 2005: 231).

So how do rituals mobilise consent? Rituals have this effect in the House of Lords, whether intended or not, because the party managers face a specific contradiction between the ethos of the place and the disciplinary processes that are needed to get the results they need. Peers are less ambitious than most politicians; most are ennobled after a long career in the House of Commons or elsewhere. They are difficult to discipline (to support the party when they speak or vote) at least in theory, because they are there for life, tend to lack political ambition and learn fast that the House thrives on an idea of itself as independent-minded. Party tribalism is a feature of the 'other place' (as they call the House of Commons) not the Lords, so they claim. And yet peers overwhelmingly vote with their own parties and seem reluctant to betray their colleagues with whom they have usually sat for years. Furthermore, as Lukes argues, the occasional success of the backbenchers in the ritualised political struggles, and the rules stressing the equality between peers as performers, give the impression that they have more power and control than they actually do. Add to the rituals of decision-making, the ceremonies - notably the State Opening of Parliament - and the combination becomes significant. State Opening is an embodied reminder of peers' ownership of their symbolic property (noble titles and ceremonial prominence indicated by their key roles in processions and ermine robes). For some this can be converted into objective power in the nation's board-rooms, media and charities and for others it is a form of cultural compensation for their secondary status as a lower house of parliament, playing second fiddle to the primary house (Crewe 2005). The state ceremonies and the rituals of debate, taken together, provide backbench peers with a powerful disincentive to challenge the status quo.

The specific relationship between status or rank and power within rituals can only be understood by tracing the historical development of that particular place (Bloch 1989: 47). So rather than rushing to reduce rituals to a conspiratorial function, it is vital to understand how and why they capture the popular imagination. 
Or not. When Jimmy Carter, imbued with a modernising zeal, dispensed with the presidential cavalcade and gold braid he was seen as 'lacking charisma, the sacred aura, that presidents should have' (Kertzer 1988: 183). The importance of history to understanding symbols of status can be clearly seen in Myanmar. Language, buildings and even dress are important political symbols in many places because they communicate with incredible immediacy much about allegiances and habitus - whether people's class, ethnicity or place of origin. Renand Egreteau explains that when Myanmar was aspiring towards becoming a decolonised society in the 1950s English was prohibited and non-indigenous designs for the Parliament were rejected. He also writes about dress. Just as the Indian National Congress politicians were encouraged to wear khadi (home-woven cloth symbolic of anti-colonialism), so in Myanmar a similar pattern prevailed:

discarding unicolour suit jackets and ties, male MPs all opted for silk longyis, pinni jackets and gaung baungs on their head, while the very few women elected lawmakers entered parliament coiffed in traditional hairstyle (sadon), wearing colourful eingyi and htamein. The Speakers of the two chambers had also specially designed gowns: a pink velvet robe for the speaker of the upper house, and a black and white one for the speaker of the lower house (New Times of Burma, 1956).

(2019: 691)

However, while successful in stressing distance from the colonisers, Myanmar's postcolonial story becomes one of a different form of colonialism over its own borderlands. The multi-ethnic conference in the Shan city of Panglong in 1947 raised expectations that Myanmar would respect ethnic diversity and equality in a federal system, under a slogan of 'unity in diversity'. Over decades ethnic minorities - the non-Bamar - have felt betrayed. The Bamar majority has dominated, expanding its grip on power through postcolonial state building and military control of politics and land, with civil wars highlighting these inequalities for decades. Until the 2021 coup, the parliamentary rules stipulated that MPs should not wear informal or Western, Indian or Chinese attire - their high status and their indigeneity should have been expressed symbolically (ibid: 685). But when the Bamar MPs wore dress that emphasised their nationalism, it was no longer symbolic of anti-Britishness, it signified their superiority over the Kachin, Shan, Karen, Mon, Rohingya and so on. Meantime, others were encouraged to wear items to indicate which group they belonged to and when you visited the national parliament you were presented with 48 mannequins ( 24 men, 24 women) dressed in the traditional costumes of the groups represented in the legislature. The result was that ethnicity was essentialised at the expense of commonality, portrayed as if it was about traditions and folklore rather than power, land, resources and inequality (ibid: 694).

It is easy to discern that dress is symbolically important in Myanmar because it communicates difference in gender, class and ethnicity, but amongst those possible differences it is ethnicity that has a contemporary pre-eminence in the sense of 
creating habitus in the political domain. So, sometimes symbols will shout in a particular direction. But in other cases you find far more contradictions. To return for a moment to the Westminster Parliament, the meaning of the symbols in the State Opening of Parliament will illustrate this multiplicity of meaning from different perspectives. The event is described as follows on the Queen's website:

The Queen officially opens Parliament with an event steeped in tradition. The State Opening is the only regular event to unite the three elements of legislature - the House of Lords, the House of Commons and The Queen together as the Crown in Parliament. ${ }^{4}$

I spent many months searching for the meaning of the State Opening of Parliament in the late 1990s, asking various people why it was important: peers, MPs, those with ceremonial roles (e.g., people called Silver Stick, Black Rod, the Sword of State, the Cap of Maintenance and the Duke of Norfolk as chief choreographer) and observers. I watched it during rehearsals, from the Royal Gallery, the House of Commons, the House of Lords, in the street, in the backyard where they feed the Queen's horses, from officials' offices and on the TV. It all looked completely different from various vantage points and, unsurprisingly, participants talked about the multiple aspects as if it were many ceremonies.

After months of confusion I finally embraced the multiplicity, ambivalence and uncertainty and abandoned any fake search for singularity. The State Opening of Parliament contains different rituals for different groups of participant (MPs, peers, Royals) as well for staff who are entertained, citizens who are awe-inspired or alienated, and journalists who have to report it. Within these groups you find diverse reactions. The peers who hate it, stay away. Those peers who do attend love the centrality of their House of Lords in the ceremony; they surround the Monarch as she reads the speech announcing the government's political agenda, explicitly underlining that they are just one rung below the semi-divine Queen in the UK social pyramid (Crewe 2005: 208-14). It may be partly a reminder of the cultural compensation for their limited political power, dressed as they are in long velvet robes that speak loudly of their status and ancient association with the land (the ermine fur).

The MPs stand at the bar of the House when the Queen reads her speech, as if inferior beings (in the minds of peers), in a position so demeaning that one told me he was worried that the Commons may abolish it in a fit of indignation. But MPs are busy with their own feelings of superiority during the State Opening. They begin by mocking the Monarch's representative - the Gentleman Usher of the Black Rod - who knocks on their door three times to demand their presence in the Lords. The door is slammed in his face. Once let in, for decades former Labour MP Denis Skinner reliably made an acerbic remark, like 'here comes Puss in Boots'. MPs then amble from the Commons to the Lords in a relaxed fashion and stand at the bar while the Queen reads her speech. They look on with disdain at the peers (and by implication the Monarch), the parts of the constitution with only 
residual political power in practice, as if they were indulging their elderly parents. The public look on in awe, loathing or indifference from a distance, watching the procession in person from Pall Mall or the various ceremonies in the Palace on the TV, perhaps amused by the drama of the basement being checked for gunpowder and a government whip being abducted and kept in Buckingham Palace for the duration. A sizeable global audience watch it on BBC news or Facebook. ${ }^{5}$ It is clear that the State Opening is a different ritual for different groups - perhaps even for individuals depending on where they are sitting that year - and even the rituals within rituals themselves are involved in shapeshifting.

Kertzer points out that symbols can be multivocal - their ambiguity is part of their power (1988: 11). This, along with their non-verbal quality, makes it possible for rituals to produce quite different experiences, meanings and emotions for those involved. Our mistaken expectation of language is that we will easily understand the sense intended, whereas the reality of human interaction is that misunderstanding is common. Symbolism tends towards the opposite. We don't expect to receive clear messages through symbolic communication whereas in practice we hear and see powerful messages conveyed that have an effect, even though we don't necessarily take much overt notice. Political ritual is far from an unimportant relic from the past - it reveals power, emotion, meaning and political significance. As a tool of research scrutiny, it is incredibly useful for showing us where to look.

\section{Rituals, solidarity and violence}

It is rituals that organise the riffs and rhythms of political work into processes that create meaning and power. Rituals are social processes with relationships at the heart that are politically, emotionally, socially and culturally significant - the more significant, the more they seem to be regulated. Rituals can't operate without rules (especially to regulate the rhythms, that is, what the bodies and voices do) and symbols (to convey significant riffs of meaning through words, objects, gestures, dress or people transformed into, for example, a 'Black Rod' in the case of the UK). This usually means rituals will be charged with symbolic meaning, regulated by rigid rules - with severe consequences for breaking them - and involved in reproducing, challenging or creating new socio-political hierarchies. So, if you want to know how important an event is, then measure the extent to which it is rule-bound, disciplines participants' and tells them through symbols what to say, do and think. Without symbols we can't think:

Only in terms of gestures as significant symbols is the existence of mind or intelligence possible; for only in terms of gestures which are significant symbols can thinking - which is simply an internalized or implicit conversation of the individual with himself by means of such gestures - take place. 
So even in everyday interactions, our gestures are symbolic - charged with more than their literal meaning.

Communication is never merely an exchange of nuggets of preference or ideology as if these could be a perfect reading of the world. As Bloch puts it: "the message of ideology cannot be maintained simply as a statement ... because it is by its very nature in contradiction with human experience in the world' (1986: 195). So, communicating ideology needs ritual to deal with these contradictions because the performance provides an opportunity for these symbols to become gestures. However, I am not making a functionalist argument here about the whole. Ritual is not resolving a contradiction so that the system works, it is embodying the paradox of being both an individual self and socially connected, and shapeshifting between identities, that all actors share. This paradox sounds like magic, the conjuring trick of kings, politicians or any people for that matter, experiencing their world as both individuals and members of different groups at the same time. But prestidigitation is a conceit, human action merely looks like a conjuring trick but it is not. The emotion of being both individual and social does not feel like magic because humans are more capable of living in paradoxes than they are of describing them in language. Ritual is an expression of this paradox.

My portrayal of ritual may remind us of Leach, as it 'serves to express the individual's status as a social person in the structural system in which he finds himself for the time being' (1954: 11). But systems theory, structuralism and post-structuralism have long been deconstructed by anthropologists (e.g., Olivier de Sardan 2005) despite their persistence in other social sciences that are trying to avoid individualism. How to think about individual freedom and structural constraint remains unfinished business for anthropologists. If we bring ritual back into the study of politics, there is still more work to be done in understanding two aspects of this individual versus structural paradox. It begs the question: for individuals, what is happening emotionally - both consciously and unconsciously - as they perform political rituals and how does this vary within and between different groups? Florence Faucher-King addresses this in UK party conferences (2005: 6-7), (and for that matter Andrew Beatty does so more broadly in everyday life in Indonesia, 2019), so there are plenty of fruitful directions for inquiry. Plus, they don't abandon the need to analyse constraints at the same time, both subtle and forceful. For example, on conferences Faucher-King suggests:

It offers a stage for a public but pacific expression of competing ideologies. It reminds citizens of what constitutes a 'proper' way to behave in politics. It celebrates political commitment and political activity. For parties it is an annual rite of renewal. In its ritualised conferment of legitimacy on political elites, it highlights the sacred dimension of politics.

(2005: 11)

The "'proper" way to behave' sounds like a form of light discipline. It can be when the conflicts are expressed with relative calm, as was the case when Faucher-King 
was observing UK politics. But more ferocious conflicts within both main parties in the UK have been starkly exposed during all political rituals - debating and voting in the House, party conferences and elections - so that insisting on 'proper' behaviour can also entail not just symbolic violence, but actual violence. It was after the challenge to Corbyn as leader (through a no confidence vote and leadership election) that the Labour Party witnessed a surge in violence between its members (mostly not physical but verbal or digital, and always emotional) not seen since the years of Militant Tendency. Corbynistas were accused of bullying and anti-Semitism and they counter-charged their critics with allegations of politically motivated tactics to bring down Corbyn. Both sides were fighting for control of the party but lashing out in retaliatory ways as both their party and their sense of self were attacked.

This kind of polarised party conflict is even more lethal in Bangladesh and no amount of ritual has created enough cohesion to fix it. In fact, the rituals of elections, and parliamentary debate, law-making and scrutiny, have entrenched or even inflamed rather than reduced conflict. Since 1971, when the former East Pakistan won independence from West Pakistan, the two main parties - Awami League and the Bangladesh National Party - have been locked into bitter power struggles. The point of ritualising elections is to ensure that all sides accept the result. However, in many countries, including Bangladesh (and the US in November 2020), they don't because they allege that their opponents rigged the election, thereby casting doubt on the legitimacy of the other side when it has claimed to win and assumed government. For this reason, politicians in Bangladesh developed a unique way to reduce this risk, introducing caretaker governments from 1990 to administer elections. However, in 2011 the Awami League-run government abolished this recent tradition on the grounds that it was out of step with modern democracy (Ahmed 2020: 188). This led to a boycott of the 2014 election, which has transformed Bangladesh into a one-party state since then (in 2018 the opposition won only seven seats).

We can't do without rituals in politics, any more than we can dispense with language, but you can't make them do what you want either. They can, but do not necessarily, resolve contradictions, create consensus, mobilise consent, shore up existing hierarchies or include/exclude groups. Rituals are not tools to be employed to do your bidding because they emerge out of the interaction between people - their riffs and rhythms - and in politics it is usually extremely difficult to marshal everyone into the new directions you want them to take. Different identities, interests and aspirations mean that people inevitably want to go in different directions, leading to power struggles within and between groups, so the results of politics are usually unpredictable. In the next chapter I will attempt to pull all the threads together to speculate about why parliamentary history unfolds as it does.

\section{Notes}

1 Lord Howe of Aberavon, HL Debates, 3 November 2005, col. 317.

2 https://www.parliament.uk/business/publications/commons/standing-orders-public11/, accessed 15 February 2020. 
172 The cultures of parliaments

3 Bingham lecture: https://www.youtube.com/watch?v=vMv69cNgUes, accessed 15 February 2020.

4 https://www.royal.uk/state-opening-parliament, accessed 19 February 2020.

5 BBC News Facebook page got 1.5m views of the 19 December 2019 state opening (https:// www.facebook.com/BBCPolitics/videos/484756375507331/) and BBC News in general reaches 394m, according to 2019 figures: https://www.bbc.co.uk/mediacentre/latestnews/ 2019/bbc-international-audience-record-high, accessed 19 February 2020. 


\section{PART III}

\section{Politics with the dial turned up}

We all do politics but politicians do it with the dial turned up. Parliament is a place where you find a magnification of politics, awash with crowds, contradictions, rituals, symbols and significant decisions. The complexity of the work of politicians means that they face overlapping and often conflicting pressures, demands and audiences to a far greater intensity than the rest of us do. The more politicians in democracies try to consult and engage, the more diversity and pressure they experience.

Part I was about the social life of politics. I described the complexity of politicians' work and how this politics is entangled with social relations, both inside and outside parliament. Elections are the starting point. In democratic political worlds they are the process for creating relationships between politicians and voters. So, in Chapter 2 I explained what anthropologists have discovered about elections from the viewpoint of both politicians and voters. Once in parliament, voting is used to determine agreement and disagreement between members of parliament. I concluded that voting is fetishised as if it is a form of magic that can make democracy on its own but it can't; I argue that deeper democracy needs other processes to be taken as seriously too. In Chapter 3 I moved onto one of these other processes of socio-political interaction - the representation of people by elected politicians. What happens to the claim of representation in practice for different groups? In Chapter 4 I looked at examples of politicians, and others, aspiring to scrutinise government - who gets involved, what do they do and what are the consequences?

In Part II I inquired into the cultural life of politics, the continuities and breakdowns in rhythms and riffs in political work, concluding that it is rituals that signal which events are of particular significance. In Chapter 5 I offered a systematic way to research the rhythms of political work - what minds and bodies do in different configurations across time and in different places. Still looking for ways to be systematic about studying the entanglement of culture and politics, in Chapter 6 I laid out what anthropologists have to say about the content of politicians' ideology, 


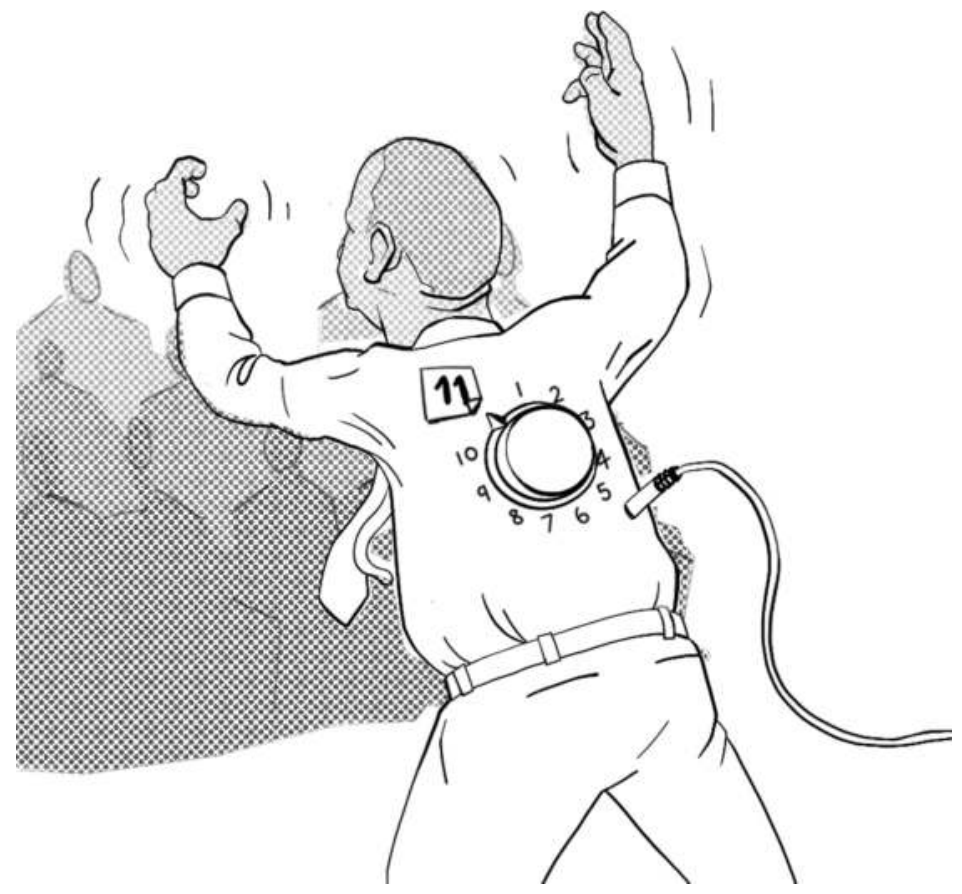

FIGURE III.1 Politicians do politics with the dial turned up.

rhetoric and advocacy - the riffs of meaning that are so vital for achieving change through politics. As more and more entanglements emerge, a researcher can get overwhelmed by the volume of data: so then rituals are methodologically useful, as I explained in Chapter 7, for discerning what is of political importance. Rituals give us a sense of proportion.

In this final part 3 of the book I want to look at research in politics and the politics of research - or power and knowledge - pulling the threads together and considering how you know what to find out about if you are a politician and what to look at as a researcher. We are all political sometimes, but politicians can rarely escape walking between friends and foes and navigating power struggles. Looking at this will help me explain in the final section what, how and why politics becomes magnified in parliaments so that one way of describing it is that parliamentarians do political work with the dial turned up. 


\section{8}

\section{A SENSE OF PROPORTION}

Politics involves strange processes of alchemy. We need to know what ingredients are involved but also how they mix, fuse and play together. In democracies the essentials are elections and winning support, representation of interests, administration of the state, and scrutiny of government. To work out how this happens in everyday culture-making and power struggles, I have suggested that you might want to consider politics as a form of work, organised by riffs, rhythms and rituals. When seen as work processes that are endlessly entangled with each other, we can begin to analyse what is going on between people from their multiple points of view. The final task is to grapple with making decisions about where to focus our gaze and how to study the entanglements with a sense of proportion. I need to disentangle the entanglements.

\section{Everyday political work: walking between friends and foes}

If everything is entangled with everything else, what is the starting point? In the rhythms of politics, we have to understand what acts as triggers or, as Veena Das puts it, critical events (1995). The same is true of processes. Given that events are entangled, you have to decide (as a matter of historical inquiry) what to study with what: what is the unfinished business of earlier processes? You have to begin somewhere and then account for your starting point. I began my explanation of parliamentary democracy in this book with voting. Democracy is always more than voting but without that specific process, it loses its credentials in the eyes of participants; without voting, you can't make a claim to be living within a democracy, in at least its most skeletal form. You would also lose much of its drama.

The vote is a blunt expression of taking sides on an issue but also declaring allegiance with one group or another. When it is a citizen voting for a politician, they are deciding who to be ruled by so the stakes are extremely high. To be seen 
as credible, the rules should be observed, cheating has to be stamped out or concealed, and any inconsistencies regulated or obscured. Technology and ritual in combination, policed by experts, ensure that the results of the vote in an election are believed and adhered to. The technology of voting is entangled with the performance of elections as a social and cultural event. The form this entanglement takes is going to be different across places because political histories create varying cultural habits. Melnikova describes how in Russian elections a celebratory space combines with disciplinary processes that are threaded through with specific historical associations of past authoritarianism for participants (2013). So, historical associations are always found but are different in content between places. You can't fathom the reaction of protest to a rigged election in 1983 in Nigeria without considering longer-standing models of political and ritual power, according to Apter, with a 'more indigenous understanding of Nigerian democracy', as I explain in more detail in the next section (1987: 490). The violent protests after an election were seen as irrational mob tribalism by outsiders but from his vantage point as an ethnographer, Apter realised that they made sense as both symbolic drama and political action.

Making an argument for taking account of cultural, political and historical specificity is easy. It is universal theorising that presents a challenge for anthropology. But it is not an insurmountable one. The focus on specificity was a reaction to the grand theorising up until the 1970s. It led Kurt Vonnegut to complain about cultural relativism - that everyone was treated as if they were the same by anthropologists teaching him in Chicago University, as if denied both individuality and the possibility of judgement (2009: 9-10). Since then the challenge for anthropology has been theorising about commonalities but doing so in a way that makes meaningful allowance for difference and individuality. We need an open mind about where commonalities might be found. Apter's point that local traditional political and symbolic power play a part in the political realm in Nigeria can also be found in societies perceived as 'modern'. When the UK held a referendum about whether or not to exit the European Union (EU), the phrase used to win support by those wishing to leave the EU - 'take back control' - appealed because it implied echoes of the early days of the welfare state or even further back to times of imperial power. The return to a past when Britain was in control of itself and of many foreigners, symbolised a promise about a future (one where we would not be ruled by foreigners) without saying so directly. When the leavers won the referendum, even though the remainers controlled the government, people behaved as if it was an election rather than a referendum. The Prime Minister resigned and eventually the campaign leader, Boris Johnson, took over in what almost felt like a coup. So, tradition can be used politically in the UK, Nigeria or anywhere else.

To return to voting: it tells us about a fundamental process in democratic politics - the taking of sides. Votes reveal sides but can also create or change sides in various ways, so this is a process that can create drama and emotional intensity. The same referendum on exiting the EU in June 2016 split the country into two new sides until the UK finally left over three years later. But more often sides are more 
enduring - political parties tend to dominate parliamentary politics although their fortunes fluctuate, swing or collapse. These groups, and factions within them, have been extensively studied by political scientists, usually seen as teams of individuals who come together to control government and form voting coalitions (Saalfeld and Strøm 2014: 371, 373). However, there is often a gap between empirical descriptions about party organisation and theoretical models (ibid: 392-3), with the latter relying heavily on typologies rather than inquiries into why party members operate as they do. From an anthropological viewpoint, they are stripped of sociality and culture - the very sources of their potential for emotional intensity.

Anthropology can help us to understand how and why people take sides, what they do about the disagreements that emerge and why politicians get so emotional about politics. I have written about how party loyalty in the UK House of Lords defies political scientists' assumptions (Crewe 2005). Parliamentary scholars have tended to assume that discipline relies on a mix of self-interest and rule-following. But I have found that peers are remarkably obedient to the whip - an instruction to support their party, usually in a vote - not in response to inducements or threats, but out of loyalty. The late Earl Russell, a Liberal Democrat peer, explained what loyalty consisted of in practice:

When I think of my loyalty to my party, I think of the people with whom I ran up steps in Oldham in a heat wave or who held the torch for me when I looked for numbers in Winchester Cathedral Close in the rain and in the dark. If I were to vote with this Whip, they would not understand me. ${ }^{1}$

Another long-standing party member explained in similar terms why she obeys the whip that it is worth repeating from Chapter 2: 'It would be very difficult to be disloyal to party people. I can't bring myself to go into the division lobby with the enemy.' 2 Peers spoke about voting with those they have worked with (or for) to avoid the shame of betrayal. They are influenced by the other peers they sit next to in the chamber or fellow party members they have canvassed with in the streets; they don't want to let them down. Ignore the emotions involved in the public performance of walking into the division lobby with friends, thereby distancing yourself from your political foes, and you fail to understand party politics in the Lords. Political sides are created by relationships - including emotions felt towards others - and not just ideology.

Party loyalty in the UK House of Commons is equally perplexing if you are wedded to rational choice theory or new institutionalist assumptions that politicians obey their party when it is in their own self-interest. Backbench government MPs have voted against 'the whip' more often in every parliament since 1945 and yet the bribes/threats are in theory still available. Despite widespread portrayals of the Westminster Parliament as weak, Cowley and Russell lay out the evidence of increased divergence by backbench MPs from the policy standpoints of party leaders (2015: 125-6). This is not just revealed in defeats in the voting lobby, but in 'retreats' - when the government withdraws from a position because they 
anticipate that they will lose - and in their amendments to bills or motions in response to backbench pressures. This increased backbench (and sometimes opposition) power emerges out of huge shifts within the UK Parliament: less exposure and deference to their party leaders; local parties flexing their muscles; as well as more expectations and involvement in constituencies both in person and via social media (Crewe 2015a: 125-39). The whips in all parties have had to drastically change their tactics. They no longer use blackmail (much), violence or even angry rebukes; they are following in the footsteps of their Lords counterparts (Crewe 2005: 160-80), acting not as bullies but as intelligence agents gathering information about backbench opinion to avoid defeats or HR managers coaxing their flock to stay in pens with no fences. Whips are not bullies; they are now closer to spies in both Houses. Far from reducing the drama in voting within the Westminster Parliament, its unpredictability makes it even more exciting.

Voting causes or throws into relief society's divisions in a democracy. More profound mechanisms of inclusion versus exclusion are found in definitions of citizenship and voting rights, for example, when people are kept off the ballot paper in the first place. In the UK those typically deemed unfit for voting, and so excluded from the electoral roll, are those who have committed election-related crimes, children (usually under 18), prisoners, the 'mentally incompetent', homeless people and non-citizens. Obviously different countries define citizenship, or belonging to a nation, in their own way, with profound consequences on the claims and rights on specific groups, including the right to vote. With the rise of nationalism, citizenship is being used to exclude huge swathes of many populations: in Myanmar Burmanisation gives Bamar people automatic rights, while the citizenship of non-Bamar people has to be fought for and of the Rohingya has been systematically denied for decades. If you can't vote, you know you are not a full citizen in the eyes of the state.

So, voting reveals much about the sides in politics - who is in agreement versus disagreement; included, excluded; and supported or opposed. But it is not the only process. Sides are also created by the claim of politicians to represent sections of the population. I have written about how individual parliamentarians represent sections of the population in Chapter 3 but it is not only individual politicians who claim to represent others. Political parties represent the interests of groups - they stand for the working class, a specific ethnic group, an independence movement or an ideological position. As Bourdieu points out, to understand how political parties represent sides you have to consider them alongside each other - you can only be left wing if there is a right wing: 'Political parties, like tendencies within these partners, have only a relational existence and it would be futile to try and define what they are and what they profess independently of what their competitors in the same field are and profess' (1991: 184).

In another sense parliaments represent all these sides - they are a 'kind of spatial projection of the political field' (ibid: 186) - which is depicted in debating chambers as political parties are always grouped together. It was in the Constituent Assembly set up during the French Revolution that the Monarchist supporters sat 
on the right of the President while the Revolutionaries sat on the left. So, although this section is about how politics involves walking between sides (friends and foes), it is also about sitting and standing with them and talking against the other side. Once one party is in government, the other sides oppose in part by scrutinising what the government does through critique, complaint and subversion. The fantasy that 'evidence-based' policy-making means politicians can rise above 'tribal politics', or the taking of sides, has become commonplace (Sanderson offers a UK history of this, 2002). But I have argued in Chapter 4 that the consideration of 'evidence' in political processes, whether making policy and law, going to war or administering departments, offers no relief from the taking of sides and amplification of emotion in work when it gets political. Evidence is always open to contestation so political and legal processes are needed to enable judgements to be made.

What has changed in the last few decades, since Bourdieu remarked on the inter- and intragenerational loyalty that made parties relatively stable (1991: 199), is that political parties have become extraordinarily unstable. After many years of contest between various right or left parties in France (the Socialist Party, the Republicans, the National Front), the shock victory of Macron's La République En Marche party in 2017 with half of its candidates coming from civil society, is an illustration of volatility. Half of the representatives elected to Bolsanaro's political party in 2018 in Brazil had never stood for election before. The rise of nationalist parties across the world - either mainstream ones with the Bharatiya Janata Party governing India or smaller ones looking for independence such as the Scottish National Party - is challenging the establishment of political sides in profound ways. Not only does democracy require organising ideas, parties, resources and narratives into sides, and factions within sides, but the pace of shifts in these divisions is accelerating.

Maybe we can find some respite from this division in the areas of parliament that are seen as most collaborative? In the UK the obvious candidate would be select committees (Crewe and Sarra 2019). Is the dial turned down when the aspiration of House of Commons select committees is to present a united front? Here both politicians and officials claim that members of select committees put aside political differences, despite belonging to different parties and pursuing individual agendas to promote their own career, to publish unanimous reports as a group based on the consideration of evidence. However, the practice departs from the claim; members often infringe rules or norms by grandstanding, speaking for too long, giving speeches rather than asking questions, leaking reports to the press, turning up late or leaving early without giving notice, demanding to ask a question without warning, asking someone else's question, or claiming attention at the cost of other members. As in all political work, committee members have to recognise each other's multiple purposes for taking part in committees rather than assuming that these infringements are merely bad behaviour. MPs might attend that committee out of interest in a specialist topic, to scrutinise and influence (most often government), to represent issues that are important in their constituency, to feel busy and 
important, or at their party's bidding. The chair has to allow MPs the time to speak for any combination of these motives and sometimes will not necessarily know which audience is uppermost in an MP's mind. If one member gets too much air time, then others may become resentful. So, norm-breaking will elicit a reprimand from the chair or, more unusually, the clerk. Their political party membership influences these disciplinary processes because the chair can admonish more easily if the wayward member is in their own party, especially if close to that member, and so will do so directly. But if the offender comes from another party they might ask one of the wayward member's allies to do it. So even in select committees the multiplicity of goals, motives and pressures means that conflict management is an inevitable aspect of the work. The rhetoric of select committees is collaborative but the reality can be conflictual, just as tribal politics, often assumed to be highly conflictual, turns out to have plenty of alliance building across parties behind the scenes. Politics is about walking between friends and foes whether the arena is habitually conflictual or aspires to be collaborative.

What about alliance and enmity between politicians and the public? The position of parliamentarians is profoundly affected by the low esteem in which they are held by the public. People beyond the bubbles created by national political worlds - especially those in and around parliaments, whether politicians, journalists or lobbyists - perceive politics as conflictual, nasty and immoral. When they see or think about politicians, they discern, or assume, that they are hypocritical, double-dealing and corrupt. Whether residing in rural Ethiopia or urban Houston, politics is seen as having hostility at its heart and politicians are bad people, allegedly. People within the bubble experience it, in contrast, as intoxicating, addictive and galvanising - full of possibility, power and excitement, heroes and villains, and friends and foes.

Commentators once had a more favourable view. In democracy the assumption is that we are offered choices and it is the taking of sides with one group of politicians against the others that surely creates a restless activity that can, famously in the words of Tocqueville, accomplish miracles. But once the election is over it is as if we take sides against all politicians in our cynicism towards the whole lot of them. This partly happens as a reaction to how politics is portrayed by MPs and journalists alike. Political parties and their members make claims about their own brilliance and the failure of their opponents at every opportunity. Politicians magnify these claims, beyond the subtler versions many convey in private, trying to impress the public that they should support their side with votes, money or other kinds of support, and distrust the other side. Then journalists focus on this antagonistic side of politics - it is good copy at a time when newspapers are struggling to survive - or even join in to promote those politicians they admire and bring down those they disdain. In the UK, as examples, John Rentoul's reporting on politics is filtered by admiration for former PM Tony Blair, Michael Crick rated former PM Teresa May highly, while Owen Jones portrayed former Labour Leader Jeremy Corbyn as the most honourable leader in Parliament. These journalists are honest about their dispositions but others feign neutrality, as if reporting politics without the filter of their own views. Those pretending to be impartial confuse the public 
with their apparently neutral damning critiques. How are readers supposed to distinguish between critical scrutiny of politics by the media as opposed to journalists doing political work on their own account? It is partly as a result of misreading the way politics in parliament and in the media is entangled that we - the citizens take sides against all politicians and even politics itself.

Taking against politics would mean taking against ourselves. Politicians become an exaggerated version of the rest of us. We all do politics in this sense of taking sides but politicians contend with larger networks of friends and foes, more public censure and exposure 24/7, more expectations from a dizzying array of groups, and more serious competitive power struggles. Politicians deal with faster rate of change and a public realm that is becoming increasingly turbulent and unstable. Dealing with this magnification of politics is emotionally demanding but addictive, both ego-boosting and ego-destroying - sometimes alternately and sometimes simultaneously. Central to these changeable struggles is the force that creates what Tocqueville wrote about as the restless energy in democracies: power.

\section{Disentangling power}

In theory anyone can become a political queen/king in a democracy. As soon as the leaders close the space for powerful scrutiny, critique and opposition, then the struggle for power, and therefore democracy, weakens or even dies. But power is difficult to write about because everyone - different academic disciplines, politicians, activists - has a different view about what it is and how it operates. The way you define power is a political strategy in itself.

While thinking about power in popular discourse, people tend to oscillate between individuals and systems. If focusing on individuals - kings, chiefs, politicians - the popular idea is of power as a quantifiable force or a commodity that can be acquired by individuals, welded, used and abused, especially by leaders of groups, organisations or countries. When a systemic or institutional view is offered, in contrast, it is the structure and disciplinary power of rules that tends to be at the core of theories on power. Anthropology used to be confined by what Gledhill has called these two straitjackets of methodological individualism versus structuralism (or systems thinking) and both are relevant but have problems if employed exclusively. We need to understand both the autonomy of individuals to pursue political strategies and how these relate to social and cultural frameworks (Gledhill 1994: 134). He cites Bourdieu to argue that social actors are like 'musicians whose improvisations are neither predictable in advance, a product of conscious intent, nor simply a "realization" of a structure which already exists in the unconsciousness' (ibid: 135). We need to be able to explain why and how particular individuals (prophets or party leaders) are persuasive at specific moments. Gledhill argues convincingly that we have to understand popular political imaginary in specific places if we want to get to the bottom of power and powerful rhetoric.

Those politicians who realise that their riffs and narratives must marshal and create the right associations out of people's political imaginary are the ones who do 
well. To return to Apter's example, he writes about how a politician in Nigeria won support in part by criticising the record of the other party (summoning bad memories of their failure); making promises about benefit (creating visionary images of better futures); and inviting others to make claims about his power (using traditional symbols of power) (1987). The performative political success of this candidate, Ajasin, was partly attributable to a speech he made near the town's shrine when standing for election in 1983. He did not just make a powerful argument for rejecting a bad government, he introduced local women leaders who marshalled powerful symbolic offerings that are used in other contexts. The chairperson of his party's women's group offered him kola nut for long life and alligator pepper to make his speech more efficacious. Her actions implied that he not only had the support of the King but that in making these offerings to the candidate, benefits would flow if he was voted in and he would become a powerful patron (ibid: 498). When he lost the election - to everyone's disbelief - a riot ensued, with Ajasin's supporters accusing the winning side of rigging the election and destroying their property. The winners were rounded up and made to swear allegiance to the party that lost, not just to its local candidates but to its national ones, and subsequently the judiciary reversed the vote in favour of Ajasin. How did he get this result? The speech was a critical event and, as Bourdieu puts it, in politics saying is a form of doing (1991: 190). And in the rhythms, riffs and ritualisation of this event he drew on various ghosts of past and future. These ghosts and symbols play important roles in the magnification of politics.

The importance of ghosts, as in associations or traces of the past, are found in the rhythms, riffs and ritualisation of politics in any part of the world. But it is only through specific examples that we can explain and fully understand the significance of these ghosts. Bloch has written about how royal rituals in Madagascar gain significance through adapting non-royal symbols because the construction of authority needs to transcend normal life without losing a connection to it (1989: 187-8). So too political rituals rely on non-political symbolism to have rhetorical power. To put it another way, you can't have power struggles without culture. I have written about two examples of this interdependence between power and culture in the Westminster Parliament. Law-making in any legislature is created through the performance of riffs, rhythms and rituals and rituals are vital for ensuring that the results stick:

Legislation is re-formed on the anvil of debate, and each debate is not only a (modestly) creative workshop, it is also a contest and negotiation over the meaning and moral value of a text. While there is a theatrical quality to rituals of debate, more importantly they constitute a web of cautionary principles conceived to ensure that in the endless series of collisions between different outlooks, each skirmish has an outcome (usually a victory for the government) that is accepted by the losers. 
Law could not be made without moral communities (usually political parties) aligning themselves to the acceptance or modification/rejection of the rules and values encoded in a document. So it is not just traces from the past but images of the future that create law and politics. The words in a bill, or proposal for law, symbolise action in the future to reorganise society or reflect existing economic, political or cultural change. To make law, law-makers need to arrange their bodies in a sanctified chamber at set times, ready to speak in prescribed ways, and take part in these rituals of debate, before the law can be approved (or not). So far this is true of any legislature but the second example of the intertwining of culture and power - implied by the claim that the government usually wins - is only true of some political systems.

In the UK, but not necessarily elsewhere, the relative powerlessness of some parliamentarians is compensated by symbolic capital. The House of Lords is grand and awe-inspiring, with its luxurious cathedral-like chamber, its regal public rooms and the deference shown to peers. Those impressed by their own titles of nobility, which they are awarded on joining the upper house, and being at the centre of dignified state ceremonies with close proximity to the Monarch, feel humility towards the institution, and the lowliness of their position within its corporate grandeur. They express their humility in their courtesy toward one another and their submission to the collective 'will of the House'. This elevated social rank is a contrast to their extremely limited power as a house of parliament. They can only revise legislation, asking the government to think again, and have positions as junior ministers in government. The elected House of Commons is the primary chamber, to which they must always defer, even if individual backbench peers can gain considerable influence and even persuade the government to revise the text of bills.

The experience of disjunction between status and power, whereby social rank compensates for lack of political clout, is shared by backbench MPs. Matthew Parris reports that as a new MP 'only slowly does it sink in that though the world will doff its cap to you ... and though the local newspaper will print your thoughts on any subject ..., nobody is actually taking any notice' (2003: 241). I am not arguing that the status of most parliamentarians is created with this intention, as if anyone could do such a thing, but merely that the effect of politicians' status is to encourage acquiescence. However, MPs' reputation is in a decline and so too is their obedience to the whip and while this could be a coincidence, that seems highly unlikely. So, some MPs are more powerful than others and none are powerful all the time. The UK politicians in powerful positions - the ministers - have a grip over their government departments but to different extents as there are hierarchies between departments and within them. UK journalist Isabel Hardman relates a junior minister's frustration with being surveilled and treated as inferior to the most senior one, the Secretary of State:

'I feel as though I've been tagged by the Probation Service,' she joked, explaining that her time wasn't her own, and that no one really wanted to 
hear about the whizzy policy ideas she'd brought into the department. A few minutes later, a departmental press officer appeared at her elbow to 'help' us with the coffee we were having. Naturally, the whole meeting become somewhat pointless, as the minister felt as though she was being monitored and was careful about what she said. Over the next few months, little was seen of this minister, buried deep within the bowels of her ministry by an overbearing secretary of state who clearly didn't trust her.

(2018: 126)

Meantime party leaders are losing the loyalty of the backbenchers in their party. The UK Commons Speaker who presided from 2009 to 2019, John Bercow, accentuated the enhancement of backbench power by giving them more opportunities to speak. He granted time for the opposition to ask 100 s of 'urgent questions' every year, in contrast to the occasional one allowed by previous speakers. In the complex power shifts that can be observed in Westminster, status and power are going in opposite directions.

The power of politicians relative to each other in other countries is so various it is difficult to generalise but we can be sure that the political and cultural are entangled. The entanglement of power and culture is illuminated by thinking about what happens when power hierarchies are ruptured. For Jastinder Kaur making sense of coups in Fiji requires a look at how power struggles can't be freed from ethnic conflict but shouldn't be reduced to this either (2017: 31, see also Chapter 5). Both the 1987 and 2000 Fiji coups were a refusal to accept the result of general elections. At first glance, the undercurrent of tension in Fiji before the first coup was about different populations - indigenous Fijians and Indian Fijians sharing power, heightened by the formation of a coalition government. Although the 1987 coup in Fiji involved no violence against the politicians, and the military did not call for mayhem, Suva was overrun with ethnic violence with the result that 12,000 Indians left the country (ibid: 90). The main coup instigator, Colonel Rebuke, used the slogan 'Fiji for Fijians' but gave several reasons in the months to follow for this action - a measure against disorder, the will of God - but finally came back to the nationalist impulse: Fijians must be ruled by Fijians. Through affirmative action, the civil service, police, military, universities and various economic sectors were indigenised. However, after the constitution was reformed, and non-ethnic seats were given more emphasis than ethnic ones, the Fiji Labour Party (FLP) won a majority in the 1999 general election which brought Indians back into Parliament with an Indian, Mahendra Chaudire, as their leader and then PM. A year later a part-Fijian businessman, George Speight, led a coup, holding the government hostage for 56 days, which became talked about as the 'unfinished business' of the previous coup (ibid: $91-8$ ).

Kaur points out that to call this 'ethnic conflict' would be a simplification, colluding with the way it is portrayed by the politicians for political reasons. It is telling that when one coup supporter was challenged after the 1987 coup to account for their support, they said: 'Oh, the Alliance Party will give us everything 
we need, we just have to ask for it, and they'll give it us' (ibid: 115). The coup was about restoring the power of the Fijian chiefs, against a different power base (partly created by trade unions), as much as (or even more than) ethnic nationalism. But the relationship between the politicians and people was complex. On the one hand, ethnicity inflamed a political rhetoric used within a power struggle between elites rather than drove the coup from the bottom up. On the other hand, when Indian and Fijian political leaders discussed the possibility of a government of national unity, Fijians in the capital went on a rampage targeting any Indian they could find (ibid: 121). The coup and its aftermath put a considerable strain on Indians as a people, but that human story was lost in the midst of the bigger politically useful story of Fijian-Indian conflict (ibid: 128). The people faced suffering, but it was the politicians (or those with the scope to do so) who skewed events towards a specific form of difference (ethnic, racial, gender).

Different theories of power in parliamentary studies tend to emphasise either agency or constraint - the possibility of a barrier to action - often without a sense of the simultaneity, contradictions, or paradoxes. Explanations about gendered power are a good example. Few social scientists would deny that female politicians around the world experience barriers to get into parliament and misogyny when they get there. Political scientists Lazarus and Steigerwalt have written about this in the US. Donald Trump ran a campaign against Hilary Clinton in 2016 labelling her 'a nasty woman' and in the 2020 Democratic primary elections Elizabeth Warren was deemed 'unelectable' (2018). The position of women politicians in the US may have improved since House member Coya Knutson received a letter from her husband in 1954 (encouraged by party leaders) asking her to give up politics and return home. But Lazarus and Steigerwalt provide ample evidence that women continue to be subjected to harassment and even death threats, negative stereotypes, endless comments about their appearance, and assumptions about their weakness and lower qualifications (ibid). Women are perceived to be less electable and face more primary and general election challenges. Everyone assumes that voters might discriminate against them, so even when they don't, women have to compensate by working harder and more collaboratively. As a consequence, women communicate more intensively with constituents than their male counterparts, procure more 'earmarks' for their constituencies (spending bills that designate money for specific projects) and introduce more legislative measures, even if they are less likely to get them through Congress (ibid). But is it 'as a consequence'? Why then did Representative Maloney (New York) focus on her constituency, mostly by trying to legislate to its benefit, even though she was 'safe', that is, had a large majority so was likely to win at the next election?

In another context UK women MPs' narratives about why constituency work is socially and emotionally important to them point to their sense of identity wanting the fulfilment of esteem within their community not just votes for the next election (see Chapter 3). It is as if the power struggle dial is turned up even higher for women politicians and not necessarily in a good way. A more complex feminist analysis of women's higher commitment to constituency work might look 
at how they are socialised into an ethos of hard work, constrained by gender inequalities and determined to challenge them at every turn, but also impelled by emotions and interests that are not only gendered but shaped by other aspects of their identity. It could be argued that emphasising women's vulnerability (as Lazarus and Steigerwalt do, 2018), without the corollary of their strength, as if they can be reduced as social actors to mere women, is an expression of the very inequality that they are observing without naming it in relational terms. Women's experience of power is not only gendered but a navigation of class, race, age, sexuality and ability. A feminist theory of power needs to go beyond this oscillation between domination and resistance and listing intersecting structured inequalities. Again, it needs to deal with simultaneity, contradiction or paradox whichever is relevant to the specific example - and the only logical way to do this is historically.

To analyse how gendered power operates in a specific context we need to know what is going on with whom, where, why, how and when. To generalise we need to compare different cases and account for similarities and differences. Consider the difference between women members' experience of the UK House of Commons and House of Lords. In contrast to my expectations, if you trace what happens between people in the two Houses in an everyday sense, you will find clear patterns (with exceptions) that women thrive in the Lords but face continual misogyny in the Commons, even though the ratio of women to men is not very different (Crewe 2014a). In the Lords women thrive in a culture that discourages heightened aggression while in the Commons MPs reproduce a highly competitive culture where many women feel alienated in the more macho events and excel when the less rewarded work of collaboration or the caring of constituents is expected:

Surgery meetings often involve discussion of intensely personal, emotional and painful matters and the women MPs seemed more at ease in this role than male MPs. But this work, like much women's labour in the domestic domain, is under-valued. Furthermore, as Judith Butler puts it, 'performing one's gender wrong initiates a set of punishments both obvious and indirect, and performing it well provides the reassurance that there is an essentialism of gender identity after all' (1988: 528). So gender inequality and difference in the UK Parliament are found in culturally constructed ideas about what it means to be feminine and masculine, the way gender is performed by both women and men, and power relations between and within the House of Lords and House of Commons and the outside world.

(ibid: 677-8)

My explanation remains plausible in 2020 as far as it goes but it privileges a gendered pattern and misses out other vital aspects of the power struggles which politicians have to navigate. Let's mention how younger women MPs are subjected to sexual taunts, working class women face snobbery, and black women MPs deal with far higher levels of rape and death threats on social media. Hardman found: 
'not only was it well known in Westminster that there were sex pests in the corridors of power; it was also acknowledged that there was a culture in which women, particularly younger women, were treated as lesser beings, sex objects who deserved comments ranging from the smutty to the obscene' (2018: 147).

The challenge is to describe a multitude of concurrent processes, each one operating as traces and possibilities in the others, as well as the relationships between these elements. In the end this becomes partly a methodological question, so I will return to this in the final chapter, where my response to this challenge is found in the role of imagination in learning with others. But before I discuss learning, I have one more suggestion for analysing the relationship between the elements and that is to use the analogy of dials. Dials are useful for writing about democratic politics with a sense of proportion.

\section{The democracy dials}

This book is about entanglements - between identities and different aspects of political work; between sociality and culture; and between traces of past power and visions for the future. To navigate these entanglements MPs have to shapeshift between audiences, demands and places. To find a way of understanding the continuities between these shifts, I have suggested that we investigate rhythms, riffs and rituals in our detective work within parliaments. But we still have to make choices about what to prioritise in our inquiries, not in the sense of finding causes and effects but creating theory that helps us understand the specific and general human condition and experience. As Julia Paley argues, we need to get beyond both the typologies and narrow cause-and-effect theories of political science, but also anthropology's focus on people's imagination without accounting for our choices, to see how democracy is both practical and imagined with a sense of proportion (2002: 471). Her definition of democracy is highly political:

the discourses labelling regimes as democracies are strategically deployed by groups with strong interests in particular definitions and contested by others differently situated in relations of power. Noting the constitutive nature of those struggles, rather than establishing an a priori definition of democracy, is one of the central contributions of an anthropological approach.

(ibid)

Rather than spending too long on defining, listing and testing how variables relate in cause and effect patterns, I am more concerned to think about the links and intensity of related elements and what they mean and do for different people. So how can we do this? Introducing the idea of 'dials' might force us to explain more systematically why specific relationships, processes or events are more significant than others. To put it another way: how, when and why is the intensity dial turned up?

Politicians do politics with the dial turned up because they walk with even more friends and foes, and engage in more bitter power struggles, with more at stake, 
than the rest of us. The dial of intensity - of emotion, pleasure, pain, cultural significance, political impact ...- is higher for politicians meaning that what they do tends to be magnified compared to ordinary people. Politicians doing politics is magnified beyond others doing politics, rather like mental illness is an amplification of the kinds of disturbance that everyone feels for short periods of time. Their relationship with the world is like a multi-dimensional hourglass with the politician placed in the narrow neck, squeezed by people from every direction. They are involved in decisions that affect whole nations and even beyond. It is always the case, irrespective of time or place, that when a great deal is at stake political events organised by the state are highly ritualised. When a parliament is being opened, law is being fought over, or the Prime Minister questioned, then the importance is conveyed by ritual - with its symbols, hierarchies and rules - because ritualisation is a way of dealing with intensity. In research terms, ritual is a good indicator for the potential of the intensity dial being turned up high.

In other ways, you find variability. While the demands on elected representatives to solve problems faced by 1000 s in constituencies has been growing in recent decades in most countries, at the same time the gaze of the media and citizens on them has intensified. What politicians do, or fail to do, is under a microscope magnified and then chewed over before an audience of millions. Digital media is transforming political relationships in ways we are only just beginning to understand. In countries with a free press, the public used to rely on print, radio and broadcast journalists to inform them about what was going on in parliament through interviews, commentary and debates. As journalists developed a more critical and less deferential approach (to put it politely), political parties increasingly employed press officers and special advisers to defend politicians (or, to put it impolitely, 'spin doctors'). The digital revolution has enabled bloggers and politicians to communicate en masse to the public directly. In countries with no free press, some people are getting access to information about politics for the first time. Politicians seem increasingly tempted to use social media to disclose secrets, win favour with potential supporters and to attack their opponents. (With the Covid-19 pandemic, and severe restrictions on face-to-face interaction, most had no choice about turning to digital online communication.) They receive savage attacks in return that may be no worse than the poisonous letters they once found in their postbag in substance, but the volume has increased exponentially. In most countries women politicians are even more disparagingly treated than men by journalists and on social media, and especially women belonging to minority groups. Twitter and Facebook have accelerated the cycle of news so that while a week was a long time in politics in the 1960s (according to British PM Harold Wilson), a few hours is now the equivalent. 'MPs are just ordinary people, and if they don't come in here with the skin of a rhino, they'll find a way to self-medicate,' MP Liam Bryne told a journalist (Hardman 2018: 161). The more politicians use social media, the higher the dial goes up.

The context for this intensity dial explains why it is higher for some MPs than others, for those engaging more on social media but also those representing populations in urban centres where social interaction is accelerating, for example. 
The German sociologist Rosa argues in his tour de force Resonance that the impact of social acceleration means the pace of change has increased and we are under pressure to do everything faster. It is not just human desire that impels this acceleration, but also the way society is developing; to keep the prevailing economic system going, it is assumed we need innovation, growth and acceleration (2019: 409). We fear we might be left behind, and we get addicted to competition, so we collude with the acceleration: 'we must run ever faster in order to maintain our place in the world' (ibid: 415). This is true for all of us, but whatever affects society in general is amplified in parliament. Politicians increase their reach but democratic politics takes time, so politicians can't keep up - they become fire-fighters not leaders.

What is the significance of magnification and acceleration? Graeber and Sahlins suggest that 'it is the ghost of divine kingship still hanging over us' and 'apparently exotic tribulations of bygone monarchs still find their echoes in forms of ultimately arbitrary power that still surround us, like so many bruised and indignant deities, in national politics to this day' $(2017: 458,464)$. This is so familiar to us because kings don't only exist on the national stage; we recognise them in our own homes. Kings, or modern day politicians, are a mix of human and superhuman - magnified versions of the rest of us - and we hate (or sometimes adore) them for it. As John Dunn puts it, the idea of democracy implies that in human political communities it ought to be ordinary people (the adult citizens) and not extra-ordinary people who rule' (1992: v). Giles Brandreth (former MP in the UK) told the BBC that fellow Conservative Ann Widdecombe (another former MP) marched him out of first class to second class when travelling by train, advising him that it was better if MPs did not set themselves apart. ${ }^{3}$ And yet, once citizens become MPs they can only survive by adapting to extraordinary work and so becoming different, and that difference so far has mostly consisted of more frequent and visible engagement.

Even when politicians have turned the intensity dial up, the public remain disappointed or even resentful towards them. People react to the dissatisfaction with democracy by calling for one of two options. They either want their political leaders to be sacked or political institutions to be reformed, mirroring both popular and political science obsessions with individuals and systems in political worlds alongside a neglect of relationships. The unfinished business of developing democracy across the world - shifting from a shallow dissatisfying form of democratic politics to a more sophisticated deeper form - will surely be found in new relationships and processes, not new leaders and structures? The skill and understanding of leaders are all important but not in the sense of accomplishing change as superhero individuals, rather in their capacity to deepen relationships within and between groups in political world. Accountability is not achieved by individuals but in relationships. So this is the second sense of my democracy dial. While politicians might long for the dial to be turned down on expectations, exposure and censure, citizens want democracy to address their demands - the democracy dial needs to go higher in the sense of accountability.

This assumption about the need for deeper democracy was the contention of a programme I created with colleagues in the UK, Bangladesh, India, Myanmar and 
Ethiopia. ${ }^{4}$ Taking Appadurai's idea of 'deep democracy', we noted his point that grassroots movements are finding new ways to combine local activism with global networking (2001: 25). Since he wrote that two decades ago, both Extinction Rebellion and Black Lives Matter, social movements demanding action against global warming and the murder of black people respectively, have emerged as powerful examples. States need to find ways to respond to these demands of civil society without insisting on their co-option by government. Rather than assuming that democratising is about changing individual politicians, reforming parliaments or insisting that civil society serves governments, we assumed in this new programme that change was needed in the relationship between parliament and society (Diamond 1999: 18). What this means will vary from place to place. We were interested to hear what citizens expected out of democracy and this relationship between politicians and people in different countries. Mandy Sadan, one of our Co-Investigators, explains, 'It is difficult to conceive of a flourishing democracy without more concerted attempts to listen to and address the profound distrust, social stresses and political marginalization experience by many of Myanmar's ethnic and religious minority groups' (2016: 2).

What did we assume about the relationship between democracy, development and conflict? Democracy in a shallow sense - merely electing representatives through the ritual of voting so with the accountability dial turned down - is no guarantee that citizens' rights will be fulfilled. Many governments within democracies have a history of using violence against those who may be in part expressing demands for inclusion. Democracy can even deepen social divisions and exclusion (Spencer 2007) and bring risks of intimidation and violence, for example when women's participation increases (Crewe 2014a). We did not assume deeper democracy would necessarily lead to peace or faster economic development either. As DFID (now FCDO) points out, a strong democracy can decrease or increase the risk of ethnic conflict, by allowing the legitimate expression of grievances: elections can often provoke violence, particularly in newly established democracies. Citizen engagement too is no guarantee for deepening democracy: it can lead to more responsive states but equally it can exacerbate elite capture, clientelism and patronage (DFID 2010: 51, 56).

We were determined not to idealise democracy but to respond to the urgent need for a detailed understanding of the politics of a country when recommending or implementing reform - or even re-imagining politics with a new sense of history - so that solutions respond to fast changing contexts and do not neglect process in the rush for results. We chose to work mainly in two countries that are important to the UK government's aid portfolio: Ethiopia and Myanmar. We wanted to create opportunities for national scholars in those two countries to undertake their own historical and cultural research on parliaments within democracy. Research has an important role in the scrutiny of democracy and the promotion of citizen engagement. We hoped that research on the relationships between elected representatives and the people they represent would generate ideas for combining representative and participatory democracy in more imaginative, 


\section{Who is an MP for the Kunama? Mitiku Gabrehiwot, Mekelle University}

The Kunama are a minority ethnic group with special protection under the Federal Democratic Republic of Ethiopia's constitution. Since 1992, the Kunama established their self-governance with elected representatives from local to national levels. At the moment, there are 202 representatives at sub-district level, seven at the district level, two at the regional level and two at the federal level (one in each house of parliament). From observation of their interaction, we found that the level and intensity of participation of the representatives at the sub-district and district level are both high. The way that representatives are scrutinised reveals a specific form of edgy intimacy; it is a form of social criticism in a cultural setting because they all live together. Since the representatives live and socialise with the people in the same area and eat what they eat and joke about what they joke, the people use jokes, sarcasm and at times ridicule of representatives as a way of scrutinising them in their own way. They tease their big bellies, a common reference to corrupt city-dwelling MPs.

Given the location of the Kunama (in a remote area of Western Tigray where the Tigray Liberation Front established a stronghold in the 1970s), they adopted the Bayto, a local constituency, the function of which is the same as parliament. Bayto is a space in the neighbourhood - a common space - and is even called the local parliament. Accessible by all, the physical space of Bayto is the most common space next to church compounds. This created a sense of belongingness among the people which makes discussion 'natural'. The success and acceptance of representation differs from local to the national levels. The physical space at the regional and national parliament level tend to intimidate MPs from disadvantaged regions or marginalised ethnic groups. Representatives at subdistrict and district level, on the other hand, are familiar with, and comfortable in, the setting (physical and social) and so perform better in people's eyes, for example, engaging in discussion from a position of knowledge. Local representatives are well versed in the language and ritual of the Bayto since it is cemented in the culture, while the regional and federal MPs are required to behave according to the designed protocols, making representation questionable. It makes people ask whether the culture and discipline of the parliaments is inclusive at all. On the other hand, representatives at Bayto are closely watched, supervised and at times, corrected by the council of elders, a social unit responsible for most socio-cultural matters at the village level.

From an agro-pastoralist perspective, representative democracy is a new arrival. Traditionally, the Kunama are less stratified, even classless, and membership of a given class / elite is less attractive. According to the elderly, unlike the Highland Ethiopians, the Kunama had no titles attached to individuals, no matter how accomplished an individual may be. The idea of representation in democracy in general, and parliament in particular, is a new phenomenon. Representation demands education and other skills that are not equally or fairly distributed. For the older generation, the education given to the youth makes them qualified for political roles but at the same time it means that the older, wiser people who know what is best for the Kunama are being sidelined. For the Kunama, representation should be more about 'wisdom' than political consciousness.

Given the rough history of the Kunama in their dealings with the state, representation is a sign of a healing process. If not part of it, they know they will be left behind. The Kunama see representatives as a sign of belongingness in the state but not as people who listen to them and address their issues on a regular basis. The values and mission of the general public are defined, drawn and re-drawn by elders who are more charismatic than elected representatives.

FIGURE 8.1 Who is an MP for the Kunama? Mitiku Gabrehiwot, Mekelle University. 
FIGURE 8.1 (Cont.)

Representatives are more about the fulfilment of state 'obligations' than adhering to democracy, more ceremonial than substantive and fashionable rather than of necessity. For the Kunama, the parliamentarians are go-betweens between the state and the collective identity of the people, but only superficially. However, representation serves two basic unintended purposes: that the healing process of the people is being expedited through belongingness to the state's democratic institutions and that inclusion in the federal structure is granted. For the Kunama, while the physical representation is welcomed and fulfils the structure, what it means and what impact representatives bring, with or without the watchful scrutiny of the council of elders, is less significant. Overall, the concept of representation is, therefore viewed from a collective angle rather than an individual MP's perspective; more symbolic than substantive and more structural than functional.

* This research was funded by the Global Research Network on Parliaments and People in SOAS as part of the AHRC and GCRF Network Plus Programme AH/ R005435/1

creative and systematic ways with a better sense of their specific historical and cultural significance. Just as Stacy Pigg found in Nepal that vernacular ideas about what 'development' means emerged out of people's relationships with each other (1992) - so that city-dwellers and elites within villages are equated with modernity - we assumed that the meaning of democracy shapeshifts across the world. We created opportunities for scholars and artists in Ethiopia and Myanmar to probe vernacular ideas about democracy and parliament's role within it by giving grants for them to inquire into politics. Figure 8.1 shows an example of what one these scholars, the anthropologist Mitiku Gabrehiwot, found about the way the Kunama view their politicians.

Colleagues across Bangladesh (Ahmed 2019 and Ahmed 2020), Ethiopia (Ayenew et al 2019) and Myanmar are beginning to reveal a spectacular range of cultures in their local and national political worlds, further enriching the scholarship on politicians and parliaments that I have inquired into within this book. I will not steal the thunder of those who are yet to publish their work; Mitiku Gabrehiwot is the exception because we are working in a new coalition together on a comparative ethnography of parliaments in six countries and I could not resist giving you a tiny glimpse into his research (with his permission, of course).

This cultural and political diversity does not preclude comparison. There are three processes that are worthy of inquiry in all democratic parliaments: (a) the sociality of parliaments - as found in the work of elections, representation and scrutiny, as examples - that I outlined in Part I, (b) the culture of parliaments - with its riffs, rhythms and rituals - as I explained in Part II, and finally (c) the democracy dial. The democracy dial can be seen from two contradictory viewpoints whichever country you are in, so is really two dials. From the viewpoint of politicians in democracies, they do political work with the intensity dial turned up high by exposure to multitudes, competitive demands, power struggles, contradictions, antagonism and emotions. We 
all do politics when we engage in the public realm, but politicians do it with the dial turned up. They might benefit, and therefore so might those they represent, from turning it down. Indeed, turning the intensity dial down might leave more room for reflection, depth and focusing on the more urgent priorities.

From the viewpoint of citizens, I have argued, we might view the democracy dial rather differently. We might want more engagement with parliaments and politicians - turning the dial up to work towards more consultation, discussion and accountability. From our viewpoint, the democracy dial is currently too low because engagement is superficial, infrequent or partial. We might want more thoughtful, reflective engagement with our own MPs and between politicians and people more generally. The challenge for all of us, whether in Ethiopia, Myanmar or the UK, is working out how we can turn these dials in opposite directions at the same time when we have yet to learn how to navigate entanglements and contradictions with equanimity. Rather than measuring democracy by its appearance, perhaps we could judge it by the quality of its relationships between politicians and the people. Let's have less aggressive noise and more compassionate resonance.

\section{Notes}

1 Earl Russell, HL Debates, 13 October 1998, col. 1324.

2 Interview with Emma Crewe, spring 2000.

3 Today Programme, BBC Radio 4, 20 October 2012.

4 For details see https://grnpp.org/partners-research/, accessed 13 February 2021. 


\section{9}

\section{IMPROVISING TOGETHER}

I realised how much improvisation was required in both politics and research when chatting to Tom Goldsmith, presently Clerk of the Committees, in Portcullis House café. This café is the main meeting place for politicians, officials and visitors within the estate of the UK Parliament. Tom is one of the officials with a ringside seat on Parliament, astute powers of observation and an ethos of discretion, which makes them the perfect informants about MPs. A prominent MP walked up to us and seeing my grey pass (which should have meant I was a member of parliamentary staff) started joking with Tom, warning me that he was unstable. They had been on a committee work trip together so knew each other well. Tom kept trying to intervene to halt this banter and finally managed to say, 'this is Dr Crewe from London University, she is doing an academic study of MPs.' The MP hardly paused. In a fraction of a second he was transformed from jovial, chatty mate leaning over us into upright back-straight, highly dignified important person, showing respect to an academic with formality, politeness and reserve. He offered his hand and announced with solemnity, 'Dr Crewe, it is delightful to meet you, if I can help in any way please do get in touch,' handing me his business card and disappearing fast.

I looked at Tom in astonishment. He patiently pointed out the obvious: all day long MPs are making judgements about how it is appropriate to behave with those in front of them - one minute being chummy with a clerk he knew well assuming from my pass I was an official too, the next showing respect to an academic who was planning to write a book. But as Bourdieu points out, such an encounter is suffused with history: 'human action is not an instantaneous reaction to immediate stimuli, and the slightest "reaction" of an individual to another is pregnant with the whole history of these persons and of their relationship' (Bourdieu and Wacquant 1992: 124). Generally even the reaction of strangers to each other, in this case an MP and an academic, emerge out of their taken-for-granted dispositions informed by their experience of other 


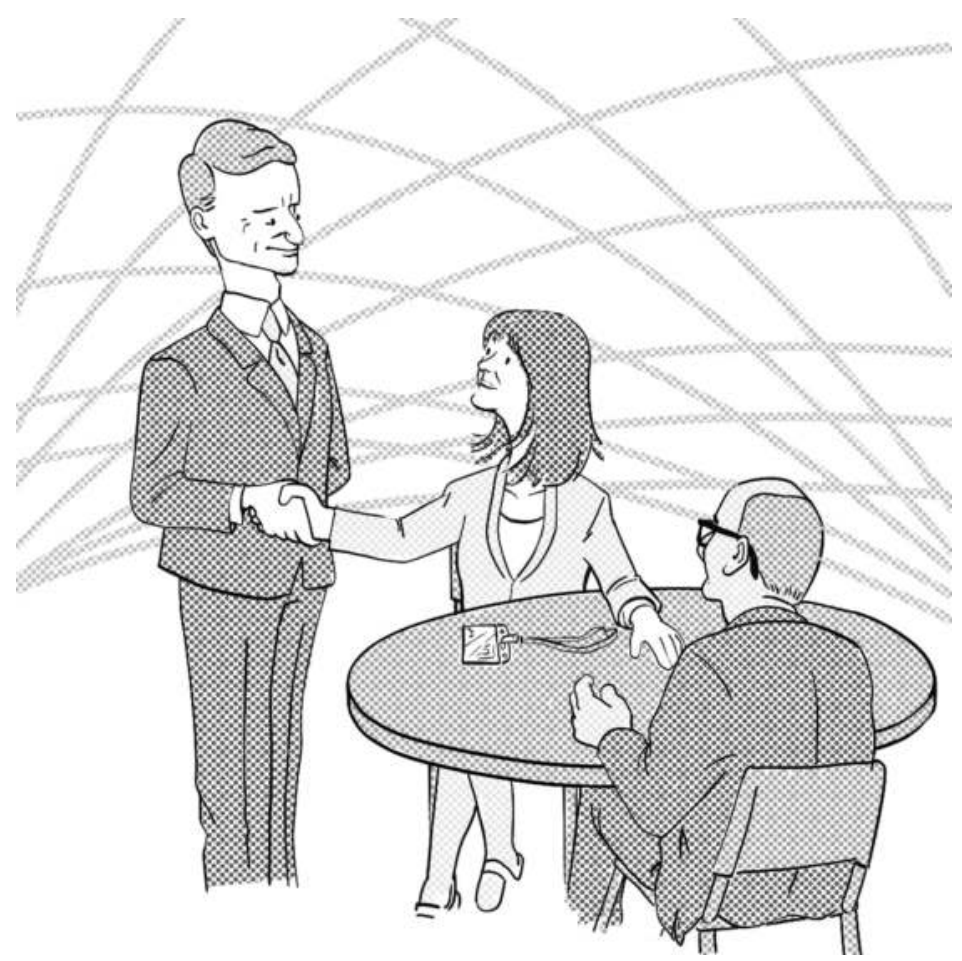

FIGURE 9.1 The improvised learning of researchers and politicians.

politicians and academics. It is always both an individualised and social encounter. The skill required to act is not merely to size up another individual; you have to read that individual in that specific encounter as a representative of a social group with a history, purpose and network. You have to react in the moment but with a sense of history and anticipation of likely impact on each other at the same time.

Why is this story about Tom, an MP and me significant? It was at this seemingly trivial moment that I realised what I was studying - the shapeshifting work of politicians: how they not only improvise from one relationship to another in a moment but respond to various pressures at the same time. But it also revealed much to me about how anthropology research unfolds: unevenly, through improvisation and by learning with people. I could identify with the MP's shapeshifting because I too make endless tiny adjustments as I navigate my relationships with others. That brief encounter changed my research because it helped me realise what both politicians and researchers are doing.

\section{Researching as learning and (in the fullness of time) advocacy}

Anthropologists don't so much study people as if they are objects as learn with them. Ingold explains, 'we observe not by objectifying others but by paying 
attention to them, watching what they do and listening to what they say. We study with people, rather than making studies of them' (2018: 11). I argued in Chapter 1 that this collaborative way of doing research requires interdisciplinarity, reflexivity and taking account of plural perspectives, but also being frequently critical. So even if intending collaboration, at times it can become conflictual. The devil is in the detail with these processes: hard graft is needed to achieve this kind of learning across disciplines, across self and other, and across conflicting viewpoints. But it is also necessary to develop a sense of proportion about what is significant. You need to look at many small things in order to develop an understanding of the big things. So, this work of learning with people (research) deserves a whole chapter of its own. Improvised research is not only obligatory for anthropologists, but is what politicians are doing in their work continually: it is a vital part of effective leadership. If politicians were better researchers (and researchers more savvy about politics), perhaps the administration of states might improve.

My starting point is to take one's own ignorance very seriously and assume that knowledge is found everywhere. People tend to be expert about their own lives; that is why anthropology has a participatory sensibility. Abélès clarifies: 'Anthropology proceeds in a different way than philosophers in their critique of sovereignty, not least because it dives into daily lives and inverts the focal point by privileging a bottom-up perspective' (2014: 92). Anthropologists aspire to challenge hierarchies of knowledge and the assumption that superior expertise resides in the Global North, urban elites or centres of learning, or that people far from those controlling capital remain in ignorance. We try to avoid stamping our own assumptions on others without noticing that we are doing so: 'In striving to transcend a view of the world based on the premises of European culture and history, anthropologists are also encouraged to look beneath the world of appearances and taken-for-granted assumptions in social life in general' (Gledhill 1994: 7). In any country you find different types of knowledge and everywhere, Olivier de Sardan points out, you get technical and scientific knowledge co-habiting with social, magical knowledge - in Europe as much as in Africa (2005: 160). You can become more even-handed in valuing knowledge by taking expertise in the Global South seriously but also by treating those in the Global North as people to learn with as well. Abélès had a seminal influence on the anthropology of parliaments by taking politician informants at home as seriously as those in foreign places, finding the exotic in the familiar, and injecting history into comparisons between different political worlds (2000). Just because his native France, for example, seemed wellknown to him, he did not shortcut the process of intense observation across different sites in a political space. When doing fieldwork in one department of France, it was only by travelling around extensively that he realised how some candidates became eligible, in the eyes of voters, as a result of their places in networks of kinship relations (Abélès 1991: 263).

My next assumption is that interdisciplinarity leads to more interesting theory than a narrow attachment to one discipline. Interdisciplinarity works better if we begin with an intense respect - a curiosity and an assumption of value - towards 
other disciplines. So sweeping assumptions that science produces more rigorous findings than humanities is an unhelpful comparison, for example. Physicist turned philosopher Thomas Kuhn taught us long ago that shifts in paradigms occur when there are too many contradictions in the established scientific way of thinking, and both old and new paradigms can be complementary and logical within their own terms (1962). The history of science doesn't invalidate science, but all current theories will eventually require revision or refinement (Bernstein 2010: 37) and some scientific theories are better for explaining certain phenomena or questions than others. Science, social science and humanities shift as culture does, after all they are embedded in culture - as Jewett explains in US history, from the civil war to the cold war (2012) - so all knowledge is both embedded and provisional.

Social anthropology has variously described itself as a science, a social science and a humanity over the years, emerging with a different way of describing itself in the US and Europe. But there appears to be a general agreement in contemporary debates that anthropology is found at the intersection of all three, even if my personal inclination is towards the humanities. Anthropology has the advantage of being in conversation with many disciplines so can gain from the capacities of each. Arendt wrote that sciences easily prove their substantive worth, but it is history and humanities that 'find out, stand guard over, and interpret factual truth' (1977: 257). What Ehrenzweig wrote about art can be extended to politics: good relationships can transform when creativeness entails giving away parts of our self, and then taking back into ourselves the accretions stemming from interacting with others (1967: 105). Through arts and humanities, we can understand the cultural processes, emotions and aesthetics in everyday politics and their role in transforming relationships. Although anthropology often resides in social science faculties, I'm with Ingold in thinking of writing ethnography as more art than science:

In thickening our descriptions, and allowing a real historical agency to the people who figure in them, we might want to qualify the sense in which these accounts could be considered to be scientific. Ethnographic description, we might well say, is more an art than a science, but no less accurate or truthful for that. Like the Dutch painters of the seventeenth century, the European and American ethnographers of the twentieth could be said to have practiced an 'art of describing' (Alpers, 1983), albeit predominantly in words rather than in line and color. Theirs is still a standard against which we measure contemporary work.

The describing of what we see and hear is taken seriously in anthropology, not just the theorising in the sense of explaining how and why, and in any case one spills into the other. You can't explain what is going on without a strong sense of its meaning and impact, which leads you quickly into serious theoretical questions and puzzles.

All social sciences are concerned with the basis of generalisation. Induction is about observing data to test a hypothesis and building the best theories out of it 
while deduction involves inferring the only possible theory in an inquiry. Deduction begins with a rule and reaches a specific conclusion, while induction begins with the observation of specific instances from which to then generalise. However, of course any approach begins with theoretical assumptions and anthropologists prefer to be far more participatory than most social scientists, aspiring to follow puzzles that bubble up because they matter to their informants. So it might be more accurate to conceive of the anthropological research approach as abduction in the sense that the pragmatist philosopher Charles Peirce proposed $(1931,1958)$. An abductive inference is also about coming to the best available explanation (like induction) but can be conceived as an ongoing, iterative and emergent process throughout the research rather than an event that takes place towards the end. The process of an inquiry begins with a puzzle - or an incomplete set of observations and conclusions, both specific and generalisable - and ends with the most plausible explanation at that point, which then generates more puzzles. The assumption is that knowledge is always incomplete, some doubt remains, and so research is never finished. The philosopher Richard Bernstein writes about this kind of approach as 'engaged fallibilistic pluralism'. It is founded on the same pragmatic principles:

such a pluralistic ethos places new responsibilities upon each of us. For it means taking our fallibility seriously - resolving that however much we are committed to our own styles of thinking, we are willing to listen to others without denying or suppressing the otherness of the other.

(1991: 335-6)

While induction and deduction (at least in the hands of social scientists) tend to demand a research plan, in practice the experience of abduction puts the emphasis on listening to multiple views and improvising according to need as an inquiry proceeds.

The process of anthropological research is iterative and emergent because the researcher learns on the job with informants and not at a distance from them. There are different kinds of learning because there are different types of knowledge and Bloch points out that language-based knowledge has been over-emphasised by anthropology (or had been up until then, i.e., 1991). Much knowledge is nonlinguistic: children can conceive of a 'house' before they can say the word (Bloch 1991: 186). We learn how to weave, farm, drive and play the piano by doing them. I'd add, you learn to play the piano in your fingers as much as your brain; your body is as involved as your mind. It would be impossible to become skilled in these activities - or in doing anthropological research - if instructed through the medium of language alone and we are only truly expert in farming or doing research when we no longer think about what we are doing in words exclusively. However, thinking is a vital part of skill and this is true for anthropologists as much as anyone else doing complex work.

How does this 'thinking' work? Bloch tells us that cognitively developing a skill is not just about using your memory to summon the endless examples of 
configurations you have met in the past, but is about learning how to learn so that you can cope with subtly new situations. In short, dealing with the familiar and the new in situations requires improvisation and the less you are distracted by the familiar, the more scope you have for navigating novelty. Bloch's argument about how we process information is extremely helpful for our understanding about how we think, and therefore learn. Rather than following single sequential trains of thought, which would be unbelievably slow, human minds engage in multiple parallel processing to analyse information (ibid: 191). Finally, he warns against adopting the first approach ourselves as anthropologists; that is, we should avoid over simplified single sequential trains of thought to explain puzzles, including when suggested by our informants:

Thus, when our informants honestly say 'this is why we do such things', or 'this is what this means', or 'this is how we do such things', instead of being pleased we should be suspicious and ask what kind of peculiar knowledge is this which can take such an explicit, linguistic form? Indeed, we should treat all explicit knowledge as problematic, as a type of knowledge probably remote from that employed in practical activities under normal circumstances.

(ibid: 193-4)

So we need to learn with informants but at the same time with a critical form of collaboration. For this reason, we learn as researchers more efficiently by doing what they do with them, rather than merely asking them to explain their culture or motives. That is also why it has been by engaging in politics myself that I begin to glimpse what being a politician might be like. This takes time; you can't learn about institutions as complex as parliaments in a rush. When I told the Gentleman Usher of the Black Rod in 1998 that I planned to learn about the House of Lords in a year, he told me it would take ten. I'm still learning 20 years later, not least because new peers keep getting made and the entangled culture and politics of the place keeps changing.

If research is about learning from others, and learning inevitably means that you are doing so actively, not merely absorbing information in a machine-like way but interacting with others with an open mind (and body), then what is the impact on the researcher? The line between self and other, researcher and researched, becomes in part blurred. Mead put it like this:

Selves can only exist in definite relationships to other selves. No hard-and-fast line can be drawn between our own selves and the selves of others, since our own selves exist and enter as such into our experience only in so far as the selves of others exist and enter as such into our experience also.

(1934: 164)

We become part of the research and research must be seen as a social process that inevitably leads to change. As researchers we have to pay attention to this and take 
account of Bloch's argument, and Mead before him, that for novelty to emerge you have to have the capacity to be several things at the same time: "The social character of the universe we find in the situation in which the novel event is in both the old order and the new which its advent heralds. Sociality is the capacity of being several things at once' (Mead 1932/2002: 75). So, research requires multiple parallel processing, improvisation and attention to old and new. I know from teaching that you can't get someone to understand something new unless they can relate it to something already existing in their mind. To convey the substance of a new idea, you have to conjure the ghosts of old ideas that you share. Since you often don't know what their old ideas are until you work together, the processes of working with the substance and the ghosts requires improvisation with students (or those you wish to influence) rather than planning. Writing books is even more difficult because you can't converse with your reader in real time and this is why I'm still learning how to make more intelligible my observations of the Westminster Parliament. This book is merely my latest attempt to keep a disjointed conversation going with strangers whose thinking I'm continually trying to understand.

The old order with its old ideas is described by another pragmatist, John Dewey, as the accretion of habits. Habits change and we need to recognise these shifts but to act ethically we should also acknowledge the possibility that we can take part in changing them. He recommends in this process of influencing that we 'foster impulses and habits which experience has shown to make us sensitive, generous, imaginative, impartial in perceiving the tendency of our inchoate dawning activities' (1922: 207). I find that more inspiring as advice for how to do research ethically than the guidelines that emanate from some university ethics committees. Anthropology can usefully recognise the habits of those who have dominated the study of parliament - critiquing the past with sensitivity and generosity - and use imagination with impartiality to suggest new habits for how to approach research. It is wise not to rush. So before engaging in advocacy, an ethical researcher needs a thorough understanding of the past, the present and possibilities and even then, should continue to assume that the next steps are also a learning process.

Curiosity is vital to advocacy but also to leadership and so I'll make a final point in this section for politicians. Mead wrote that leaders try to change their community, enlarging and enriching it. Great religious leaders like Jesus, Mohammed and Buddha have increased the size of their communities by appealing to them about cosmological relationships in ways that are distinctive to that group (old ideas) but relevant to the future (new substance), and persuasive for existing and potential new members too (respectively: 'love your neighbour', 'justice will come to all if we submit to the will of the one god', 'reach enlightenment'). Then those leaders stand out as symbolic, 'representative of the community as it might exist if it were fully developed along the lines that they had started. New conceptions have brought with them, through great individuals, attitudes which enormously enlarge the environment within which these individuals live' (Mead 1934: 217). ${ }^{1}$ To change others, that is, to teach them, you have to have first learned what is their generalised attitude, which is why great leadership always entails both learning and 
teaching. The pressure on politicians to teach, and the taboo on admitting that they have to learn, does neither them nor those they serve and represent any good at all.

\section{Entangled, reflexive anthropology: how and why?}

Entanglements have been a thread throughout this book. Anthropology can only be done with a sense of other disciplines - geography, history, cultural studies, feminism, political science, psychology and so on. But we also need to have a sense of what makes us unique as a discipline, otherwise we may as well merge with sociology. One of the most important contributions of anthropology to the study of parliaments is to show how the separation of the political from the social or cultural is artificial in all societies including those in Europe. The political work of parliamentarians in democracies is organised around elections, representation and scrutiny; each of these processes entails alliance-building and dealing with conflicts. Politics is a process of walking and talking between friends and foes. It means creating and communicating riffs, navigating space and time with familiar and new rhythms, and getting things done through rituals. In the inevitable power struggles that ensue within parliament (and in any social group, for that matter), people develop skill in summoning ghosts, accumulating symbolic capital and creating irresistible new riffs, rhythms and rituals. But they are constrained, and especially so in the competitive environments of politics, by hierarchies of power, knowledge and value. Globally women face greater constraints than men when doing politics in the public realm. This doesn't stop them becoming leaders necessarily, and older, richer, well-connected women have more room for manoeuvre than younger, poorer and isolated ones, but they have to work harder than men. Other inequalities based on difference, whether structured by class, age, race, ethnicity, ability or sexuality, are too complex to summarise here. But their relevance to the study of parliament is obvious when you consider how deeply these structuring processes affect friendship and enmity. It is harder to build an alliance with someone who hates or despises you or assumes you hate them.

To research politics, power and political institutions, you have to look at the uneven, complex social relations between politicians, between the governing and the governed, and also between researcher and researched. Part of the reason that we need to study our own relationships with the politicians we want to know about is to deal with the tricky problem of getting access to them. Comparing the way parliamentary and council debates and decision-making are ritualised across the world is skewed by the difficulty of gaining access to some institutions. While some nations welcome visitors into political chambers, many remain inaccessible and hostile. Simone Abram found Norway much easier to study than the UK:

In the Norwegian case, elements such as the public access to council meetings, public broadcast of those meetings, and availability of contact with participants reveal an entirely different set of assumptions about whom government is for than that found in the United Kingdom. Sitting in the segregated public 
gallery of a local authority in England recently, I was threatened with eviction for taking out a camera, accused of being a threat to security rather than being seen as a citizen with intense interest in the means by which I was governed.

(2017: 42)

MPs tend to ignore letters from researchers begging for an interview. Why wouldn't you? They have more important tasks like running the country, scrutinising government and answering constituents' inquiries. I'm impressed more than hurt if I get a response from an MP saying that an interview it is not a priority for their constituents, such as this one when I asked for permission to shadow:

\section{Dear Emma}

It is good to hear from you, and thank you for getting in touch. I'm flattered, especially as your blog is so humorous. And it was great to meet you recently. I have thought seriously about your kind offer but I am afraid I've decided that it doesn't make sense for my constituents or for myself to go ahead with such a project at the moment. Many apologies and I hope you find a good opportunity somewhere else in the country.

Best wishes

xxxx MP

The vast majority of letters and emails I've written to MPs get no reply. That seems reasonable given that they are dealing with so many other pressures. But there are risks for them in ignoring writers or journalists. Although our ethics committees constrain us in peculiar ways (obsessing about obtaining consent to research, as if we were conducting a medical trial, rather than avoiding other forms of harm), a researcher might get it into their head that whistleblowing on an MP was justifiable in the public interest. People already in the public eye are constantly exposed to risks of further exposure and can explain neither this (it sounds as if they are worrying about being found out) nor their reasons for avoidance and unreliability (it sounds as if they are moaning). It is difficult to get in the room with well-known people because there are so many claims on their time and their reputation is both precious and fragile.

The way I got close to politicians involved flattery. A former MP told me: 'a politician has, by and large, an infinite capacity to absorb flattery ... They can be persuaded of virtually anything if it's skilful enough' (Crewe 2015a: 3). This works well on everyone as a persuasive technique but you have to mean it. Since flattery implies insincerity, in practice I tried to offer MPs genuine praise. I would watch MPs in a debate, or in a committee meeting, and look them up on Wikipedia and their own website on my iPhone. Then I would catch them after the meeting broke up as they moved towards the door and ask:

Would you mind if I asked a quick question? I'm a researcher from London University. My word you put the minister on the spot! When you argued for 
that change in social care policy it sounded slightly different from your line last month. Have you seen new evidence or ...?

Whether they were pleased to be recognised for the specific expertise, or delighted to talk about their political obsession, it usually worked as a strategy for securing an interview.

I have only managed to secure occasional access to the other parliaments that my close colleagues have studied - in Myanmar, Bangladesh and Ethiopia - which all operate with fortress-like impenetrability. I wasn't long enough in any of these countries to develop the necessary contacts and alliances. It was easier for me in the UK than it might be for some because my private school education gave me a feeling of ease with some, while my career in the voluntary and public sector gave me much in common with others. How did my background then influence what I discovered? Trained in the post-structuralist sociology of Bourdieu and Foucault, it is many decades since I abandoned an individualistic conceptualisation of power in favour of a relational view. Since then I have become more dissatisfied with the cruder post-structuralist accounts that imply that power is found in deterministic structuring processes. To get beyond oscillating between individual and structure in this theory of power, I will now reflect on what happens in between - in processes of relating - which means not only getting into my own history, but into how to think about memory, history and imagination more generally.

My views on gendered leadership are influenced by old family memories, harking back to a remote father from a privileged white English family who in his turn rarely saw his own parents and was traumatised by fighting in the Second World War. During his life he struggled to find a professional sense of purpose but rarely spoke about it. It was not his male authority I resented, it was his lack of it. It was my failing in turn not to understand him until after he had died. However, when people die your relationship with them obviously persists in your memory and thoughts, affecting not just that relationship but the other ones in your life. Family relationships still influence how I experience authority and leadership. In my family it is my mother who was good at politics, which in turn shaped how I viewed leadership - she knows how to make collaborative alliances inside and outside the family with those close to her like no one I have ever met - and my daughters follow in her footsteps. This gendered experience of my parents meant that feminist theories of power that failed to accommodate divergent patterns grated (and continue to grate) on me. Of course, I am a feminist - in the sense that I recognise sedimented patterns of women's subordination in every time and place and feel committed to challenging them - but I need a theory of gendered power that allows for divergent relationships and individual freedom as well as sedimented hierarchy and constraint.

I have learned about politics through childcare: take the example of the politics of blankets. When my husband, Nicholas, and I became parents we were clear that the responsibility for our daughters' care was shared between us. The only issue we intractably argued about was the number of blankets that small babies need on a 
cold winter's night. Nicholas was influenced by knowing a baby who died of cot death (overheating is one of the possible explanations). I hate the cold and despite our shared value (believing we were equally responsible for protecting our children), I was the main carer in terms of time and work when they were tiny babies, so I felt I knew best that cold would be more likely to bring suffering. We discussed the evidence but in comparing likely discomfort against the unlikely possibility of death (as I saw it), it felt impossible to be cool, calm and rational. We got heated - the dial was turned up - at least internally in our heads, doubting each other's expertise and throwing evidence at each other in a bid to persuade the other; in short, we got political. The conflict was not expressed with vehemence. We somehow resolved this disagreement each evening peacefully, sometimes by sneaking into the child's bedroom and taking on/off blankets, and it never became difficult, even verbally, but the point here is that the number of blankets, as part of the social and emotional work of protecting our children, became political. At which point did this social work turn political? When a difference of opinion over the issue of blankets became fraught - it mattered and we couldn't find a consensus - creating a form of concentrated, emotional and charged sociality that couldn't be easily resolved, it was at that moment that it became political.

One way of understanding politics is to see it as an intense form of sociality: turbo-charged social, where everything is magnified with the dial turned up. And 'everything' is not just conflictual as there is as much co-operation, resonance and potential harmony in politics as hostility and alienation. It wasn't just the expression of conflict I remember in our politics of blankets, we found an everyday way of dealing with difference by improvising with a mix of concession, compromise and subterfuge, until the babies grew up enough to decide on their own number of blankets. Gradually parenting requires a shift of responsibility from adult to child and as the dependents get less dependent, the social relationships expressed in decision-making (e.g., about what is safe and allowed) can become more political too. As long as politics is possible - debate, compromise and subterfuge between parents and children - then the relationship tends to keep moving along even when disagreements persist. So, good political work is about moving along in the face of difference despite a concentration and intensity of emotion - a magnification of the social.

I have allowed myself this tangent into my own family politics to give an example of how the social can get political. Whether navigating social relationships or family politics, my identity is influenced by age, class, race and gender, by working at SOAS, being a Londoner, and so on. It is embarrassing to write about oneself; but if we shrink from it - for example, by resorting to a shallow reflexivity that implies that one's account is determined by a few facets of one's social identity, or worse only one - how can we write with honesty and rigour? If the rigour of anthropology depends on explaining our own partiality, then we must do this with some sense of proportion. The alternative is to bore you with endless detail that appears disconnected from the research. So, although I have only revealed a little and there is so much you (and I) don't know about my six decades of life so far, 
partly because most of it has been forgotten - what I tell you should be pertinent. This is what Faucher-King does when she writes:

My aim is to 'exoticise' modern western polities and denaturalise the world that we would otherwise take for granted. I have turned my attention to Britain because as a native of France its political culture is both familiar and unfamiliar to me.

(2005: 5)

I share her aim but suggest that diversity within countries is so great, that the unfamiliar is easily found just beyond one's own doorstep.

To be honest about past influences, I still need to explain how I am studying these entanglements of disciplines, past, present and future, researcher and researched, when it involves holding in mind many processes at the same time. Stacey and Mowles propose a helpful analogy from complexity sciences in their exploration of change that gets to the heart of this entanglement. They point out that patterns in the natural world (or in simulated computer models) display paradoxes of stability and instability, predictability and unpredictability, at the same time (2016). Rather than Kant's dualistic 'both ... and' type explanations, we need to hold the idea of human experience as paradoxical in the same moment and space, they propose (ibid: 298), in order to theorise about how processes and actions relate to each other. Paradox here is not meant in the casual conversational sense of an irony or a contradiction; it is a particular kind of irresolvable contradiction. Mowles, with whom I teach at the University of Hertfordshire, ${ }^{2}$ clarifies that it is a form of contradictory thinking and doing where one idea defines and negates the other but neither can be banished. It creates 'an absurdity, "para doxa" - or against common sense - because the two ideas are mutually exclusive' (2015: 5, 13). For our purposes, the most significant example of this is the $\mathrm{I} / \mathrm{me}$ dialectic of Mead. His idea of self intersubjectivity means that we 'are capable of seeing ourselves as others see us, a peculiar property of our central nervous system, we are able to take ourselves as objects to ourselves ... we are social even in our private thought processes', as Mowles explains (ibid: 22-3). At last, we have a way of understanding the contradiction between individual and social experience, of freedom and constraint, of agency and structure as paradoxical - each is defined and negated by each other, so never resolved.

The problem with many existing theories about parliament is that they fail to take a hard look at these entangled paradoxes of social life. Rational choice theories that assume MPs act on the basis of an assessment of individual self-interest ignore the way MPs are embedded in social relations. The other main strand of scholarly theory usually aimed at parliament - institutionalism with its assumptions about how people are governed by rules - fails to explain individual variation, why people ignore norms, and how institutions change. MPs experience paradoxes as socially embedded individuals like but also unlike other human beings. The $\mathrm{I} / \mathrm{me}$ dialectic for politicians is amplified by their claim to represent 10,000 s of people 
and their daily interaction with endless overlapping audiences that present conflicting, complex and confusing demands. The paradox for them is the same in its logic as it is for other humans, but magnified by exposure to an enlarged audience representing even more complex differences and expectations than the rest of us. MPs are ordinary in experiencing the paradox of being individual and social, but extraordinary in dealing with a far greater intensity; they operate in a higher key.

The discipline of anthropology has something unique to offer but only if we are in conversation with other disciplines: critiquing, debating and borrowing from each other. We are not alone in arguing that developing a methodology for studying parliament requires a theory as part of your approach. Our focus on interdisciplinarity, but also reflexivity, a plurality of views and entanglements, is shared with strands of sociology and philosophy. It is combining these with a continual return to everyday practices and social relationships, and comparing with other communities, that enables anthropology to provide unique and rigorous perspectives. That does not mean that what we find is holistic, in the sense of comprehensively describing the whole, as the job is never finished. Which is why it makes sense to end on pointing to what we don't know.

\section{What we don't know}

There are several types of ignorance about parliaments. First, there is what we don't know because we have ignored it, we are yet to research or make sense of it. Second, there is what we don't know because understanding people is never complete. Third, there is what we don't know we don't know - or unknown unknowns, as popularised by US politician Donald Rumsfeld. So, I will end on some remarks about these various unknowns.

Beginning with the kind of ignorance born of ignoring, the study of parliaments by the dominant disciplines - political science, history, gender studies, public administration and legal studies - give us a focus on powers, functions, rules, roles and outputs. These tend be studied in documents - laws, rules, standing orders, reports - by watching parliamentary debates or committee meetings, and by deriving knowledge from interviews. In most countries we know a huge amount about individual politicians and their identity by gender and background; in the UK this is detailed in Dod's Parliamentary Companion and all MPs appear in media interviews, have websites, Twitter accounts and much besides, although what we 'know' is more about their claims and performative representation of themselves than their thoughts, values and relationships. Traditional scholars of parliament rarely tell us about the areas that are more complex to study: processes, relationships and rituals.

Strangely parliaments have been mostly ignored by disciplines that you might think would be extremely interested in them - organisational and management studies. If you do a search on 'parliament' and 'legislature' in the journals Organisation and the Journal of Management you do not get one article with either in its title. Research on parliaments is often published in specialist journals (Parliamentary 
Affairs, the Journal of Legislative Studies), or broader ones about politics, so organisational studies scholars may have published there. But in the UK parliament I have only rarely heard of them venturing into these political institutions. ${ }^{3}$ So we have yet to find out what management scholars make of parliaments.

In this book I have drawn together the research undertaken by anthropologists in recent decades. What have we anthropologists ignored in terms of themes? Now that I have worked with a psychotherapist in the House of Commons, and read Andrew Beatty's book on emotions (2019), I would argue that the psychology of politicians around the world and the group dynamics they create around them is a serious gap in our knowledge. The affectual states created in and for politics, why shared and divergent emotions emerge and their impact on political work - these are all fruitful lines of inquiry.

There is much more to be studied within political parties. Bignell (2018) has researched the Green Party in New Zealand, William Schumann (2009) the Liberal Democrats in Wales and Faucher-King (2005) party conferences in the UK. But what happens within and between political parties deserves anthropological attention across time and space, as they are changeable in both their internal dynamics and relations with others.

The political economy of parliamentarians deserves attention by anthropologists in every country. How are different individuals and groups of politicians entangled with lobbyists, journalists and civil/corporate interests, and how and why is this changing? What are the everyday patterns of patronage between politicians, and between politicians and other people they encounter, from the beginning to the end of their careers? How does this relate to inequalities that politicians are embedded in, challenging and contributing to, whether based on gender, age, class, ethnicity, nationality, sexuality, ability and so on?

We need to know more about the digital revolution and its impact on political communication, made even more urgent by the response to and impact of the Covid-19 pandemic, climate breakdown, the decline in mental health and other emergencies. Finally, while I have been biased towards researching parliament's (i.e., backbenchers and opposition parties) scrutiny role, the far more difficult task of doing anthropological research on government has become urgent. Governments have been scrutinised by anthropologists in the Global South (for examples, see Crewe and Axelby 2013), but far less in Europe, the US and other countries in the Global North and very rarely from the viewpoint of different groups of politicians and civil servants.

The second area of ignorance - what we don't know because research is always incomplete - is endlessly demanding. Diversity across time and space, and within communities, means our job is never done. Finding out what is specific to a culture, or even to an individual, as opposed to generalisable is never finished, and made more complex still by the inevitability of change. Anna Tsing in her beautifully written The Mushroom at the End of the World tells us about forests: destroyed in specific ways but also connected in a chain of destruction: 
It is impossible to explain the situation though the actions of a single hammer striking every nail with the same stroke. The difference between disappearing forests, forests plagued by overcrowding and pests, and forests left to grow when conversions to plantations prove uneconomic, matter. Intersecting historical processes produced forest ruins in Oregon and Japan, but it would be preposterous to argue that forest-making forces and reactions are therefore everywhere the same. The singularity of interspecies gatherings matters; that's why the world remains ecologically heterogeneous despite globe-spanning powers.

My equivalent to forests is parliaments. I have tried to bring out the differences in parliaments and the relationships politicians have with each other and others. There is so much we don't know about relationships and everyday interactions between MPs and those they claim to represent across the world in parliaments and constituencies; between politicians and those in the private sector, civil society and government; and between politicians within their various political parties and factions. Like Tsing's forests, it would be absurd to argue they were either all the same or unconnected; after all, democracy has become a global idea, even if the effects vary. Tsing continues:

The intricacies of global coordination also matter; not all connections have the same effects. To write a history of ruin, we need to follow broken bits of many stories and to move in and out of many patches. In the play of global power, indeterminate encounters are still important.

(ibid)

These broken bits require careful selection. How do we know which bits are vital to the story? Where should we start? Bourdieu counsels:

The difficulty in sociology, is to manage to think in a completely astonished and disconcerted way about things you thought you had always understood. That is why you sometimes have to begin with the most difficult things in order to understand easier things properly.

(1991: 207)

So, we take nothing for granted (or as little as possible) and begin with what is difficult in the sense that it looks obvious but isn't. In my own study of parliament I have spent most of my research trying to find out what peers and MPs actually do (rather than what they say they do) and it is been surprisingly difficult because I realised as I went along that it is not clear what politics means - it means different things to different people. Once I decided it was a form of work with friends and foes (or at least this is a good definition for thinking with), then it became easier.

When choosing which bits to watch, think with and write about we have to improvise and experiment, creating narratives that are as persuasive as possible for 
that moment, warranted assertions, as John Dewey called them. Like historians maybe we need to keep revising important old stories to update them in the light of the present; after all, since history changes as we get further away from it, so an anthropology entangled with history and geography surely has to keep iterating its empirical and theoretical narratives? Indeed I have re-written a story about lawmaking (in a book on the Commons [Crewe 2015a], an article [2017] and now in Chapter 4) and although the skeleton is recognisable, I have added more flesh on the bones - improvising on a narrative riff. In thickening descriptions Geertz-style we need to get away from the idea of splitting context and substance. If the political and social are entangled, then they do not serve as 'context' - both are part of the substance of what is going on.

Jastinder Kaur writing about political coups points to various forms of entanglement. Gluckman's idea of the peace in the feud is central to what she found. Even during the violence supposed foes offered each other hospitality and even at times of peace ethnic tensions erupted into quarrels (Kaur 2017: 21-2). One protagonist told her, 'They're fine drinking grog with each other, partying together, working together, and helping each other out in times of need. But we have to fight the bigger conflict that government and history keep forcing on everyone' (ibid: 26). This is far from unique to Fiji. History is not as abrupt as it appears, even when there are coups. Some have a long, gradual build-up and surprise no one whereas others are abrupt and shocking, except obviously to those involved in the planning. The same is true of any event. When we are shocked by critical events, it is often because we haven't been paying enough attention - there are warning signs that go unnoticed because we are busy looking elsewhere. The spread of Covid-19 was both a shock but also exposed existing and rising inequalities. In India it was Tablighi Jamaat, a Muslim missionary movement, who were told by the government not to hold an event and subsequently blamed for a spike in Covid-19 cases, while Hindu religious events were unnoticed and unblamed. ${ }^{4}$ When India's PM Nahendra Modi announced a lockdown to prevent the virus spreading, 100,000s of daily labourers left the cities to make their way home, often by walking, knowing that being unable to work was more dangerous to them than Covid-19. When politicians ignore the warning signs, it can cause terrible suffering.

Finally, we have a third area of ignorance - the unknown unknowns. By definition I don't know what I don't know; but that doesn't mean I have nothing to say about this state of unknowing. It can be broken by fresh perspectives, new scholars (with different points of view, histories and identities from the established ones) taking a look at parliaments. Understanding the impact of the digital revolution and artificial intelligence on parliaments, and how they relate to various emergencies (democracy, mental health, climate change, Covid-19, poverty), contains plenty of unknown unknowns. If I am allowed only one wish for this book, it is that it might encourage other anthropologists to study parliaments around the world or better still, to work in governments and stand for election. Perhaps we anthropologists will only be able to provide properly thick descriptions and theories 
of parliaments once we work for and with them or are even members of them ourselves, genuine parliamentary participant-observers. Those anthropologists that are doing this already deserve our respect and support.

I hope to continue learning about parliaments. To discover the unknown unknowns, I try to keep my mind open and avoid the rush to moral judgement. That is especially difficult with politicians; we think we know them and we know we are disappointed, but it is when we have a sense of certainty before we have begun that anthropology fails to delight. Let's begin with uncertainty.

\section{Notes}

1 Thank you to my colleague Kiran Chauhan for alerting me to this passage in Mead, which we will write about in a new book we are editing together about leadership.

2 Chris Mowles is the Director of a multi-disciplinary postgraduate course on management, which I teach on with five others: https://www.herts.ac.uk/courses/dmanma-by-research

3 André Spicer and Jo Silvester from CASS Business School are rare exceptions (https://www. theguardian.com/commentisfree/2017/nov/09/house-commons-less-toxic-workplace-mpshr-procedures, accessed 10 April 2020) and Weinberg's 2011 edited volume The Psychology of Politicians is extremely unusual for the UK. These contributions are largely normative, advising on sexual harassment, induction and training for MPs, as examples.

4 See https://www.aljazeera.com/news/2020/04/tablighi-jamaat-event-india-worst-corona virus-vector-200407052957511.html and https://www.soas.ac.uk/news/newsitem146991. html, accessed 12 April 2020. 


\section{REFERENCES}

Abélès, M. 1988. 'Modern Political Ritual', Current Anthropology, 29 (3), pp. 391-404.

Abélès, M. 1991. Quiet Days in Burgundy. A Study of Local Politics. Cambridge: Cambridge University Press.

Abélès, M. 2000. Un ethnologue à l'Assembleé. Paris: Odile Jacob.

Abélès, M. (ed.). 2006. 'Parliament, Politics and Ritual', in (eds) E. Crewe and M.G. Müller, Rituals in Parliament. Frankfurt am Main: Peter Lang.

Abélès, M. 2014. Thinking Beyond the State. New York: Cornell University Press.

Abram, S. 2017. 'Contradiction in Contemporary Political Life: Meeting Bureaucracy in Norwegian Municipal Government', Journal of the Royal Anthropological Institute, 21 (S1), pp. 27-44.

Ahmed, N. 2020. Parliaments in South Asia. India, Pakistan and Bangladesh. London: Routledge.

Ahmed, Z. 2019. 'From Shape-shifting to Collusion in Violence: An Ethnography of Information Relationships between Bangladeshi Members of Parliament and their Constituents', Journal of Political and Legal Anthropology, 42 (1), pp. 5-20.

Alaszewski, A. 2015. 'Anthropology and Risk: Insights into Uncertainty, Danger and Blame from Other Cultures - A Review Essay', Health, Risk \& Society, 17 (3-4), pp. 205-225.

Ansell, A. 2018. 'Clientelism, Elections, and the Dialectic of Numerical People in Northeast Brazil', Current Anthropology, 59 (S18), pp. 128-137.

Appadurai, A. 2001. 'Deep Democracy', Environment and Urbanization, 13 (2), pp. 23-43.

Appadurai, A. 2004. 'The Capacity to Aspire: Culture and the Terms of Recognition', in (eds) Vijayendra Rao and Michael Walton, Culture and Public Action. Stanford: Stanford University Press.

Apter, A. 1987. 'Things Fell Apart? Yoruba Responses to the 1983 Elections in Ondo State, Nigeria', Journal of Modern African Studies, 25 (3), pp. 489-503.

Arendt, H. 1977. Between Past and Future. New York: Penguin Books.

Aronoff, M.J. 1989. Israeli Visions and Divisions. Abingdon: Routledge.

Ayenew, M. with Wubie, N. and Mekonnen, T. 2019. Parliament-Public Engagement in Ethiopia: Selected Notes and Case Studies on a Politically Fragile State. Addis Ababa: Forum for Social Studies. 
Bailey, F.G. 1969. Stratagems and Spoils: A Social Anthropology of Politics. New York: Schocken.

Banerjee, M. 2014. Why India Votes. New Delhi: Routledge.

Barth, F. 2002. 'An Anthropology of Knowledge', Current Anthropology, 43 (1), pp. 1-18.

Bauer, G. and Burnet, J. 2013. 'Gender Quotas, Democracy and Women's Representation in Africa: Some Insights from Democratic Botswana and Autocratic Rwanda', Women's Studies International Forum, 41 (2), pp. 103-111.

Beatty, A. 2019. Emotional Worlds. Beyond an Anthropology of Emotion. Cambridge: Cambridge University Press.

Bellier, I. 2002. 'European Identity, Institutions and Languages in the Context of the Enlargement', Journal of Language and Politics, 1 (1), pp. 85-114.

Bernstein, A. and Mertz, E. 2011. 'Introduction, Bureaucracy: Ethnography of the State in Everyday Life', Political and Legal Anthropology Review, 34 (1), pp. 6-10.

Bernstein, R. 1991. 'Pragmatism, Pluralism, and the Healing of Wounds', in Richard J. Bernstein, The New Constellation. Cambridge: Polity Press, pp. 323-340.

Bernstein, R. 2010. The Pragmatic Turn. Cambridge and Malden: Polity Press.

Best, H. and Vogel, L. 2014. 'The Sociology of Legislators and Legislatures. Socialization, Recruitment, and Representation', in (eds) S. Martin, T. Saalfeld and K.W. Strøm, The Oxford Handbook of Legislative Studies. Oxford: Oxford University Press.

Bevir, M. and Rhodes, R.A.W. 2010. The State as Cultural Practice. Oxford: Oxford University Press.

Bierschenk, T. and Olivier de Sardan, J-P. 2014. States at Work, Dynamics of African Bureaucracies. Leiden: Brill.

Bignell, J. 2018. Political Messaging, Parliament, and People. Or Why Politicians Say the Things They Do the Way They Do: The Parliamentary Green Party of Aotearoa New Zealand in 2013. Unpublished thesis, Massey University, Aotearoa, New Zealand.

Birhanu, R. and Senbeta, E. Forthcoming. Quest for Ethnic Representation at Regional Level: A Challenge for Ethiopia's Transition towards Genuine Democracy.

Blair, Tony. 2010. A Journey. London: Hutchinson.

Bloch, M. 1986. From Blessing to Violence. History and Ideology in the Circumcision Ritual of the Merina of Madagascar. New York: Cambridge University Press.

Bloch, M. 1987. 'The Ritual of the Royal Bath in Madagascar: The Dissolution of Death, Birth and Fertility into Authority', in (eds) D. Cannadine and S. Price, Rituals of Royalty: Power and Ceremonial in Traditional Societies. Cambridge: Cambridge University Press.

Bloch, M. 1989. Ritual, History and Power, Selected Papers in Anthropology. London: Athlone.

Bloch, M. 1991. 'Language, Anthropology and Cognitive Science', Journal of the Royal Anthropological Institute, 26 (2), pp.183-198.

Blundo, G., Olivier de Sardan, J-P. and Arifari, N.B. 2006. Everyday Corruption and the State. London: Zed.

Bourdieu, P. 1977. An Outline of a Theory of Practice. Cambridge: Cambridge University Press.

Bourdieu, P. 1990. In Other Words. London: Polity Press.

Bourdieu, P. 1991. Language and Symbolic Power. Cambridge: Polity.

Bourdieu, P. and Wacquant, L.J.D. 1992. An Invitation to Reflexive Sociology. Chicago: University of Chicago Press.

Brack, N., Costa, O. and Kerrouche, E. 2016. 'MPs between Territories, Assembly and Party - Investigating Parliamentary Behaviour at the Local Level in France, Belgium and Germany', French Politics, 14, pp. 395-405.

Brown, H., Reed, A. and Yarrow, T. 2017. 'Introduction: Towards an Ethnography of Meeting, Special Issue: Meetings; Ethnographies of Organization Process, Bureaucracy and Assembly', Journal of the Royal Anthropological Institute, 21 (S1), pp. 10-26. 
Bueno de Mesquita, B., Marrow, J.D. and Siverson, R.M. 1999. 'Policy Failure and Political Survival: The Contribution of Political Institutions', Journal of Conflict Resolution, 43 (2), pp. 147-161.

Bull, M.J. and Newell, J.L. (eds). 2003. Corruption in Contemporary Politics. Basingstoke: Palgrave Macmillan.

Burghart, R. 1987. 'Gifts to the Gods: Power, Property, and Ceremonial in Nepal', in (eds) D. Cannadine and D. Price, Rituals of Royalty: Power and Ceremonial in Traditional Societies. Cambridge: Cambridge University Press.

Burke, E. 1854. The Works of the Right Honorable Edmund Burke. Vol. I. London: Henry G. Bohn.

Burkitt, I. 1999. Bodies of Thought: Embodiment, Identity and Modernity. London: Sage.

Busby, A. 2013. The Everyday Practice and Performance of European Politics: An Ethnography of the European Parliament. Unpublished PhD thesis, University of Sussex, Brighton.

Butler, J. 1990. Gender Trouble. New York: Routledge.

Campbell, R. and Childs, S. 2015. 'Parents in Parliament: "Where's Mum?”, Political Quarterly, 85 (4), pp. 487-492.

Campbell, R. and Cowley, P. 2014. 'What Voters Want: Reactions to Candidate Characteristics in a Survey Experiment', Political Studies, 62 (4), pp. 745-765.

Carrithers, M. 1992. Why Humans Have Cultures: Explaining Anthropology and Social Diversity. Oxford: Oxford University Press.

Carrithers, M. 2005. 'Why Anthropologists Should Study Rhetoric', Journal of the Royal Anthropological Institute (N.S.), 11, pp. 577-583.

Clark, A. 2003. Diaries: In Power 1983-1992. London: Phoenix.

Coles, K. 2004. 'Election Day: The Construction of Democracy through Technique', Cultural Anthropology, 19 (4), pp. 551-580.

Comaroff, J.L. and Comaroff, J. 1997. 'Postcolonial Politics and Discourses of Democracy in Southern Africa: An Anthropological Reflection on African Political Modernities', Journal of Anthropological Research, 53 (2), pp. 123-146.

Corbett, J. 2015. Being Political. Leadership and Democracy in the Pacific Islands. Honolulu: University of Hawaii Press.

Cowley, P. 2005. The Rebels: How Blair Mislaid His Majority. London: Politico.

Cowley, P. and Russell, M. 2015. 'The Policy Power of the Westminster Parliament: The "Parliamentary State" and the Empirical Evidence', Governance: An International Journal of Policy, Administration, and Institutions, 29 (1), pp. 121-137.

Cramer, K.J. 2016. The Politics of Resentment. Rural Consciousness in Wisconsin and the Rise of Scott Walker. Chicago and London: Chicago University of Press.

Crampton, R. 2019. 'Why Do Politicians Lie? Because Voters Don't Want the Truth', The Times, 6 December, https://www.thetimes.co.uk/article/why-do-politicians-lie-becausevoters-dont-want-the-truth-zpbdwllb2, accessed 15 February 2020.

Crewe, E. 2005. Lords of Parliament. Manners, Rituals and Power. Manchester: Manchester University Press.

Crewe, E. 2006. 'Rituals and the Usual Channels in the British House of Lords', in (eds) E. Crewe and M.G. Müller, Rituals in Parliaments: Political, Anthropological and Historical Perspectives on Europe and the United States. Frankfurt am Main and New York: Peter Lang.

Crewe, E. 2010a. 'An Anthropology of the House of Lords: Socialization, Relationships and Rituals', Journal of Legislative Studies, 16 (3), pp. 313-324.

Crewe, E. 2010b. 'Protecting Children in Different Contexts: Exploring the Value of Rights and Research', Journal of Children's Services, 5 (1), pp. 43-55.

Crewe, E. 2014a. 'Ethnographic Research in Gendered Organizations', Politics and Gender, 10, pp.1-7. 


\section{References}

Crewe, E. 2014b. 'Westminster Parliamentarians: Performing Politics', in (eds) S. Rai and R. Johnson, Democracy in Practice: Ceremony and Ritual in Parliament. Basingstoke and New York: Palgrave Macmillan.

Crewe, E. 2015a. House of Commons: An Anthropology of the Work of MPs. London: Bloomsbury.

Crewe, E. 2015b. Commons and Lords. A Short Anthropology of Parliament. London: Haus Publishing.

Crewe, E. 2017. 'Reading the Runes: Conflict, Culture and "Evidence" in Law-making in the UK', Redescriptions: Political Thought, Conceptual History and Feminist Theory, 20 (1), pp. 32-48.

Crewe, E. 2018. 'Ethnographies of Parliament: Culture and Uncertainty in Shallow Democracies', Journal of Organizational Ethnography, 7 (1), pp. 16-30.

Crewe, E. and Axelby, R. 2013. Anthropology and Development: Culture, Morality and Politics. Cambridge: Cambridge University Press.

Crewe, E. and Harrison, E. 1998. Whose Development? An Ethnography of Aid and Development. London: Zed.

Crewe, E. and Müller, M.G. (eds). 2006. Rituals in Parliaments: Political, Anthropological and Historical Perspectives on Europe and the United States. Frankfurt am Main and New York: Peter Lang.

Crewe, E. and Evans, P. 2018. 'The Significance of Rituals Parliament', in (eds) Cristina Leston-Bandeira and Louise Thompson, Exploring Parliament. Oxford: Oxford University Press.

Crewe, E. and Sarra, N. 2019. 'Chairing UK Select Committees: Walking between Friends and Foes', Parliamentary Affairs, 72 (4), pp. 841-859.

Crewe, E. and Sarra, N. 2021. "Constituency Performances: The "Heart" of Democratic Politics', in (eds) S. Rai, M. Gluhovic, S. Jestrovic and M. Saward, The Oxford Handbook of Politics and Performance. Oxford: Oxford University Press.

Crewe, E. and Walker, A. 2019. An Extraordinary Scandal. The Westminster Expenses Crisis and Why it Still Matters. London: Haus Publishing.

Das, V. 1995. Critical Events: An Anthropological Perspective on Contemporary India. Oxford: Oxford University Press.

Das, V. and Poole, D. 2004. Anthropology in the Margins of the State. Oxford: James Currey.

Dewey, J. 1922. Human Nature and Conduct: An Introduction to Social Psychology. New York: Henry Holt.

DFID. 2010. The Politics of Poverty: Elites, Citizens and States. Findings from Ten Years of DFID-funded Research on Governance and Fragile States 2001-2010. A synthesis paper.

Diamond, L. 1999. Developing Democracy, Towards Consolidation. Baltimore: Johns Hopkins University Press.

Dunbar, R.I.M. 1996. Grooming, Gossip and the Evolution of Language. Cambridge, MA: Harvard University Press.

Dunn, J. (ed.). 1992. Democracy: The Unfinished Journey, 508 BC to AD 1993. Oxford: Oxford University Press.

Dunn, J. 2000. 'Trust and Political Agency', in (ed.) D. Gambetta, Trust: Making and Breaking Cooperative Relations, http://www.sociology.ox.ac.uk/papers/dunn73-93.pdf, accessed 11 October 2014.

Dunn, J. 2005. Democracy: A History. Boston: Atlantic Monthly Press.

Edensor, T. 2010. 'Introduction', in (ed.) T. Edensor, Geographies of Rhythm. Farnham: Ashgate.

Egreteau, R. 2019. 'Fashioning Parliament: The Politics of Dress in Myanmar's Postcolonial Legislatures', Parliamentary Affairs, 72, (3), pp. 684-701. 
Ehrenzweig, A. 1967. The Hidden Order of Art. Berkeley: University of California Press.

Engelke, M. 2018. How to Think Like an Anthropologist. Princeton: Princeton University Press.

Ewing, K.P. 1990. 'The Illusion of Wholeness: Culture, Self, and the Experience of Inconsistency', Ethos, 18 (3), pp. 251-278.

Fassin, D. (ed.) 2015. At the Heart of the State. The Moral World of Institutions. London: Pluto.

Faucher-King, F. 2005. Changing Parties. An Anthropology of British Political Conferences. Basingstoke: Palgrave Macmillan.

Fenno, R. 1978. Home Style, House Members in their Districts. New York: Harper Collins.

International Political Anthropology, 3 (1), pp. 55-77.

Flynn, P. 2012. How to Be an MP. London: Biteback Publishing.

Foret, F. 2010. 'European Political Rituals: A Challenging Tradition in the Making', International Political Anthropology, 3 (1), pp. 55-77.

Fortes, M. and Evans-Prichard, E.E. 1940. African Political Systems. Oxford: Oxford University Press.

Foulkes, S.H. 1948. Introduction to Group Analytic Psychotherapy. London: Karnac Books.

Geddes, M. and Rhodes, R.A.W. 2018. 'Towards an Interpretive Parliamentary Studies', in (eds) J. Brichzin, D. Krichewsky, L. Ringel and J. Schank, Soziologie der Parlamente, Politische Soziologie. Wiesbaden: Springer VS.

Geertz, C. 1973. The Interpretation of Cultures. Selected Essays. New York: Basic Books.

Geertz, C. 1980. Negara: The Theatre State in Nineteenth-Century Bali. Princeton: Princeton University Press.

Geoghegan, P. 2020. 'Cronyism and Clientelism', London Review of Books, 42 (21), 5 November, https://www.lrb.co.uk/the-paper/v42/n21/peter-geoghegan/cronyism-andclientelism, accessed 22 November 2020.

Gershon, I. 2011. 'Critical Review Essay: Studying Cultural Pluralism in Courts versus Legislatures', Political and Legal Anthropology Review, 34 (1), pp. 155-174.

Giesen B. 2011. 'Ritual, Power, and Style: The Implications of Negara for the Sociology of Power', in (eds) J.C. Alexander, P. Smith and M. Norton, Interpreting Clifford Geertz. Cultural Sociology. New York: Palgrave Macmillan.

Gledhill, J. 1994. Power and its Disguises: Anthropological Perspectives on Politics. London: Pluto.

Goffman, E. 1959. The Presentation of Self in Everyday Life. New York: Anchor Books.

Graeber, D. 2005. 'Fetishism as Social Creativity: Or, Fetishes Are Gods in the Process of Construction', Anthropology Theory, 5 (4), pp. 407-438.

Graeber, D. 2017. 'The Divine Kinship of the Skilluk: On Violence, Utopia, and the Human Condition', in D. Graeber and M. Sahlins, On Kings. Chicago: Hau Books.

Graeber, D. and Sahlins, M. 2017. On Kings. Chicago: Hau Books.

Greenhouse, C.J. 2018. 'Political Anthropology', The International Encyclopedia of Anthropology, https://doi.org/10.1002/9781118924396.wbiea1987, accessed 17 May 2020.

Grey, S. and MacAskill, A. 2020. 'Special Report: Johnson Listened to His Scientists about Coronavirus - But They Were Slow to Sound the Alarm', 7 April 2020, Reuters, https:// www.reuters.com/article/us-health-coronavirus-britain-path-speci-idUSKBN21P1VF, accessed 1 May 2020.

Grice, A. 2006. 'The Homophobic Campaign that Helped Win Bermondsey', The Independent, 27 January, http://www.independent.co.uk/news/uk/politics/the-homophobic-campaignthat-helped-win-bermondsey-524703.html, accessed 2 May 2013.

Gulrajani, N. 2011. 'Transcending the Great Foreign Aid Debate: Managerialism, Radicalism and the Search for Aid Effectiveness', Third World Quarterly, 32, pp. 199-216.

Hagman, T. and Reyntjens, F. (eds). 2016. Aid and Authoritarianism in Africa. London: Zed. Hardman, I. 2018. Why We Get the Wrong Politicians. London: Atlantic Books. 
Hart, K. 2002. 'World Society as an Old Regime', in (eds) C. Shore and S. Nugent, Elite Cultures. Anthropological Perspectives. London: Routledge.

Hellen, N. and Grimston, J. One in six new Tory MPs Suffer Split, The Times, 3 February 2013, http://www.thesundaytimes.co.uk/sto/news/Politics/article1206644.ece, accessed 3 April 2021.

Hocart, A.M. 1970 (1936). Kings and Councillors: An Essay in the Comparative Anatomy of Human Society. London and Chicago: University of Chicago Press.

Honneth, A. 1996. The Struggle for Recognition. The Moral Grammar of Social Conflicts. London: Polity. Howe, G. 2006. 'Book Reviews', The Journal of Legislative Studies, 12 (1), pp. 115-125.

Ingold, T. 2013. Making. Anthropology, Archaelogy, Art and Architecture. Abingdon and New York: Routledge.

Ingold, T. 2014. 'That's Enough about Ethnography', Journal of Ethnographic Theory, 4 (1), pp. 383-395.

Ingold, T. 2018. Anthropology: Why It Matters. Cambridge: Polity.

Jewett, A. 2012. Science, Democracy and the American University: From the Civil War to the Cold War. Cambridge and New York: Cambridge University Press.

Judge, D. and Partos, R. 2018. 'MPs and Their Constituencies', in (eds) Cristina LestonBandeira and Louise Thompson, Exploring Parliament. Oxford: Oxford University Press.

Kaganas, F. 2018. 'Parental Involvement: A Discretionary Presumption', Legal Studies, 38 (4), pp. 549-570.

Kam, C. 2014. 'Party Discipline', in (eds) S. Martin, T. Saalfeld and K.W. Strøm, The Oxford Handbook of Legislative Studies. Oxford: Oxford University Press.

Kaur, Jastinder. 2017. Towards an Anthropology of Coups in Fiji. Unpublished PhD thesis, SOAS, University of London.

Kenny, M. 2013. Gender and Political Recruitment. Basingstoke: Palgrave Macmillan.

Kertzer, D. 1988. Ritual, Politics and Power. New Haven and London: Yale University Press. King, A. and Crewe, I. 2013. The Blunders of Our Governments. London: OneWorld.

Koch, I. 2018. Personalizing the State: An Anthropology of Law, Politics, and Welfare in Austerity Britain. Oxford: Oxford University Press.

Kuhn, T. 1962. The Structure of Scientific Revolutions. Chicago: University of Chicago Press.

Kumarasingham, H. 2013. 'Exporting Executive Accountability? Westminster Legacies of Executive Power', Parliamentary Affairs, 66 (3), pp. 579-596.

Larsen, S.B. 2020. Are You Impressed? An Exploration of the Pressure to Perform and Impress from the Perspective of an Organisational Development Consultant. Unpublished $\mathrm{PhD}$ thesis, University of Hertfordshire.

Latour, B. 2003. 'What if We Talked Politics a Little', Contemporary Political Theory, 2, pp. 143-164.

Latour, B. 2007. 'Turning around Politics - A Note on Gerard de Vries' Paper', Social Studies of Science, 37 (5), pp. 811-820.

Latour, B. 2010. Making of Law. An Ethnography of the Conseil d'Estat. London: Polity.

Laver, M. 2008. 'Legislatures and Parliaments in Comparative Context', in (eds) D.A. Wittman and B. Weingast, The Oxford Handbook of Political Economy. Oxford: Oxford University Press.

Lazarus, J. and Steigerwalt, A. 2018. Gendered Vulnerability: How Women Work Harder to Stay in Office. Ann Arbor: University of Michigan Press.

Lazarus-Black, M. 2001. 'Law and the Pragmatics of Inclusion: Governing Domestic Violence in Trinidad and Tobago', American Ethnologist, 28 (2), pp. 388-416.

Leach, E.R. 1954. Political Systems of Highland Burma: A Study of Kachin Social Structure. London: Berg.

Lee, M. 2006. 'Looking at the Politics-Administration Dichotomy from the other Direction: Participant Observation by a State Senator', International Journal of Public Administration, 24 (4), pp. 363-384. 
Lefebvre, H. 2013. Rhythmanalysis. Space, Time and Everyday Life. London: Bloomsbury.

Leston-Bandeira, C. 2004. From Legislation to Legitimation: The Role of the Portguese Parliament. London: Routledge.

Leston-Bandeira, C. 2016. 'Why Symbolic Representation Frames Parliamentary Public Engagement', British Journal of Politics and International Relations, 18 (2), pp. 498-516.

Lewellen, T. 2002. The Anthropology of Globalisation: Cultural Anthropology Enters the 21st Century. Westport: Bergin and Garvey.

Lewis, D. 2012. Bangladesh. Politics, Economy and Civil Society. Cambridge: Cambridge University Press.

Lukes, S. 1975. 'Political Ritual and Social Integration', Sociology, 9 (2), pp. 289-308.

Lukes, S. 1977. Essays on Social Theory. London: Macmillan.

Maber, E.J.T. and Aung, K.M. 2019. 'Gender, Ethnicity and Disability: Approaching Inclusivity in Myanmar's Education Reforms?', in (eds) M.J. Schuelka, C.J. Johnstone, G. Thomas and A.J. Artiles, Sage Handbook of Inclusion and Diversity in Education. London: Sage.

Maclean, M. with Kurcezewski, J. 2011. Making Family Law. Oxford: Hart.

Mansbridge, J. 2003. 'Rethinking Representation', American Political Science Review, 97 (4), pp. 515-528.

Martin, S., Saalfeld, T. and Strøm, K.W. (eds). 2014. The Oxford Handbook of Legislative Studies. Oxford: Oxford University Press.

Mawdsley, E. 2019. The War for the Seas. A Maritime History of World War II. New Haven and London: Yale University Press.

McDougall, L. 1998. Westminster Women. London: Vintage.

McLennan, D. and Miles, J. 2018. 'A Once Unimaginable Scenario: No More Newspapers', The Washington Post, 21 March.

Mead, G.H. 1932/2002. The Philosophy of the Present. New York: Prometheus Books.

Mead, G.H. 1934. Mind, Self and Society. Chicago and London: University of Chicago Press.

Melnikova, E. 2013. 'Notes on the Ethnography of Elections. The Anthropology of Russian Politics', Forum for Anthropology and Culture, 9, pp. 124-153, http://anthropologie.kunstkamera. ru/files/pdf/eng009/melnikova.pdf, accessed 8 November 2019.

Michelutti, L. 2008. The Vernacularisation of Democracy. Politics, Caste and Religion in India. New Delhi: Routledge.

Minoletti P. 2019. 'Myanmar: Women's Political Life', in (eds) S. Franceschet, M. Krook and N. Tan, The Palgrave Handbook of Women's Political Rights. London: Palgrave Macmillan.

Mitchell, T. 2006. 'Society, Economy and the State Effect', in (eds) A. Sharma and A. Gupta, The Anthropology of the State: A Reader. Oxford: Blackwell.

Mohanty, C.T. 1986. 'Under Western Eyes. Feminist Scholarship and Colonial Discourses', Boundary 2, 12 (3), pp. 333-358.

Mohanty, C.T. 2003. 'Under Western Eyes Revisited: Feminist Solidarity through Anticapitalist Struggles', Signs, 28 (2), pp. 499-535.

Molyneux. M. 1985. 'Mobilization without Emancipation? Women's Interests, the State, and Revolution in Nicaragua', Feminist Studies, 11 (2), pp. 227-254.

Mooney, A., Oliver, C. and Smith, M. 2009. The Impact of Family Breakdown on Children's Well-Being. Evidence Review. London: Thomas Coram Research Unit, Institute of Education, University of London.

Mosse, D. 2010. 'A Relational Approach to Durable Poverty, Inequality and Power', The Journal of Development Studies, 46 (7), pp. 1156-1178.

Mosse, D. 2020. 'Outside Caste? The Enclosure of Caste and Claims to Castelessness in India and the United Kingdom', Comparative Studies in Society and History, 62 (1), pp. 4-34. 
Mouffe, C. 2000. The Democratic Paradox. London and New York: Verso.

Mowles, C. 2010. 'Successful or not? Evidence, Emergence, and Development Management', Development in Practice, 20 (7), pp. 757-770.

Mowles, C. 2015. Managing in Uncertainty: Complexity and the Paradoxes of Everyday Organizational Life. Abingdon: Routledge.

Mullin, C. 2010, 2011, 2012. The Diaries of Chris Mullin, vols 1-3. London: Profile.

Munslow, B. 1983. 'Why Has the Westminster Model Failed in Africa?', Parliamentary Affairs, 36 (2), pp. 218-228.

Nay, O. 2013. 'Fragile and Failed States: Critical Perspectives on Conceptual Hybrids', International Political Science Review, 34 (3), pp. 326-341.

Norton, P. 1994. 'The Growth of the Constituency Role of the MP', Parliamentary Affairs, 47 (4), pp. 705-720.

Norton, P. 2019. 'Power behind the Scenes: The Importance of Informal Space in Legislatures', Parliamentary Affairs, 72 (2), pp. 245-266.

O'Farrell, J. 2013. 'Why I'm Standing for Labour in the Eastleigh Byelection', The Guardian, 13 February, http://www.guardian.co.uk/commentisfree/2013/feb/13/john-ofarrell-whystanding-eastleigh-labour, accessed 12 April 2013.

Olivier de Sardan, J-P. 2005. Anthropology and Development: Understanding Contemporary Social Change. London: Zed.

O'Toole, C. and Roxan, A. 2019. Local Democracy, Journalism and Public Relations. The Changing Dynamics in Local Media and Public Sector Communications. London and New York: Routledge.

Paley, J. 2002. 'Towards an Anthropology of Democracy', Annual Review of Anthropology, 32, pp. 469-496.

Parris, M. 2003. Chance Witness: An Outsider's Life in Politics. London: Penguin.

Pascoe-Watson, G. 2007. 'John Reid's Brain is Missing', Sun, 7 September, http://www. thesun.co.uk/sol/homepage/news/29723/John-Reids-brain-is-missing.html, accessed 11 February 2014.

Peirce, C.S. 1931, 1958. Collected Papers, 8 vols, (eds) C. Hartshorne, P. Weiss (vols I-VI) and A.W. Burks (vols VII-VIII). Cambridge, MA: Harvard University Press.

Phillips, A. 1995. The Politics of Presence. Oxford: Oxford University Press.

Pigg, S.L. 1992. 'Inventing Social Categories through Place: Social Representations and Development in Nepal', Comparative Studies in Society and History, 34, pp. 491-513.

Piliavsky, A. 2014. 'Introduction', in (ed.) A. Piliavsky, Patronage as Politics in South Asia. Cambridge: Cambridge University Press.

Pitkin, H.F. 1967. The Concept of Representation. Berkeley: University of California Press.

Pommerolle, M-E. 2016. 'Donors and the Making of "Credible" Elections in Cameroon', in (eds) T. Hagman and F. Reyntjens, Aid and Authoritarianism in Africa. London: Zed.

Price, D.E. 1992. The Congressional Experience: A View from the Hill. Boulder: Westview.

Puwar, N. 2004. Space Invaders: Race, Gender and Bodies out of Place. London: Berg.

Puwar, N. 2014. 'The Archi-Texture of Parliament at Westminster', in (eds) S. Rai and R. Johnson, Democracy in Practice: Ceremony and Practice in Parliament. Basingstoke: Palgrave Macmillan.

Rai, S. (ed.). 2000. International Perspectives on Gender and Democratisation. Basingstoke: Macmillan Press.

Rai, S. 2014. 'Political Aesthetics of the Political Nation', Interventions: International Journal of Postcolonial Studies, 16 (6), pp. 898-915.

Rai, S. and Johnson, R. (eds). 2014. Democracy in Practice: Ceremony and Ritual in Parliament. Basingstoke: Palgrave Macmillan. 
Rai, S. and Spray, C. 2019. Performing Representation: Women Members in the Indian Parliament. Oxford: Oxford University Press.

Rehfeld, A. 2009. 'Representation Rethought: On Trustees, Delegates, and Gyroscopes in the Study of Political Representation and Democracy', American Political Science Review, 103 (2), pp. 214-230.

Rhodes, R.A.W. 2011. Everyday Life in British Government. Oxford: Oxford University Press.

Riles, A. (ed.). 2006. Documents: Artifacts of Modern Knowledge. Ann Arbor: University of Michigan Press.

Robbins, J. 2013. 'Beyond the Suffering Subject: Toward an Anthropology of the Good', Journal of the Royal Anthropological Institute (N.S.) 19 (3), pp. 447-462.

Rogers, R. 2012. Who Goes Home? A Parliamentary Miscellany. London: Biteback Publishing. Rosa, H. 2019. Resonance: A Sociology of Our Relationship to the World. London: Polity.

Runciman, D. 2008. Political Hypocrisy. The Mask of Power, from Hobbes to Orwell and beyond. Princeton: Princeton University Press.

Rush, M. and Giddings, P. 2011. Parliamentary Socialisation. Learning the Ropes or Determining Behaviour. Basingstoke: Palgrave Macmillan.

Russell, M. and Glover, D. 2017. Legislation at Westminster. Parliamentary Actors and Influence. Oxford: Oxford University Press.

Russell, M. and Serban, R. 2020. "The Muddle of the "Westminster Model": A Concept Stretched Beyond Repair', Government and Opposition, pp. 1-21. doi:10.1017/ gov.2020.12.

Ruud, A.E. 2001. 'Talking Dirty about Politics: A View from a Bengali Village', in (eds) C. J. Fuller and V. Benei, The Everyday State and Society in Modern India. London: Hurst.

Saalfeld, T. 1995. 'Rational-choice Theory in Legislative Studies: Models of Politics without Romanticism', The Journal of Legislative Studies, 1 (1), pp. 32-64.

Saalfeld, T. and Strøm, K. 2014. 'Political Parties and Legislators', in (eds) S. Martin, T. Saalfeld and K.W. Strøm, The Oxford Handbook of Legislative Studies, Oxford: Oxford University Press.

Sadan, M. 2016. 'Can Democracy Cure Myanmar's Ethnic Conflicts', Current History, a Journal of Contemporary World Affairs, 115 (782) (September), pp. 214-219.

Sanderson, I. 2002. 'Evaluation, Policy Learning and Evidence-Based Policy Making', Public Administration, 80 (1), pp. 1-22.

Sawar, M. 2000. 'Parliamentary Representation of Women: From Discourses of Justice to Strategies of Accountability', International Political Science Review, 21 (4), pp. 361-380.

Saward, M. 2007. 'The Representative Claim', Contemporary Political Theory, 5 (3), pp. 297318.

Schonhardt-Bailey, C. 2017. 'Nonverbal Contention and Contempt in U.K. Parliamentary Oversight Hearings on Fiscal and Monetary Policy', Politics and the Life Sciences, 36 (1), pp. 27-46.

Schuler, P. and Malesky, E.J. 2014. 'Authoritarian Legislatures', in S. Martin, T. Saalfeld and K.W. Strøm, The Oxford Handbook of Legislative Studies. Oxford: Oxford University Press.

Schumann, W. 2009. Toward an Anthropology of Government: Democratic Transformations and Nation Building in Wales. New York: Palgrave Macmillan.

Scott, J. 1998. Seeing Like a State. How Certain Schemes to Improve the Human Condition Have Failed. New Haven: Yale University Press.

Scott Crines, A., Jeffery, D. and Heppell, T. 2018. 'The British Labour Party and Leadership Election Mandate(s) of Jeremy Corbyn: Patterns of Opinion and Opposition within the Parliamentary Labour Party', Journal of Elections, Public Opinion and Parties, 28 (3), pp. 361-379.

Searing, D. 1985. 'The Role of the Good Constituency Member and the Practice of Representation in Great Britain', The Journal of Politics, 47 (2), pp. 348-381. 
Searing, D. 1994. Westminster's World. Understanding Political Roles. Cambridge, MA and London: Harvard University Press.

Shamir, J. and Shikaki, K. 2005. 'Public Opinion in the Israeli-Palestinian Two-Level Game', Journal of Peace Research, 42 (3), pp. 311-328.

Sharma, A. and Gupta, A. 2006. 'Introduction: Rethinking Theories of the State in an Age of Globalization', in (eds) A. Sharma and A. Gupta, The Anthropology of the State: A Reader. Oxford: Blackwell.

Shils, E. and Young, M. 1953. 'The Meaning of the Coronation', Sociological Review, 1 (2), pp. 63-81.

Shore, C. and Wright, S. 2015. 'Audit Culture Revisited. Rankings, Ratings, and the Reassembling of Society', Current Anthropology 56 (3), pp. 421-444.

Skjerdal, T.S. 2011. 'Development Journalism Revived: The Case of Ethiopia', Ecquid Novi: African Journalism Studies, 32 (2), pp. 58-74.

Spencer, J. 1997. 'Post-colonialism and the Political Imagination', Journal of the Royal Anthropological Institute, 3 (1), pp. 1-19.

Spencer, J. 2007. Anthropology, Politics and the State. Democracy and Violence in South Asia. Cambridge: Cambridge University Press.

Spencer, P. 1971. 'Party Politics and the Processes of Local Democracy in an English Town', in (eds) A. Richards and A. Kuper. Councils in Action. Cambridge University Monographs in Social Anthropology, no. 6. Cambridge: Cambridge University Press.

Spray, C., Armitage, F. and Johnson, R.E. 2014. 'Disrupting Deliberation? Comparing Repertoires of Parliamentary Representation in India, the UK and South Africa', in (eds) S.M. Rai and R.E. Johnson, Democracy in Practice: Ceremony and Ritual in Parliament. Basingstoke: Palgrave Macmillan.

Stacey, R. and Mowles, C. 2016. Strategic Management and Organisational Dynamics: The Challenge of Complexity to Ways of Thinking about Organisations. London: Pearson Education.

Strathern, M. (ed.). 2000. Audit Cultures: Anthropological Studies in Accountability, Ethics and the Academy. London and New York: Routledge.

Street, B.V. 1993. 'Culture is a Verb: Anthropological Aspects of Language and Cultural Process', in (eds) D. Graddol, L. Thompson and M. Byram, Language and Culture. Clevedon: British Association of Applied Linguistics.

Svaleryd, H. and Vlachos, J. 2009. 'Political Rents in a Non-corrupt Democracy', Journal of Public Economics, 93 (3-4), pp. 355-373.

Tamale, S. 1999. When Hens Begin to Crow. Gender and Parliamentary Politics in Uganda. Boulder: Westview Press.

Teixeira, C.C. 2004. 'The Price of Honor: The Press versus Congress in the Rhetoric of Brazilian Politics', Public Culture, 16 (1), pp. 31-46.

Tidey, S. 2018. 'A Tale of Two Mayors. Configurations of Care and Corruption in Eastern Indonesian Direct District Head Elections', Current Anthropology, 59 (18) pp. 117-127.

Tilche, A. and Simpson, E. 2017. 'On Trusting Ethnography: Serendipity and the Reflexive Return to the Fields of Gujarat', Journal of the Royal Anthropological Institute, 23 (4), pp. 690-708.

Trouillot, M-R. 2003. Global Transformations: Anthropology and the Modern World. New York: Palgrave Macmillan.

Tsing, A. 2015. The Mushroom at the End of the World. On the Possibility of Life in Capitalist Ruins. Princeton: Princeton University Press.

Türesay, Özgür. 2013. 'The Ottoman Empire Seen through the Lens of Postcolonial Studies: A Recent Historiographical Turn', Revue d'histoire moderne et contemporaine, 60 (2), pp. 127-145. 
Vonnegut, K. 2009 (1969). Slaughterhouse-Five. New York: Dial Press.

Weatherford, J. 1985. Tribes on the Hill. The US Congress Rituals and Realities. Westport: Bergin and Garvey.

Weinberg, A. 2011. The Psychology of Politicians. Cambridge: Cambridge University Press.

Wesendorf, K. 2005. An Indigenous Parliament? Realities and Perspectives in Russia and the Circumpolar North. Copenhagen: International Work Group for Indigenous Affairs.

Whale, S. 2020. "Power Concedes Nothing without Demand" - Black MPs on the Ongoing Struggle for Equality', The House, 13 June, https://www.politicshome.com/thehouse/arti cle/power-concedes-nothing-without-demand-black-mps-on-the-ongoing-struggle-for-rac ial-equality, accessed 14 June 2020.

Whiteley, P., Poletti, M., Webb, P. and Bale, T. 2019. 'Oh Jeremy Corbyn! Why did Labour Party Membership Soar after the 2015 General Election?', The British Journal of Politics and International Relations, 21 (1), pp. 80-98.

Wilenius, Heikki. 2020. Routine Work: Authorizing Representation in East Javanese Regional Politics. Research Series in Anthropology 31. Helsinki: University of Helsinki.

Wodak, R. 2003. 'Multiple Identities: The Role of Female Parliamentarians in the EU Parliament', in (eds) J. Holmes and M. Meyerhoff, The Handbook of Language and Gender. London: Blackwell.

Workneh, T.W. 2020. 'Ethiopia's Hate Speech Predicament: Seeking Antidotes beyond a Legislative Response', African Journalism Studies, 40 (3), pp. 123-139.

Wouters, J.P. 2015. 'Polythetic Democracy: Tribal Elections, Bogus Votes, and Political Imagination in the Naga Uplands of Northeast India', Hau: Journal of Ethnographic Theory, 5 (2), pp. 121-151.

Wouters, J.P. 2018. 'Nagas as a "Society against Voting?" Consensus-building, Party-less Politics and a Culturalist Critique of Elections in Northeast India', Cambridge Journal of Anthropology, 36 (2) pp. 113-132.

Wydra, H. and Thomassen, B. 2018. Handbook of Political Anthropology. Cheltenham: Edward Elgar Publishing. 


\section{INDEX}

Note: References in italics are to figures, 'n' refers to chapter notes.

Abbot, Diane 62 abduction 198

Abélès, Marc 66, 156, 160-1, 196

Abram, Simone 157-8, 201-2

accountability 189-92, 191-2

Adams, John 146-7

affect 34, 73, 77

African bureaucracy 81

agendas and diaries of time and space

104-16, 113, 114, 115

Ahmed, Abiy 96, 138-9

Ahmed, Z. 67

aid 85-6

Alaszewski, A. 133

Anderson, Kirsten 88

Ansell, Aaron 45

anthropology 2, 3, 6; abduction 198;

culture-making 134; defined 9-11, 77;

entangled, reflexive anthropology 201-6;

interdisciplinarity $14,196-8$; plurality

14-16; reflexivity 11-13; research

195-201, 207; rigour 11-16

Appadurai, A. 60, 77, 190

Apter, A. 176, 182

Arctic region 68

Arendt, H. 52, 197

Aronoff, M.J. 135-6

Attlee, Clement 137

audit 99

Aung San Suu Kyi 65

Australia: Kalgoorlie 65-6
Ayenew, M. et al. 67-8

Azande, South Sudan 133

Bailey, F.G. 156, 188

Bali 165

Banerjee, Mukulika 30, 32-3, 50

Bangladesh 136; Awami League 38, 136; National Party 38, 136; parliament 22; parliament building 8 ; party conflict 171; patronage 38-9; representation 66, $67,189,192$; voting 5 ; women in parliament 30

Barth, Fredrik 5, 133-4

Beatty, Andrew 116, 120, 121, 127, 170, 207

Begg, Dame Anne 74

Benger, John 27

Bercow, John 55, 69, 121, 122, 129, 163-4, 184

Bernstein, A. 81

Bernstein, Richard 198

Bierschenk, T. 81

Bignell, Jessica 140-1, 207

Birhanu, R. 136

Black Lives Matter 190

Blackwood, Nicola 46

Blair, Tony 48, 91, 137, 138, 180

Bloch, Maurice 21, 165, 170, 182, 198-9, 200

Blunkett, David 161

Bolivia 59

Bolsonaro, Jair 99-100, 140, 179 
Boothroyd, Betty 37-8

Botswana 51, 61

Bourdieu, P. 12, 14, 15, 21, 107, 132, 134, 140, 164, 178, 179, 181, 182, 194, 203, 208

Boyd, Emma Howard 147

Brack, N. et al. 58

Brandreth, Giles 189

Brandt, Willy 127-8

Brazil 9, 45, 65, 95, 100, 140, 179

Bristol Airport 145-9, 157, 158-9

Brooke, Heather 93

Brooks, Rebekah 95

Brown, Gordon 48, 112, 138

Bryant, Chris 131

Bueno de Mesquita, B. et al. 38

buildings 7-8, 107-9

Burghart, R. 165

Burke, Edmund 55-6

Burkitt, I. 129

Burma see Myanmar

Burn, Hilary 146, 148, 149

Busby, Amy 141

Butler, Dawn 62

Butler, Judith 63, 186

Butler, Robin 91

Butler-Sloss, Baroness 87, 88, 89, 161

Byrne, Liam 188

Cameron, David 39, 50, 137

Cameroon 49-50

Campbell, Alastair 91

Campbell, R. 46

Canada 92, 154

candidates for election 31

Carrithers, M. 103, 127, 134, 139

Carter, Jimmy 167

caste discrimination 14-15, 98, 134

ceremonies of state 165-9, 188

Chaudire, Mahendra 184

children 61, 97-8, 114, 115

Chorley, Matt 91

Churchill, Winston 107

civil society 5

Clark, Alan 112

Clegg, Nick 39, 40

climate change 145, 146, 149

Clinton, Hilary 185

Coles, Kimberley 32

Comaroff, J. 49, 51

Comaroff, J.L. 49, 51

Congress 9

constituencies $7,8,27,28,30,34-6,44-6$, $48,65,69-75,100,104,110,112-5$, 150, 159, 185-6, 191
Corbett, Jack 62, 68, 161

Corbyn, Jeremy 48, 137, 138, 171, 180

corruption 44-5

Covid-19 pandemic 44, 72, 78, 94, 99-100, 105, 129, 135, 137, 188, 209

Cowley, Philip 46, 47, 177

Cramer, Katherine 57-8

Crampton, Robert 144

Cranborne, Lord 16-17

Crewe, Ivor 86

Crick, Michael 180

Cuba 59

cultural analysis 10-11

cultural relativism 176

cultures of parliaments $3,4,5,103-5$, 173-4; power and culture 182, 184; rhythms of performance 5, 104, 107-30; riffs of meaning 5, 104, 131-52, 160, 162-3, 173-4; rituals and symbols 6, 20, 76, 104-5, 154-70, 174

Cummings, Dominic 117

Das, Veena 171

Davies, Sir Michael 16, 17

Davison, Emily 115

decision-making see ritualised decisionmaking

deduction 198

democracy $3,30,49,50-3,187$

democracy dials 187-8, 192-3; accountability 189-92, 191-2; intensity 188-9; variability 188

development 135

Dewey, John 75, 200, 209

DFID 190

digital revolution 145, 152, 188, 207

Doran, Frank 121

Dumont, Louis 15

Dunn, Derek 18

Dunn, John 30, 51, 53, 189

Durkheim, Émile 166

Eagle, Angela 138

Edensor, T. 109

Egreteau, Renand 167

Ehrenzweig, A. 197

elections 4, 5, 28, 31-4, 37, 157, 173

Elizabeth II, Queen 75-6, 168

emotional gestures of minds and bodies $116-27,123-6$

emotions 77, 207

encounters 105

Engel, Natascha 44

Engelke, M. 155

entangled, reflexive anthropology 201-6 
Ethiopia: ethnic federalism 136; parliament 12-13, 22, 27; Prime Minister 139-40; represention $66,67-8,190,191-2,192$; state-media relations $96-7$; women MPs 12-13

ethnography 26, 142, 197; defined 9-10, 17

European Parliament 141-2

European Union 50

Evans, Graham 142-3

Evans, Paul 116, 162-3

Evans-Pritchard, E.E. 133, 156

Ewing, Katherine 121

Extinction Rebellion 78, 146, 148, 190

Facebook 67, 146, 147, 152, 188

family law 86-91, 88, 97-8

Farrell, Cassie 146-7

Faucher-King, Florence 111, 138, 141, 170, 205, 207

feminism: theories of power 186, 203; theories of under-representation 59-65

Fenno, Richard 56

Fiji 30, 128, 184-5, 209

fission and fusion 76

Flynn, Paul 69, 74, 75

Foret, F. 143

Fortes, M. 156

Foucault, Michel 81, 85, 203

Fox, Liam 146, 148

Fox, Ruth 22

framing 136

France 51, 66, 154, 160-1, 178-9

Gabrehiwot, Mitiku 27, 192, 192-3

Geddes, M. 26

Geertz, C. 10-11, 26, 156, 165, 209

gender: inequalities 12, 37-8, 60, 72, 201; leadership 203; and power 185-7, 203; representation 59-62, 63; theory of performativity $63,155-6,167$; intersectionality $64-5,98,128,167$, 186-7

Geoghegan, Peter 94

geography 105, 107

Germany $127-8,154$

Gershon, Ilana 97

Ghana 49

Giesen, B. 165

Gledhill, J. 181-2, 196

Global Research Network on Parliaments and People 22, 137

globalisation 145

Glover, D. 86

Goffman, E. 67
Goldsmith, Tom 194

gossip 18, 19, 41, 95, 142-3

government: anthropological research on 80-6, 207; defined 80-1; 'Westminster' model 81-3

Graeber, D. 50, 75, 189

Greenhouse, C.J. 81

Gupta, A. 83-4

Habermas, Jürgen 52

Hain, Peter 122

Halfon, Robert 46

Hamilton, Carolyn 88

Hansard Society 22

Hardman, Isabel 43, 70, 94, 95, 144, 183-4, 186-7, 188

Harrison, Elizabeth 19

Hart, Keith 78

history 14, 87, 93, 105, 107, 128, 129, 167, 195-7, 209

Hocart, A.M. 154, 156

Hogg, Quentin 118

Hogg, Steve 65n6, 148, 150, 151-2, 164

Honneth, A. 146

House of Commons 20-1, 21, 183; backbenchers 184; clerks 20, 27, 116-17, 118-19, 121, 122, 126, 162-3, 180, 194; committees 116-17; Erskine May 162-3; evidence to select committee 121-7, 123-6; expenses scandal 92-4, 122; gossip 142-3; ministers 183-4; party loyalty 166, 177; 'plebgate' 95; Prime Minister's Questions (PMQs) 110; ritualised debates 157, 161, 162-3; select committees 179-80; Speaker 162-5, 184; standing orders 162; State Opening of Parliament 116, 168-9; voting 161; whips 46-7, 48-9, 110-11, 177, 178 see also Members of Parliament, UK

House of Lords 16-20, 21, 21, 30; ceremonies of state 166, 168-9; clerks 16 , 17,18 ; hereditary peers 30 ; party loyalty 177; ritualised debates 157, 162, 166; State Opening of Parliament 166, 168; symbolic capital 183; whips 47, 177, 178; women 186

Howe, Geoffrey 19, 154

Hughes, Simon 41-2

Hutchings, Maria 40-1, 43

ideology and knowledge 105, 132-9 improvising together 194-5, 195, 199; entangled, reflexive anthropology 201-6; researching as learning 195-201; what we don't know 206-10 
India: Bharatiya Janata Party 179; caste 14-15, 98; Covid-19 209; democracy 50; National Congress 1, 6, 167; Parliament 157; parliament buildings 8, 107-8; patronage 32 ; representation $63,64-5$, 68 , 189; voting $28,32-4$; women 6 , 64-5

indigenous peoples 68

Indonesia 45, 141, 170

induction 197-8

Ingham, Bernard 91

Ingold, T. 9-10, 11, 132, 195-6, 197

institutionalist theory 25,205

intensity 188-9

interdisciplinarity $14,196-8$

Ireland 56, 137

Irvine, Derry (Lord Chancellor) 23n3

Israel 135-6

Jack, Sir Malcolm 20

James, Diane 43

Japan 128

Jenkins, Simon 98

Jewett, A. 197

Johnson, Boris 48, 99, 112, 117, 163, 176

Johnson, R. 155

Jones, Owen 180

Judge, D. 75

Julius Caesar 143

Kaganas, Felicity 97-8

Kahn, Louis 8

Kant, I. 205

Kaur, Jastinder 128, 184-5, 209

Kent, Hazel 88

Kertzer, D. 156-7, 167, 169

King, Anthony 86

Kinnock, Neil 141

Kirkwood, Archie 93

knowledge 10, 23; embedded and provisional 197, 199; evidence 90; and ideology 105, 132-9; incompleteness of 198; of MPs 70, 71; and power 3, 6; reflexivity 11-12, 13; types of 5, 141-2, 198; ubiquity of 196; what we don't know 206-10

Knutson, Coya 185

Koch, I. 81

Krishnamurty, Mekhala 33

Kuhn, Thomas 197

Kurcezewski, J. 89

Lakoff, George 140

Larsen, S.B. 104

Latour, Bruno 90, 151, 152 law: critique as scrutiny 97-100; family law, Trinidad 97-8; legislation 182-3; making law in the UK 86-91, 88, 182

Law, Chris $72-3,74$

Lazarus, J. 185

Lazarus-Black, M. 97

Leach, Edmund 26-7, 139, 156, 170

leadership 52-3, 128, 200, 203

Lee, Mordecai 57

Lefebvre, Henri 109, 116

Leigh, Edward 129

Lesotho 30

Leston-Bandeira, C. 26

Leveson Inquiry 94

Lévi-Strauss, Claude 133

Lewellen, Ted 145

Lewis, David 136

Lewis, Ivan 95

Livesey-Hayworth, Richard 22

Lloyd, Selwyn 91

Lloyd, Stephen 69

Lukes, Stephen 20, 157, 166

McBride, Damian 95

McDonnell, John 48

McDougall, L. 38, 114

Maclean, M. 89

Macmillan, Harold 91

Macron, Emmanuel 179

Madagascar 165, 182

Madison, James 56

Malinowski, Bronislaw 132, 156

Maloney, Carolyn 185

Mansbridge, Jane 60

map of this book 3-6

Marshall Islands 68, 100

Martin, S. et al. 25, 26

masculinity 97, 104, 115

Mawdsley, E. 152

May, Theresa 112, 180

Mead, George Herbert 73, 120-1, 129, 169, 199, 200, 205

media: digital media 145, 152, 188, 207; during elections $38,39,40$; scrutiny of the state $38,91-7,188$; social media 39 , 67, 69, 91, 96, 188-9

Media Reform Coalition 92

Melnikova, Ekaterina 31, 49, 176

Members of Parliament, UK 164, 206; agendas and diaries 110-16, 113, 114, 115; and alcohol 104, 105-6n1; backbenchers 184; constituencies 8,28 , 30, 44-6, 48, 65, 69-74; and divorce 104, 106n1; gossip 142-3; induction and training 27-8; knowledge of 70, 71; 
paradoxes 205-6; and the public 180; at State Opening of Parliament 168-9; status 20; women 13, 37-8, 72, 74, 114, 114-16, 185-7, 188; work 2-4, 7, 21, 29 Merkel, Angela 128

Mertz, E. 81

Michelutti, L. 68

Micronesia, Federated States of 62, 78n5

Miliband, Ed 39, 98, 138

Mitchell, Andrew 95

Mitterand, President 66

modernity $85,90,134-5$

Modi, Narendra 107, 209

Mohanty, Chandra Talpade 61, 78n4

Molyneux, Maxine 60

Mosse, David 27, 77, 98

Mouffe, Chantal 89

Mowles, Chris 22, 89, 205

Müller, Marion G. 20, 154

Mullin, Chris 112

Munslow, Barry 82

Myanmar: as Burma 26-7, 139, 156; ethnicity 167-8, 190; history and status 167; National League for Democracy 65; parliament 22; Parliament building 8; represention 66, 67, 190, 192; voting rights 178 ; women 65

Naoroji, Dadabhai 1-2, 62

Needham, Rodney 15

Nepal 19, 165

Netherlands 30, 157

networked advocacy 145-52

New Public Management 99

New Times of Burma 167

New Zealand 59, 82, 140, 207

News of the World 95

Nigeria 82, 176, 182

norms 15, 27, 65, 156

Norton, P. (Lord) 66-7, 79n9

Norway 157-8, 201-2

Obama, Barack 74, 155

O'Farrell, John 41, 43

Olivier de Sardan, J-P. 81, 170, 196

Onwurah, Chi 62

Oppong-Asare, Abena 62

Orthodox Jews 135

O’Toole, C. 91

Ottoman Parliament, Istanbul (1908) 1

Pacific Islands 62, 68

Pakistan 121

Palestinians 135, 136
Paley, Julia 81, 187

Papua New Guinea 62, 78n5

Parish Councils Airport Association 148

Parris, Matthew 183

participant observation 9, 10, 196

Partos, R. 75

patronage 32, 37, 38-9, 207

Peirce, Charles 198

People-Power Index 69-70

performativity 27, 34, 36, 43, 63, 67, 69, 76-7, 81, 104-5, 109-10, 118-21, 126, 131, 159-60, 165, 170, 176, 182

Pew Research 92

Phillips, Anne 61-2

Pickles, Eric 69, 92, 98

Pigg, Stacy 34, 192

Piliavsky, a. 39

Pitkin, Hanna 60

plurality $11,14-16,52-3,58,64-5,76$, 198, 206

Poddar, Aparupa 65

political parties 30, 144, 178-9, 207; conferences 111, 141, 157, 170, 207

political science $26,57-8,63-4,75,81,83$, 103, 155, 187, 189

politics $2,173-4,174,175,208$; everyday political work 175-81; significance of 4, 173-4; and sociality 3, 203-4; values and ideology 138-9

Pommerolle 50

Portugal 56, 104

post-structuralism 203

poverty 77

power: and culture 182, 184; disentangling power 181-7; and gender 185-7, 203; and knowledge 3, 6; and race 186

presidential systems 9,80

proportion 175, 196; democracy dials 187-93; disentangling power 181-7; everyday political work $175-81$

Puwar, Nirmal 62, 115-16

race: language of $78 \mathrm{n} 4$; and power 186, 190; and representation 57, 62-3, 74; and women 60-1, 62, 186

Rai, Shirin 6, 26, 59-60, 63, 64, 107, 155

Rainsborough, Thomas 58-9

Ramachandram, M.G. 156

rational choice theory 25, 177, 205

Rebuke, Colonel 184

Rees-Mogg, Jacob 134-5

reflexivity $11-13$

Rehfeld, A. 56

Reid, John 95

Rentoul, John 180 
representing 5, 173; anthropology of representing and ignoring 65-9; feminist theories of under-representation 59-65; political representation, defined 55-9; and race $62-3$; resonance and alienation 74-8; trustee approach 55-7; UK constituencies: the collective MP 8, 27, $28,30,44-6,48,69-74$

research 4, 201-3; as learning 195-6, 198-9; curiosity 200-1; ethics 200; impact on researcher 199-200; interdisciplinarity 196-8; participatory sensibility 196; process 198-9; sense of proportion 196

resonance $10,52,57$; and alienation 74-8

rhetoric: communicating riffs of meaning 139-44

Rhodes, R.A.W. 26, 142

rhythms of performance 5, 104, 107-10, 173; agendas and diaries of time and space 104-16, 113, 114, 115; breaking rhythms: moving on or staying put 127-30; emotional gestures of minds and bodies 116-27, 123-6; in ritualised decision-making 159, 160-2

Richard, Lord 17

Richmond, Herbert 152

Ricoeur, Paul 104

riffs of meaning 5, 104, 131-2, 173-4; ideology and knowledge 105, 132-9; networked advocacy 145-52; rhetoric: communicating riffs of meaning 139-44; in ritualised decision-making 160, 162-3 rigour 11-16

Riles, A. 159

ritualised decision-making 157-9, 188; breakdowns in 163-5; rhythms 159 , $160-2$; riffs $160,162-3$

rituals and symbols in politics $6,20,76$, 104-5, 154-7, 174; ceremonies of state 165-9, 188; ritualised decision-making 157-65, 188; rituals, solidarity and violence 169-70; symbols 164-5, 169-70

Robbins, J. 78

Rogers, Robert (Lord Lisvane) 121

Rosa, Hartmut 10, 52, 76-7, 189

Roxan, A. 91

Rumsfeld, Donald 206

Runciman, D. 144

Russell, Earl 47, 177

Russell, M. 83, 86, 177

Russia 31-2, 176

Ruud, A.E. 68

Rwanda 49, 59, 61
Saalfeld, T. 25

Sadan, Mandy 190

Sahlins, M. 189

Salisbury, Lord 62

Samoa 161

Sanderson, I. 179

Sarra, Nicholas 72-3, 77, 116, 117, 118, 119

Saward, Michael 63-4

Schonhardt-Bailey, Cheryl 118

Schumann, William 207

Scotland: Dundee West 72-4; Scottish National Party 137, 179; Scottish

Parliament 8

Scott, James 84-5

Scott, Libby 147

scrutiny of the state 5, 173; anthropologists on the shape of the state 83-6; critique as scrutiny 97-100; crocodiles and snakes 91-7; making law in the UK 86-91, 88, 182; as part of shapeshifting work 100-1, 101; state, defined 80-3

Searing, D. 66-7

Selassie, Haile 139

Senbeta, E. 136

Serban, R. 83

shapeshifting 4, 100-1, 109, 121, 131-2, 169-70, 195

Shapps, Grant 137

Sharma, A. 83-4

Shils, E. 166

Simpson, Edward 13

Skelton, Mick 18

Skinner, Denis 168

Slaughter, Andy 41, 164

Smith, Lord 98

social class 32, 33, 108, 112, 167, 189, 191

social media 39, 67, 69, 91, 94, 96, 188-9

Social Research Association 28

sociality of parliaments, the $3-4,25-9,29$, 173; the alchemy of voting $4-5,30-53$; defined 200; representing 5, 55-78; scrutiny of the state $5,80-101$

South Africa 128, 155, 157

space $62,75,87,98,101,104,107,109-16$, 129, 176, 191, 196

Spectator 94

Speight, George 184

Spencer, Jonathan 21, 30, 52, 81, 156

Spray, Carole et al. 6, 63, 64, 128

Sri Lanka 134

St John-Stevas, Norman 118

Stacey, R. 205

state: ceremonies of 165-9; defined 80-3 see also scrutiny of the state

status $13,20,65,110,155$ 
Steigerwalt, A. 185, 186

Straw, Jack 94

suffragettes 115

Sun, The 95

Sustainable Development Goals 59

symbolism 60, 66, 73, 75-6, 156-7, 164-5, 169-70 see also rituals and symbols in politics

Taiwan 128

Tamale, Sylvia 61

Tanzania 85

Tebbit, Sir Kevin 122

Teixeira, C.C. 95

Telegraph, The 92, 93

Thatcher, Margaret 74, 91, 134, 137

thinking 121, 126, 129, 139, 140, 198-9, 205, 208

Thomassen, B. 81

Thornton, Mike 40

Thunberg, Greta 146

Tidey, Sylvia 45

Tilche, A. 13

Timpson, Edward 89

Tocqueville, Alexis de 51, 180

Trinidad: family law $97-8$

Trobriand Islands 132

Trouillot, Michel-Rolph 84

Trump, Donald 53, 99-100, 185

trust $28,49,50,55-7,135$

Tsing, Anna 207-8

Tsoukas, Haridimos 99

Turkey: Ottoman Parliament 1

Twitter 49, 67, 69, 94, 96, 142, 143, 146, 152, 188

Uganda 49, 61

Ukraine 128

United Kingdom: 1922 Committee 142-3; Bermondsey 43; Brexit 50, 111-12, 117 . 137, 162, 163, 176; Bristol Airport and North Somerset 145-9, 157, 158-9; caste discrimination 98; Conservative Party 40-1, 43, 50, 136-8, 141, 142-3, 148; constituencies $8,27,28,30,34-6,44-6$, 48, 65, 69-74; coronation of the Monarch 166; Covid-19 44, 72, 78, 94 , 99; Dundee West 72-4; Eastleigh 39-43; election games 5, 34-44, 37; family law 87-91, 88; Freedom of Information Act 93; gendered inequalities 37-8, 59-60; Green Party 137, 141, 148; Independence Party 43, 137; Independent Parliamentary Standards Authority 93-4; International
Development Select Committee (IDSC) 86; relationship with Ireland 56, 137; Labour Party 41, 43, 48, 137, 138, 141, 148, 171; law making 86-91, 88, 182; Liberal Democrats 39-40, 41-2, 43, 137, 141, 148, 207; media 91-7; Momentum 138; party conferences 111, 141, 170; patronage 37, 38; Police Federation 95; political parties 47, 111, 137-8, 177;

Putney Debates (1647) 58-9; race 62-3; representation 62-3, 68-74; Scotland 8, 72-4, 137, 179; Teenage Pregnancy Strategy 144; UK Independence Party 43, 137; voting shifts and social change 44-9; Wales 137, 207see also House of Commons; House of Lords; Members of Parliament, UK; Westminster Parliament

United States: Congress 9, 160; Covid-19 99-100; democracy 51; gender and power 185; media 92; representatives $56-7$; voters 28

University of Hertfordshire 22

Vanuatu 62, 78n5

Vaz, Valerie 122

Vester, Nicholas 19, 130n2, 203-4

Vester, Scarlett 146, 147, 149

Vonnegut, Kurt 176

voting 30-1, 173, 175-6; Bangladesh 5; and corruption 44-5; elections 4, 5, 28, 31-4, 37,157 ; fetishising the vote 49-53; India 28, 32-4; within parliaments 4-5, 31, 161 ; right to vote 178 ; shifts as indicator of social change 44-9; technology and ritual 176-7; vernacular election games in the UK 34-44

Wacquant, L.J.D. 14, 107, 194

Wales: Liberal Democrats 207; Plaid Cymru 137

Walker, Andrew 92-3, 99

Walker, Charles 106n1

Walker, Chris 92

Warren, Elizabeth 185

Weatherford, Jack 160

Wesendorf, Kathrin 68

'Westminster' model of goverment 81-3

Westminster Parliament 1-2, 3, 7, 86-91; legislation $86-91,88,182$; Palace of Westminster 7-8, 108, 108-9, 114, 115; power and culture 182; research 16-22, 21; State Opening of Parliament 166, 168-9; symbolic capital 183 see also House of Commons; House of Lords; Members of Parliament, UK 
Whale, Sebastian 62

WhatsApp 112, 142, 152

whips 46-9, 110-11, 177, 178

Widdecombe, Ann 189

Wilenius, Heikki 141

Wilson, Harold 188

Wollstonecraft, Mary 59

women: abuse of 97-8; political representation 59-65; and power 186, $188,201,203$; and race $60-1,62$; suffragettes 115

women politicians: Bangladesh 30; Ethiopia 12-13; India 6, 64-5; UK 13, 37-8, 72,
74, 114, 114-16, 185-7, 188; United

States 185

Workneh, Téwodros 96-7

Worku, Bethel 8

World Health Organisation 99

Wouters, Jelle 33-4

Wydra, H. 81

Young, M. 166

Young, Sir George 40-1

Zenawi, Meles 136

Zionism 135 


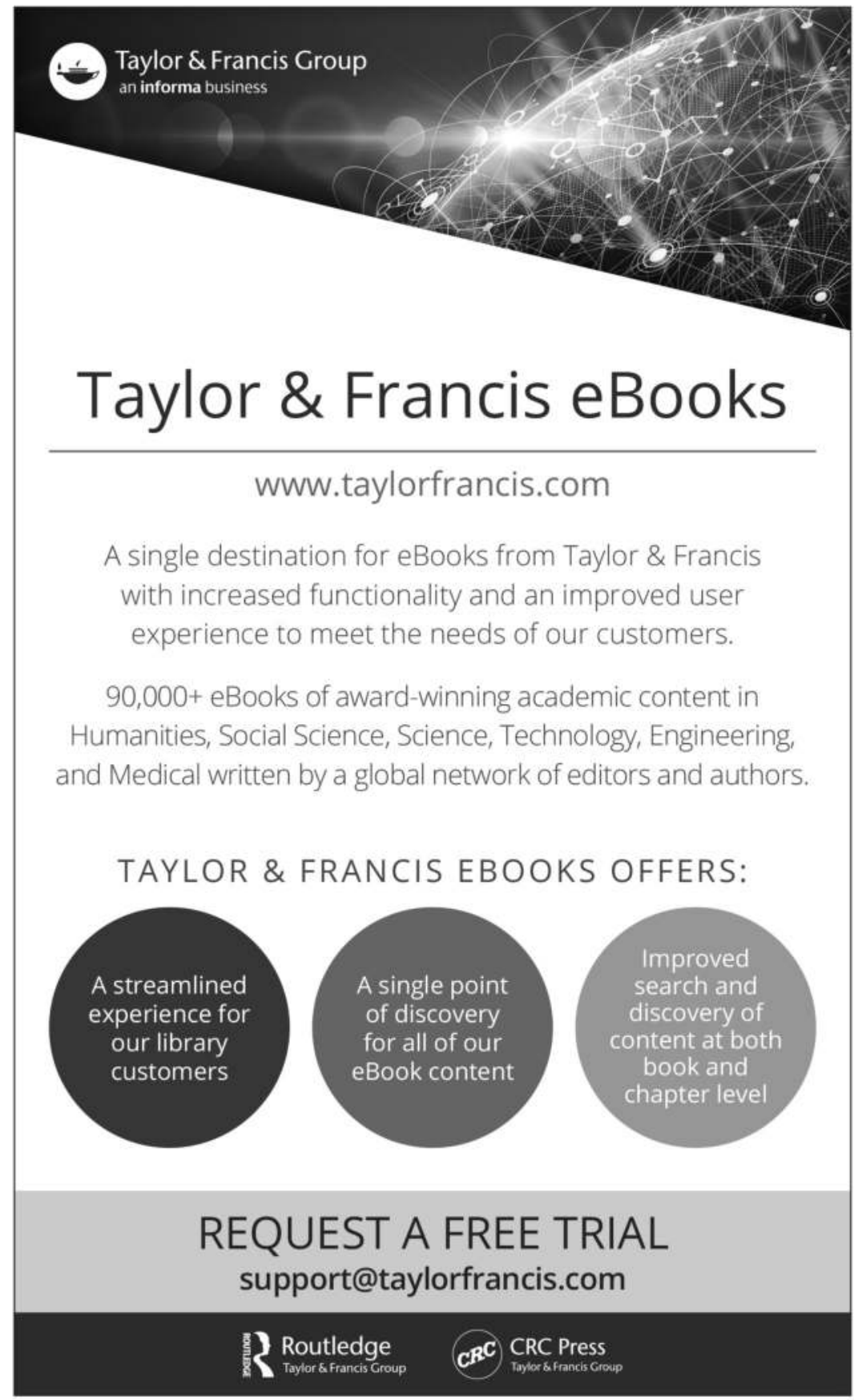

